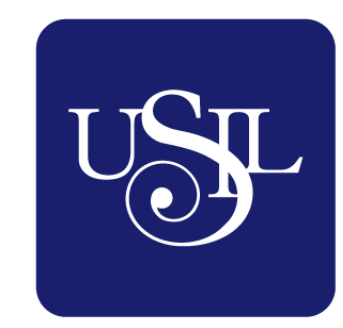

UNIVERSIDAD

SAN IGNACIO

DE LOYOLA

ESCUELA DE POSTGRADO

Maestría en Ciencias Empresariales

\title{
PLAN DE NEGOCIOS PARA CRIANZA, INDUSTRIALIZACIÓN Y COMERCIALIZACIÓN DE CARNE DE CUY ECOLÓGICO EN LA REGIÓN DEL CUSCO
}

Tesis para optar el grado de Maestro en Ciencias Empresariales

INGMAR APARICIO GUTIÉRREZ

ERICK BOCÁNGEL ANAYA

HELMUT ESCOBAR CÁCERES

\section{Asesor:}

Gino Felix Dodero Ortiz de Zevallos

$$
\text { Lima - Perú }
$$




\section{Dedicatoria}

A mi hijo por su inmenso amor y cariño

A mis padres por ser ejemplo de paciencia y fuerza de voluntad,

A mis hermanos ejemplo de superación

\section{Ingmar}

A mis dos hermosas hijas María Fernanda y Mía Valentina por sus sonrisas que fortalecen.

A mi madre por su ejemplo de fortaleza.

Erick

Con todo el amor del mundo a la luz de mis ojos y razón de mi vida Miccelita por ser el motor que me impulsa para ser cada día mejor.

A mi mamita Luz Marina y mi pequeña gigante Luz Arianita por ser siempre mi sostén en los momentos importantes de mi vida, sin su apoyo no lo hubiera logrado.

A mi compañera de toda la vida Jacqui por estar presente en todo momento.

\section{Helmut}




\section{INDICE}

Dedicatoria ii

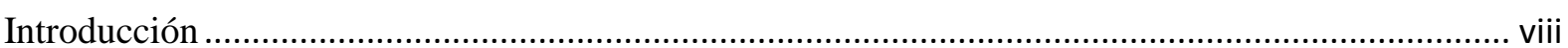

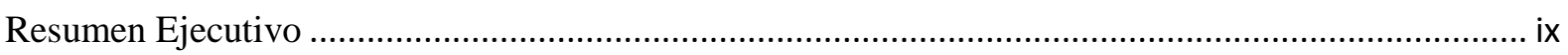

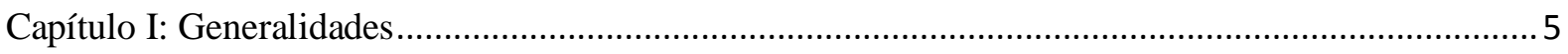

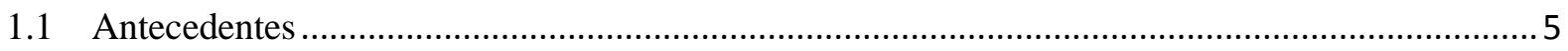

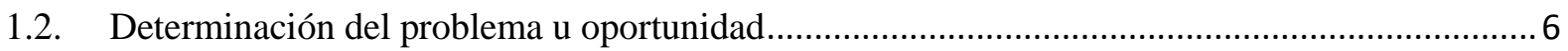

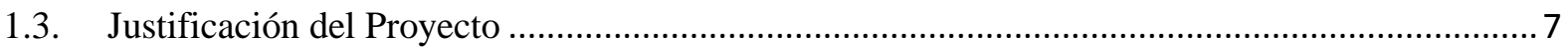

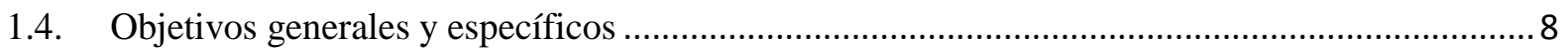

1.5. Alcances y limitaciones de la investigación ........................................................................... 9

Capítulo II: Estructura Económica Del Sector.......................................................................................... 10

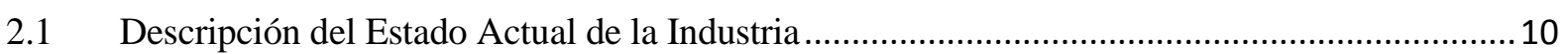

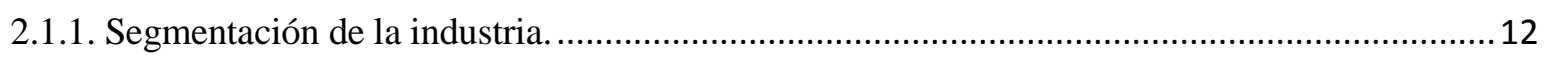

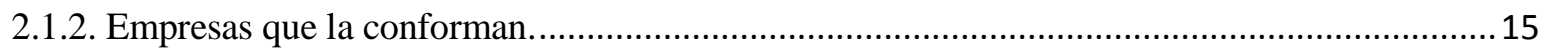

2.2. Tendencias De La Industria (Crecimiento Inversiones)..........................................................17

2.3. Análisis Estructural Del Sector Industrial ........................................................................... 17

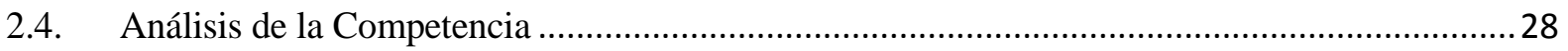

2.4.1. Empresas que ofrecen el mismo producto, indicando las semejanzas y diferencias que tienen

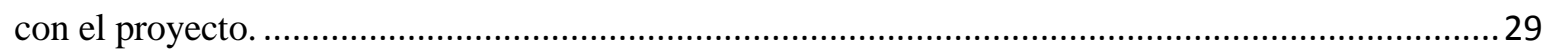

2.4.2. Participación de mercado de cada uno de ellos diferencias que tienen con el proyecto............31

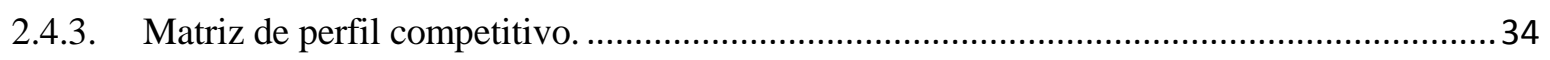

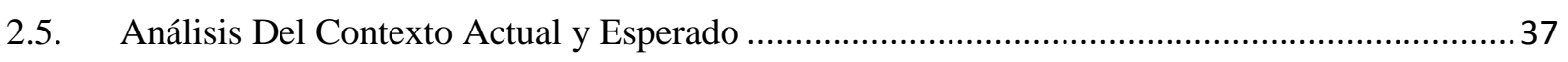

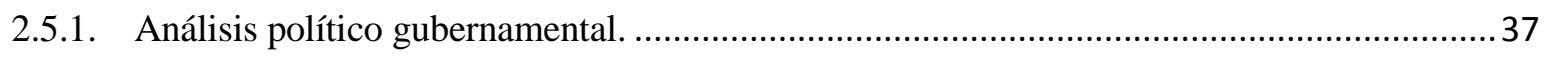

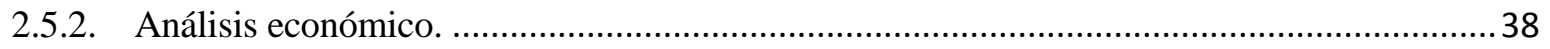

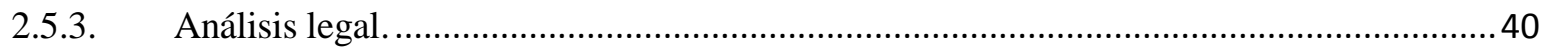

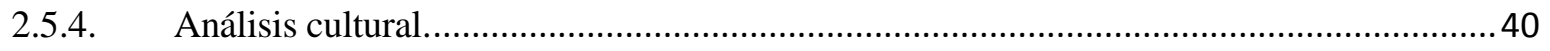

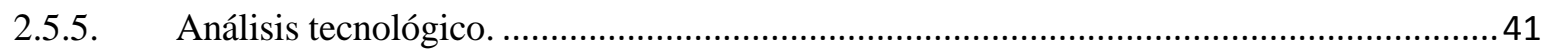

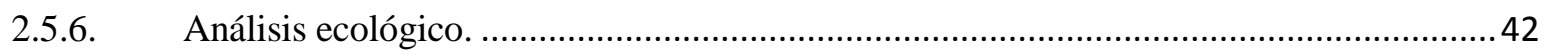

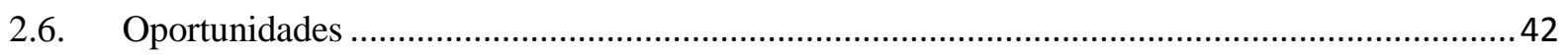

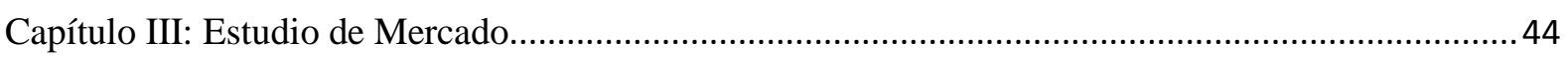

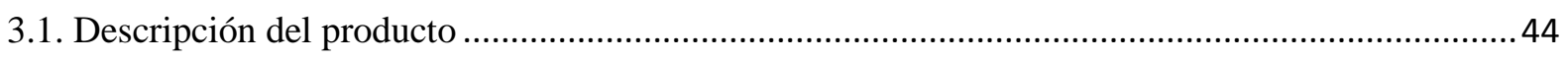

3.2. Selección del segmento o mercado .................................................................................... 46

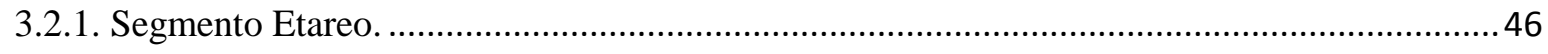

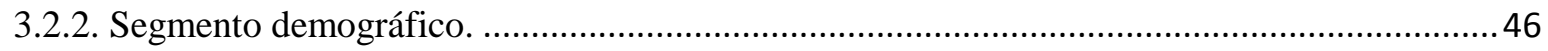




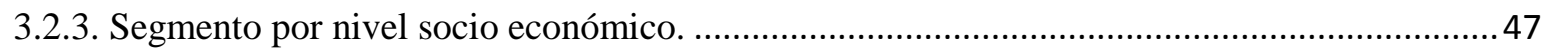

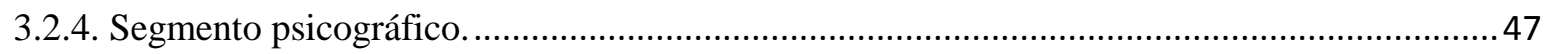

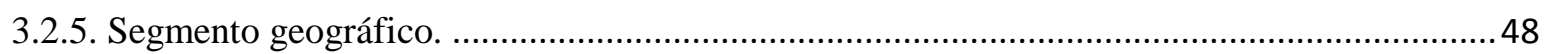

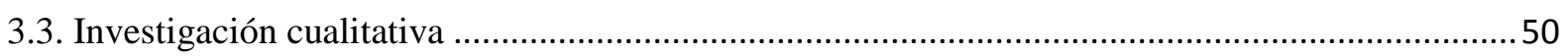

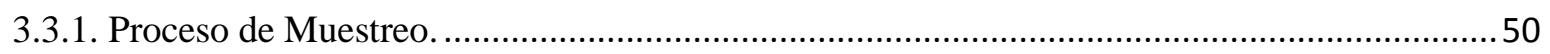

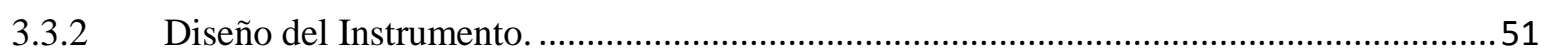

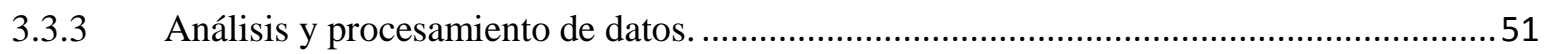

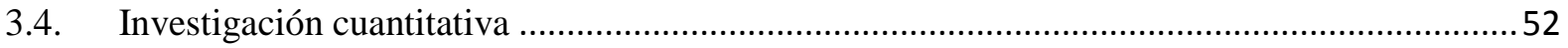

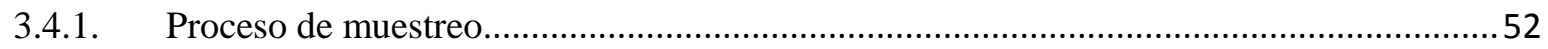

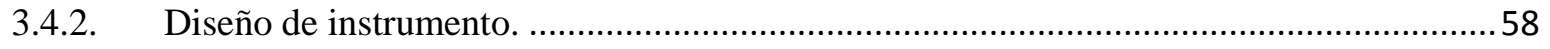

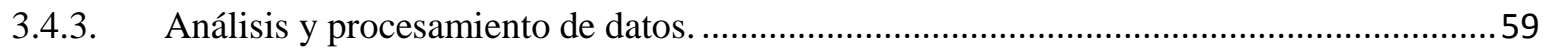

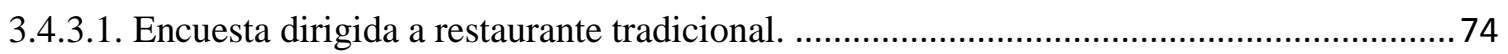

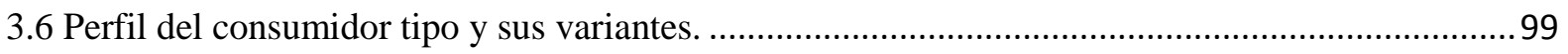

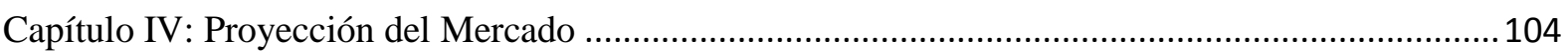

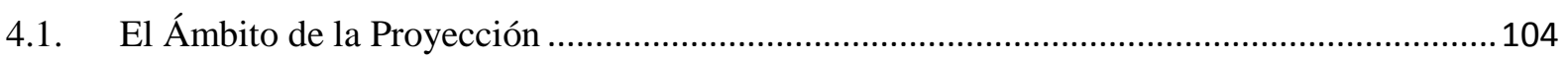

4.2. Selección del Método de Proyección ........................................................................................ 104

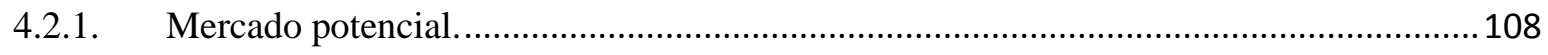

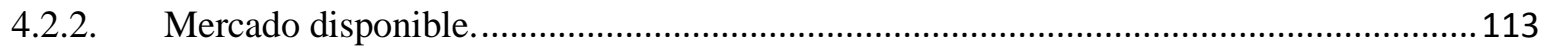

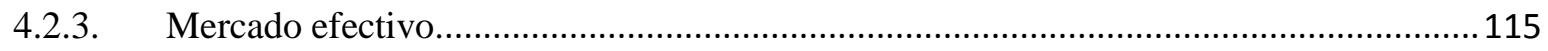

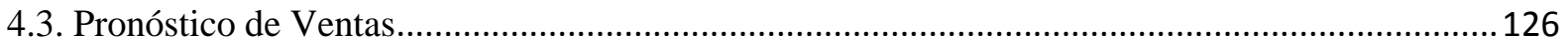

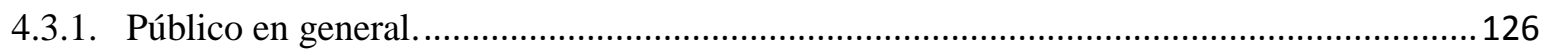

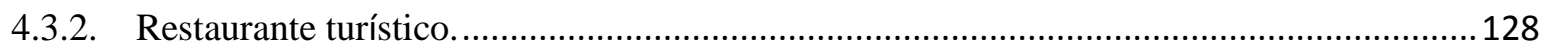

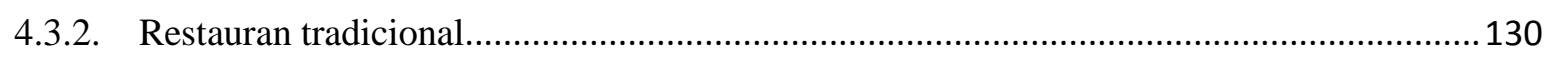

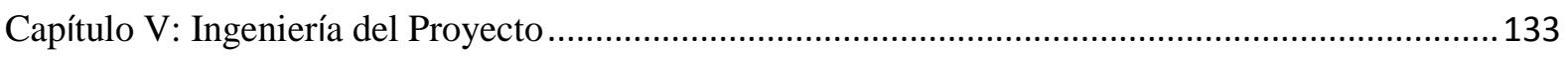

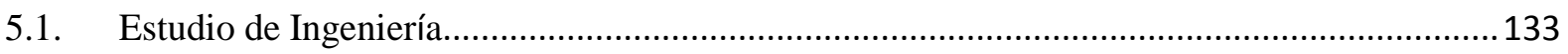

5.1.1. Modelamiento y selección de procesos productivos...................................................133

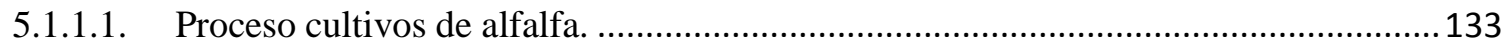

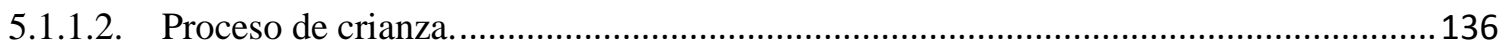

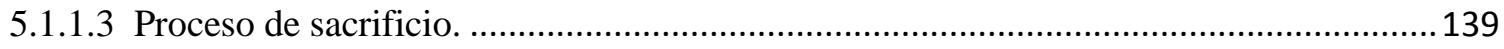

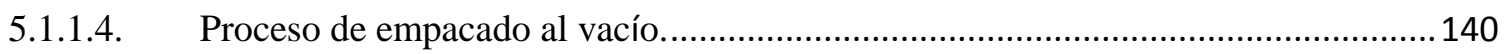

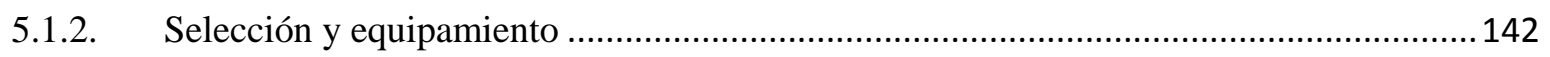

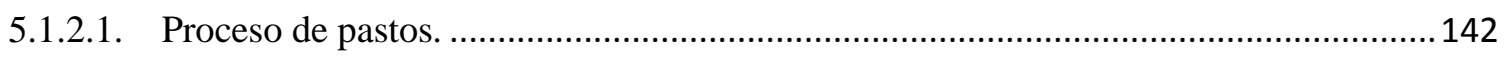

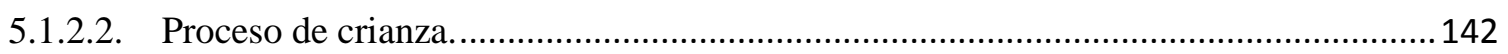

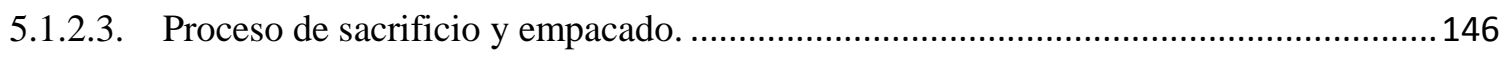




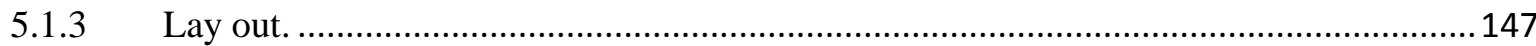

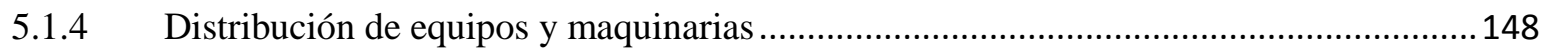

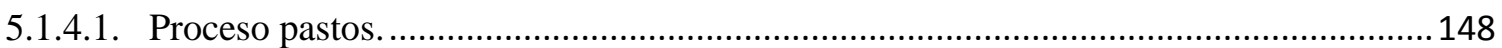

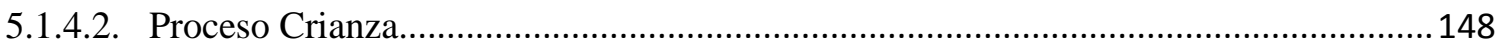

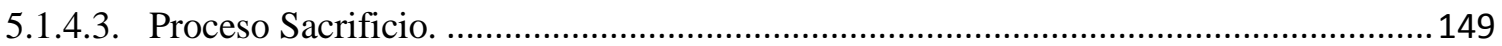

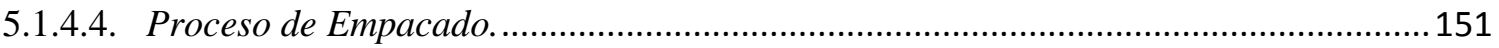

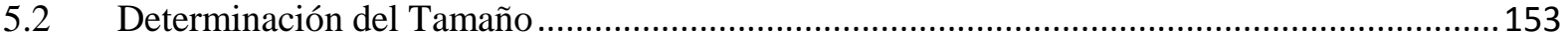

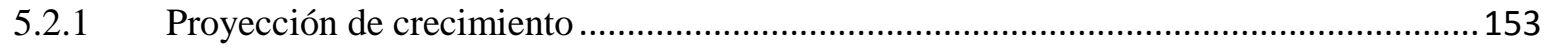

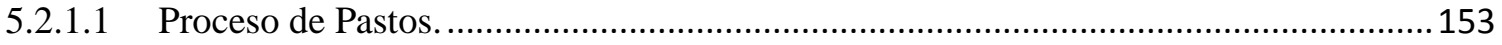

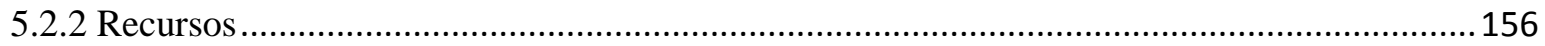

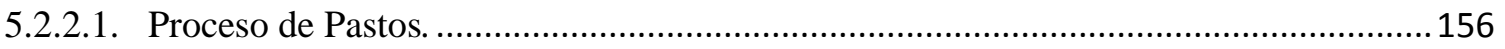

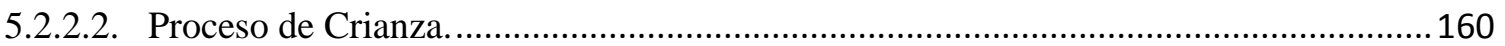

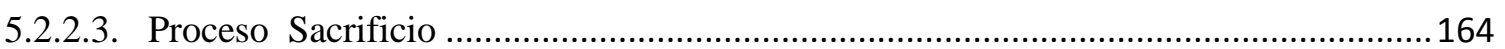

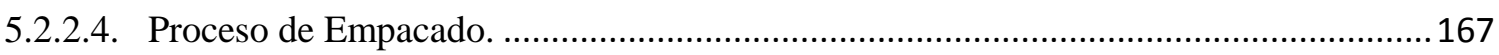

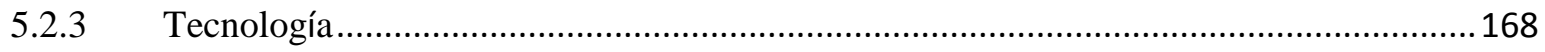

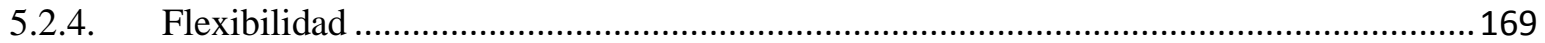

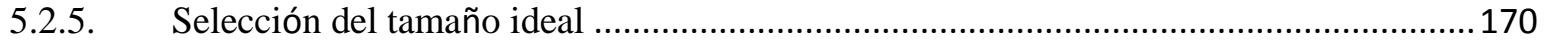

5.3. Estudio de Localización .................................................................................................. 170

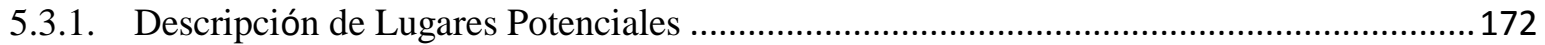

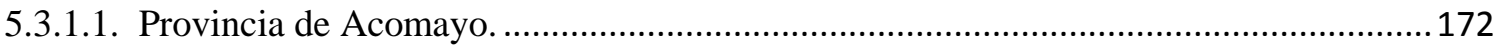

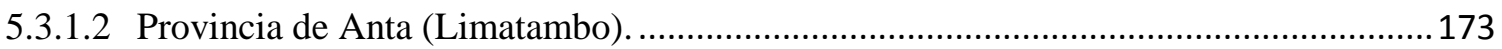

5.3.1.3. Definición de factores de localización. ........................................................................ 175

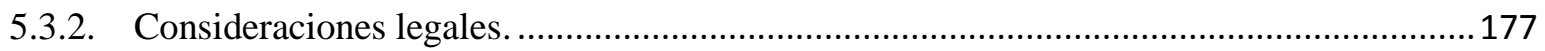

5.3.2.1. Identificación del Marco Legal........................................................................... 177

5.3.2.2 Ordenamiento Jurídico de la Empresa.................................................................. 178

5.4. Determinación de la Localización Óptima.............................................................................179

Capítulo VI: Aspectos Organizacionales ...................................................................................... 180

6.1. Caracterización de la cultura organizacional deseada............................................................. 180

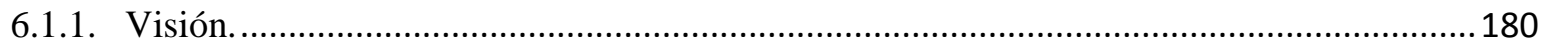

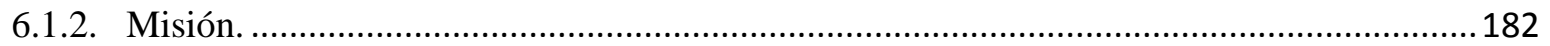

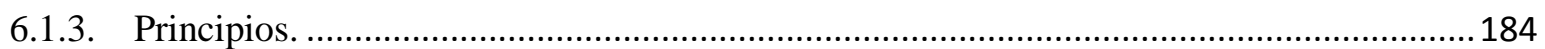

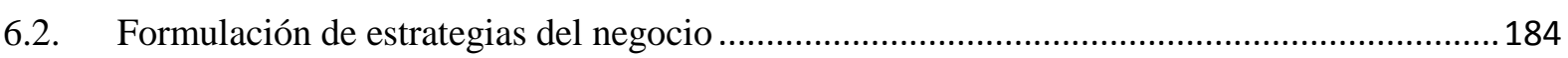

6.3. Determinación de las ventajas competitivas críticas .......................................................... 185

6.4. Diseño de la estructura organizacional deseada ..................................................................... 186 


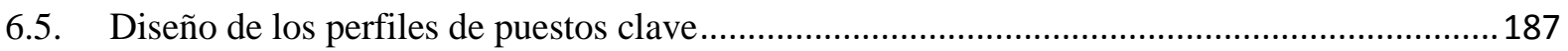

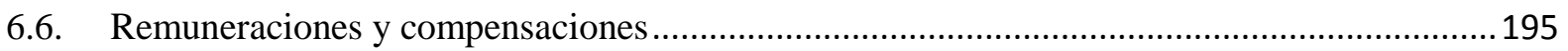

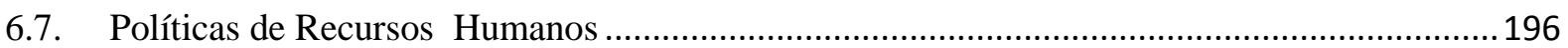

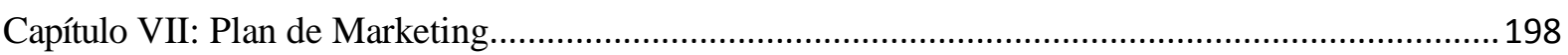

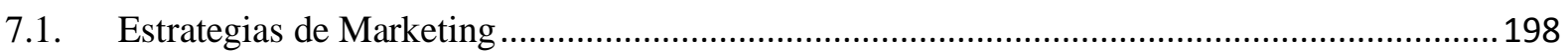

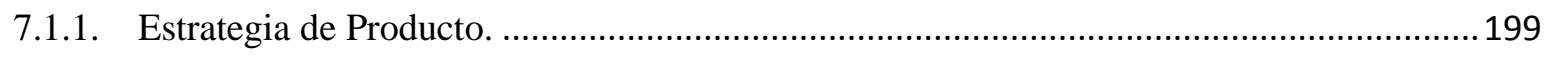

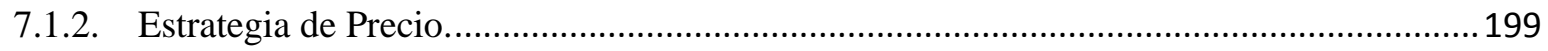

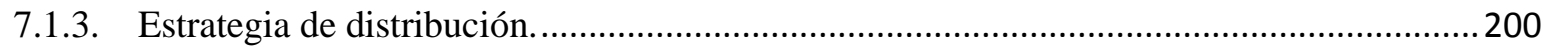

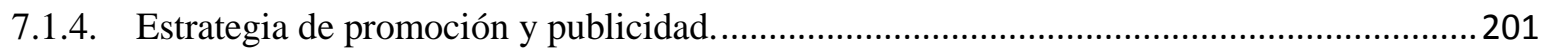

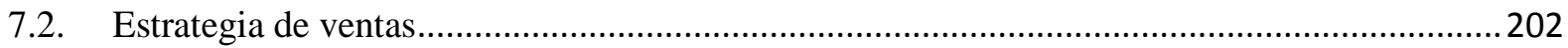

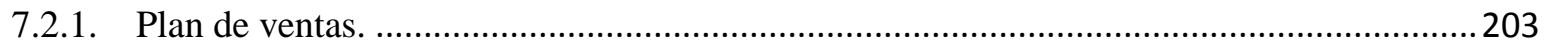

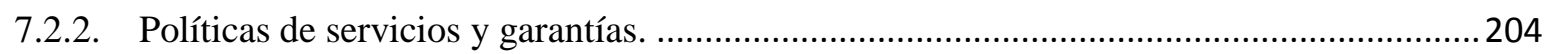

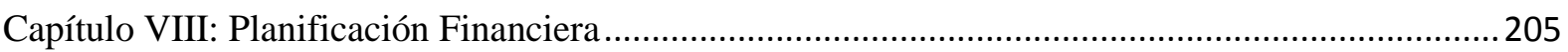

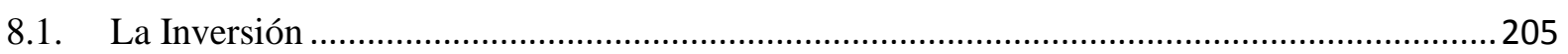

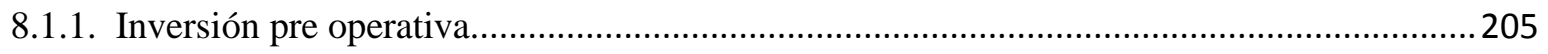

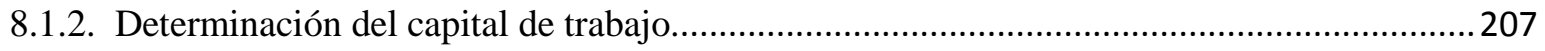

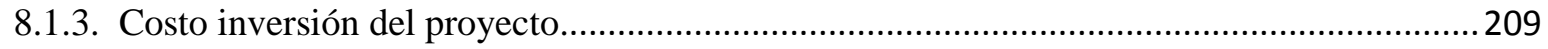

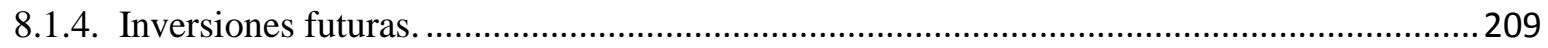

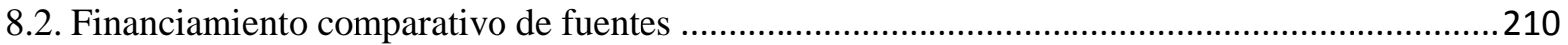

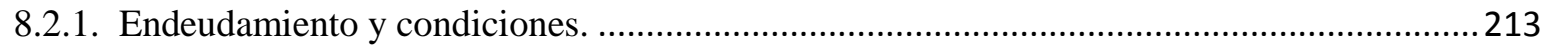

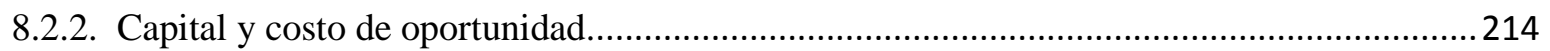

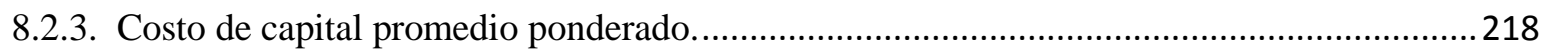

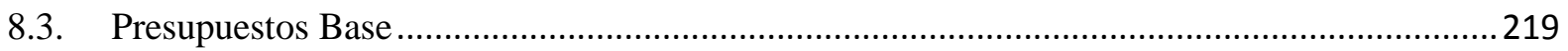

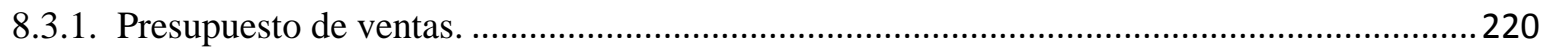

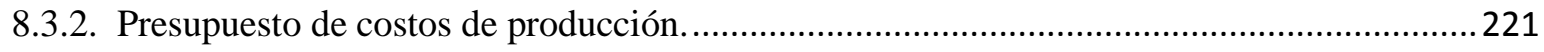

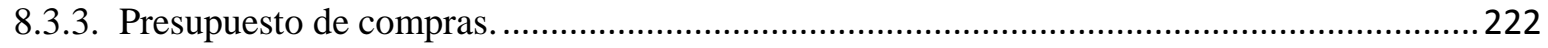

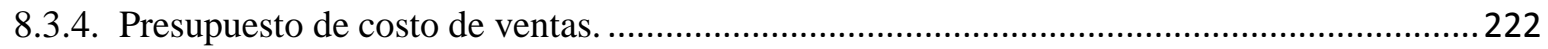

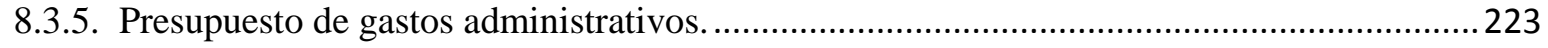

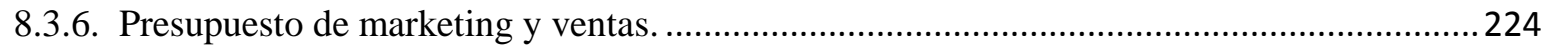

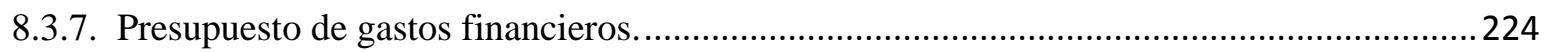

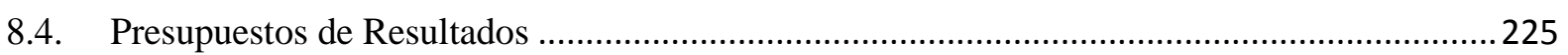

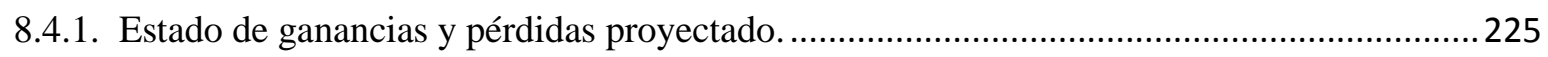

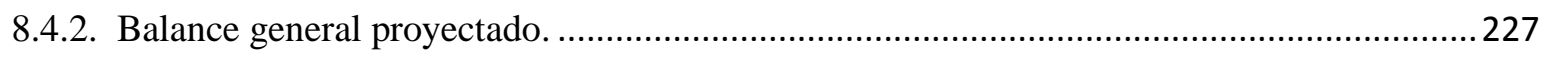

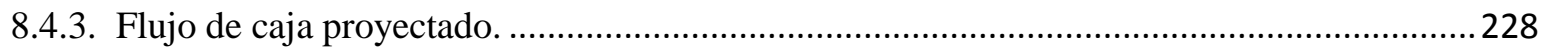




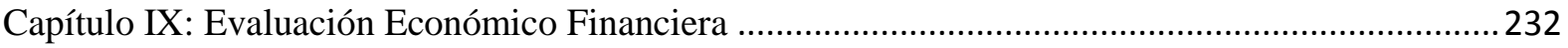

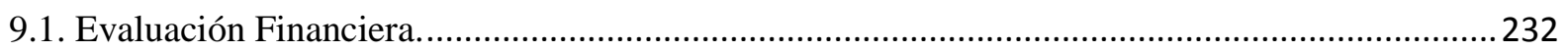

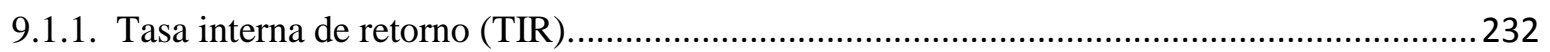

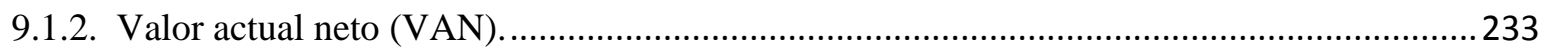

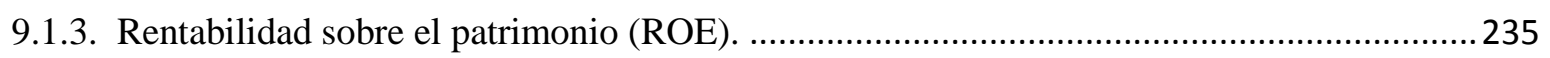

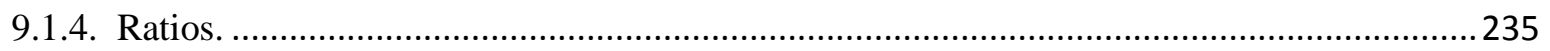

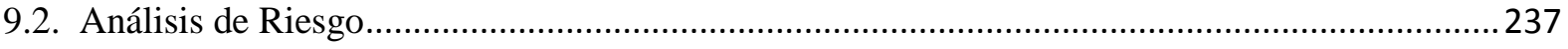

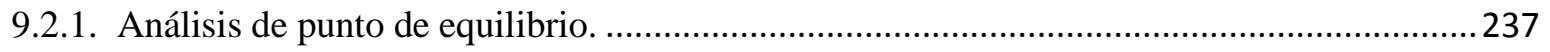

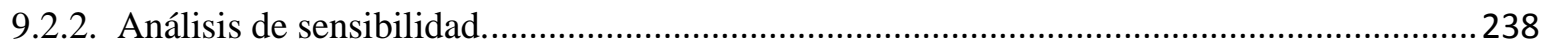

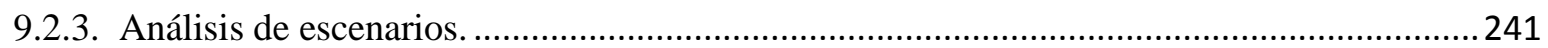

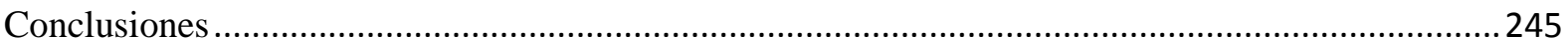

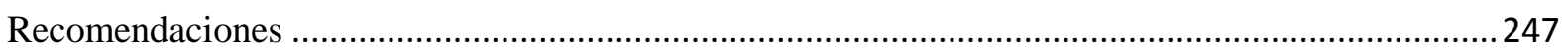

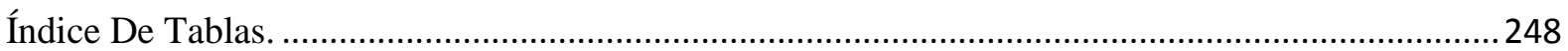

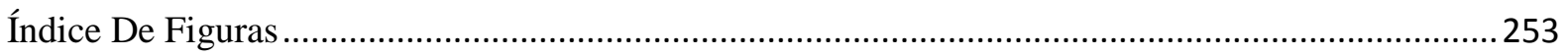

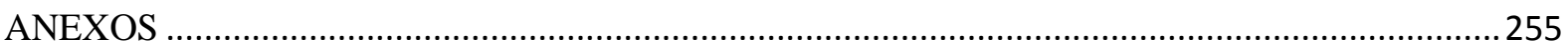




\section{Introducción}

La presente investigación nace de la necesidad de contar con un producto representativo de la zona, el mismo que brinde las mejores condiciones para el consumo humano, debido a que en la región no existe un centro tecnificado que cuente con técnicas y tecnologías apropiadas que permitan industrializar la carne de cuy, es por ello, que se cree necesario contar con un centro de producción industrial, el cual permita brindar un producto ecológico y de calidad. Las ventajas de la crianza de cuyes a través de un proceso industrializado se ve reflejado en la calidad de esta especie herbívora, con un ciclo reproductivo corto, la facilidad de adaptación a diferentes ecosistemas y su alimentación versátil. El cuy es pues, un animal de importancia no solo económico y nutricional para la población de la región del Cusco, sino que engloban aspectos de gran importancia sociocultural.

El análisis efectuado arroja resultados sumamente importantes los cuales serán materia de estudios posteriores, siendo el presente proyecto una base para evaluar las acciones de apoyo futuras, especialmente aquellas orientadas al desarrollo de la región Cusco. El consumo de carne de cuy se viene incrementado de manera sostenida en el mercado local; probablemente debido al turismo gastronómico, a las corrientes de cocina Novo andina, que tienen como insumo esta carne

Finalmente se ha demostrado que el cuy que se cría en la actualidad hasta los 3 meses el mismo que tiene demanda el mercado local, con carcasas de entre 650 a 720 gr., pesos fácilmente obtenidos a través de una crianza industrializada. 


\section{Resumen Ejecutivo}

El presente Plan de Negocio "Crianza, Industrialización y Comercialización de Carne de Cuy Ecológico en la Región del Cusco”, es un estudio que consiste en brindar la viabilidad de la propuesta de inversión en la implementación de una planta de producción de carne a base de cuy dirigida al consumidor de las provincias de Calca, Urubamba y Cusco cumpliendo con todos los estándares de salubridad requeridos, cubriendo toda la cadena productiva de este tipo de carne, desde el cultivo de pastos, crianza, reproducción, sacrificio, empacado y comercialización, con la finalidad de poner al mercado un producto ecológico que reúna todas la normas en higiene y brinde un valor nutricional garantizado.

La planta se localizaría en la provincia de Anta, distrito de Limatambo ubicado a 85 km. de la ciudad del Cusco a 2,554 m.s.n.m. ya que reúne condiciones de suelo favorable que garantiza el cultivo de pastos con seis cortes al año así como un clima apropiado para la crianza de este animal con tres meses de engorde, únicamente con alfalfa, además de ofrecer terrenos para estos propósitos con precios bajos. El traslado del producto final se realizara en furgoneta y en bandejas con un tiempo estimado de traslado de 1 hora con 30 minutos hasta el centro de expendio y de este a los restaurantes turísticos y tradicionales.

Para la inversión del presente plan se estimó como inversión pre operativo nueve meses, en los cuales se consideraron las siguientes etapas:

Cultivo de pastos: alquiler de terreno, preparación de terreno, cultivo de terreno, adquisición de semilla, motoneta y personal entre otros para la implementación de cinco hectáreas de pastos. 
Construcción de Galpones y Jaulas para Reproducción y Cría: adquisición total del terreno, construcción de galpones para reproducción y cría de acuerdo al volumen proyectado.

Compra de Reproductores: La adquisición de dos lotes de reproductores machos y hembras a razón de siete hembras por cada macho.

Construcción de Camal: adquisición de instrumental para beneficio, pago de personal especializado en dicho proceso e implementación del área de empacado.

Este esfuerzo exige una inversión total de S/. 689,708 en la etapa pre operativo distribuido en inversiones de activos fijos, intangibles y capital de trabajo.

La fuente principal de ingresos es la venta de los cuyes empacados al vacío con tres meses de edad que se ofrece a s/.20.50 sin IGV. Asimismo se considera un margen del 10\% del volumen de producción para venta como producto no vendido el mismo que se otorgara a los trabajadores como bonos de productividad y/o como degustación a los pasantes de restaurantes y público en general, de igual manera se castiga este volumen de producción con un $5 \%$ de mortandad en el proceso de engorde

El mercado mercado objetivo está conformado por el Público en General (entre los 18 a 75 años de edad de los niveles A, B y C), Restaurantes Turísticos y Restaurantes Tradicionales de los principales distritos de Cusco y las provincias de Calca y Urubamba. Siendo estos negocios aquellos que expenden en su carta la carne de cuy en sus diferentes presentaciones.

Los resultados económicos financieros proyectados producto de la evaluación aplicada arrojan índices de gestión, rentabilidad y solvencia favorables en el horizonte estimado, proyectando un margen de utilidad de $18 \%$ frente al volumen de ingresos y un 
grado de apalancamiento de $32 \%$ frente al endeudamiento adquirido para la puesta en marcha.

Luego de estimar la tasa de costo de oportunidad de $14.98 \%$ más el agregado adicional de $5 \%$ por prima de riesgo por negocio nuevo se obtuvo una tasa de descuento por $19.98 \%$ la cual determino un valor actual neto de los resultados obtenidos por S/. 628, 832 y una tasa interna de retorno por $49.62 \%$ lo cual nos indica que la actividad es rentable desde el punto de vista económico y financiero con un VANF de S/.1, 435,230 y TIRF de 58.55\% por lo que se decide favorablemente la intención de inversión sobre el proyecto.

Los periodos de recuperación de capital estimados, fueron determinados en el primer año de puesta en marcha en relación a los resultados netos proyectados, frente a las inversiones realizadas en cada periodo.

El punto de equilibrio estima un nivel de 17,0266 unidades producidas para la recuperación de la inversión realizada en el primer año reduciéndose a 15,565 unidades para el último periodo, es decir cuando la utilidad operativa es igual a cero, lo que nos da una holgura muy interesante frente a riesgos y factores de contingencia que detallaremos a lo largo del estudio.

El plan de negocios incluye una descripción de los factores claves de éxito, así como la ingeniería necesaria para obtener un producto diferenciado que genere valor agregado hacia el consumidor, las cuales según las encuestas nos evidencian la aceptación del producto. Así mismo tenemos propuesto un equipo de expertos en crianza, sacrificio que cumplirán las funciones técnicas necesarias para gestionar apropiadamente el proceso de producción, comercialización y dirección del proyecto en el largo plazo. 


\section{Capítulo I: Generalidades}

\subsection{Antecedentes}

Se ha escrito mucho sobre el cuy, cuya crianza y utilización se atribuye a las culturas preincas, por el hecho de haberse encontrado restos óseos de este roedor alrededor de las viviendas. También conocido como cavia porcellus, cobayo, curi, conejillo de indias o guinea pig, es una carne que se consume tradicionalmente desde tiempos ancestrales por el poblador andino que ha sido la base de su alimentación y economía doméstica.

La teoría de la escuela Alemana indica que el cuy se originó en el Gran Guayano Brasilero, en la vertiente oriental de la cordillera de los andes, dicha región es de clima templado y caluroso, según esta escuela los cuyes vivían en comunidad con el magaz, tigrillo, armadillos y otros animales. Esta teoría sostiene que a la fecha existen 17 géneros de Cavia, en estado salvaje y solo el Cavia Porcellus es doméstico, hecho suficiente para sustentar dicha teoría con base científica, ya que vendrían a ser los ancestros de los actuales cuyes, este era más grande y de mayor peso.

Con este antecedente se han dado estudios desde puntos de vista muy distintos pasando desde el económico, nutricional y productivo. Como señaló la Dirección Regional de Agricultura Cusco (2012), el cuy se cría desde tiempos milenarios de manera fácil, ofreciendo la carne de este animal un alto valor nutricional proteico y bajo contenido en grasas saturadas en comparación a otros animales de crianza para consumo humano .

Asimismo, el cuy representa un costo bajo de crianza por tener un ciclo de vida corto y facilidad de alimentación. Hoy en día la crianza de cuyes se puede hacer a través de dos sistemas de producción claramente diferenciados; el primero, el sistema "Tradicional", realizado por las familias de la región de Cusco, que tiene como objetivo el autoconsumo y la venta de su excedente, con bajo nivel técnico y menor calidad del producto final. El segundo 
llamado "Tecnificado", que ha sido introducido de manera incipiente en los últimos años; el cual pretende lograr estándares de calidad, producción a escala con un fin completamente industrial y comercial. La carne de cuy es un producto con gran potencial de ser comercializado tanto en el mercado regional, nacional e incluso internacional; desde hace 30 años el Instituto Nacional de Investigación Agraria (INIA), ha invertido en el desarrollo de la RAZA PERU, ideal para el plan de negocios propuesto.

En Lima y Huancayo se han implementado centros de producción de carne de cuy en sus distintas presentaciones, por otro lado en la región del Cusco no se cuenta con un centro de producción adecuado el cual pueda satisfacer la demanda del mercado que se tiene, contando solamente con algunos productores que tratan cubrir el mercado netamente turístico.

\subsection{Determinación del problema u oportunidad}

Actualmente en la región del Cusco hay poca oferta de cuyes de calidad y condiciones sanitarias, debido a que no existen productores que utilicen métodos y técnicas adecuadas de crianza que permitan obtener un producto ecológico el cual pueda ser industrializado y comercializado de manera masiva en el mercado.

Esto se da como resultado de la falta de conocimientos por parte de los productores de cuy que hacen este proceso de manera empírica y tradicional. En este entender al no contar con métodos y técnicas adecuadas de crianza no es posible una articulación entre la producción y los mercados donde se registra una demanda insatisfecha.

La escasez de pastos como alimento representa un problema para la cría y producción de carne de cuy, ya que ante la disminución del alimento orgánico los productores reemplazan este con suplementos alimenticios alternativos lo que afecta el valor nutricional, la calidad y alterando el sabor de la carne de cuy como producto final.

De acuerdo a la Dirección Regional de Agricultura de Cusco (2012) solo el 5.8\% de los productores se dedican a comercializar un promedio de 400 carcazas mensuales, los 
demás criadores lo destinan para subsistencia; ofreciendo una oportunidad para desarrollar un plan de negocios el cual pueda satisfacer la demanda insatisfecha que existe actualmente en el mercado, también hay que considerar que la región de Cusco cuenta con las condiciones necesarias para el cultivo de la alfalfa principal alimento que consumen los cuyes. (p. 25)

En los últimos años la ciudad del Cusco ha registrado un aumento en la implementación y puesta en marcha de restaurantes turísticos y picanterías tradicionales, los cuales han incluido en sus cartas platos a base de cuy.

\subsection{Justificación del Proyecto}

La falta de un centro de crianza e industrialización que cuente con las técnicas y métodos adecuados, hace que no sea posible el desarrollado de canales de comercialización que permitan a las familias, establecimientos comerciales y restaurantes en general tener a la mano este producto. Existiendo suficientes elementos de juicio para percibir una buena aceptación masiva del producto.

Por lo que el plan de negocios propuesto constituiría una alternativa que permita revalorar una especie altamente nutritiva impulsando su consumo de una manera en la cual se perciba un valor agregado al industrializarlo.

De igual manera que cumpla con todas las normas sanitarias en los procesos de cultivos de pastos, crianza, sacrificio, empacado y comercialización 
Tabla 1

Raza de Cuy Mejorada con Mayores Índices de Ganancia de Peso, Número de Crías y

Mortalidad.

\section{Criterios de Evaluación}
a. Sistema de crianza.
En jaula con galpones técnicamente
b. $\%$ de mortalidad.
diseñados.
a. Alimentación.
$10 \%$
a. $\mathrm{N}^{\circ}$ de pariciones al año.
$100 \%$ pastos naturales.
b. $\mathrm{N}^{\circ}$ de crías por año.
5.0
c. Frecuencia de saca (sacrificio).
10
e. Peso promedio de venta al mercado.
A los 90 días
f. Peso promedio de cuyes para el consumo
560 gr. en carcasa
g. Consumo per cápita.
S/. 8.00 peso vivo
h. Precio promedio de cuyes para reproducción S/. 15 peso vivo

Nota. Adaptado del Estudio realizado por el Equipo - UFPI-Dirección Regional de Agricultura Cusco 2010

\subsection{Objetivos generales y específicos}

\section{Objetivo General.}

Elaborar un plan de negocio que permita la crianza, industrialización y comercialización de la carne de cuy como un producto ecológico de consumo masivo en la Región del Cusco, a través de una propuesta eficiente en la producción y comercialización de esta carne, que genere una alternativa de desarrollo económico y social para la región y que sea sustentable económicamente para los inversionistas en el proyecto.

\section{Objetivos Específicos.}

1. Elaborar el estudio de mercado para conocer el nivel de aceptación de la carne de cuy ecológico, con las condiciones de calidad y precios propuestos. 
2. Localizar, dimensionar e implementar una planta que cuente con las técnicas y métodos adecuados de crianza e industrialización para lograr un producto ecológico de alto valor nutritivo y precio competitivo en el mercado.

3. Desarrollar estrategias para implementar un canal de distribución que pueda satisfacer la demanda insatisfecha de este producto ecológico.

4. Analizar la viabilidad económica-financiera del proyecto así como de los indicadores e evaluación y su impacto ambiental.

\subsection{Alcances y limitaciones de la investigación}

El plan de negocios se concentra en la crianza, industrialización y comercialización de carne cuy ecológico, que comprenderá la Región del Cusco debido a que actualmente presenta condiciones favorables para la producción de pastos como alimento base de estos animales. Se propone que el alcance cubra un ámbito local dentro de los primeros cinco años para luego expandir el ámbito de comercialización a las regiones de Arequipa y Lima metropolitana por presentar condiciones adversas para el desarrollo de este producto como son la no producción de pastos para alimento y representar mercados potenciales para la comercialización de este tipo de carnes ecológicas.

El plan de negocios tiene limitaciones referente a información estadística del consumo per cápita de la carne de cuy al presentar estadísticas muy dispersas las cuales no brindan una información precisa sobre los niveles de producción, oferta en el mercado, crecimiento registrado, entre otras, esto debido a que la mayor concentración de este tipo de actividad se desarrolla de manera empírica en sectores rurales. Los estudios realizados por parte del ministerio de agricultura y direcciones encargadas del sector son orientados a desarrollo técnico y sanidad, sin embargo aún se mantiene una baja formación y capacitación a nivel empresarial. 


\section{Capítulo II: Estructura Económica Del Sector}

\subsection{Descripción del Estado Actual de la Industria}

El presente plan de negocios está fundamentado en la carencia actual en el mercado de métodos y técnicas adecuadas de crianza de cuyes, en este sentido se elegirá razas que guarden características de excelencia en genotipo de carne y adaptabilidad a la zona como son las razas Mi Perú e Inti, métodos y técnicas que podrían ser aplicadas en un centro tecnificado, que permita la industrialización y comercialización masiva de esta carne con la que se puede poner en valor sus cualidades nutritivas, así como se pueda cubrir la demanda insatisfecha existente en el mercado regional en sitios como restaurantes turísticos, picanterías, festividades de distritos tradicionales del Cusco donde el consumo de esta carne es habitual, ferias gastronómicas dominicales y público en general, haciendo de esta manera que el cuy se constituya en un producto con muchas posibilidades y de fácil introducción al mercado regional.

Para desarrollar el análisis de la industria es necesario tomar en cuenta cómo se comporta la producción mundial, nacional y local lo que nos ha de permitir con una mayor objetividad la viabilidad del proyecto propuesto, es así que:

A Nivel Mundial, el cuy siendo originario de la zona andina de Perú, Bolivia, Colombia, y Ecuador, se constituye como un producto nativo de alto valor alimenticio y bajo en costos de producción, que de acuerdo a Sierra Exportadora en su Informe acerca del Perfil Comercial del Cuy del año 2013 indica que el 41\% de la producción de carne de cuy fue realizada por China con 684,961 toneladas, y en la región, Venezuela era el país que exportaba la mayor cantidad de carne de cuy con 270,000 toneladas que representaba el $16 \%$ de la producción en ese entonces , también es sabido que esta carne tiene gran demanda en 
países donde existen colonias de los países donde su consumo es habitual siendo Estados Unidos el país que más demanda la carne de cuy con 76,091 toneladas para el año 2012.

A Nivel Nacional, de acuerdo al Censo Agropecuario del Instituto Nacional de Estadística e Informática (2012), se estima que el Perú produce más de 12,695,030 cuyes, esto debido a que en el país hay mayor producción y consumo de esta carne, con un sistema de crianza familiar. Por tener una capacidad de adaptabilidad el cuy se encuentra en casi todo el territorio, actualmente se está desarrollando con existo un sistema de producción en mayor proporción en los departamentos de Cajamarca, Cusco, Ancash, Junín, Huánuco, La Libertad, Apurímac, Lima, Huancavelica y Arequipa. Siendo Cajamarca la región que tiene la mayor producción con 2, 408,094 cuyes criados anualmente. Como señala la Ingeniero Liliana Chauca (1997) la capacidad de adaptabilidad de este animal menor a diversas condiciones climáticas permite que podamos encontrarlo desde la costa o el llano hasta alturas de 4,500 metros sobre el nivel mar y en zonas tanto frías como cálidas.

La Región del Cusco; con una producción de cuyes anual de 1,715,174 (Instituto Nacional de Estadística e Informática [INEI], 2012), producción que se encuentran en las zonas de Anta, el valle sagrado comprendido por Calca y Urubamba, Cusco, y en la zona sur tenemos la provincia de Canchis, Quispicanchis, donde existe la mayor cantidad de productores de la Región del Cusco, congregados en asociaciones de criadores los cuales realizan una crianza de tipo familiar, no habiendo actualmente una empresa capaz de satisfacer por completo la demanda del mercado regional y por constituirse el cuy como una carne de consumo habitual en todos los hogares cusqueños desde tiempos inmemoriales, y que en la actualidad es ofertado de una manera poco adecuada sin que preste las condiciones de calidad y sanidad exigidos, también es sabido que por constituirse en un alimento de consumo habitual en la población del Cusco este es consumido en todos los estratos sociales, habiendo fechas importantes que por tradición la población prefiere consumir platos a base de carne de 
cuy como es el caso de la festividad del Corpus Christi fecha en donde se expende el plato llamado Chiriuchu que está a base de carne de cuy, también es importante mencionar que existes restaurantes especializados que ofertan platos solo en base a la carne de cuy ubicados en la zona de Tipón y el barrio de Independencia, lugares que semanalmente son visitados por la población local. De la misma manera, este producto es expendido en restaurantes tradicionales y que a pesar de haber platos a base de otro tipo de carnes (pollo, res, pescado, porcino) se tiene preferencia a los platos a base de carne de cuy por parte de los comensales.

\subsubsection{Segmentación de la industria.}

De acuerdo a lo indicado por el Ministerio de Agricultura al 2016 no se cuenta con estadísticas actualizadas sin embargo se sabe que en la actualidad quien tiene la mayor producción de cuy es la sierra, seguido de la costa y en menor proporción la selva, lo que se puede observar en la tabla siguiente:

Tabla 2

Producción Nacional por Región Natural

\begin{tabular}{ccc}
\hline Región & Producción & \% \\
\hline Costa & 888,652 & $7 \%$ \\
Sierra & 1679,428 & $92 \%$ \\
Selva & 126,950 & $1 \%$ \\
Total producido & 12695,030 & $100 \%$ \\
\hline
\end{tabular}

Nota. Adaptado del Censo Agropecuario 2012-INEI y Producción Nacional 2010-Ministerio de Agricultura

En la tabla se observa que de los 12, 695,030 de cuyes producidos, el $92 \%$ pertenece a la región sierra, seguido por el 7\% que se realiza en la costa y en una mínima cantidad en la selva.

De acuerdo al Ministerio de Agricultura y lo señalado en el censo agrario 2012, el cual ayuda a tener un panorama de cómo actualmente está distribuida segmentación de la industria, 
se tiene el siguiente resumen de volumen de producción por región como resultado consolidado anual:

Tabla 3

Distribución de la Producción Nacional por Región.

\begin{tabular}{cccc}
\hline Región & Poblacion & Cantidad de cuyes & $\%$ \\
\hline Cajamarca & $1,529,755$ & $2,408,094$ & $19 \%$ \\
Cusco & $1,316,729$ & $1,715,374$ & $14 \%$ \\
Ancash & $1,148,634$ & $1,643,415$ & $13 \%$ \\
Junín & $1,350,783$ & 958,796 & $8 \%$ \\
Huánuco & 860,548 & 687,311 & $5 \%$ \\
La Libertad & $1,859,640$ & 721,021 & $6 \%$ \\
Apurímac & 458,830 & $1,012,181$ & $8 \%$ \\
Lima & $9,834,631$ & 740,812 & $6 \%$ \\
Huancavelica & 494,963 & 348,223 & $3 \%$ \\
Arequipa & $1,287,205$ & 437,274 & $3 \%$ \\
Totales & $20,141,718$ & $12,695,030$ & $100 \%$ \\
\hline
\end{tabular}

Nota. Adaptado del Censo Agropecuario 2012-INEI

El 19\% de la producción nacional se realiza en la región de Cajamarca seguido por un 14\% que realiza en Cusco, en un porcentaje similar al de Cusco se observa que Ancash produce 1,643,415 del total de la producción nacional lo que representa el 13\%, y le siguen los departamentos de Junín, Huánuco, La Libertad y Apurímac con el 8\%,5\%,6\% y 8\% respectivamente, lugares donde es consumido en todos los niveles socioeconómicos por ser este un alimento tradicional y de consumo habitual, también hay que mencionar que una de las regiones que menos produce cuyes es la región de Lima la cual representa el 6\% de la producción nacional. 
De este $14 \%$ de producción de la región del Cusco, en la actualidad se cuenta con un número importante de productores que están distribuidos en seis provincias las cuales detallamos a continuación por cantidad de productores y segmentos de consumidores:

Tabla 4

Segmentación de Criadores y Consumidores

Segmentación de Criadores

Distrito

Anta

Calca

Cusco

Canchis

Quispicanchi

Urubamba
Nro de Criadores

25

17

08

13

10

\section{Segmentación de Consumidores}

Estratos A-B-C-D

Consumen en fiestas familiares, costumbristas, Restaurantes tradicionales al Horno o Chaqtao
Turistas

Consumen en Restaurantes Turísticos en diferentes Tipos de Preparación

Nota: Adaptado de la Dirección Regional de Agricultura Cusco "Censo agropecuario" por gerencia de estadística - 2006 .

Del cuadro se puede notar que la mayor cantidad de asociaciones de criadores se encuentran en la zona de Anta, esto debido que en estos cinco últimos años se ha promovido la crianza de estos animales menores gracias a la intervención del estado a través de la Dirección Regional de Agricultura y Organizaciones No Gubernamentales (ONG) ; también podemos observar que la zona de menor cantidad de productores es la zona de Urubamba ubicada en el valle Sagrado de los Incas, zona que presenta un gran potencial por ser paso obligado de turistas que visitan Machupicchu.

Como ya se mencionó este tipo de carne es consumido por los distintos estratos sociales en festividades familiares (cumpleaños, bautizos, matrimonios, etc) costumbristas (en las fiestas de Corpus de los distritos de Cusco como San Jerónimo, San Sebastián, Santiago, 
etc.), así mismo en picanterías tradiciones todos ellos lo preparan al Horno o Chaqtado y restaurantes turísticos que elaboran diferentes tipos de preparación a base de esta carne.

\subsubsection{Empresas que la conforman.}

Perú, Bolivia y Ecuador actualmente son los tres países que más carne de cuy exportan, en nuestro país se encuentra la mayor producción de carne de cuy para consumo tanto interno como externo, contando con un consumo nacional de 116,500 toneladas de carne. Es así que en la actualidad se cuenta con las siguientes empresas a nivel nacional, las cuales aportan la mayor cantidad de la producción del país, siendo estas:

1. Comercial Mayorista S.A.

2. Empresa Comunal Valle Hermoso.

3. E.E. INIA-Lima.

4. Universidad Nacional La Agraria La Molina.

5. Granja EL Cuyero.

6. Granja San Pedro.

7. Comunidad Campesina de Michivilca.

8. APROCUP

Además como se ha mencionado el Perú es uno de los países que exporta carne de cuy junto a Ecuador y Bolivia, según informe de Sierra Exportadora se tiene que la principal empresa que exportaba carne de Cuy es Megabusiness Perú con un 97.96\% de la producción total exportada seguida de The Green Farmar SAC con un 2\%, siendo el principal destino el mercado Estadounidense, Español y Japonés en menores cantidades. 
Tabla 5

Principales Empresas que Exportan Carne de Cuy al Exterior

\begin{tabular}{|c|c|c|c|c|c|c|c|}
\hline Empresa & 2008 & 2009 & 2010 & 2011 & 2012 & $\begin{array}{c}\% \\
\text { Partic. } \\
2012\end{array}$ & $\begin{array}{c}\% \text { Variac. } \\
2011-2012\end{array}$ \\
\hline $\begin{array}{l}\text { Megabusiness } \\
\text { Perú SAC }\end{array}$ & 0 & 3,758 & 30,584 & 39,660 & 74,536 & 97.96 & 87.94 \\
\hline $\begin{array}{l}\text { The Green } \\
\text { Farmer SAC }\end{array}$ & 59,281 & 15,234 & 0 & 5,282 & 1,555 & 2.04 & -70.56 \\
\hline $\begin{array}{l}\text { Andino } \quad \text { Food } \\
\text { SAC }\end{array}$ & 0 & 7,692 & 13,087 & 15,565 & 0 & 0 & -100.00 \\
\hline $\begin{array}{l}\text { LR Consultores } \\
\text { SAC }\end{array}$ & 0 & 0 & 5,750 & 0 & 0 & 0 & 0 \\
\hline $\begin{array}{l}\text { Expoagro DIGI } \\
\text { SCRL }\end{array}$ & 0 & 1 & 0 & 0 & 0 & 0 & 0 \\
\hline Sasil Export SAC & 0 & 1,249 & 0 & 0 & 0 & 0 & 0 \\
\hline Jaks Corp SAC & 3,180 & 0 & 0 & 0 & 0 & 0 & 0 \\
\hline Keru-Fish EIRL & 800 & 0 & 0 & 0 & 0 & 0 & 0 \\
\hline $\begin{array}{l}\text { Macro Trade Peru } \\
\text { SAC }\end{array}$ & 2,595 & 0 & 0 & 0 & 0 & 0 & 0 \\
\hline $\begin{array}{l}\text { Macro Export } \\
\text { Peru SAC }\end{array}$ & 3,019 & 0 & 0 & 0 & 0 & 0 & 0 \\
\hline $\begin{array}{c}\text { Taste Latino SAC } \\
\text { Total }\end{array}$ & $\begin{array}{c}2,107 \\
70,982\end{array}$ & $\begin{array}{c}0 \\
27,934\end{array}$ & $\begin{array}{c}0 \\
49,421\end{array}$ & $\begin{array}{c}0 \\
60,507\end{array}$ & $\begin{array}{c}0 \\
76,091\end{array}$ & $\begin{array}{c}0 \\
100.00\end{array}$ & $\begin{array}{c}0 \\
-82.62\end{array}$ \\
\hline
\end{tabular}

Nota. Tomado de la Asociación Regional de Exportadores de Lambayeque 2012- AREX.

En la Región del Cusco en la actualidad se tienen empresas de productores de esta carne los cuales se denominan Asociaciones de productores de cuy, que como ya habíamos mencionado se encuentran en Anta, el valle sagrado comprendido por Calca y Urubamba, Cusco, y en la zona sur tenemos la provincia de Canchis, Quispicanchis. (Véase el anexo 1Tabla de Criadores de Cuyes de la Región del Cusco). 


\subsection{Tendencias De La Industria (Crecimiento Inversiones)}

A nivel nacional se tiene programas como Sierra Exportadora, Promperu, Asociación de Exportadores (ADEX), Instituto Nacional de Investigación Agraria (INIA) y el Ministerio de Agricultura, instituciones encargadas de promocionar e incrementar la producción de carne de cuy tanto para el consumo interno como para exportaciones a países como Estados Unidos, Japón y España.

De la misma forma en la Región del Cusco el crecimiento de esta industria está a cargo del gobierno Regional a través de sus distintas direcciones las cuales desde el 2013 vienen incentivando proyectos que contribuyan a desarrollar la producción de cuy (Véase el anexo 2Tabla del Programa de Inversiones 2013-Gobierno Regional del Cusco.)

De acuerdo al Programa de Inversiones para el año 2013 se invirtió s/.3,493,935.60 en 37 programas que tiene como fin mejorar la producción de la crianza y comercialización del cuy, programas que garantizan que en el futuro se pueda contar con una industria que ayude al desarrollo de la Región; sin embargo a la fecha no se cuenta con información de empresas del sector privado que tengan la intensión de desarrollar este sector y menos se tiene referencia de que exista en la actualidad empresa que presente la propuesta de valor del presente Plan de Negocios.

\subsection{Análisis Estructural Del Sector Industrial}

En el presente análisis se brindara información del sector agroindustrial en referencia a la crianza y producción de animales menores, propiamente referido a la crianza, industrialización y comercialización del cuy, se analizara la rivalidad que existe en el mercado, quienes son los proveedores, participantes potenciales y posibles sustitutos, esto con el fin de 
analizar la interactividad de la industria, para este análisis se usara como herramienta la matriz de las cinco Fuerzas de Porter: 


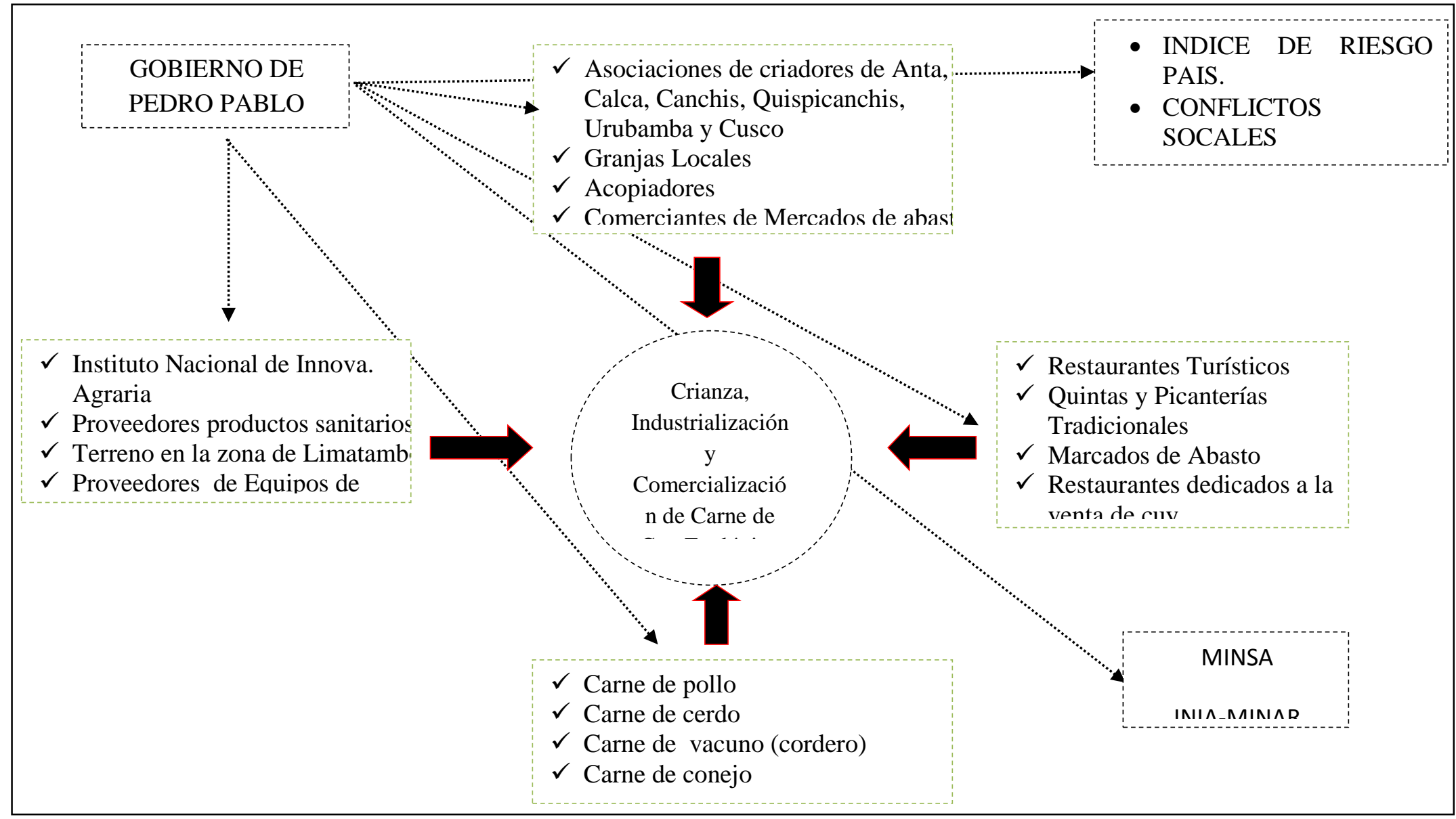

Figura 1. Análisis De La Industria: Análisis Del Entorno Competitivo De La Industria Del Cuy De Acuerdo A Las Cinco Fuerzas De Porter 
Una industria que se encuentra en crecimiento como es el de la Producción y Comercialización de carne cuy, actividad ligada estrechamente con la gastronomía y el Turismo en la región de Cusco pues este producto es ofertado en restaurantes de tipo tradicional y turísticos en donde es habitual observar la concurrencia de visitantes extranjeros, la cual representa el 4.7\% del PBI regional (según el último censo del 2007proyectada a valores constantes hasta el 2014), actividad que tiene un aporte importante al PBI regional después de Extracción y Turismo, ofrece una oportunidad de crecimiento y desarrollo para el Plan de negocios propuesto, el cual merece un análisis a detalle si estas cifras se verán reflejadas en el desarrollo de esta nueva e innovadora propuesta de negocio; para lo cual se hará un análisis si el entorno es atractivo a partir de:

\section{Primera fuerza: EI Poder Negociador de los Proveedores:}

“El poder negociador de los proveedores determina el costo de las materias primas y de otros insumos." (Porter, 2013, p. 5).

- Proveedores de Reproductores:

Al contar con varios proveedores de cuyes reproductores los cuales se encuentran dentro de la Región como a nivel nacional por ser estos un factor clave para el negocio y al existir varios ofertantes en el mercado garantiza que el poder de negociación de estos no sea considerado como una debilidad para el proyecto.

- Proveedores de productos sanitarios

Al tener una propuesta de comercializar un producto ecológico el cual utilizara muy pocos productos sanitarios, hace que esta clase de proveedores no tengan mayor impacto en la producción de los cuyes de acuerdo a nuestra idea de negocio, en este entender su poder es también bajo. 
- Proveedores De Terrenos Zona De Limatambo

Por las condiciones que ofrece la zona de Limatambo tanto en clima, accesos viales y sobretodo suficiente oferta de terrenos tanto para la venta como para alquiler a precios bajos, este aspecto no representa una amenaza ni tiene un grado de negociación determinante para el proyecto.

- Proveedores de equipos de crianza

Al ser una Región en la cual por costumbre se cría y comercializa habitualmente cuyes se cuenta en el mercado con proveedores locales que pueden cubrir las exigencias que se necesita para criar de manera adecuada el cuy para su industrialización, de igual modo también se cuenta con proveedores nacionales que ofertan equipos que se usaran para el proceso de industrialización (envasado al vacío), no siendo un problema para la viabilidad del proyecto.

- Proveedores de Semillas de Pastos Naturales y Alfalfa

Dentro de la propuesta de valor del proyecto se ha contemplado la producción del alimento el cual garantice contar con un productos que cumpla con los estándares exigidos es así que se ha identificado una gran cantidad de proveedores que se dedican a la venta de semilla de pastos y alfalfa por lo que se mitiga cualquier tipo de poder de negociación que pudiese existir por algún proveedor de pastos que sirva de alimento para cuy.

Después de analizar el poder de negociación de cada uno de los proveedores que intervienen directamente en el proyecto se ha llegado a la conclusión que su poder de negociación es bajo y no representan amenaza ni debilidad para el proyecto. 


\section{Segunda Fuerza: Poder Negociador de los Clientes.}

"La fuerza de los compradores incide en precio, lo mismo que en la amenaza de la sustitución, así mismo estos influyen en los costos y en la inversión porque los clientes más poderosos exigen un servicio caro.”(Porter, 2013, p. 5).

Se ha identificado como clientes a los Restaurantes Turísticos, Restaurantes Tradicionales, dedicados a la venta de platos a base de cuy y público en general los cuales requieren comprar este producto en fechas importantes como fiestas tradicionales y familiares, en las cuales se consume platos a base de cuy. Siendo estos los que tienen mayor fuerza de negociación, en este sentido y conocedores de esto son capaces de negociar mayores ventajas, descuentos, precios diferenciados entre otros beneficios adicionales. En este entender la liquidez, rentabilidad y solvencia dependen directamente de ellos y es importante conservar buenas relaciones con estos, satisfaciendo sus expectativas y necesidades a través de un servicio de calidad y oportuno.

Para haber llegado a esta conclusión se ha formulado las siguientes preguntas para saber del poder que tienen: 
Tabla 6

Interrogantes Formuladas

\section{INTERROGANTE FORMULADA}

RESPUESTA

¿Qué importancia tienen los restaurantes turísticos, tradicionales y Importancia Alta especializados para el proyecto?

¿Tienen poder para negociar?

SI

¿Cuánto poder tienen sobre nosotros?

Poder Alto

¿Alguno está en la capacidad de desarrollar o adquirir una empresa como esta?

¿Qué pasa si mañana deciden ya no comprar nuestro producto?

No, por no estar en

su CORE de negocio

Existen otros demandantes

\section{Tercera Fuerza: Posibilidad de Nuevos Competidores Potenciales.}

"La amenaza de entrada limita los precios y modela la inversión necesaria para disuadir a otros participantes." (Porter, 2013, p. 5).

El entorno donde se desarrolla las operaciones del plan de negocios, tiene barreras de entrada relativamente bajas, en este entender en la región existen familias, asociaciones y granjas dedicadas a la venta de reproductores, los cuales podrían convertirse en ofertantes de carne de cuy para restaurantes y público en general, es así que cabe la posibilidad de que existan muchos competidores potenciales, pudiendo aparecer más competidores debido a cambios en la legislación que incentiva la promoción y estímulo de la actividad agroindustrial y nuevas normas que apoyan a la micro y pequeña empresa, aumento de la demanda del mercado de cuy, ingreso de nuevos restaurantes o cadenas los cuales representan una oportunidad atractiva para que nuevos competidores quieran ingresar a competir con una propuesta similar a la presentada en el presente Plan de Negocios, siendo necesario plantear algunas interrogantes tales como: 
Tabla 7

Interrogantes Formuladas

\begin{tabular}{lc}
\hline \multicolumn{1}{c}{ INTERROGANTE FORMULADA } & RESPUESTA \\
\hline ¿Quiénes pueden ser los nuevos competidores? & $\begin{array}{c}\text { Cualquiera que sepa de } \\
\text { crianza de cuy }\end{array}$ \\
$\begin{array}{l}\text { ¿Estos son conocidos? } \\
\text { ¿Son locales o nacionales y con fuertes capitales? }\end{array}$ & $\begin{array}{c}\text { Ambos, depende cuanto de } \\
\text { participación de mercado } \\
\text { quieran ganar }\end{array}$ \\
¿Cómo pueden cambiar el mercado? & $\begin{array}{c}\text { Con estrategias de precio } \\
\text { Depende del grado de } \\
\text { iTienen capacidad para maniobrar? }\end{array}$ \\
¿Qué política de precios pueden utilizar? & $\begin{array}{c}\text { Precio bajo, con estrategias de } \\
\text { consumo masivo }\end{array}$ \\
\hline
\end{tabular}

Teniendo como respuesta que no se tiene suficientes barreras de entradas que garantice la no existencia de más actores en el mercado a menos que el proyecto sea capaz de crear ventajas competitivas que permitan crear barreras de entrada fuertes al mercado.

\section{Cuarta Fuerza: Posibilidad de Productos Sustitutivos:}

"La amenaza de sustitución incide en los precios y en la inversión.” (Porter, 2013, p. $5)$.

En el análisis de esta fuerza se tiene que al contar con varios sustitutos, los cuales también se ofrecen en los restaurantes tradicionales y turísticos y que son adquiridos por el público en general como son platos a base de carne de pollo, cordero, cerdo y conejo de castilla. Empero estos productos no representan una amenaza para el cuy en esta parte del país pues los clientes que concurren a estos los restaurantes y principales centros de abasto ya tienen una decisión de compra, convirtiéndose otros productos en sustitutos de la carne de cuy cuando no se cuenta con esta en la carta del establecimiento o no se tiene disponible para 
la venta. Esta aseveración se afianza debido a la existencia de restaurantes especializados en la venta de Cuy, a los cuales concurren clientes los cuales no piden otros platos que no sea a base de esta carne.

Para saber si realmente estos sustitutos impactaran directamente en el proyecto se plateo las siguientes interrogantes:

Tabla 8

Interrogantes Formuladas

INTERROGANTE FORMULADA

¿Qué productos pueden afectarnos?

¿Cuál puede ser el impacto de estos productos?

¿Los sustitutos, pueden llevar a que fracase el proyecto?

¿Qué productos pueden afectar al desarrollo del proyecto?

¿Cuál puede ser el impacto de estos productos?

\section{RESPUESTA}

Carne de Pollo, Cerdo, cordero

Bajo

No porque cada uno tiene su propia preferencia y oferta en el mercado

Carne de pollo por temas de precio

Bajo en vista de que cada uno de estos tiene su propia demanda en el mercado.

\section{Quinta Fuerza: Rivalidad en El Sector:}

"La intensidad de la rivalidad afecta a los precios y a los costos de competir en las siguientes áreas: planta, desarrollo de productos, publicidad y fuerza de ventas”(Porter, 2013, p. 5).

En el sector Agroindustrial donde se comercializa de carne de cuy, no existe una rivalidad significativa y como se mencionó solo el 5.8\% de los productores se dedican a la comercialización de esta carne, siendo la competencia directa los acopiadores de la zona. Es 
bien sabido que actualmente en las zonas de Anta, Calca; Canchis, Quispicanchis, Urubamba y Cusco se está promoviendo la producción de cuy con fines comerciales, sin embargo estos volúmenes no logran satisfacer la demanda que tiene el mercado, a pesar de estos incentivos no se cuenta con la capacidad, el Kwon how y el financiamiento necesario que ofrece el proyecto propuesto.

También se ha determinado que instituciones como de INIA y principales granjas ven como negocio más rentable la venta de reproductores. Tampoco no existe rivalidad en el mercado ya que este producto es demandado de manera habitual y más aún en fiestas específicas como el Corpus y fiestas tradicionales lo que garantiza que haya mercado para todos los ofertantes, esto se corrobora con las entrevistas realizadas a restaurantes tradicionales y no tradicionales en los cuales su promedio de compra semanal va desde los 200 a 1250 cuyes.

Unas vez determinadas las cinco fuerzas que interviene directamente, se elaboró la matriz de atractividad considerando una ponderación de uno a cinco, siendo uno el grado de menor y cinco el de mayor atractividad, para esto se consideraron los cinco factores decisivos y resultado del análisis realizado se ha llegado a la conclusión que, a pesar de tener una alta dependencia al poder de negociación de los clientes, el entorno donde se plantea el presente Plan de Negocio es Atractivo y Rentable desde el punto de vista estratégico frente a las condiciones y cualidades que presenta el entorno en el que se desempeña el sector. 
Tabla 9

Matriz de Atractividad de las Cinco Fuerzas de Porter

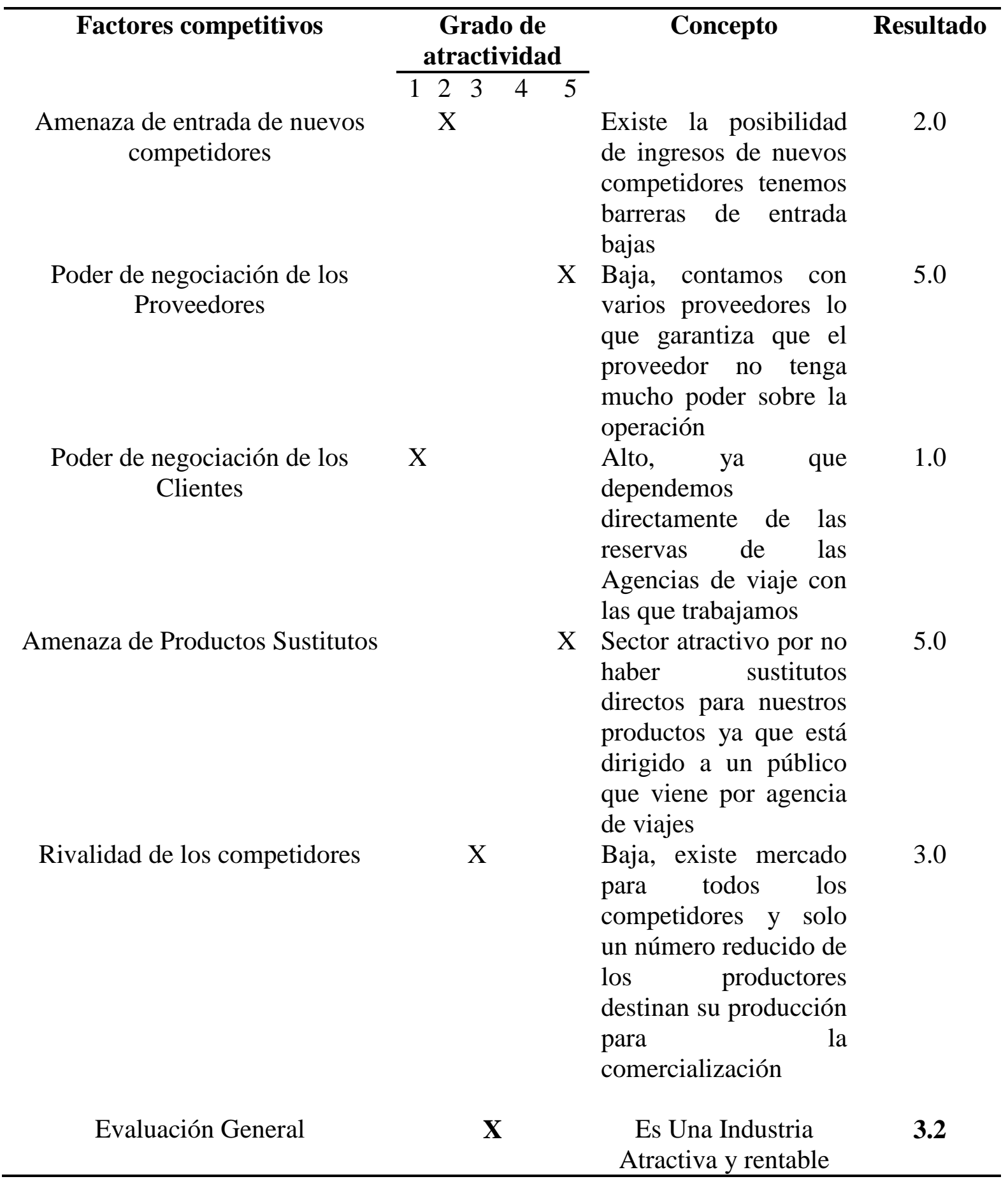

Del análisis realizado de cada una de las cinco fuerzas en relación al entorno competitivo del Plan de Negocios se observa que al tener un bajo poder de negociación por 
parte de los proveedores y no contar con muchos sustitutos ayuda a reducir el poder que ejercen los clientes, la rivalidad de los posibles competidores y las barreras bajas que se tiene de ingresos de nuevos competidores lo que hace que el proyecto se desarrolle en una Industria Atractiva y rentable, respondiendo de manera adecuada el entorno al plan negocio.

\subsection{Análisis de la Competencia}

"Es el proceso de identificar a los principales competidores, evaluar sus objetivos, estrategias, puntos fuertes y débiles y patrones de reacción, así como seleccionar a los competidores que se enfrentaran o se evitaran”. (Kotler y Armstrong, 2012, p.528).

Competencia Directa, actualmente en Cusco se cuenta con cinco asociaciones que se dedican a la producción de cuyes cantidades que van desde los 1,000 a 2,000 unidades mensuales; estas asociaciones se ubican en las provincias de Calca y Canchis. Estas asociaciones están conformadas por pequeños productores que tienen una producción mensual que va desde los 50 a 100 cuyes mensuales con una crianza empírica de tipo de tradicional, carente de todo método tecnificado, actividad económica que no es la principal viéndose obligados a dedicarse a otras actividades a parte de la crianza de cuyes (crianza de animales mayores y trabajos agrícolas). Es importante mencionar que los principales ofertantes de carne de cuy en la región son acopiadores, que la venden en condiciones que no prestan garantías de calidad y salubridad, personas que se concentran en la zona de Cascaparo (mercado donde se expende la carcasa de cuy)

Competencia Indirecta, representada por todos los productores de otro tipo de carnes que forman parte de los hábitos alimenticios de las familias cusqueñas 
2.4.1. Empresas que ofrecen el mismo producto, indicando las semejanzas y diferencias que tienen con el proyecto.

En la actualidad en la región existen cinco asociaciones de productores de 77 existentes (con una producción de 9,700 cabezas de cuyes mensuales), que se dedican a la producción de esta carne, las cuales solo consideran el proceso productivo desde el cultivo de pastos para alimento de los animales y la crianza más no las etapas de sacrificio y empacado al vacío las cuales no son desarrolladas por estos debido a que prefieren vender su producto a los acopiadores, que son los encargados de realizar la venta al cliente final (restaurantes, mercados y público en general); como ya se mencionó su producción promedio de mil a dos mil cuyes mensuales las cuales son: 
Tabla 10

Asociaciones de Productores de la Región Cusco

\begin{tabular}{|c|c|c|c|}
\hline \multicolumn{4}{|c|}{ Nombre de la Asociacion } \\
\hline ASOCIACION SAN JUAN DE URCO & DATOS GENERALES & PROVINCIA & DISTRITO \\
\hline Dirección & C.C Urco & Calca & Calca \\
\hline Cantidad de Produccion por mes & 1000 cuyes mensuales & & \\
\hline Telefono & 084-202197 & & \\
\hline Contacto & Agencia Agraria Calca & & \\
\hline ASOCIACION DE CRIADORES Y & & & \\
\hline $\begin{array}{l}\text { PRODUCTORES DE CUYES HATUN QOWE } \\
\text { DE COYA }\end{array}$ & DATOS GENERALES & PROVINCIA & DISTRITO \\
\hline Dirección & Calca & Calca & Calca \\
\hline Cantidad de Produccion por mes & 2000 cuyes mensuales & & \\
\hline Telefono & 084-202197 & & \\
\hline Contacto & Agencia Agraria Calca & & \\
\hline $\begin{array}{c}\text { ASOCIACION DE JOVENES PRODUCTORES } \\
\text { DE CCUYO }\end{array}$ & DATOS GENERALES & PROVINCIA & DISTRITO \\
\hline Dirección & C.C. Ccuyo & Canchis & Marangani \\
\hline Cantidad de Produccion por mes & 1000 cuyes mensuales & & \\
\hline Telefono & 084-351027 & & \\
\hline Contacto & Agencia Agraria Canchis & & \\
\hline $\begin{array}{l}\text { ASOCIACION DE PRODUCTORES DE SUMAC } \\
\text { CCOE }\end{array}$ & DATOS GENERALES & PROVINCIA & DISTRITO \\
\hline Dirección & C.C. Ccuyo & Canchis & Marangani \\
\hline Cantidad de Produccion por mes & 1000 cuyes mensuales & & \\
\hline Telefono & 084-351027 & & \\
\hline Contacto & Agencia Agraria Canchis & & \\
\hline $\begin{array}{c}\text { ASOCIACION DE PRODUCTORES LOS } \\
\text { GAZAPOS }\end{array}$ & DATOS GENERALES & PROVINCIA & DISTRITO \\
\hline Dirección & C.C. Ccuyo & Canchis & Marangani \\
\hline Cantidad de Produccion por mes & 1000 cuyes mensuales & & \\
\hline Telefono & 084-351027 & & \\
\hline Contacto & Agencia Agraria Canchis & & \\
\hline
\end{tabular}

Nota. Tomado de la Dirección Regional de Agricultura

Como se puede observar estas asociaciones están concentradas en las provincias de Calca y Canchis, evidenciando que la asociación que tiene la mayor producción de cuyes es la Asociación de Criadores y Productores Hatun Qowe de Coya con una producción mensual de dos mil unidades, además se puede notar que la producción de estas cinco asociaciones alcanza las seis mil cabezas de cuy, que no es suficiente para satisfacer la demanda del mercado puesto que existen restaurantes locales caso del Moqueguano que requieren cinco mil cabezas mensuales de cuy pelado y eviscerado, existiendo una demanda insatisfecha en el 
mercado Regional, lo que obliga a los demás restaurantes y consumidores a comprar cuyes provenientes de otras zonas como Arequipa y Puno o se ven obligados a acopiar de toda la región lo que ocasiona que no puedan tener un producto de garantía y que reúna un estándar necesario para su consumo y que pueda variar en sabor por el tipo de alimento, edad, peso y tamaño.

También como se mencionó en la tabla de Segmentación de criadores y consumidores que la mayor cantidad de asociaciones de criadores está en la zona de Anta, su producción no es proporcional a la cantidad de asociaciones existentes, esto debido a que el promedio de cuyes producidos varia ente los 50 a 100 lo que no permite atender al mercado demandante de carne de cuy.

\subsubsection{Participación de mercado de cada uno de ellos diferencias que tienen con el proyecto.}

Como se mencionó el $62 \%$ de la producción total mensual de la Región es realizada por cinco asociaciones siendo su participación actual en el mercado:

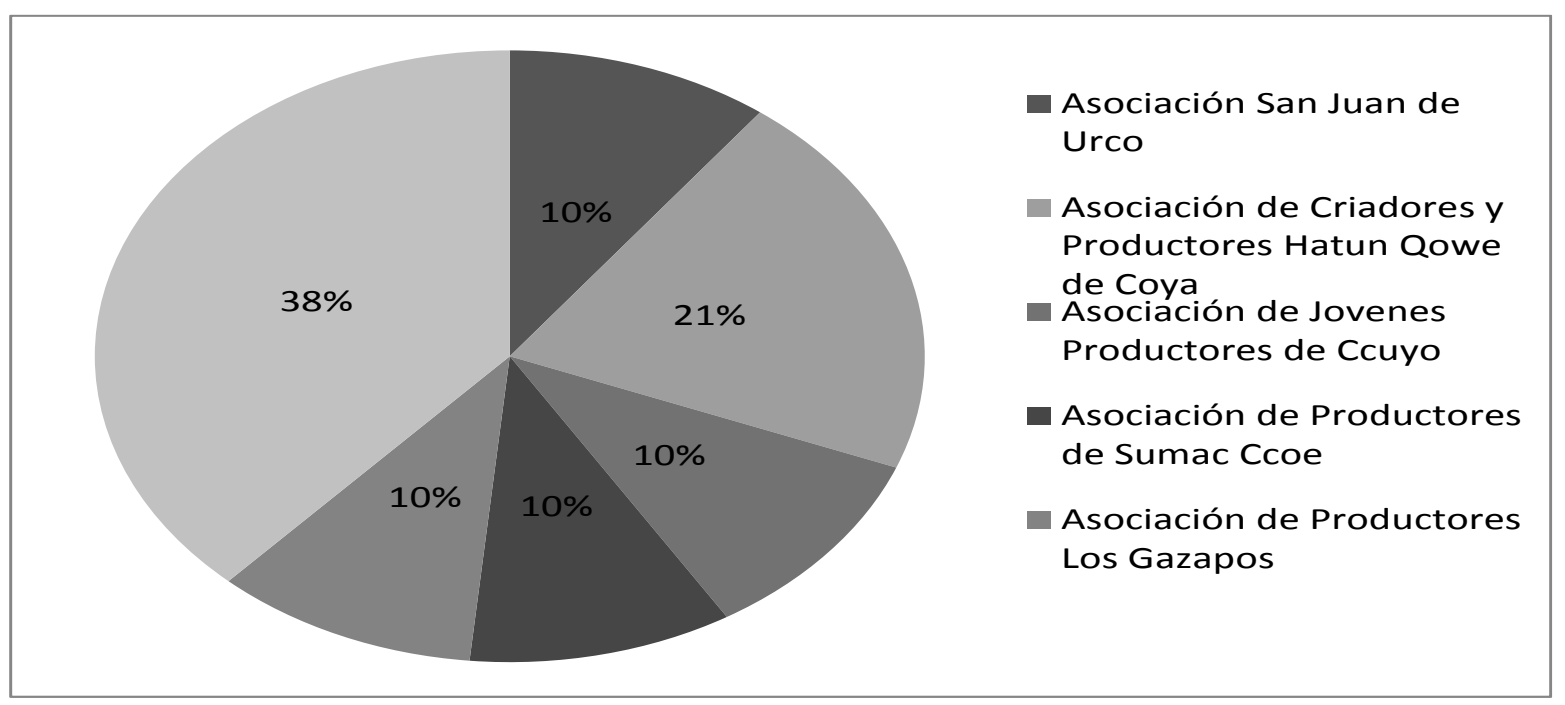

Figura 2. Participación de Mercado de los Productores Región Cusco 
Se observa que la mayor participación del mercado la tiene las asociaciones menores con un $38 \%$, sin embargo si consideramos que este porcentaje representa a 72 asociaciones de productores que tienen una producción que varía entre los 50 a 120 cuyes mensuales esta cifra no es representativa, siendo la Asociación de Criadores y Productores Hatun Qowe de Coya con un $21 \%$ la que tiene mayor participación del mercado de la producción regional seguido de las Asociaciones de San Juan de Urco, Asociación de Jóvenes Productores de Ccuyo, Asociación de Productores de Sumac Ccoe y Asociación de Productores de Los gazapos que tienen el $10 \%$ de la participación del mercado de carne de cuy respectivamente.

Empero como se había mencionado que el $100 \%$ de estas asociaciones solo consideran el proceso productivo desde el cultivo de pastos y crianza, más las etapas de sacrificio y empacado al vacío no son desarrolladas por estos por no contar con las herramientas tecnológicas y conocimientos necesarios el cual ofrece el plan de negocios propuesto.

Para un mejor entendimiento se presenta el proceso productivo realizado por estas asociaciones y el propuesto en el presente plan de negocios: 


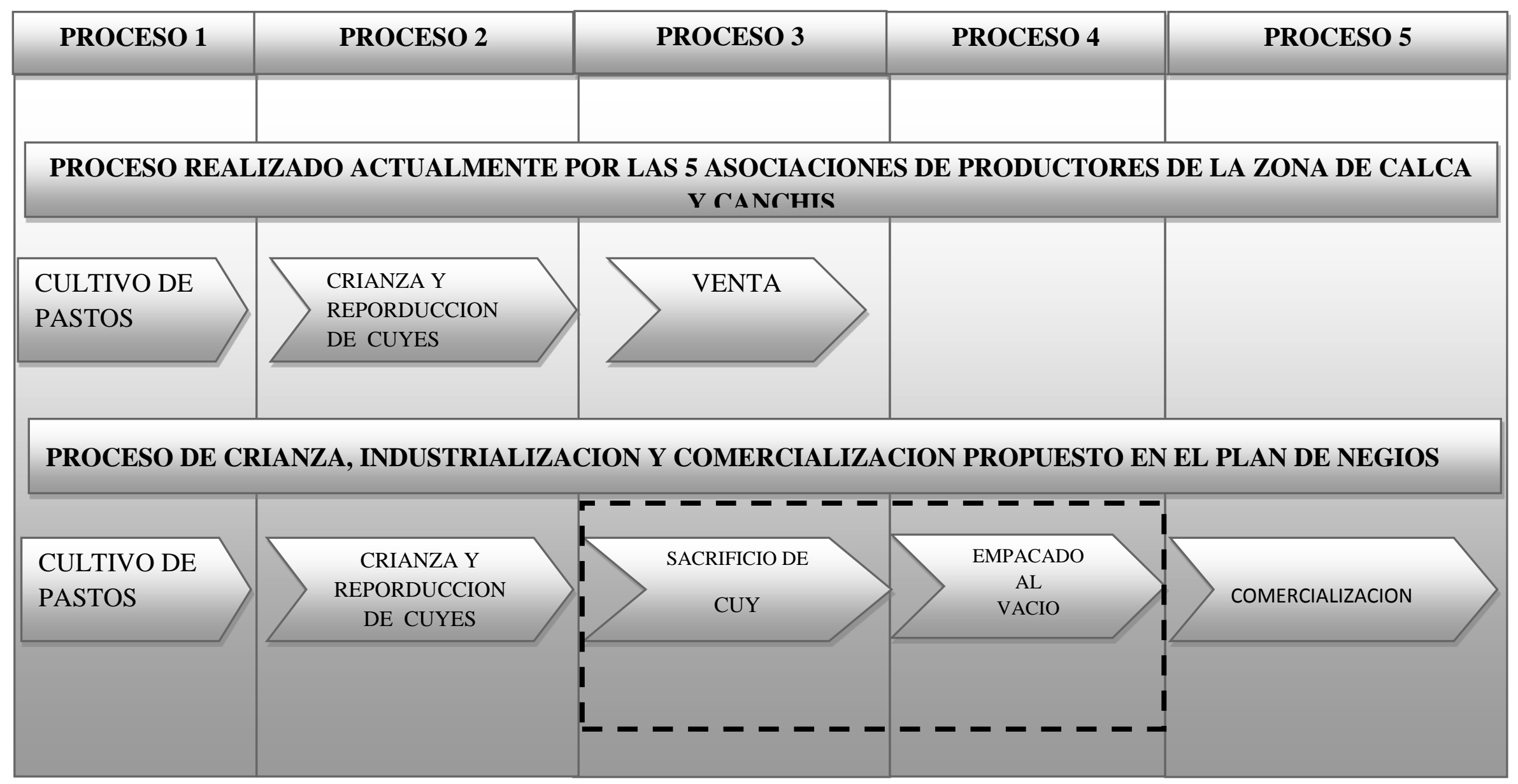

Figura 3.Comparación de Procesos Productivos Actuales y Propuesto en el Plan de Negocio 
Como se observa, el proceso planteado para el presente Plan de Negocios es igual solo en los dos primeras etapas, diferenciándose a partir del proceso de sacrificio y empacado al vacío; etapas en las que comienza el proceso de industrialización de la carne de cuy ecológico la cual contará con un peso de 720 gramos, que tendrá una edad de tres meses, carcasa que estará limpia, eviscerada y empacada al vacío en un empaque sellado que contendrá impreso una etiqueta con la descripción nutricional y certificación respectiva del producto según los organismos reguladores correspondientes; para culminar el proceso con la comercialización en los restaurantes turísticos y tradicionales de la Región del Cusco, producto que también estará a la venta del público en general, siendo a partir de este proceso de industrialización la diferenciación que tiene el producto propuesto y que viene a ser la propuesta de valor del proyecto.

\subsubsection{Matriz de perfil competitivo.}

Una vez definido el entorno en que se desempeñará la empresa y considerando los atributos y factores que influyen entre los competidores directos y sustitutos se elaboró la siguiente matriz que identifica los principales antagonistas de la empresa así como los factores críticos para el éxito que presentan cada uno de ellos, comparando estos de acuerdo a una ponderación general que se asigna a cada factor y las calificaciones que obtienen con respecto a la puntuación registrada según la información proporcionada en las entrevistas y visitas realizadas a las diferentes empresas que conforman la oferta del producto en el mercado local

La calificación refiere a las fortalezas y debilidades que presentan cada uno de los competidores evaluados donde cuatro $=$ fortaleza principal, tres $=$ fortaleza menor, dos=debilidad menor y uno= debilidad principal. Siendo el resultado: 
Tabla 11

Matriz del Perfil Competitivo Sector de Venta de Carne de Cuy en la Región del Cusco

\begin{tabular}{|c|c|c|c|c|c|c|c|c|c|c|c|}
\hline \multirow[t]{2}{*}{$\begin{array}{l}\text { Factores críticos para el } \\
\text { éxito }\end{array}$} & \multirow[t]{2}{*}{$\begin{array}{l}\text { Pondera } \\
\text { ción }\end{array}$} & \multicolumn{2}{|c|}{ Proyecto } & \multicolumn{2}{|c|}{$\begin{array}{l}\text { Asociación San } \\
\text { Juan de Urco }\end{array}$} & \multicolumn{2}{|c|}{$\begin{array}{c}\text { Asociación de } \\
\text { Criadores y } \\
\text { Productores } \\
\text { Hatun Qowe de } \\
\text { Coya }\end{array}$} & \multicolumn{2}{|c|}{$\begin{array}{l}\text { Asociación de } \\
\text { Jóvenes } \\
\text { Productores de } \\
\text { Ccuyo }\end{array}$} & \multicolumn{2}{|c|}{$\begin{array}{l}\text { Asociación de } \\
\text { Productores de } \\
\text { Sumac Ccoe }\end{array}$} \\
\hline & & $\begin{array}{l}\text { Califica } \\
\text { ción }\end{array}$ & $\begin{array}{l}\text { Puntua } \\
\text { ción }\end{array}$ & $\begin{array}{l}\text { Califica } \\
\text { ción }\end{array}$ & $\begin{array}{l}\text { Puntua } \\
\text { ción }\end{array}$ & $\begin{array}{l}\text { Califica } \\
\text { ción }\end{array}$ & $\begin{array}{l}\text { Puntua } \\
\text { ción }\end{array}$ & $\begin{array}{l}\text { Califica } \\
\text { ción }\end{array}$ & $\begin{array}{l}\text { Puntua } \\
\text { ción }\end{array}$ & $\begin{array}{l}\text { Califica } \\
\text { ción }\end{array}$ & $\begin{array}{l}\text { Puntua } \\
\text { ción }\end{array}$ \\
\hline Capacidad instalada & $15 \%$ & 3 & 0.45 & 4 & 0.60 & 1 & 0.15 & 1 & 0.15 & 1 & 0.15 \\
\hline $\begin{array}{l}\text { Estandarización y calidad } \\
\text { del producto }\end{array}$ & $12 \%$ & 4 & 0.48 & 3 & 0.36 & 2 & 0.24 & 2 & 0.24 & 2 & 0.24 \\
\hline Ubicación & $9 \%$ & 3 & 0.27 & 2 & 0.18 & 4 & 0.36 & 4 & 0.36 & 3 & 0.27 \\
\hline Infraestructura & $9 \%$ & 3 & 0.27 & 2 & 0.18 & 1 & 0.09 & 1 & 0.09 & 1 & 0.09 \\
\hline Estructura orgánica & $8 \%$ & 3 & 0.24 & 2 & 0.16 & 2 & 0.16 & 1 & 0.08 & 1 & 0.08 \\
\hline Apoyo técnico & $5 \%$ & 1 & 0.05 & 4 & 0.20 & 1 & 0.05 & 1 & 0.05 & 1 & 0.05 \\
\hline Administración & $5 \%$ & 4 & 0.20 & 1 & 0.05 & 3 & 0.15 & 2 & 0.10 & 2 & 0.10 \\
\hline TOTAL & $100 \%$ & & 2.99 & & 2.84 & & 1.88 & & 1.44 & & 1.35 \\
\hline
\end{tabular}


La calificación indicada fue estimada por las cualidades que presenta cada competidor, donde se puede observar que para nuestro proyecto los principales factores críticos de éxitos estarían definidos en la capacidad instalada que poseería la planta así como la tecnología a utilizar y el equipamiento con el que contaría ya que es por ello que se puede obtener un producto diferenciado que se encuentre en la preferencia de los consumidores.

Así mismo la estandarización del producto representa para los consumidores un factor importante ya que conforme a la investigación de gustos y preferencias realzada, el total de los consumidores encuestados indicó que preferiría un proveedor que le garantice un producto que mantenga una apropiada relación entre el precio y el tamaño del animal pelado.

En referencia a los competidores identificados, se puede observar que estos presentan factores mínimos que reducen sus ventajas competitivas siendo estos los siguientes.

Las asociaciones de productores de la zona de Urco presenta la mayor semejanza frente a nuestro producto, puesto que ellos registran un producto que cumple el mismo ciclo de producción, sin embargo el tipo de distribución que posee (cuy pelado y eviscerado) presenta un impacto en la disminución de los factores competitivos que posee, por presentar menos preferencia sobre los clientes, los principales factores de éxito que presenta están en obtener asistencia técnica por parte del estado como organización productiva local.

En cuanto a los demás competidores identificados se tiene un mayor posicionamiento en el mercado concentrado en la zona comercial ubicada en la calle General Buen Día del distrito del cusco, donde se ubican tres puntos de venta de este tipo de carne, siendo estos acopiadores de los diferentes centros de producción rural en toda la región del Cusco.

Actualmente el competidor principal que presenta mayores ventajas competitivas frente a los actuales comerciantes de carne de cuy en la ciudad es la asociación de San Juan de Urco, 
registrando un mayor posicionamiento de mercado frente a los competidores directos por contar con una ubicación preferente, sin embargo las debilidades que presenta en cuanto a los otros factores críticos de éxito son debido a que se trata de una cadena productiva de acopiamiento lo cual limita la capacidad de producción y calidad del producto.

Los otros dos establecimientos no presentan ventajas competitivas altas en el mercado debido a que se tratan de comercios menores de acopio de cuy pelado que presenta lotes de venta mínimos para el público en general.

\subsection{Análisis Del Contexto Actual y Esperado}

Actualmente el mercado de carne de cuy presenta particularidades que definen el comportamiento de los diferentes consumidores en cada segmento a evaluar, siendo este un producto demandado tanto por el público en general y turistas presenta características y condiciones definidas por el entorno en el que se desempeña, habiendo sido estos definidos en los siguientes análisis de factores externos:

\subsubsection{Análisis político gubernamental.}

Desde hace varios periodos atrás el Estado Peruano a través de los órganos específicos establece como interés nacional la promoción, el fomento y el desarrollo de actividades rurales así como la industrialización y potenciación de productos tradicionales. Para tal efecto se desarrollaron diferentes proyectos regionales por parte de la Dirección Regional de Agricultura de Cusco y el Ministerio de Agricultura en todo el ámbito nacional. Así mismo como la creación de un programa público descentralizado como Sierra Exportadora que se encargan de brindar apoyo técnico para el desarrollo de estas actividades.

Con relación a la crianza de cuyes estos proyectos y programas proponen unificar un paquete tecnológico que permita incrementar la producción sostenible de la carne de cuy, 
contribuyendo al incremento del ingreso del criador y elevar la producción de este animal a fin de cubrir la demanda actual de carne de cuy tanto para consumo interno como externo.

Desde el punto de vista legal a través del proyecto de Ley $\mathrm{N}^{\circ} 1773-2001 / \mathrm{CR}$ se busca declarar a esta especie como patrimonio natural de la nación y especie nativa del Perú, con la finalidad de promover su producción y consumo bajo un plan de crianza y que contemple las particularidades de cada región.

El proyecto por tratarse de la producción de un alimento de consumo humano deberá contar con la certificación de la Dirección regional de Salud, a través de la emisión de una licencia de registro sanitario que certifique que dicho producto cumple con todos los requerimientos para el consumo humano.

\subsubsection{Análisis económico.}

Los agentes económicos que influyen en el desarrollo de esta actividad están relacionados al comportamiento de los sectores comerciales donde se demanda el consumo de este tipo de carne, estando dirigida al consumo del público en general, restaurantes tradicionales y por el púbico extranjero a través de los restaurantes turísticos que incluyen este tipo de carne en sus cartas.

La tendencia actual refleja un crecimiento en el número de restaurantes turísticos y tradicionales en la ciudad del Cusco y los distritos de Tipon, Lamay y Anta.

Actualmente el rubro de restaurantes y hoteles registro un incremento del $2.23 \%$ la nota refiere que “...en el índice del PBI nacional, correspondiendo al sector específico de restaurantes un crecimiento de $2.23 \%$ este crecimiento es determinado por la expansión de los rubros de comidas rápidas, pollerías, restaurantes, carnes y parrillas, chifas y comida japonesa; los que fueron impulsados por la atención personalizada que presentan, publicidad, 
nuevos complementos innovaciones culinarias,, y acondicionamiento de inmuebles..." esta tendencia marca como factor el ingreso de la carne de cuy como atractivo culinario potencial en el mercado local.

Así mismo también indica que “...la tendencia es creciente y se espera un mayor crecimiento en este rubro de manera sostenible por los próximos cuatro años ...”, con lo cual al estar dentro del horizonte de evaluación del proyecto se espera desarrollar esta actividad en condiciones favorables desde el punto de vista económico.

Como se puede observar en el recorte de la nota de prensa, incluir este producto representa un factor de éxito adicional al rubro de restaurantes que presenta escenarios favorables para el desarrollo y fomento del PBI nacional.

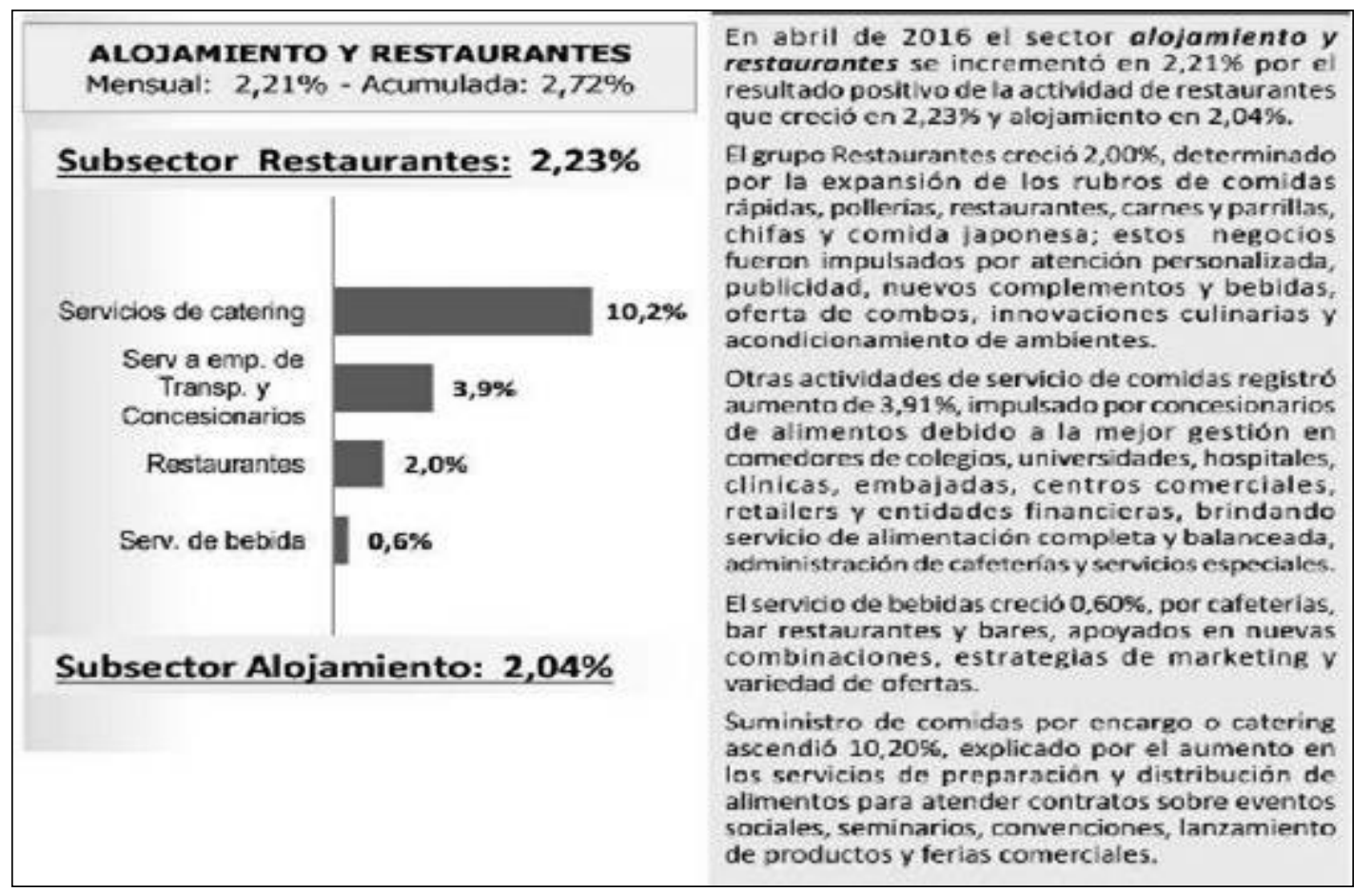

Figura 4. Adaptado de Diario Gestión publicación 12 de Mayo del 2016 "Evolución mensual de la producción nacional" sección Economía" Crecimiento en el PBI 2015 de los restaurantes a nivel nacional. 


\subsubsection{Análisis legal.}

Desde el punto de vista legal a través del proyecto de Ley $\mathrm{N}^{\circ} 1773-2001 / \mathrm{CR}$ se busca declarar a esta especia como patrimonio natural de la nación y especie nativa del Perú, con la finalidad de promover su producción y consumo bajo un plan de crianza y que contemple las particularidades de cada región.

El proyecto por tratarse de la producción de un alimento de consumo humano deberá contar con la certificación de la Dirección Regional de Salud, a través de la emisión de una licencia de registro sanitario que certifique que dicho producto cumple con todos los requerimientos para el consumo humano así como todas las condiciones especificadas en la ley de inocuidad de alimentos $\mathrm{N}^{\circ} 1062-2008$ donde se especifica las condiciones que se deben cumplir para elaborar los productos para consumo humano.

Las condiciones organizacionales, la estructura organizacional y marco tributario en el que se desempeñaran las operaciones se encuentran reguladas dentro del marco legal de la ley general de sociedad $\mathrm{N}^{\circ} 26887$ aprobada el 19 de noviembre de 1997 de acuerdo al tipo de empresa que se determina.

\subsubsection{Análisis cultural.}

Como aspecto de influencia para la demanda del consumo de este tipo de carne en nuestro ámbito se ha considerado que el aspecto cultural y costumbrista del consumo de esta carne de cuy está basado en la crianza tradicional como animal doméstico la cual es consumida por la población en fiestas costumbristas y fechas importantes como bautizos, matrimonios y cumpleaños

Al estar considerado esta especie como especie nativa y tradicional se considera como un insumo para la preparación de platos tradicionales especialmente en fiestas patronales, 
costumbristas y de carácter familiar ya que este animal representa el plato de más alta alcurnia en los niveles sociales dentro de la cultura andina.

Sin embargo existen paradigmas en cuanto a la relación de este tipo de animal con otras especies, los cuales generan que se distorsione y se evite el consumo de este animal en personas mal informadas.

Para el consumidor extranjero representa un atractivo turístico por tratarse de un animal tradicional que solo es posible apreciarlo como alimento en el Perú y otros países de Latinoamérica.

\subsubsection{Análisis tecnológico.}

En la actualidad esta actividad se desarrolla de manera empírica a través de centros de producción rurales y galpones domésticos lo cual delimita la capacidad y volúmenes de producción, sin embargo estudios han identificado que la inclusión de nuevas tecnologías para mejorar el sistema de cría, reproducción y sacrificio incrementa los niveles de producción de este animal.

La optimización del ciclo de producción de este tipo de carne incluye la participación de procesos en cuanto a la producción de pastos que generen un abastecimiento permanente de alimento para una adecuada ganancia de peso en el tiempo esperado.

Así mismo el sistema de sacrificio aún no ha desarrollado equipos especializados para este tipo de animal, sin embargo se aplican técnicas tradicionales de sacrifico como son el desangrado y desnuque, que cumplen de manera eficiente este proceso pero a un ritmo que retrasa los volúmenes de producción.

Se identificaron escasos sistemas y herramientas tecnológicas para realizar el proceso de sacrificio y pelado de manera industrializada, actualmente las técnicas utilizadas son 
mediante empacadoras al vacío en bolsas de poliuretano posterior a métodos de sacrificio y eviscerado manual, los cuales no garantizan la sanidad y desinfección del producto final.

\subsubsection{Análisis ecológico.}

Considerando que el Perú es un país que cuenta con una alta biodiversidad de especies animales y ecosistemas diversificados que permiten domesticar estos amínales con fines comerciales, se cuentan con múltiples oportunidades que facilitan la cría, reproducción y sacrificio de los mismos sin afectar así el ecosistema en que se desarrollan ni generar polución y contaminación ambiental.

Este animal no está considerado como una especie amenazada de extinción o con periodos de veda en su sacrificio, por lo contrario como se indicó en factores políticos existen políticas estatales que impulsan la cría y comercialización de este tipo de carne.

Sin embargo se debe considerar que la industrialización de este animal para alimento de consumo humano requiere de incluir en el proceso de comercialización empaques que generaran polución en escalas controlables.

El desarrollo de esta actividad dentro del proceso cría y reproducción genera un volumen regular de excretas de este animal, el cual representa una oportunidad para las zonas de cultivo colindantes por utilizarse como un abono natural para su uso en diferentes actividades agropecuarias.

\subsection{Oportunidades}

Del análisis realizado por los factores anteriormente indicados se puede identificar las siguientes oportunidades que influenciaran en el desempeño de la actividad del producto a desarrollar, constituyéndose el aprovechamiento de estos como los factores claves de éxito de este sector. 
1. Demanda creciente e insatisfecha de la carne de cuy.

2. Bajas barreras de entrada para el ingreso al mercado.

3. Bajo nivel de investigación sobre tecnologías o procesos de producción.

4. Existen consumidores dispuestos a adquirir este tipo de carne en diferentes presentaciones.

5. Existe una creciente tendencia al consumo de comida saludable y nutritiva.

6. El estado promociona e incentiva la producción y consumo de esta especie.

Sin embargo, estos escenarios generan amenazas que se deben tomar en cuenta, con son las siguientes:

1. La tendencia que presenta el mercado consumidor refleja una mayor preferencia a carnes tradicionales como la res, pollo o pescado.

2. Existen débiles políticas con relación a sanidad del cuy.

3. El ingreso de otros productos cárnicos del exterior a menor precio.

4. El consumo de la carne de cuy es muy sensible al precio, haciendo este muy volátil frente a posibles aumentos debido a que la inflación perjudicaría los volúmenes de compra.

5. El poco desarrollo de tecnologías dirigidas específicamente a este animal limita o retrasa los volúmenes de producción de cuy. 


\section{Capítulo III: Estudio de Mercado}

\subsection{Descripción del producto}

El producto propuesto está elaborado en base a la carne de cuy ecológico de la raza Mi Perú, alimentada con alfalfa, de edad de tres meses, con un peso 650 a 720 gramos, de tiempo de vida de treinta días; la cual estará empacada al vacío y que contara con una tabla informativa del valor nutricional.

Este producto cumple con todos los estándares de calidad, higiene y salubridad; para lo cual es necesario cubrir todos los procesos de crianza e industrialización de este animal menor; garantizando peso, tamaño, olor, color y sabor propios de esta carne; para lo cual es necesario una alimentación ecológica a base de pastos que garantiza contar con un producto estandarizado, apoyado en un proceso adecuado de sacrificio que posibilite una adecuada manipulación de esta carne con buenas prácticas sanitarias y para que finalmente sea expendida en su presentación de empacado al vacío para el consumo humano.

Con este propósito se contaran con un animal de 3 meses de edad, entre de $650 \mathrm{~g}$ a 720 kg.; que posee una fuente importante de proteínas, muy superior a otras especies, bajo contenido de grasas; colesterol y triglicéridos, alta presencia de ácidos grasos linoleico y linolenico esenciales para el ser humano. Carne que será apreciada por sus dotes de suavidad, palatabilidad, calidad proteica y digestibilidad. Esta carcasa que estará con cabeza y eviscerado será empacada al vacío, técnica que consiste en la eliminación de casi la totalidad del aire del interior del envase, sin que este sea reemplazado por otro gas, que ayudara a conservar todas las propiedades nutricionales del cuy y aumentará su tiempo de vida útil, permaneciendo jugosa, fresca y madurado dentro del envase. 
Siendo la presentación final del producto la que a continuación se presenta en la figura:

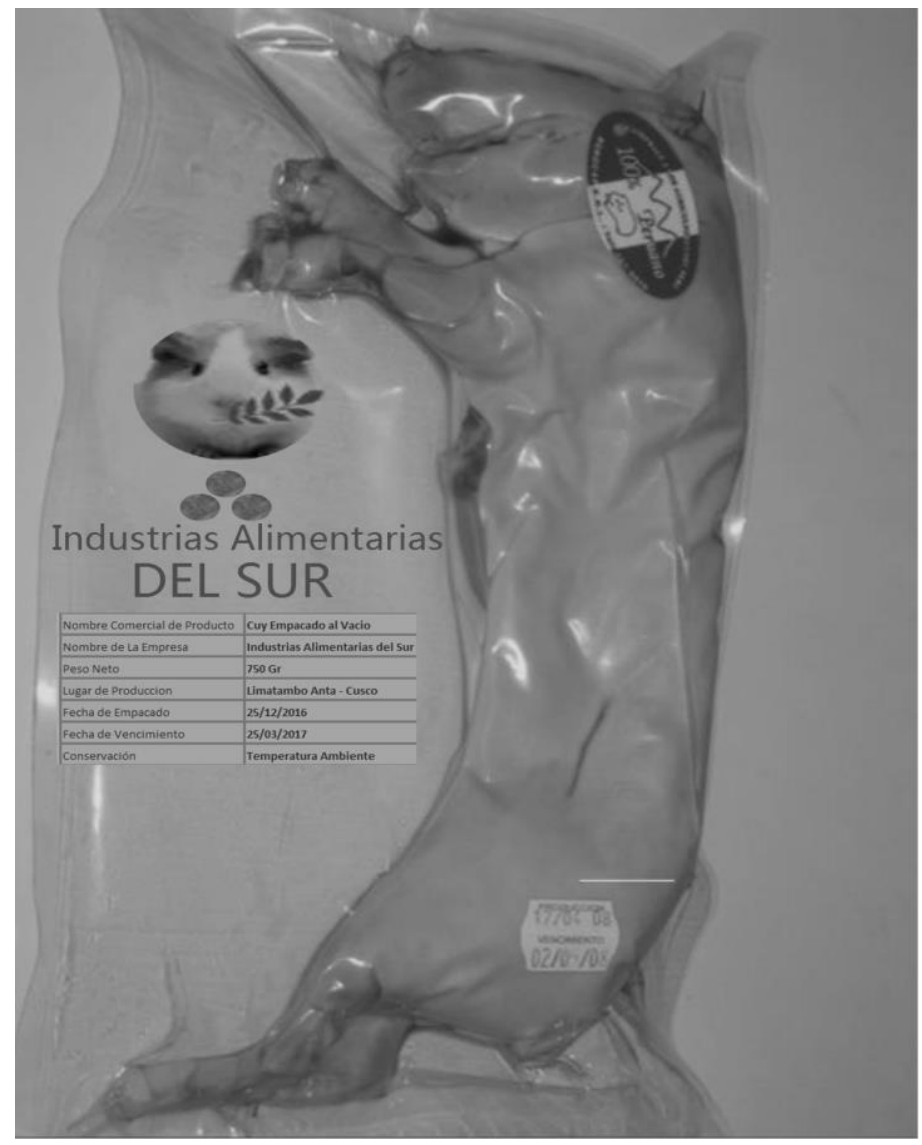

Figura 5 Carne de Cuy en carcasa y envasado al vacío

Nótese que la bolsa ideal para el empaque al vacío de este producto es aquella que ofrece resistencia mecánica al rasgado y la punción, de calibre recomendado ente 90 y 120 micras, además de ello proporcionan una excelente barrera contra la humedad, gases y grasas, la transparencia de los mismos permite que el consumidor vea las características del producto como color de la carne y permite además de todo lo indicado la refrigeración y congelación

El modelo de etiqueta debe de contar con la información relevante para consumidor, cumpliendo con los requisitos establecidos por las normas internacionales vigentes, debe considerarse lo siguiente. 


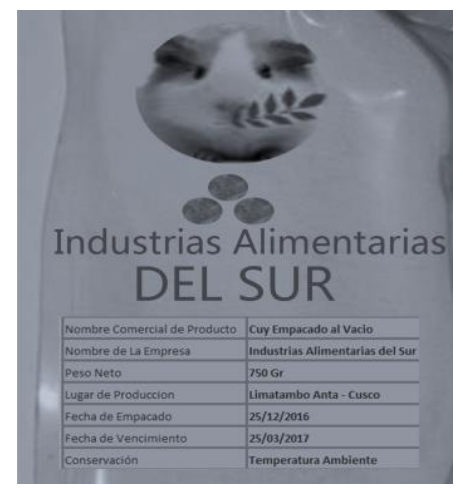

Figura 6 Etiqueta del Producto

\subsection{Selección del segmento o mercado}

Como lo define Kotler (2012), la segmentación del mercado se realiza tomando en cuenta las características comunes del público en general al que estará dirigido el producto, así entonces para la selección del segmento de mercado se consideraron los siguientes tipos de segmentos:

\subsubsection{Segmento Etareo.}

Comprendidos por la población en el rango de edad entre 18 a 75 años de edad de sexo masculino y femenino que adquieren carne cuy con determinada frecuencia y en determinado volumen.

\subsubsection{Segmento demográfico.}

Comprendidos por la población de los distritos de Cusco, San Sebastián, San Jerónimo, Saylla, Wanchaq, Santiago de la provincia del Cusco y las provincias de Calca y Urubamba, que consumen carne de cuy en su dieta regular con relativa frecuencia y en determinado volumen. 


\subsubsection{Segmento por nivel socio económico.}

Comprendido por la población integrante de los niveles socioeconómicos A, B y C con ingresos hasta los s/. 6379, de los distritos y los rangos de edad y sexo indicados anteriormente, que consumen carne de cuy en su dieta diaria regular con una frecuencia y volumen determinado.

\subsubsection{Segmento psicográfico.}

Comprendido por la población de los segmentos indicados anteriormente con estilos de vida, personalidad y conducta positiva frente al consumo del cuy considerando que este presenta familiaridad con las costumbres, festividades, eventos, tradiciones e inclusive creencias dentro de la medicina oncológica andina y cosmovisión andina arraigada en Cusco, por ser el cuy un alimento que se prepara en platos como el Chiri Uchu plato que se sirve en fiestas como la de Corpus Christi entre otras, lo cual representa un atractivo al momento de la decisión de compra del público consumidor.

Entonces considerando estas características del universo compuesto por público en general, se selecciona el mercado con nivel socio económico A, B y C, comprendiendo el rango de edad entre los 18 a 75 años y de ambos sexos según instrumento aplicado. Lo cual fue validado con el cuestionario aplicado al público en general; demostrando voluntad de compra y características psicográficas positivas frente al consumo y compra de carne de cuy. Considerando estas características se tiene: 
Tabla 12

Perfil de la Segmentación del Público en General

\begin{tabular}{|c|c|}
\hline Característica & Descripción \\
\hline Edad & De 18 a 75 años \\
\hline Genero & Masculino y Femenino \\
\hline NSE & A,B y C con ingresos hasta los s/. 6379. \\
\hline Zona Geográfica & $\begin{array}{l}\text { Seis principales distrito de la provincia del } \\
\text { Cusco y las provincias de Calca y } \\
\text { Urubamba }\end{array}$ \\
\hline Estilo de vida & $\begin{array}{l}\text { - Conducta positiva al consumo de carne } \\
\text { de cuy } \\
\text { - } \\
\text { El cuy es un alimento que se consume } \\
\text { desde la época inca. } \\
\text { - } \quad \text { Consumo de la carne de cuy está } \\
\text { arraigada en la cultura popular de la } \\
\text { región del Cusco. } \\
\text { - Consumo de platos a base de carne de } \\
\text { cuy como el Chiri Uchu en ocasiones } \\
\text { especiales como fiestas religiosas y } \\
\text { otras ocasiones importantes. }\end{array}$ \\
\hline
\end{tabular}

Otro segmento de mercado elegido fue determinado por las empresas y unidades de negocio jurídicas y naturales comprendidos por los restaurantes tradicionales y turísticos que presenten las siguientes tipos de segmento:

\subsubsection{Segmento geográfico.}

Comprendido por las empresas naturales y jurídicas pertenecientes al sector Comercio debidamente registradas y acreditadas en la Dirección Regional de Comercio y Turismo del Cusco, dedicadas al rubro de la restauración que se encuentran en los en los distritos de 
Cusco, Wanchaq, Santiago, San Sebastián, San Jerónimo, Saylla de la provincia del Cusco y las provincias de Calca y Urubamba de orden tradicional y turístico que presenten dentro de su carta platos a base de carne de cuy con una frecuencia y volumen determinado de venta de este tipo de carne.

La determinación de este segmento fue validada por la entrevista a expertos mediante la aplicación del instrumento de investigación y entrevista aplicada en focus group realizado, así como cuestionario aplicado a propietarios de restaurantes tradicionales y turísticos indicados. De lo detallado se tiene como perfil:

Tabla 13

Perfil de la Segmentación de Restaurantes

Característica $\quad$ Descripción

Tipo de empresa Naturales y Jurídicas

Sector Comercio

Giro del negocio $\quad$ Restaurantes

Tipo de restaurantes Tradicionales y turísticos

Zona Geográfica Seis principales distrito de la provincia del

Cusco y las provincias de Calca y

Urubamba 


\subsection{Investigación cualitativa}

La investigación cualitativa es la recolección de datos en forma de texto o imágenes con preguntas abiertas, observación o datos hallados (Hair, Bush y Ortinua, 2010, p. 146)

Parte de la investigación del presente proyecto está basada en fuentes primarias cualitativas poniendo énfasis en primer lugar en estudios previos relacionados a la producción, comercialización y consumo de la carne de cuy; para posteriormente emplear focus group y entrevistas como fuentes primarias de recolección de información básica de carácter técnica y preferencias de consumo.

Una vez revisado los estudios previos se realizó dos focus group y una entrevista a expertos, con el propósito de saber las preferencias del consumo de la carne de cuy y los factores que intervienen para ampliar la comercialización y consumo de esta; así mismo conocer los procesos de cultivo de alfalfa, crianza y sacrificio de estos animales. Obtenida esta información se elaboró encuestas, determinando atributos y permitiendo el análisis de los datos obtenidos.

\subsubsection{Proceso de Muestreo.}

Para el proceso de muestreo se aplicó dos focus group de 6 personas cada uno; Kotler\& Keller (2006) manifiestan que de 6 a 10 personas integran un focus group, el primero de ellos dirigido a propietarios de restaurantes turísticos y tradicionales, el segundo a público consumidor habitual de esta carne, y finalmente se realizó una entrevista a expertos conocedores en la crianza de este animal menor de la región de Cusco.

Para el primer focus group se contó con la participación de dos propietarios de restaurantes turísticos y cuatro propietarios de restaurantes tradicionales, para el segundo focus group se invitó a seis amas de casa de diferentes distrititos de Cusco, que compartieron 
sus experiencias acerca de sus preferencias y hábitos más importantes al momento de su compra.

Finalmente se hizo una entrevista a un grupo de expertos en el cual participaron seis especialista entre ingenieros zootecnista, ingenieros agrónomos y técnicos agropecuarios del proyecto Cuyes del Ministerio de Agricultura, personas conocedoras del proceso de cultivo de alfalfa, crianza, sacrificio empacado al vacío de cuyes.

\subsubsection{Diseño del Instrumento.}

Para la elaboración de los focus group se preparó guía de pautas y cuestionario de entrevistas en el caso de la entrevista a expertos (ver anexo 03) que está compuesta por la presentación tanto del moderador, así como la presentación de los participante para dar paso a los objetivos de las reuniones. Después de entrar en un ambiente confianza entre el moderador y los participantes se dio paso a las preguntas relacionadas tanto a la crianza de los animales y principales atributos tomados en cuenta para la compra de la carne de cuy, para esto se estableció que los grupos estarían conformados por 6 participantes, las reuniones que duraron entre 1 a 2 horas se dieron en un ambiente adecuado donde estos se sintieran a gusto; que se llevaron a cabo los días 10, 13 y 15 de julio del 2016, fechas las cuales garantizaron que los asistentes concurrieran en su totalidad, también se indicó a los participantes que estas reuniones serian grabadas con el fin de realizar un procesamiento adecuado a la información proporcionada por ellos.

\subsubsection{Análisis y procesamiento de datos.}

De los focus group realizados a los dueños de restaurantes turísticos-tradicionales (ver anexo 04 y anexo 05) y público en general (anexo 06), se pudo obtener datos relevantes como: tipo de presentación de este producto, edad, peso, condiciones sanitarias en el lugar de expendio y valor nutricional. 
La entrevista dirigida a expertos criadores, permitió conocer el proceso de cultivo de alfalfa, cantidad de alimentación por día, así mismo para la crianza el número de animales por pozas (cantidad adecuada un macho por cada siete hembras), periodo de gestación, tipo de cuy ideal para este producto y en el proceso de sacrificio las actividades para la obtención del producto final empacado al vacío.

\subsection{Investigación cuantitativa}

La investigación cuantitativa es el diseño de encuestas en la que se recalca el uso de preguntas formales uniformadas y opciones de respuestas determinadas en cuestionarios aplicados a muchos entrevistados (Hair, Bush y Ortinua, 2010, p. 145)

En este entender, el tipo de investigación que se aplicó para realizar el análisis cuantitativo fue de tipo no experimental donde se observó situaciones ya existentes no provocadas intencionalmente ( no se manipuló las variables), de corte transversal recolectando datos en un solo momento, describiendo variables para analizar su incidencia e interrelación en un momento determinado y de tipo correlacional -causal, que permitió describir y explicar relaciones de causa-efecto de como la aplicación de métodos y técnicas adecuadas de crianza permite obtener un producto ecológico que satisfaga la demanda existente en el mercado.

\subsubsection{Proceso de muestreo.}

Conforme a Hernandez Sampieri (2014) la muestra es un subgrupo del universo o población del cual se recolectan los datos y que deben de ser representativos de esta. En este sentido el tipo de muestreo elegido fue el probabilístico estratificado, que consiste en el proceso de selección de una muestra en la que todos los individuos o elementos de una población, tienen alguna probabilidad de ser. 
Para esto se determinó la población objeto a todas aquellas personas que se encuentran entre los 18 a 75 años de género masculino y femenino que están en los NSE A,B, C de la región del Cusco con ingresos de llegan hasta los 6379 nuevos soles según los estudios de APEIN 2016. Determinando la población por medio de una estimación y proyección en base al último censo del INEI de los años 2007 tomando como criterio para la proyección la tasa de crecimiento de cada provincia y distrito materia de estudio del presente plan de negocios, a continuación se detalla en la tabla 13 la proporción de los habitantes por los distritos y provincias objetos de estudio con el fin de distribuir proporcionalmente la muestra:

Tabla 14

Distribución de la Población Proyectada por Estratos de la Provincia Cusco, Calca y Urubamba al año 2016

\begin{tabular}{cccccccccccc}
\hline Distritos & TC & 2007 & 2008 & 2009 & 2010 & 2011 & 2012 & 2013 & 2014 & 2015 & 2016 \\
\hline Cusco & $1.11 \%$ & 108,798 & 110008 & 111232 & 112469 & 113720 & 114985 & 116264 & 117557 & 118865 & 120187 \\
San Jeronimo & $5.40 \%$ & 31,687 & 33399 & 35204 & 37106 & 39111 & 41225 & 43453 & 45801 & 48276 & 50885 \\
San Sebastián & $6.21 \%$ & 74,712 & 79353 & 84282 & 89518 & 95079 & 100985 & 107258 & 113921 & 120998 & 128514 \\
Santiago & $0.97 \%$ & 83,721 & 84534 & 85355 & 86184 & 87021 & 87866 & 88719 & 89580 & 90450 & 91328 \\
Wanchaq & $0.98 \%$ & 59,134 & 59714 & 60299 & 60890 & 61487 & 62090 & 62699 & 63314 & 63935 & 64562 \\
Saylla & $8.34 \%$ & 2,934 & 3179 & 3444 & 3731 & 4042 & 4379 & 4744 & 5140 & 5569 & 6033 \\
Calca & $1.11 \%$ & 65,407 & 66133 & 66867 & 67609 & 68359 & 69118 & 69885 & 70661 & 71445 & 72238 \\
Urubamba & $1.16 \%$ & 56,685 & 57343 & 58008 & 58681 & 59362 & 60051 & 60748 & 61453 & 62166 & 62887 \\
Total & & 483,078 & 493663 & 504691 & 516188 & 528181 & $\mathbf{5 4 0 6 9 9}$ & $\mathbf{5 5 3 7 7 0}$ & $\mathbf{5 6 7 4 2 7}$ & $\mathbf{5 8 1 7 0 4}$ & $\mathbf{5 9 6 6 3 4}$ \\
\hline
\end{tabular}

Nota. Tomado en base a la información INEI- Censo de Población y vivienda del año 2007

Como se mencionó al utilizar el método probalístico estratificado la cual divide la población en estratos, se procedió a seleccionar de manera aleatoria por cada estrato, para esto y con el fin de determinar la muestra y proporción de personas por cada estrato se empleó: 


$$
n=\frac{\frac{\partial}{z} \sum_{h=1}^{L} W_{h} p_{h}\left(1-p_{h}\right)}{e^{2}}
$$

Dónde:

$\mathrm{n}=$ Tamaño de la muestra $=?$

$\mathrm{Z}=$ Valor en tabla $\mathrm{Z}$ para un nivel de confianza del $95 \%=1.96$

$\mathrm{e}=$ Margen de error $\quad=4 \%$

$\mathrm{Wh}=$ Proporción del tamaño de estrato h con respecto al total

$\mathrm{h}=8$, estratos

$\mathrm{Ph}=$ Probabilidad de éxito $=50 \%$

1- $\mathrm{Ph}=$ Probabilidad de fracaso $=50 \%$

Para esto se aplicará la distribución de la población por estratos y determinación de la proporción en las siguientes tablas: 
Tabla 15

Distribución de la Población Proyectada por Proporción según Proporción de la Provincia Cusco, Calca y Urubamba al año 2016

\begin{tabular}{|c|c|c|c|}
\hline Estratos & Distritos & Población al 2016 & $\begin{array}{c}\text { Proporción del total } \\
\text { de la población h }\end{array}$ \\
\hline 1 & Cusco & 120189 & 0.201445107 \\
\hline 2 & San Jeronimo & 50886 & 0.085288468 \\
\hline 3 & San Sebastián & 128514 & 0.215398385 \\
\hline 4 & Santiago & 91327 & 0.153070392 \\
\hline 5 & Wanchaq & 64561 & 0.108208718 \\
\hline 6 & Saylla & 6033 & 0.010111727 \\
\hline 7 & Calca & 72239 & 0.121077579 \\
\hline 8 & Urubamba & 62885 & 0.105399625 \\
\hline \multicolumn{2}{|r|}{ Total } & 596634 & 1 \\
\hline
\end{tabular}

Nota. Adaptado de la Tesis Doctoral "Influencia de la Motivaciones Hedónicas y Utilitarias de la intención de compra de departamentos para vivienda", Lima 2017.

Determinada la proporción de la población por estrato de proceder a determinar la

proporción total

Tabla 16

Distribución de la Población Proyectada por Proporción según Proporción de la Provincia Cusco, Calca y Urubamba al año 2016

\begin{tabular}{|c|c|c|c|c|c|c|}
\hline Estratos & Distritos & Población al 2016 & $\begin{array}{l}\text { Proporción del total } \\
\text { de la población } \mathrm{Wh}\end{array}$ & $\mathrm{Ph}$ & $1-\mathrm{Ph}$ & $\mathrm{Wh}^{*} \mathrm{ph}^{*}(1-\mathrm{ph})$ \\
\hline 1 & Cusco & 120189 & 0.201445107 & 0.5 & 0.5 & 0.050361277 \\
\hline 2 & San Jeronimo & 50886 & 0.085288468 & 0.5 & 0.5 & 0.021322117 \\
\hline 3 & San Sebastián & 128514 & 0.215398385 & 0.5 & 0.5 & 0.053849596 \\
\hline 4 & Santiago & 91327 & 0.153070392 & 0.5 & 0.5 & 0.038267598 \\
\hline 5 & Wanchaq & 64561 & 0.108208718 & 0.5 & 0.5 & 0.027052179 \\
\hline 6 & Saylla & 6033 & 0.010111727 & 0.5 & 0.5 & 0.002527932 \\
\hline 7 & Calca & 72239 & 0.121077579 & 0.5 & 0.5 & 0.030269395 \\
\hline 8 & Urubamba & 62885 & 0.105399625 & 0.5 & 0.5 & 0.026349906 \\
\hline \multicolumn{6}{|c|}{ Total } & 0.25 \\
\hline
\end{tabular}

Nota. Adaptado de la Tesis Doctoral "Influencia de la Motivaciones Hedónicas y Utilitarias de la intención de compra de departamentos para vivienda”, Lima 2017. 
Una vez determinada la proporción de estrato se procede a sustituir en la fórmula, siendo el valor de " $n$ " determinado de 600 encuestas que se realizaran al personas de los NSE y edades mencionadas y con poder adquisitivo a los cuales se aplicó un cuestionario que servirá como fuente de información primaria para el análisis de los gustos, preferencias y hábitos de consumo que posee el público objetivo al momento de decidir por la compra de este tipo de carne.

Se considera $\mathrm{p}=\mathrm{q}=0.5$ ya que no existe encuestas anteriores con respecto a este producto y un error aceptable del cuatro porciento.

Sin embargo y por considerarse un tipo de muestra probabilista estratificada la cual aumenta la precisión de la muestra y que implica el uso de diferentes tamaños de muestras para cada estrato y con el fin de reducir la varianza se aplica la desviación estándar (Hernández, 2014, p. 181) que consiste en:

nh

$\mathrm{ksh}=--$

$\mathrm{Nh}$

Dónde:

ksh: Desviación estándar

nh: muestra

Nh: Población

600

ksh=---------------- $=0.0010$

596634 
Aplicando este coeficiente a la población por cada estrato se tiene:

Tabla 17

Número de Encuestas por Distrito

\begin{tabular}{|c|c|c|c|}
\hline Estratos & Distritos & Población al 2016 & Muestra \\
\hline 1 & Cusco & 120189 & 121 \\
\hline 2 & San Jeronimo & 50886 & 51 \\
\hline 3 & San Sebastián & 128514 & 129 \\
\hline 4 & Santiago & 91327 & 92 \\
\hline 5 & Wanchaq & 64561 & 65 \\
\hline 6 & Saylla & 6033 & 6 \\
\hline 7 & Calca & 72239 & 73 \\
\hline 8 & Urubamba & 62885 & 63 \\
\hline & Total & 596634 & 600 \\
\hline
\end{tabular}

También se ha considerado poder atender a restaurantes turísticos y tradicionales para lo cual se recurrió a la fórmula para calcular el tamaño de muestra en una población finita, según Suarez (2011) el valor de "n” está definido por la siguiente relación, tomando como fuente de información la Dirección de Regional de Turismo, con un cálculo para 84 restaurantes turísticos y 60 tradicionales.

$$
n=\frac{Z^{2} N P q}{E^{2}(N-1)+Z^{2} P q}
$$

$$
n=74
$$

Dónde:

$\mathrm{n}=$ Tamaño de la muestra $=$ ?

$\mathrm{N}=$ Población o universo

$Z=$ Valor en tabla $Z$ para un nivel de confianza del $95 \%=1.96$ 


$$
\begin{aligned}
& \mathrm{e}=\text { Margen de error }=4 \% \\
& \mathrm{p}=\text { Probabilidad de éxito }=50 \% \\
& \mathrm{q}=\text { Probabilidad de fracaso }=50 \%
\end{aligned}
$$

Cálculos para 60 restaurantes tradicionales

$$
n=\frac{Z^{2} N P q}{E^{2}(N-1)+Z^{2} P q}
$$

$$
n=55
$$

Para lo cual se tiene una muestra de 74 restaurantes turísticos y 55 tradicionales con un nivel de confianza del $95 \%$ y un error aceptable del $4 \%$

\subsubsection{Diseño de instrumento.}

Se realizaron encuestas por medio de cuestionarios como instrumento que fueron aplicados a público en general de los NSE A,B y C entre las edades de los 18 a 75 años de las provincias y distritos que figuran en la tabla que antecede. De la misma manera se aplicó un cuestionario estructurado y estandarizado para dueños o propietarios, gerentes y administradores restaurantes turísticos y tradicionales de la ciudad del Cusco con capacidad de decisión de compra y cuyos establecimientos expenden platos a base de carne cuy en sus distintas presentaciones (Ver Anexo y Modelos de encuesta y Anexo ficha técnica de encuesta). 
3.4.3. Análisis y procesamiento de datos.

\section{Encuesta dirigida al poblador cusqueño por distrito.}

\section{Pregunta 1. Grupo atareo}

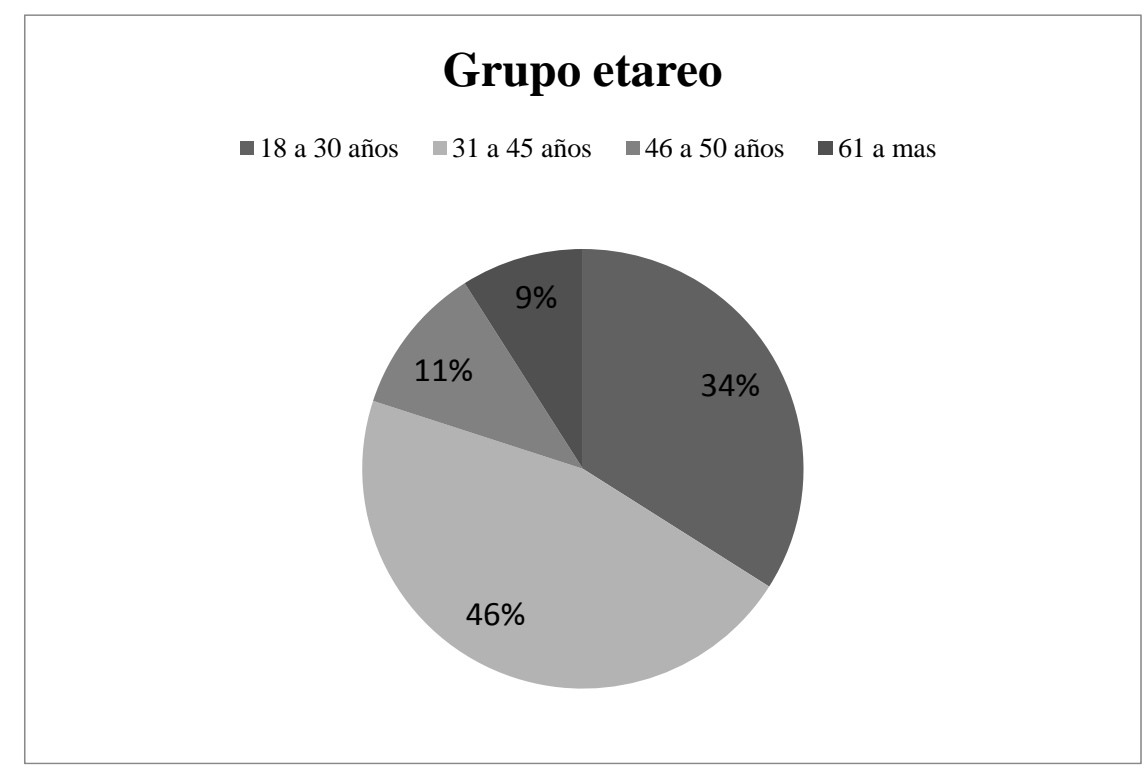

Figura 7. Número de Encuestas por Distrito

Como se puede apreciar en la figura que antecede, el mayor índice porcentual de los encuestados oscilan entre edades que oscilan entre los 31 a 45 años que representa el $46 \%$ seguido por un $34 \%$ de encuestados cuyas edades varían entre 18 a 30 años, un $11 \%$ distribuidos son personas que están entre los 46 a 50 años siendo un 9\% de la población encuestada que tiene edades entre 51 a más.

El cuadro nos demuestra que la población que más consume cuy son relativamente jóvenes constituyéndose un mercado que ha de aceptar algunos nuevos cambios favorables en la comercialización del producto. 


\section{Pregunta 2. Género}

Figura 8. Genero.

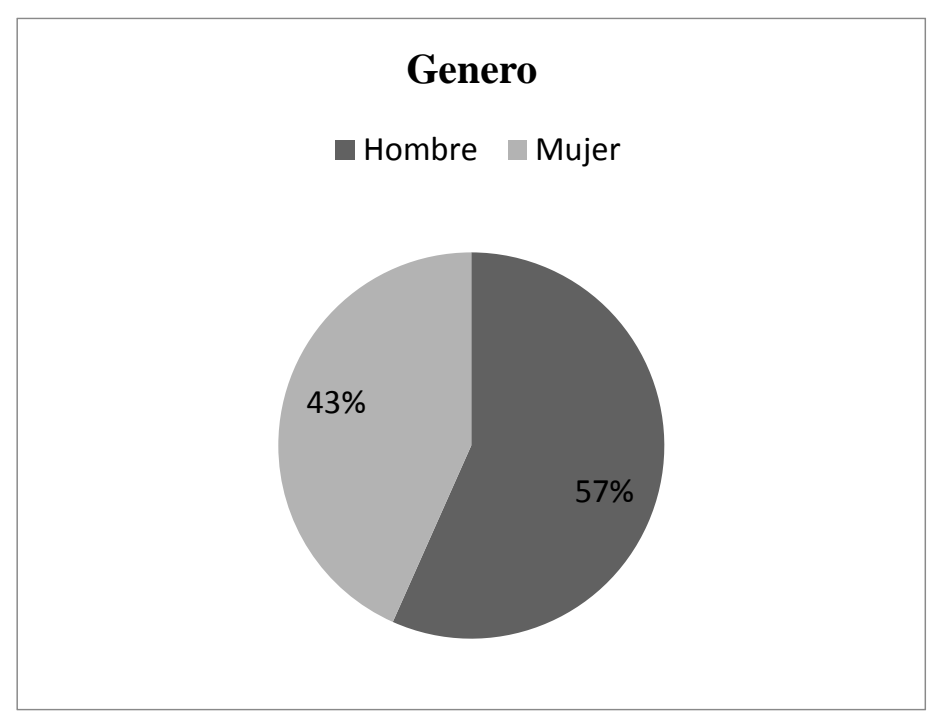

En la figura se observa que del $100 \%$ de la población encuestada un $43 \%$ de éstos pertenecen al género femenino que viene a ser aquella población que en su mayoría se dedica a labores culinarias, notándose también la presencia de un $57 \%$ de personas encuestadas pertenecientes al género masculino.

\section{P3. ¿Por cuantas personas está compuesta su unidad familiar?}

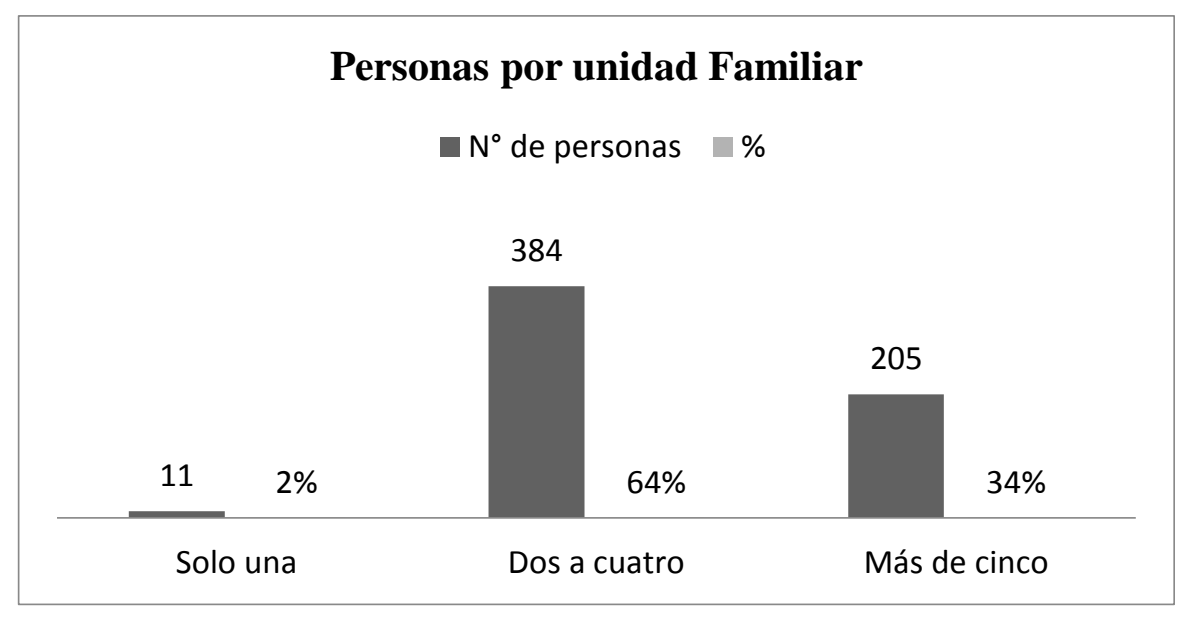

Figura 9. Número de familias.

En la figura se aprecia que las familias encuestadas en su mayoría están conformadas de dos a cuatro personas representadas por el $64 \%$ habiendo un $34 \%$ de familias cuyo número 
fluctúa entre más de cinco personas de la población y solo un $2 \%$ de personas que solo están conformadas por un integrante en su unidad familiar.

\section{P4. ¿En qué distritos del Cusco y provincias se encuentran viviendo actualmente?}

Tabla 18

Distrito en los que se Encuentran Viviendo

\begin{tabular}{ccc}
\hline Distritos & 2016 & $\%$ \\
\hline Cusco & 120189 & $20 \%$ \\
San Jerónimo & 50886 & $9 \%$ \\
San Sebastián & 128514 & $22 \%$ \\
Santiago & 91327 & $15 \%$ \\
Wanchaq & 64561 & $11 \%$ \\
Saylla & 6033 & $1 \%$ \\
Calca & 72239 & $12 \%$ \\
Urubamba & 62885 & $11 \%$ \\
Total & 596634 & $100 \%$ \\
\hline
\end{tabular}

Como se puede observar la tabla, el mayor porcentaje de población que vive en la provincia de Cusco se encuentra en el distrito de San Sebastián representado por un 22\%, seguido por el distrito del Cusco con un 20\%, también se puede advertir que el distrito donde menos personas viven es el distrito de Saylla que está representando por el 1\%, distritos como San Santiago y Wanchaq tienen una población de $15 \%$ y 11\%. Además se tiene que en las provincias de Calca y Urubamba tienen un $12 \%$ y $11 \%$ de personas que viven en estas zonas respectivamente. 
P5. ¿Cuál es el ingreso mensual que actualmente percibe como familia?

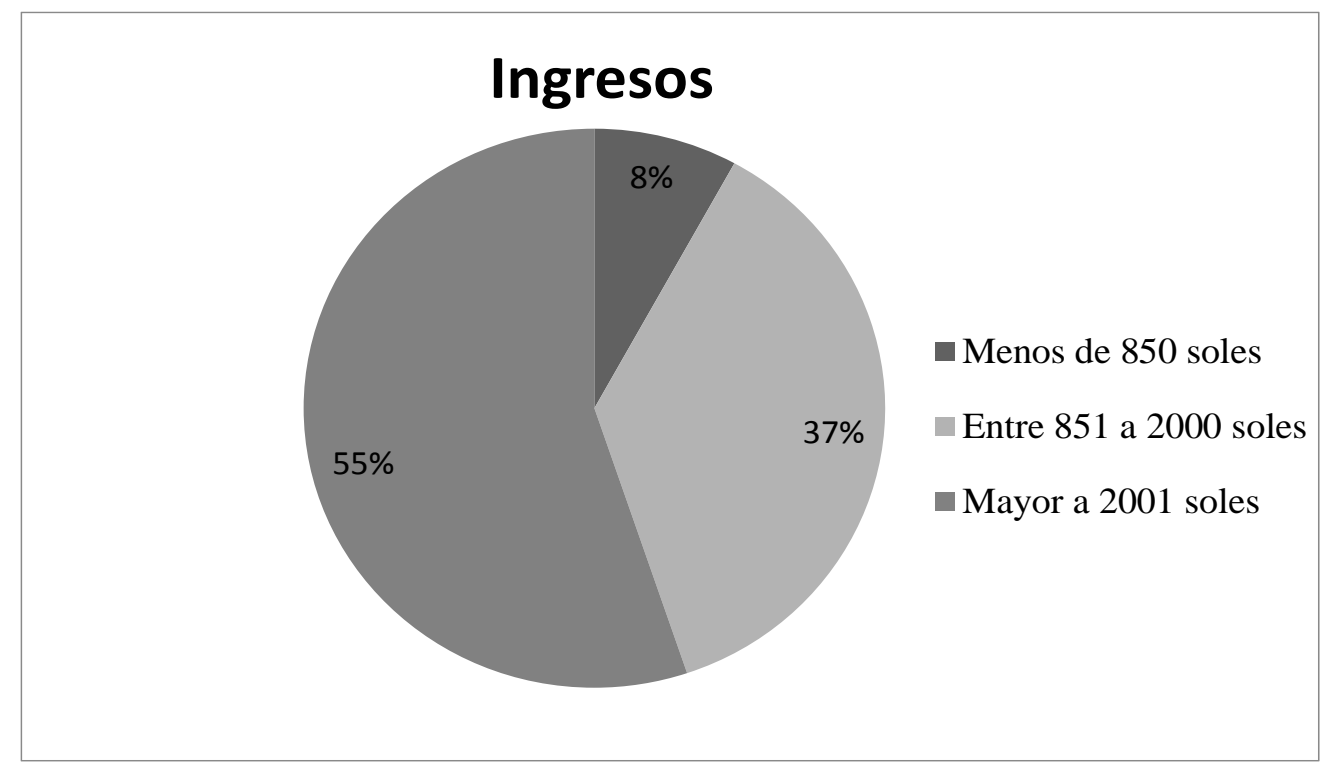

Figura 10. Ingreso mensual

De la población objeto de estudio y de acuerdo a su NSE se puede advertir que existe un $55 \%$ de los encuestados perciben ingresos mayores a los 2001 soles, seguido por un $37 \%$ de personas que tienen ingresos que van desde los 851 a 2000 soles y solo hay un $8 \%$ que tiene ingresos menores a los 850 soles.

P6. ¿Usted consume carne en su menú diario?

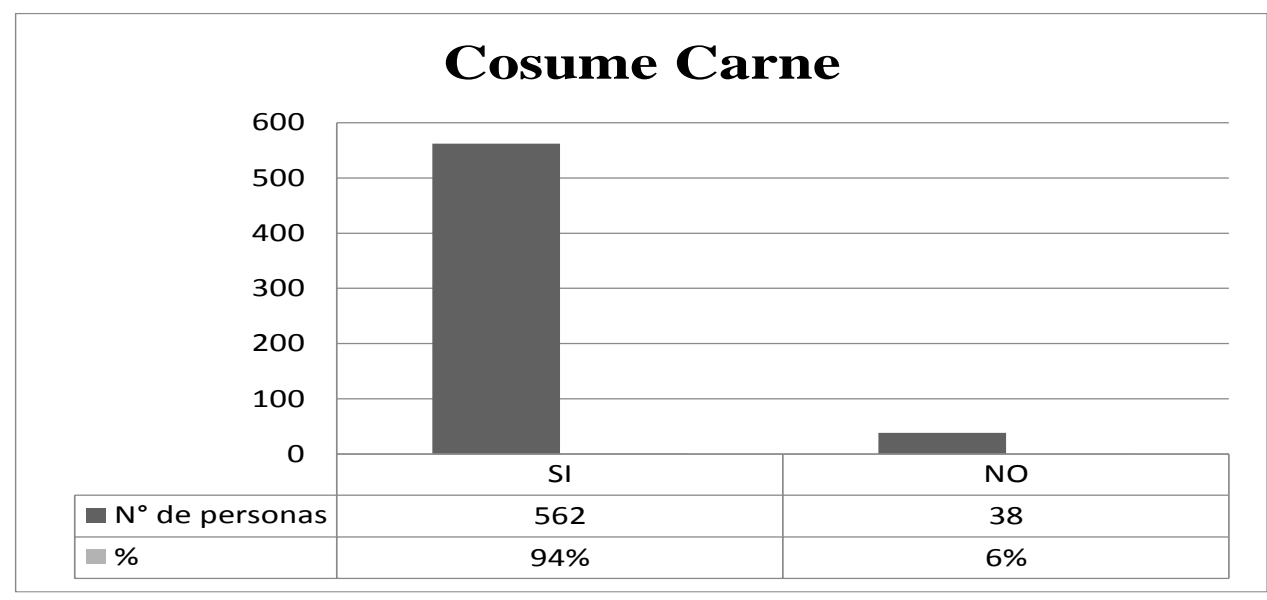

Figura 11. Consumo de carne 
En referencia a la preferencia que tienen las personas encuestadas se tiene que el $94 \%$ consumen algún tipo de carne en su menú diario; sin embargo hay un $6 \%$ que manifiesta no estar acostumbrado a consumir ningún tipo de carme esto debido a que no tienen este hábito de consumo.

P7. ¿Conoce las ventajas de comer carne de cuy?

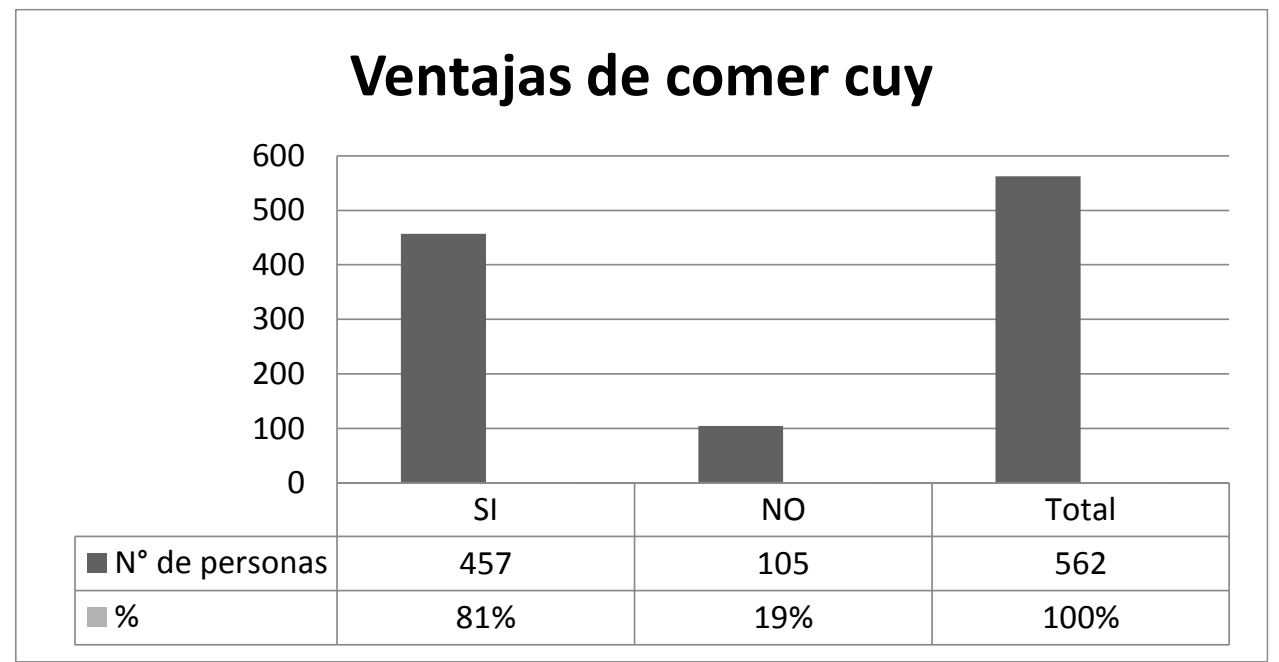

Figura 12. Ventajas de comer carne de cuy

De la figura presentada, se observa que el $81 \%$ de personas encuestadas son conocedoras de las ventajas de comer carne de cuy, ya sea por temas médico, nutricional y bondades de la carne, y solo un $19 \%$ de los encuestados manifiestan no conocer que ventajas trae comer este tipo de animal menor. 
P8. ¿En el año usted consume carne de cuy?

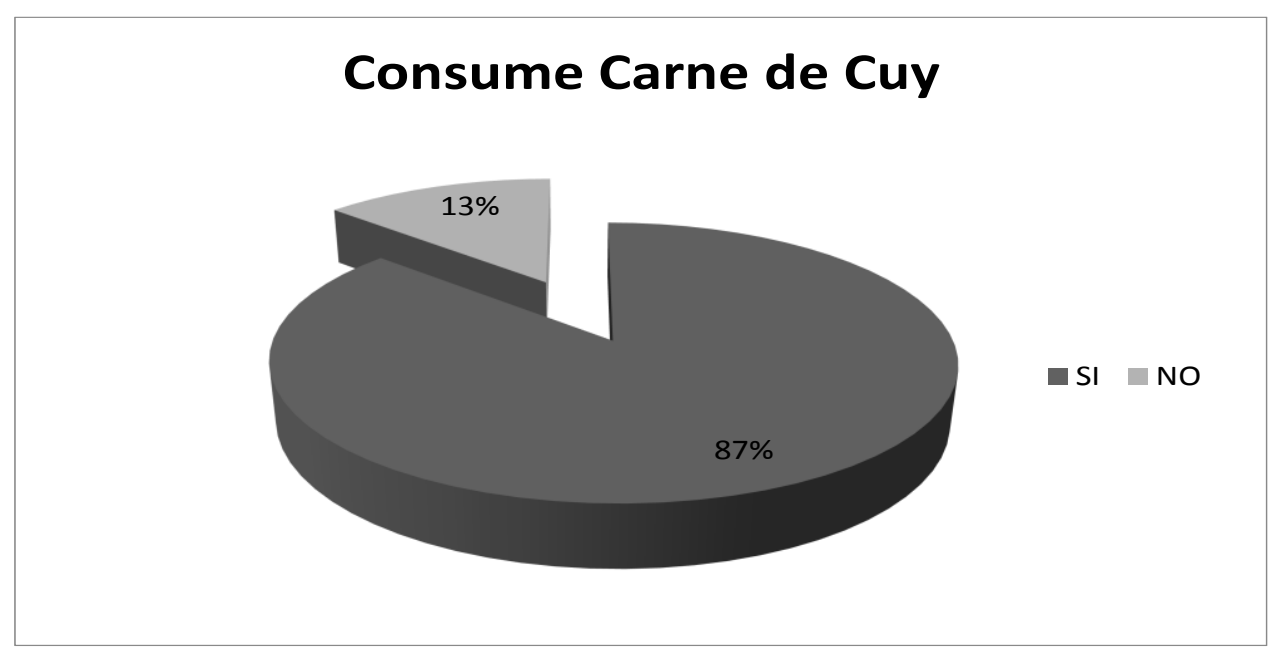

Figura 13. Consume carne de cuy

De la población encuestada representada por 562 personas se observa que hay 487 personas que representan el $87 \%$ manifiestan comer carne de cuy, mientras que la diferencia de estos manifiestan no consumir carne de cuy por no estar dentro de sus hábitos alimenticios representados por el $13 \%$.

P9. ¿Alguna persona de su familia compra carne de cuy para preparar en casa?

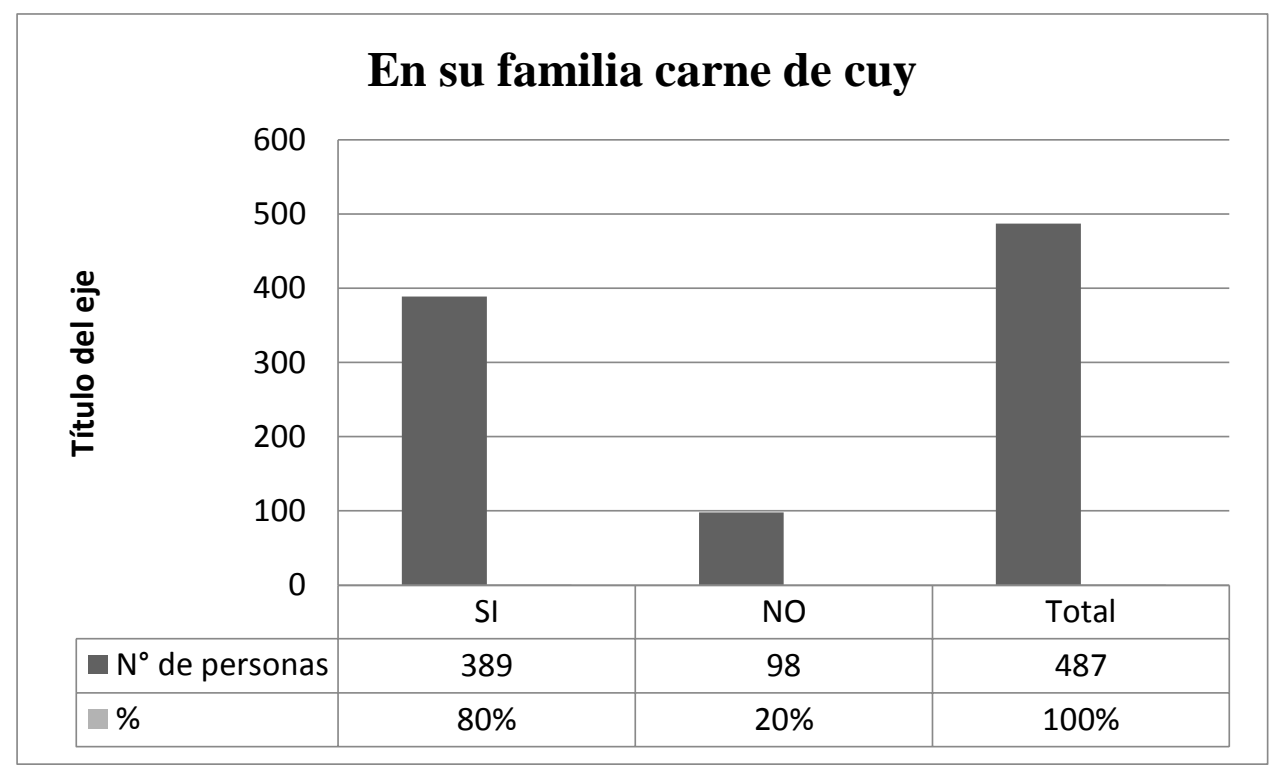

Figura 14. Consume carne de cuy 
De 487 personas que respondieron a esta pregunta el $80 \%$ representados por 389 personas indican que existe por lo menos una persona en su familia que compra carne de cuy para preparar, sin embargo hay 98 encuestados que indican que nadie en sus familias compran carne de cuy para preparar.

\section{P10. ¿Cómo lo compra?}

Tabla 19

Manera de Comprar la Carne de Cuy

\begin{tabular}{ccc}
\hline Variable & $\mathrm{N}^{\circ}$ de personas & $\%$ \\
\hline Vivo & 114 & $29 \%$ \\
Sacrificado eviscerado & 158 & $41 \%$ \\
Envasado & 0 & $0 \%$ \\
Cocido & 38 & $10 \%$ \\
Otros & 79 & $20 \%$ \\
Total & 389 & $100 \%$ \\
\hline
\end{tabular}

El $41 \%$ de los encuestados manifiestan que compran la carne de cuy de sacrificado eviscerado, seguido por un $29 \%$ que indican que lo compran vivo y que ellos lo sacrifican en su casa para consumo y en ningún caso los encuestados indicaron que no lo compran envasado por no haber una oferta actualmente en el mercado.

Es importante reconocer para efectos del presente Plan de Negocios que hay deseo de querer adquirir el cuy en mejores condiciones y con una mejor presentación, lo que nos demuestra que la propuesta del plan de negocios si sería viable aplicando una adecuada estrategia de marketing. 


\section{P11. ¿Dónde lo adquiere?}

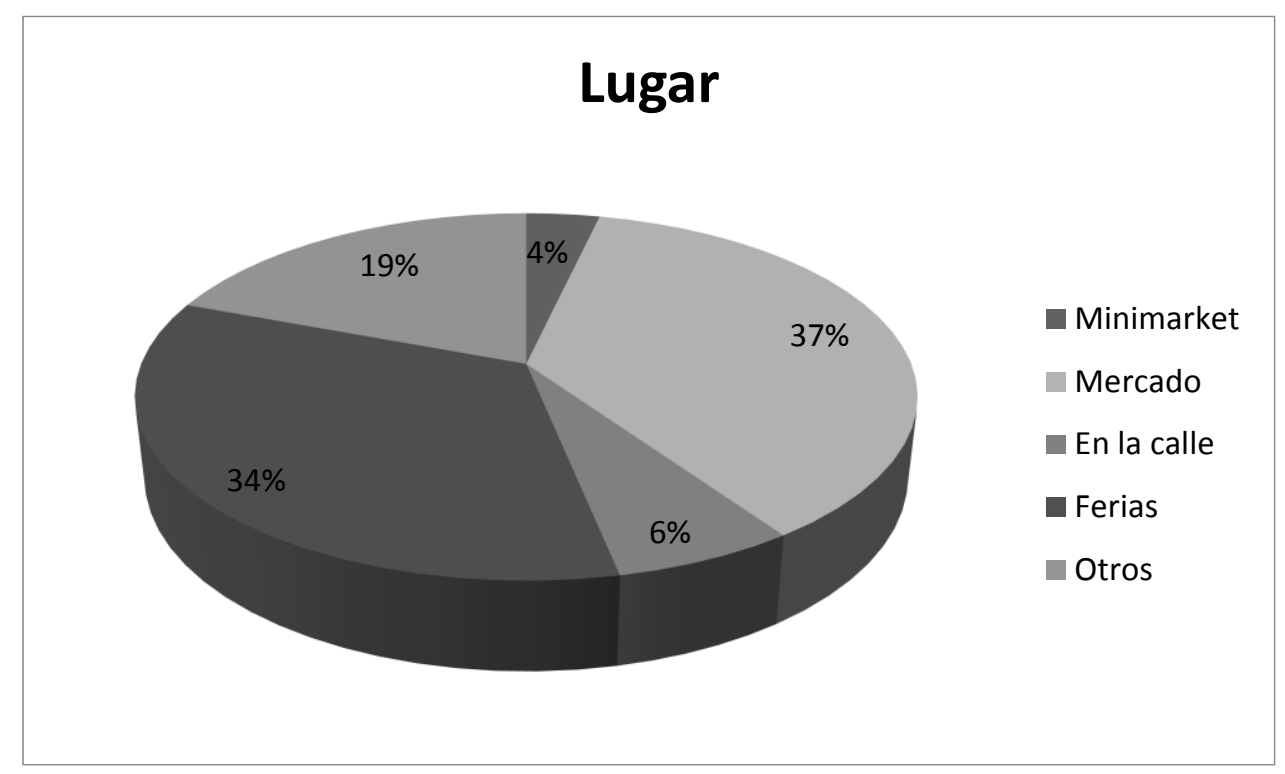

Figura 15. Lugar de compra.

La tabla que antecede refleja que el $37 \%$ de los encuestados refieren que no compran en el mercado de su zona, el $34 \%$ acuden a ferias sabatinas y dominicales para realizar su compra, existiendo solo un $4 \%$ que lo adquieren en minimarket cercanos a sus domicilios.

\section{P12. ¿Para qué ocasiones lo compra?}

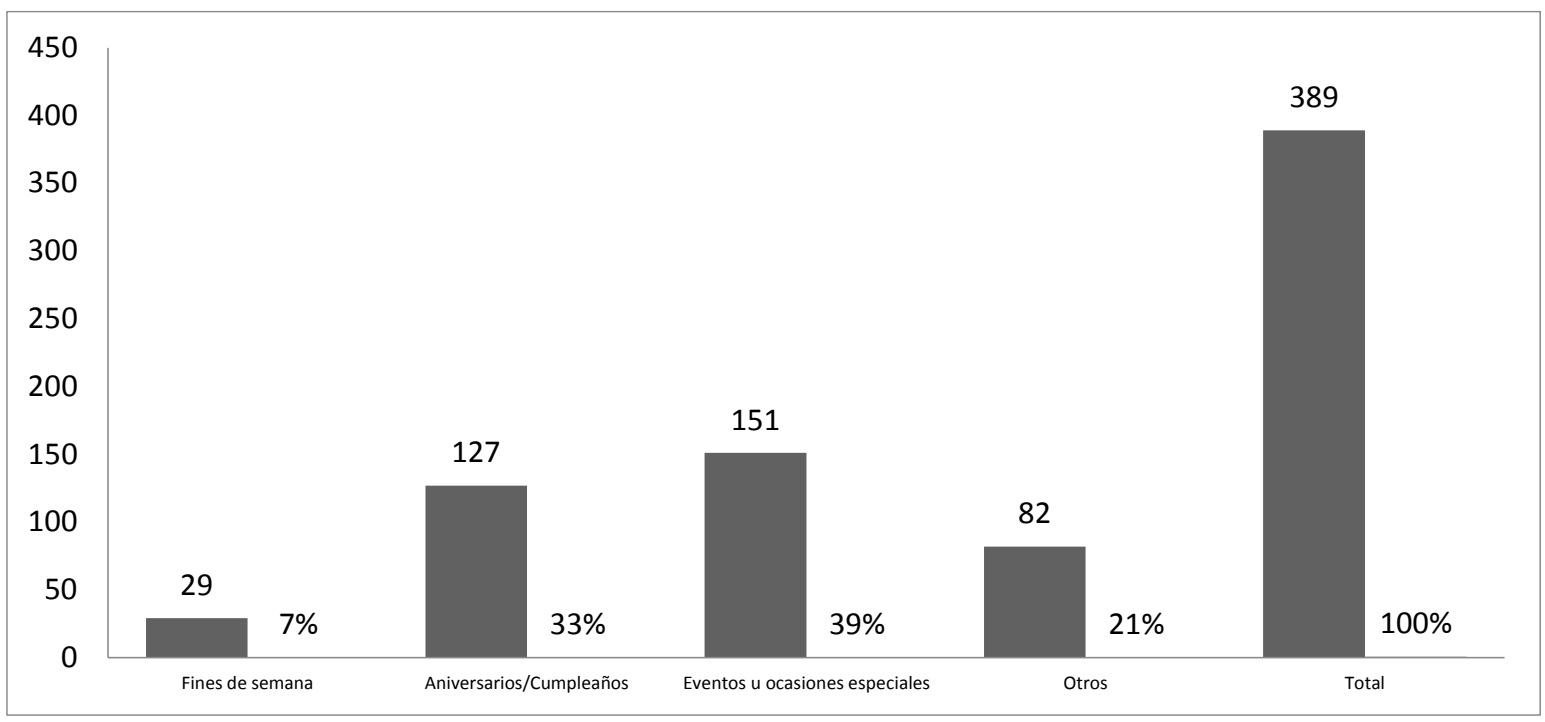

Figura 16. Ocasión de compra. 
De acuerdo a la figura 13, la principal ocasión de compra de los encuestados el 39\% lo hacen para eventos u ocasiones especiales, un $33 \%$ indican que compran este producto para aniversarios o cumpleaños, mientras que el $21 \%$ lo compra para otras ocasiones como elaborar platos típicos en fiestas de orden patronal como Corpus Christi y en otras ocasiones y un 7\% lo hacen cuando desean cumplir un antojo de momento pues este animal menor está relacionado a la gastronomía regional desde tiempos del incanato.

\section{P13. ¿Cuantas veces y con qué frecuencia al año en su casa compran carne de cuy?}

Tabla 20

Cuantas Veces y Frecuencia de Compra

\begin{tabular}{|c|c|c|c|c|c|c|c|c|c|c|c|c|c|c|}
\hline \multirow[b]{2}{*}{$\begin{array}{l}\text { Frecuencia } \\
\text { Nro de veces }\end{array}$} & \multicolumn{2}{|c|}{ Semanal } & \multicolumn{2}{|c|}{ Quincenal } & \multicolumn{2}{|c|}{ Mensual } & \multicolumn{2}{|c|}{ Trimestral } & \multicolumn{2}{|c|}{ Semestral } & \multicolumn{2}{|c|}{ Anual } & \multicolumn{2}{|c|}{ Total } \\
\hline & $\begin{array}{l}\mathrm{N}^{0} \text { de } \\
\text { personas }\end{array}$ & $\%$ & $\begin{array}{l}\mathrm{N}^{0} \mathrm{de} \\
\text { personas }\end{array}$ & $\%$ & $\begin{array}{c}\mathrm{N}^{0} \mathrm{de} \\
\text { personas }\end{array}$ & $\%$ & $\begin{array}{l}\mathrm{N}^{0} \text { de } \\
\text { personas }\end{array}$ & $\%$ & $\begin{array}{l}\mathrm{N}^{0} \mathrm{de} \\
\text { personas }\end{array}$ & $\%$ & $\begin{array}{l}\mathrm{N}^{0} \text { de } \\
\text { personas }\end{array}$ & $\%$ & $\begin{array}{l}\mathrm{N}^{0} \text { de } \\
\text { personas }\end{array}$ & $\%$ \\
\hline De 1 a 3 veces & 0 & $0 \%$ & 9 & $75 \%$ & 8 & $67 \%$ & 25 & $45 \%$ & 39 & $38 \%$ & 11 & $5 \%$ & 92 & $24 \%$ \\
\hline De 4 a 6 veces & 0 & $0 \%$ & 3 & $25 \%$ & 3 & $25 \%$ & 19 & $34 \%$ & 24 & $23 \%$ & 50 & $24 \%$ & 99 & $25 \%$ \\
\hline De 7 a 9 veces & 0 & $0 \%$ & 0 & $0 \%$ & 1 & $8 \%$ & 2 & $4 \%$ & 16 & $15 \%$ & 16 & $8 \%$ & 35 & $9 \%$ \\
\hline De 10 a 12 veces & 0 & $0 \%$ & 0 & $0 \%$ & 0 & $0 \%$ & 9 & $16 \%$ & 20 & $19 \%$ & 13 & $6 \%$ & 42 & $11 \%$ \\
\hline De 12 a más & 0 & $0 \%$ & 0 & $0 \%$ & 0 & $0 \%$ & 1 & $2 \%$ & 5 & $5 \%$ & 115 & $56 \%$ & 121 & $31 \%$ \\
\hline Total & 0 & $0 \%$ & 12 & $3 \%$ & 12 & $3 \%$ & 56 & $14 \%$ & 104 & $27 \%$ & 205 & $53 \%$ & 389 & $100 \%$ \\
\hline
\end{tabular}

De la tabla refleja que de 389 personas que constituyen el 100\%, se aprecia que el $31 \%$ de la población objeto de estudio compra el cuy de 12 a más veces al año, seguido por el $25 \%$ que lo hacen de cuatro a seis veces, en un porcentaje similar aquellas personas que compran de uno a tres veces que está representado por el $24 \%$, el11\% de los encuestados manifiestan que compran de 10 a 12 veces y solo $9 \%$ lo adquieren entre siente a nueve veces.

Por otro lado considerando la frecuencia de compra se observa que el 53\% lo hacen de manera anual, seguido por un $27 \%$ de los mismos que indican que lo hacen con una frecuencia semestral, un $14 \%$ indican que lo hacen de manera trimestral, mientras que el $3 \%$ 
lo hacen de maneta quincenal y mensual respectivamente, en ninguna caso compran de manera semanal.

Considerando los resultados obtenidos con los mayores porcentajes de frecuencia de compra y cantidad de compra consolidan el objetivo del proyecto al haber demanda constante por esta carne.

\section{P14. ¿Qué cantidad de cuyes compra para su consumo familiar al año?}

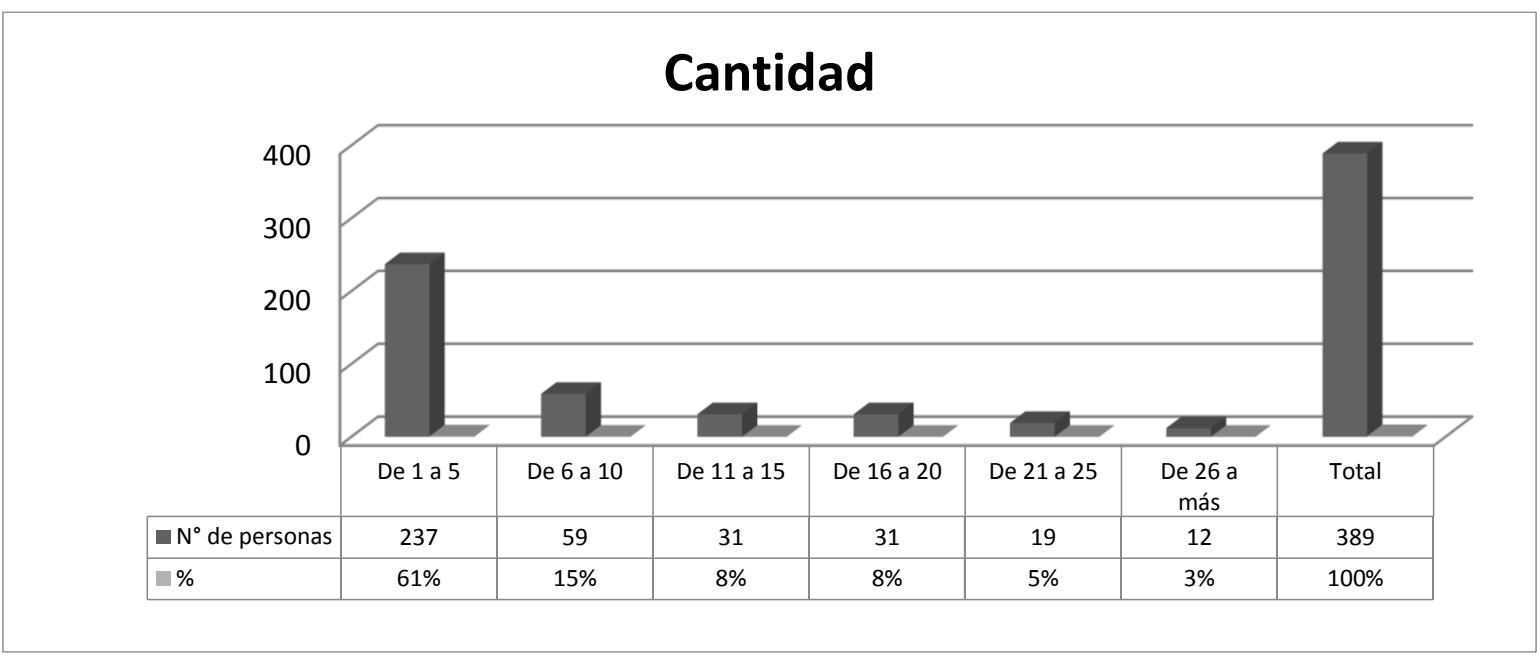

Figura 17. Cantidad de cuyes que compra.

De la figura se puede observar que el $61 \%$ de las personas encuestadas compran de uno a cinco cuyes, seguido por el $15 \%$ que indican que compran de seis a diez cuyes, también existe un ocho por ciento de los encuestados que compran de 11 a 15 cuyes lo que demuestra que el producto tiene demanda; y en menor proporción se tiene un $3 \%$ que compran entre 26 a más cuyes respectivamente. 
P15. ¿Cuál es el precio que paga por cada cuy?

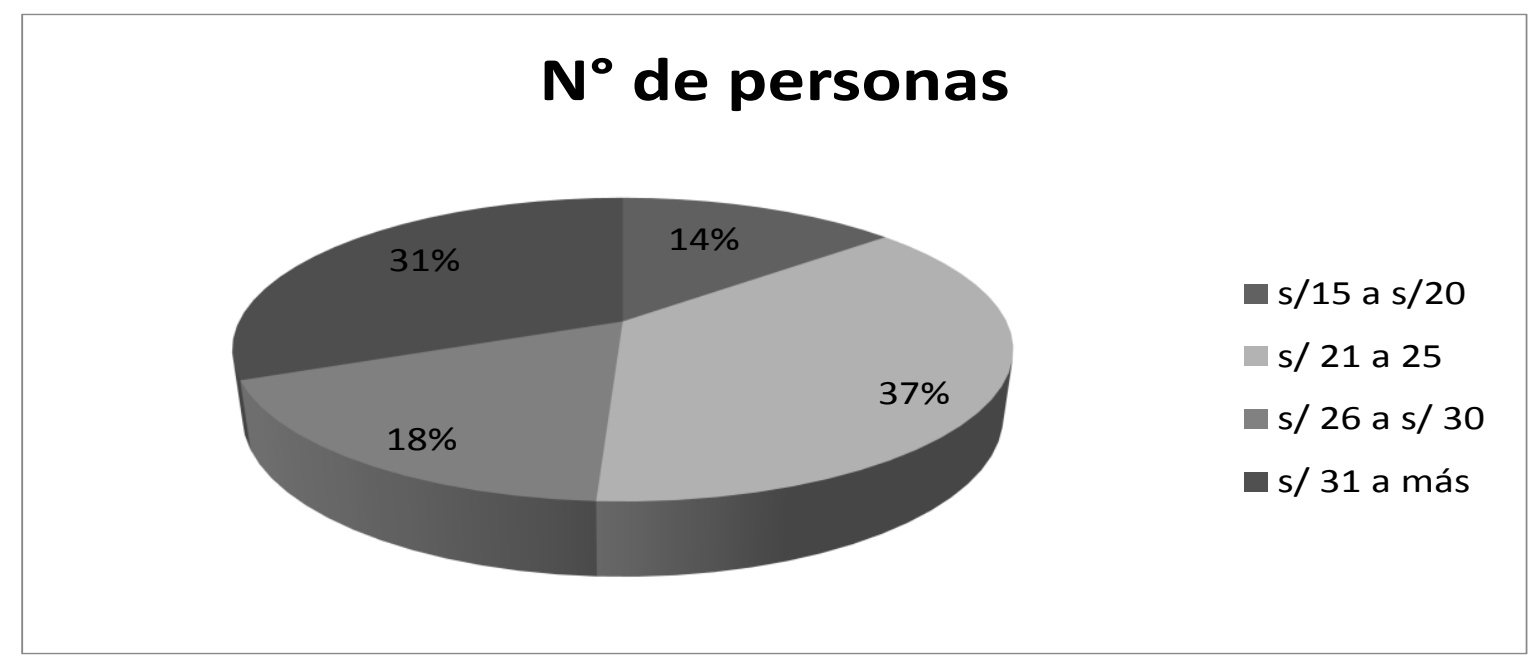

Figura 18. Precio que paga.

En cuanto al precio de compra indicado por los encuestados estos fluctúa entre a 15 a más de 31 soles, los cuales se distribuyen de la siguiente manera:

Un $37 \%$ adquiere el cuy entre 21 a 25 soles, seguido por el $31 \%$ cuyo precio de adquisición es de 31 soles a más, un $18 \%$ menciona que paga entre 26 a 30 soles y solo el $14 \%$ compra el cuy entre 15 a 20 soles.

De esta encuesta nos indica que el precio fluctúa acorde a la propuesta del plan de negocios. 
P16. Marque la característica que considera usted determinante para adquirir este animal como alimento

Tabla 21

Características que Considera Determinante

\begin{tabular}{lcc}
\hline \multicolumn{1}{c}{ Precio } & $\begin{array}{c}\mathrm{N}^{\circ} \text { de } \\
\text { personas }\end{array}$ & $\%$ \\
\hline Que tenga peso y tamaño ideal & 135 & $35 \%$ \\
Facilidad de preparación & 20 & $5 \%$ \\
Valor nutricional & 50 & $13 \%$ \\
Precio & 120 & $31 \%$ \\
Presentación del producto & 64 & $16 \%$ \\
\multicolumn{1}{c}{ Total } & 389 & $100 \%$ \\
\hline
\end{tabular}

El 35\% de los encuestados manifiestan que el peso y tamaño es la características más importante que consideran para la compra, mientras que para el $31 \%$ el factor precio es lo determinante, la presentación y valor nutricional son importantes para el $16 \%$ y el $13 \%$ respectivamente, solo un 5\% indican que la facilidad de preparación es lo más importante para ellos.

P17. ¿Estaría dispuesto Ud. a comprar carne de cuy empacada al vacío?

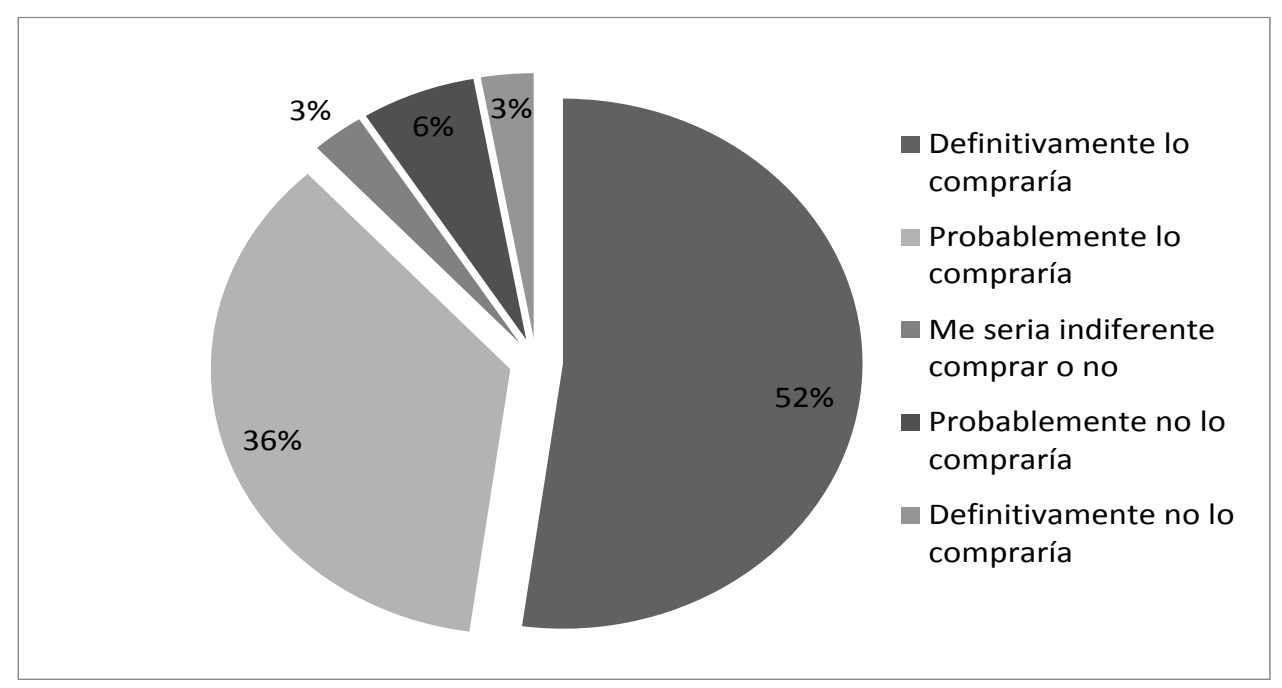

Figura 19. Precio que paga. 
En la figura que antecede se aprecia que un $52 \%$ de los entrevistados, desearía cambios en la forma de presentación de venta de la carne de cuy, sobre todo que esta carne sea ecológica por el tipo de alimentación que se le daría, tendencia que está en boga, también el resultado refleja que las personas prefieren un producto que guarde las garantías de salubridad y calidad que no existe actualmente en el mercado regional y que definitivamente comprarían el producto propuesto; también se observó que existe un $36 \%$ que probablemente comprarían un cuy envasado al vacío, seguido por un $6 \%$ que probablemente no lo adquirirían y solo un $3 \%$ de manifiesta que les es indiferente y que definitivamente no adquirirían el producto planteado.

\section{P18. ¿Conoce usted algún establecimiento en el que vendan carne de cuy empacada?}

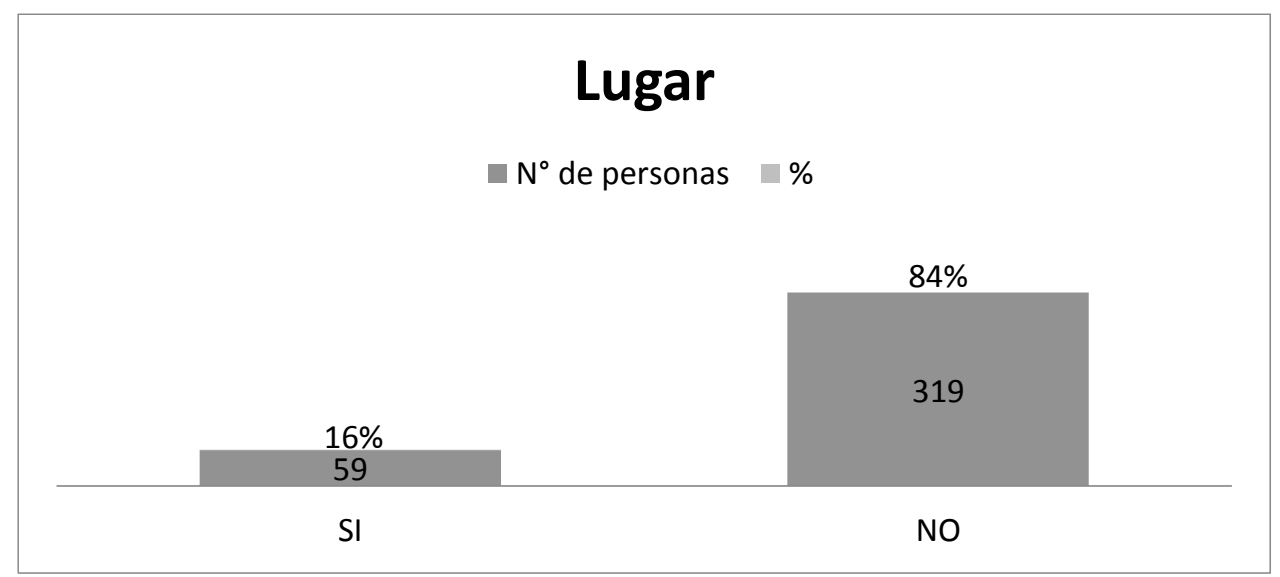

Figura 20. Conoce algún lugar.

A la pregunta planteada se tiene que el $84 \%$ de los encuestados no conocen algún establecimiento en donde venden carne de cuy empacada y solo un $16 \%$ manifiestan que si conocen donde se expende carne de cuy empacada. 


\section{P19. ¿Dónde le gustaría adquirirlo?}

Tabla 22

Donde le Gustaría Adquirirlo

\begin{tabular}{ccc}
\hline Lugar & $\mathrm{N}^{\circ}$ de personas & $\%$ \\
\hline Minimarket & 166 & $44 \%$ \\
Mercados & 81 & $21 \%$ \\
Ferias & 42 & $11 \%$ \\
Tiendas & 4 & $1 \%$ \\
Otros & 85 & $22 \%$ \\
Total & 378 & $100 \%$ \\
\hline
\end{tabular}

Las versiones vertidas por los encuestados objeto de estudio al no precisar del por qué no tienen preferencia por en un minimarket por ser este lugar que presta mayores garantías de salubridad para adquirir cuy expresado por el $44 \%$ de la población investigada. Un $22 \%$ manifiestan que les gustaría adquirirlos en otros lugares con especificando cuales serían; el $21 \%$ le gustaría adquirir el producto en el mercado aprovechando que hacen sus compras habituales, el $11 \%$ indica desear comprar este producto en ferias, solo un $1 \%$ indica que le gustaría encontrar el producto en las tiendas de barrio.

\section{P20. ¿Cuánto estaría dispuesto a pagar por unidad de este producto?}

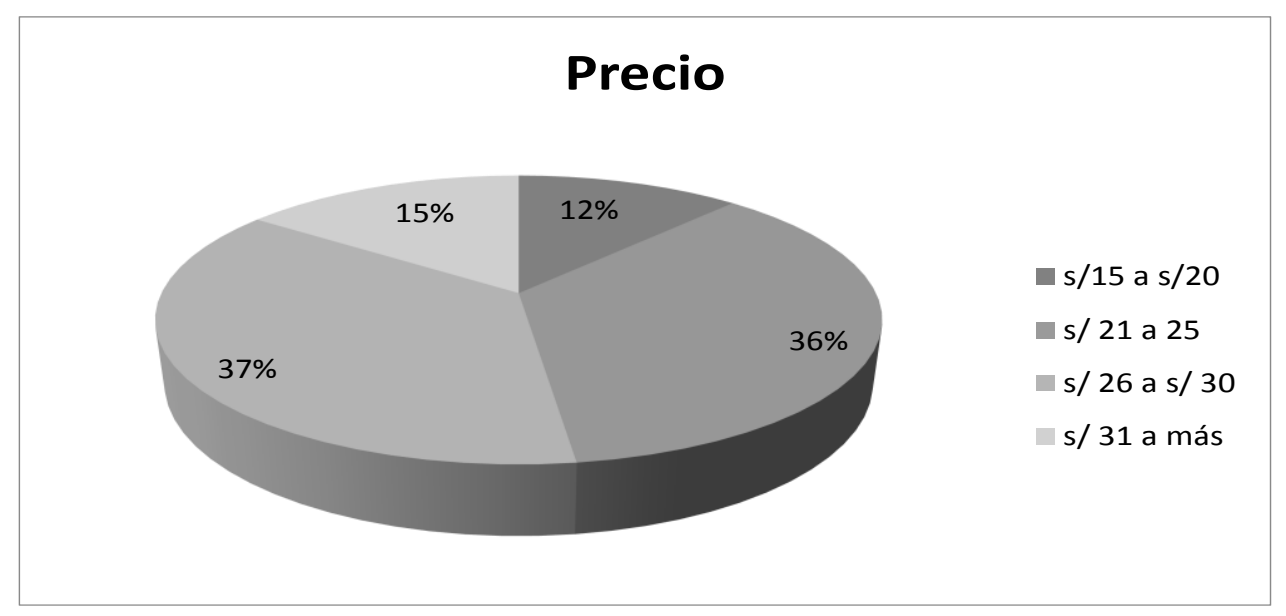

Figura 21. Precio 
Como se aprecia en la tabla que antecede, existe un $37 \%$ de encuestados que estarían dispuestos a pagar por este nuevo producto entre 26 a 30 soles, pareciéndole un precio bastante razonable; mientras que el $36 \%$ indica poder pagar entre 21 a 25 soles, un $15 \%$ sugieren que podrían pagar de 31 a más, y solo un 12\% podría pagar de 15 a 20 soles. Esta pregunta nos ayuda a determinar de mejor manera el precio de venta producto planteado en el plan de negocios.

\section{P21. ¿Por qué medio de comunicación recibe usted más publicidad de productos}

\section{alimenticios?}

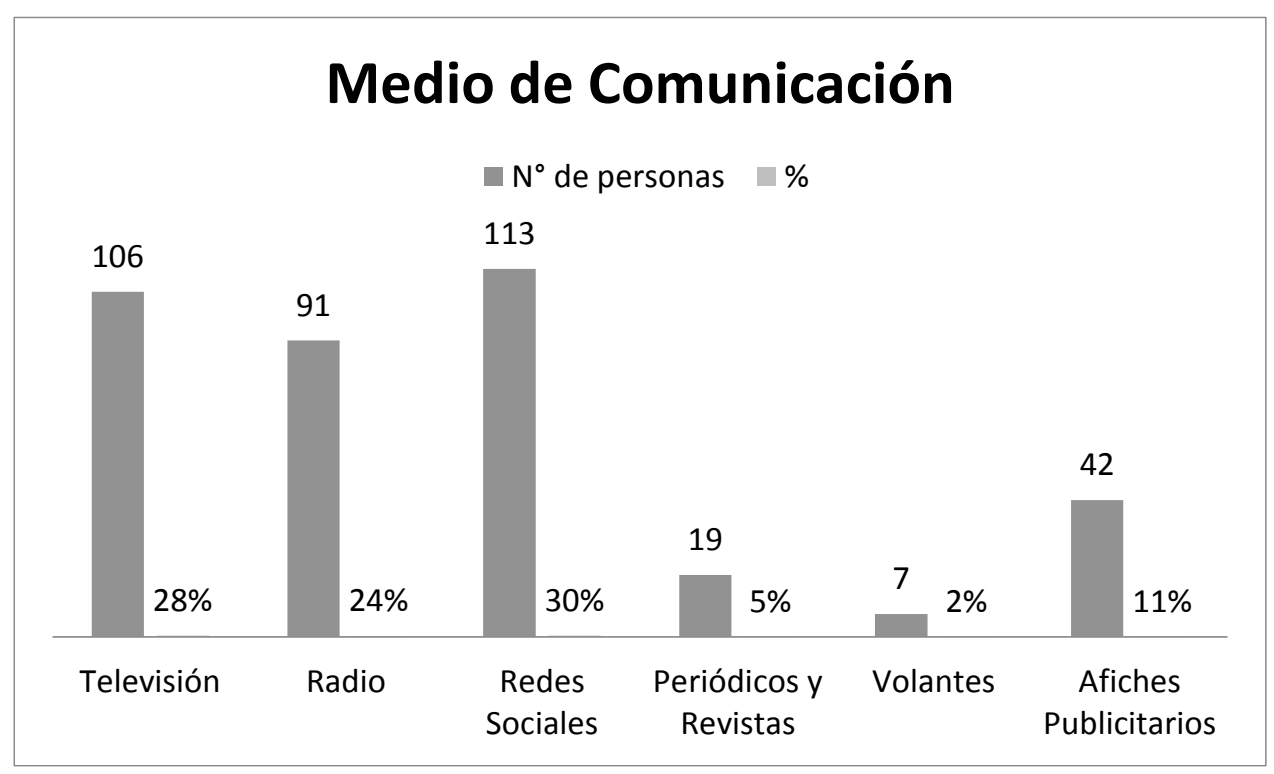

Figura 22. Medios de comunicación

De los 378 encuestados se tiene un 30\% que indican que reciben información de productos alimenticios por medio de redes sociales, seguido por el $28 \%$ que manifiestan hacerlo por medio de la televisión, un $24 \%$ lo hace por medio de radio y un 5 y $2 \%$ lo hacen por medio de periódicos y volantes respectivamente. Estos indicadores nos da una pauta de cuales con los medio que se utilizaran para promocionar y publicitar el producto. 


\subsubsection{Encuesta dirigida a restaurante tradicional.}

Como se había determinado en la segmentación y considerando que uno de los mercados a atender sería el de los restaurantes de corte tradicional en un número de 55 , y de acuerdo al orden del cuestionario referente al tipo de restaurante al indicar lo antes mencionado ya se estaría respondiendo a esta interrogante, por lo que se prosigue con el análisis de las demás preguntas.

\section{P2. ¿Cuál es el cargo que ocupa en el restaurante?}

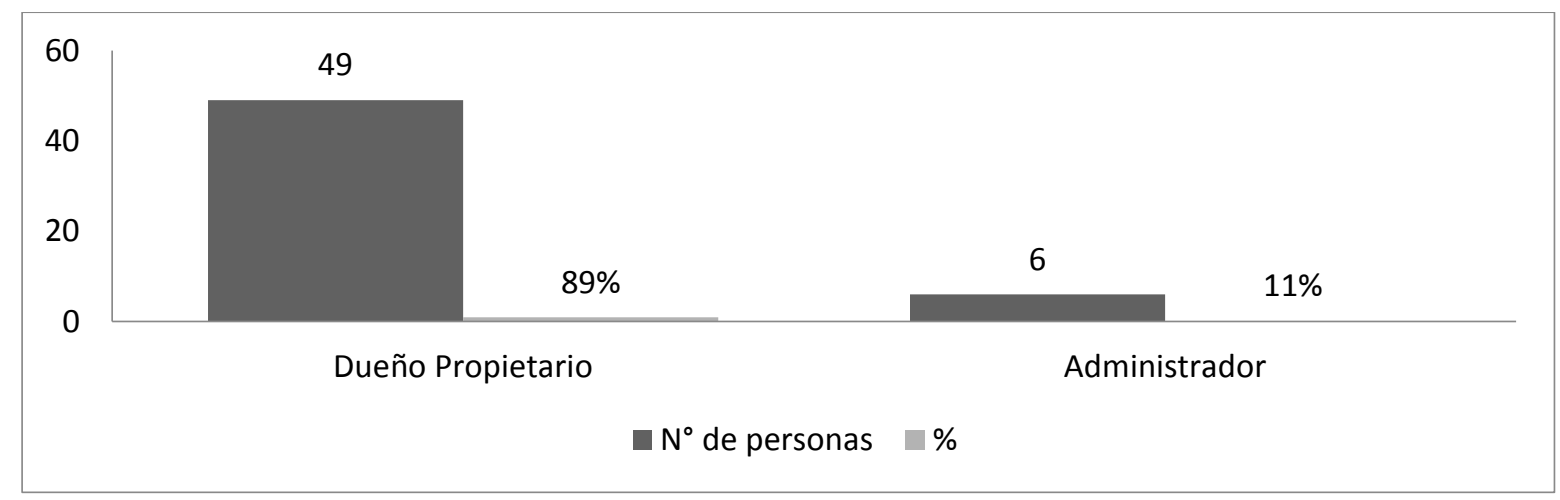

Figura 23.Cargoque ocupa en el restaurante

En la figura se puede apreciar que según refieren el $89 \%$ de los encuetados son dueños o propietarios, mientras que solo el $11 \%$ de los entrevistados son administradores que tienen algún grado de parentesco con los propietarios de los restaurantes tradicionales.

\section{P3. ¿Este cargo le da la facultad de decidir las compras de alimentos para el restaurante?}

Tabla 23

¿Este Cargo le da la Facultad de Decidir las Compras de Alimentos para el Restaurante?

\begin{tabular}{ccc}
\hline Variable & $\mathrm{N}^{\circ}$ de personas & $\%$ \\
\hline SI & 55 & $100 \%$ \\
NO & 0 & $0 \%$ \\
Total & 55 & $100 \%$ \\
\hline
\end{tabular}


Del total de encuestados se puede apreciar que el $100 \%$ de estos tienen la facultad de decidir las compras en los restaurantes, esto se da en gran medida por la condición de propietarios o parientes de estos en relación al cargo que ocupa en dentro del restaurant.

\section{P4. ¿En qué distrito del Cusco se encuentra su restaurante?}

Tabla 24

Distrito en que se Encuentra su Restaurante

\begin{tabular}{ccc}
\hline Distritos & $\begin{array}{c}\text { Nro de } \\
\text { Restaurantes }\end{array}$ & $\%$ \\
\hline Cusco & 9 & $16 \%$ \\
San Jerónimo & 6 & $11 \%$ \\
San Sebastián & 6 & $11 \%$ \\
Santiago & 6 & $11 \%$ \\
Wanchaq & 3 & $5 \%$ \\
Saylla & 19 & $35 \%$ \\
Calca & 3 & $5 \%$ \\
Urubamba & 3 & $5 \%$ \\
Total & 55 & $100 \%$ \\
\hline
\end{tabular}

Del total de los encuestados se puede apreciar que la mayor cantidad de restaurantes se encuentran en el distrito de Saylla representado por el $35 \%$ esto se debe a que en la zona se concentra la mayor cantidad de restaurantes que ofrecen platos a base de cuy ubicados en el centro poblado de Tipón, seguido por un $16 \%$ que se encuentran en el distrito de Cusco, también se tiene que considerar que existe un $11 \%$ que se concentran en las zonas de San Jerónimo, San Sebastián y Santiago y en menor proporción en Wanchaq, Calca y Urubamba con un $5 \%$. 
P5. ¿Cuál es la capacidad de comensales con la que cuenta su local?

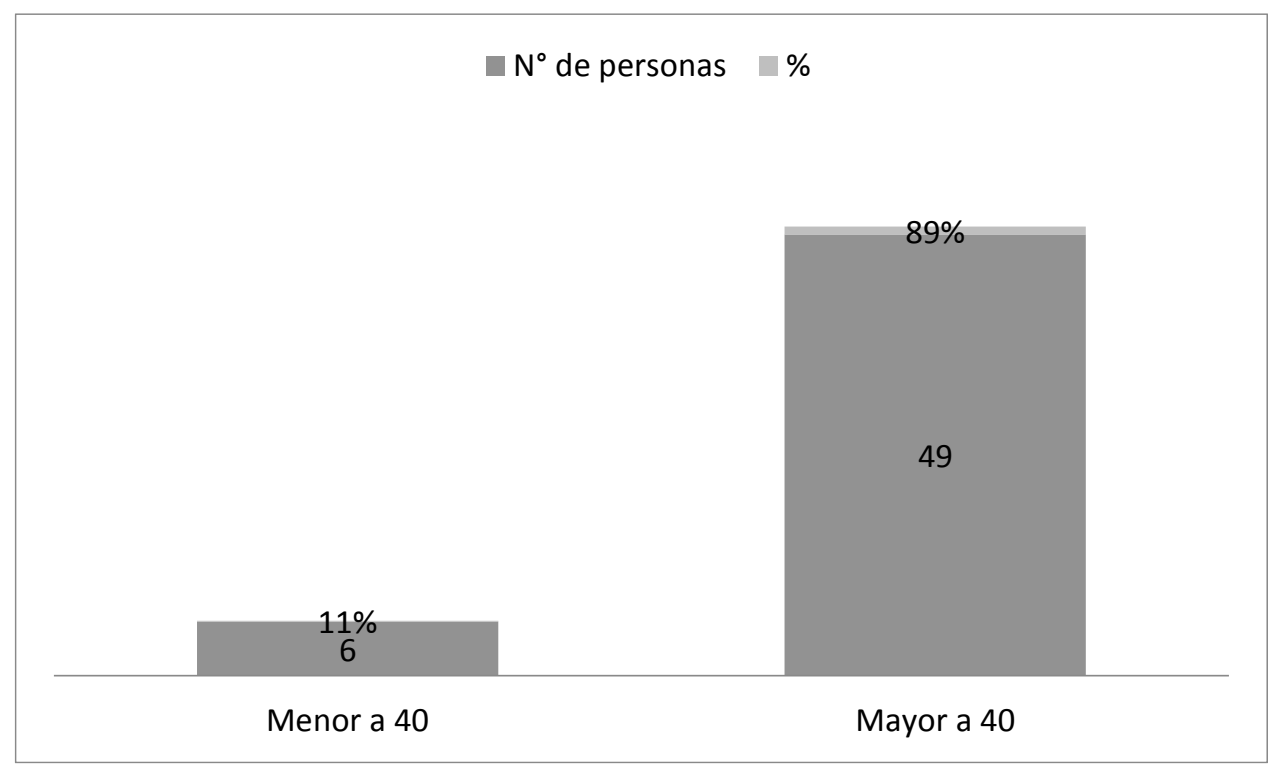

Figura 24.Capacidad de comensales

De la figura se puede inferir que del total de estos, el $89 \%$ están en la posibilidad de atender a más de 40 comensales a la vez y solo el $11 \%$ de los encuestados cuentan con locales que pueden atender a menos de 40 comensales.

P6. ¿En su restaurante prepara platos a base de carne de cuy?

Tabla 25

En sus locales se preparan Platos a Base de Carne de Cuy

\begin{tabular}{ccc}
\hline Variable & $\mathrm{N}^{\circ}$ de personas & $\%$ \\
\hline SI & 55 & $100 \%$ \\
NO & 0 & $0 \%$ \\
Total & 55 & $100 \%$ \\
\hline
\end{tabular}

Del total de los encuestados y por la naturaleza de estos establecimientos el $100 \%$ si preparan platos a base de cuy por ser un alimento tradicional y que los comensales piden frecuentemente. 
P7. ¿Conoce usted proveedores de carne de cuy?

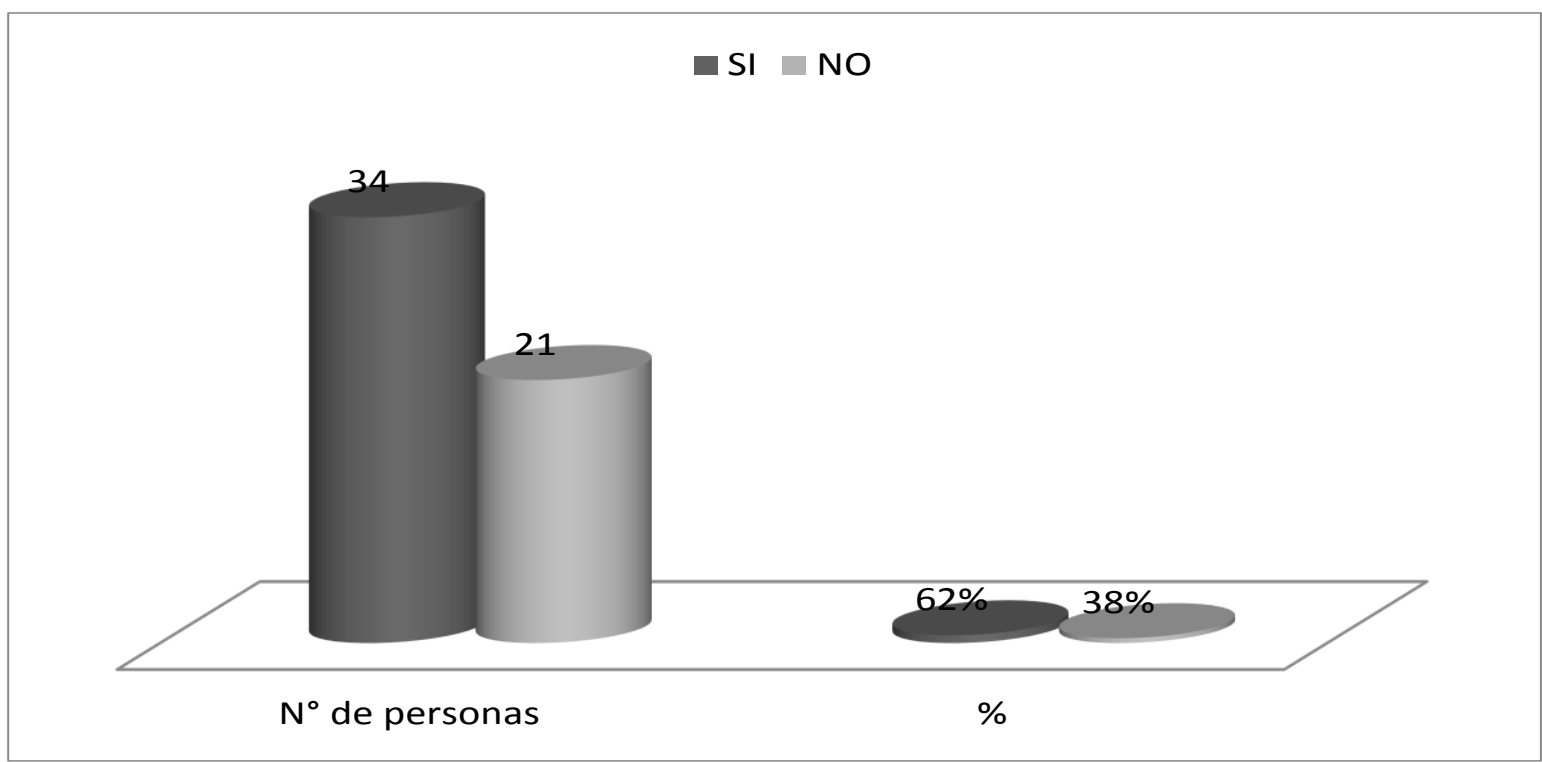

Figura 25.Conoce a su proveedor

En la figura se puede observar que el $62 \%$ de los encuestados manifiestan si conocer a su proveedor esto se debe a que en la mayoría de los casos lo compran en mercados o los traen a sus locales y las personas que les venden esta carme son los mismos criadores, sin embargo existe un $38 \%$ que manifiestan no conocer a los sus proveedores, pues para ellos no es relevante esta información.

\section{P8. ¿Cómo compra la carne cuy que prepara?}

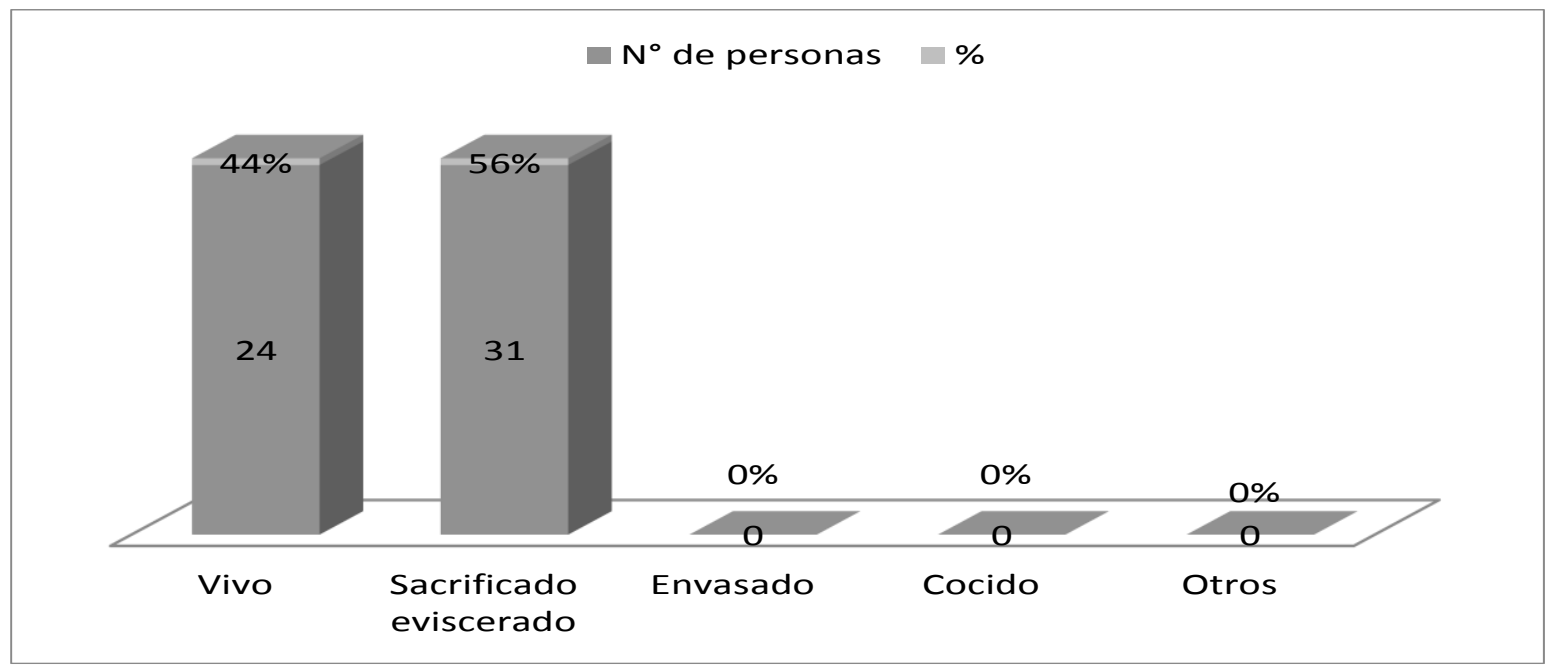

Figura 26.Como se compra 
Se los resultados obtenidos se tiene que el $56 \%$ de los encuestados prefieren adquirir la carne de cuy ya sacrificada y eviscerada con lo que evitan el proceso de sacrificio, sin embargo existe un $44 \%$ que manifiestan que por temas de costo y criterio adquieren el cuy vivo y por consiguiente tienen que hacer todo el proceso desde el sacrificio hasta el eviscerado. También se puede observar que en ninguno de los casos lo compran ni envasado, cocido o de otra modalidad.

\section{P9. ¿Dónde adquiere la carne de cuy que prepara?}

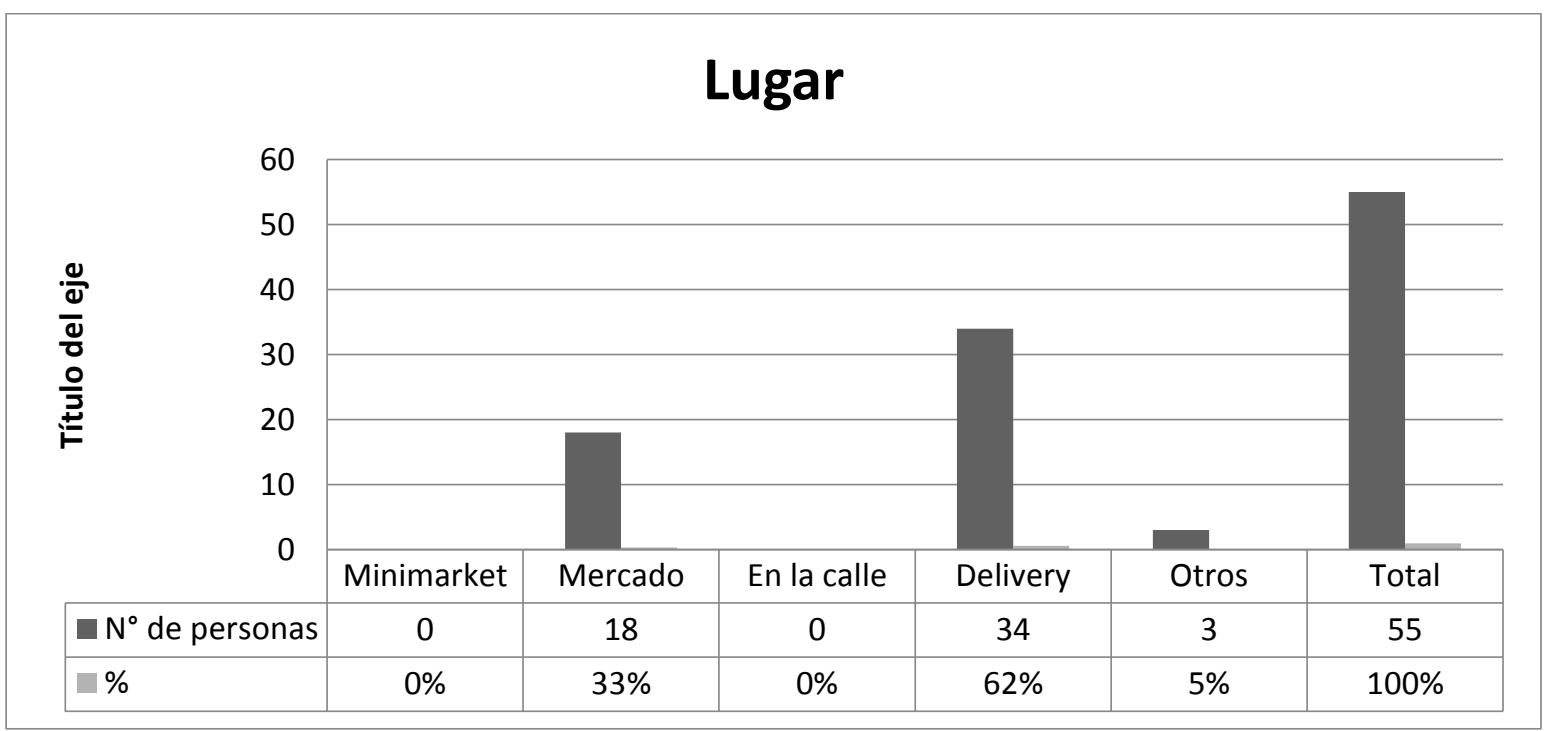

Figura 27.Lugar de compra

$\mathrm{Al}$ observar la figura que antecede, este refleja que el $62 \%$ de los establecimientos encuestados se abastecen de cuy en el mismo lugar de su negocio, siendo la venta directa del productor, un $33 \%$ mencionan que se abastecen de carne de cuy en mercados, habiendo solo un 5\% que compran el producto en cualquier sitio dependiendo de la situación. 
P10. ¿Conoce las condiciones de crianza y de higiene del cuy que compra?

Tabla 26

Condiciones de Crianza y de Higiene del Cuy que Compra

\begin{tabular}{ccc}
\hline Condiciones & $\mathrm{N}^{\circ}$ de personas & $\%$ \\
\hline SI & 3 & $5 \%$ \\
NO & 52 & $95 \%$ \\
Total & 55 & $100 \%$ \\
\hline
\end{tabular}

Del $100 \%$ de los encuestados el $95 \%$ de estos manifiestan no conocer la condiciones en las que son criados los cuyes que compran para preparar en sus locales, solo un $5 \%$ indica si estar informados de esto.

\section{P11. De manera mensual ¿con que frecuencia compra carne de cuy?}

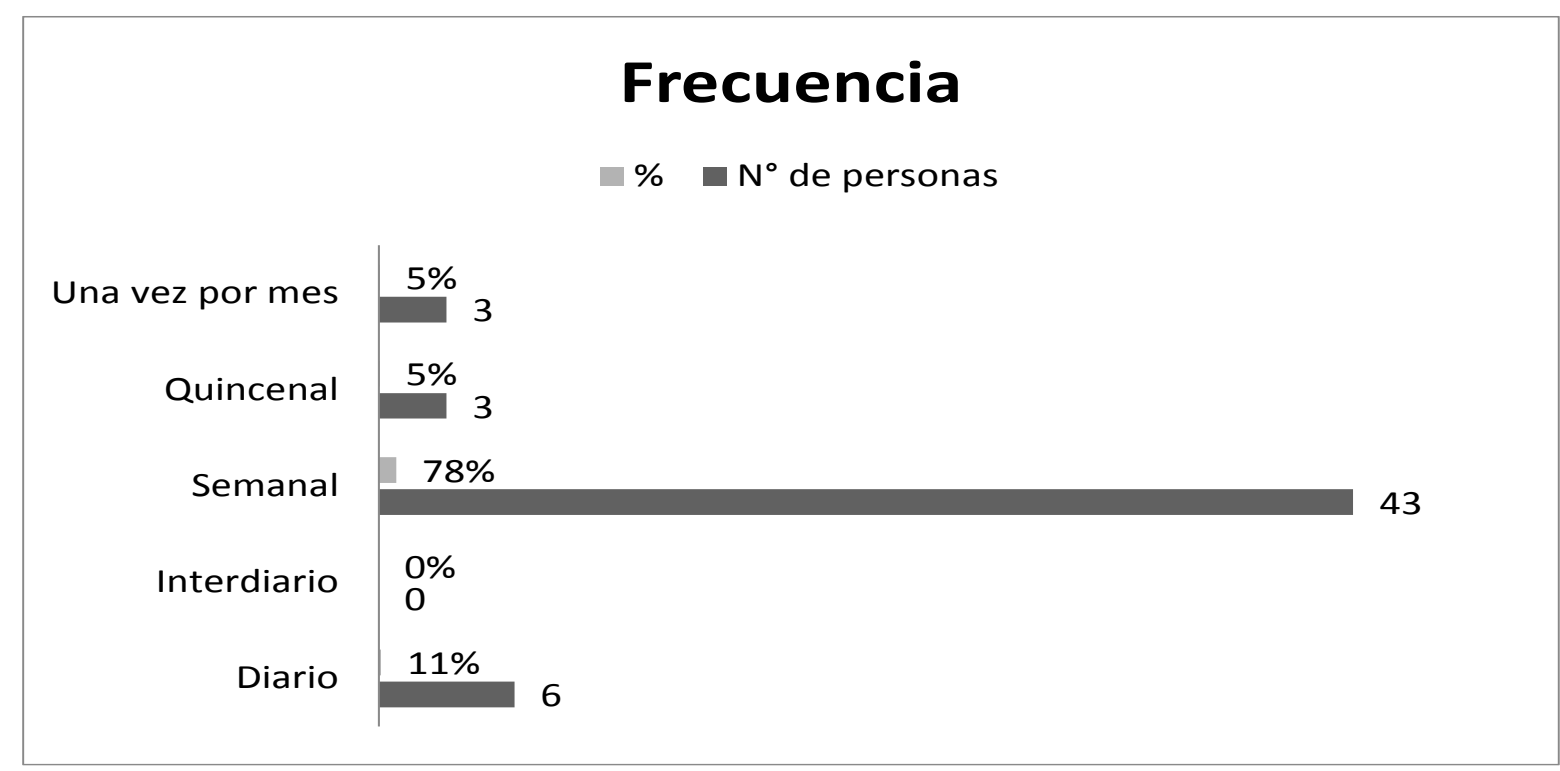

Figura 28. Frecuencia de compra

De acuerdo a la investigación se encuentra que el $78 \%$ de la población encuestada se abastece del cuy semanalmente, un $11 \%$ adquiere esta carne diariamente y un $5 \%$ la adquiere de manera quincenal y mensual de acuerdo a la demanda que tengan, mencionando que lo hace porque no se le malogre la carne. 
P12. ¿Qué cantidad de cuyes compra de manera mensual?

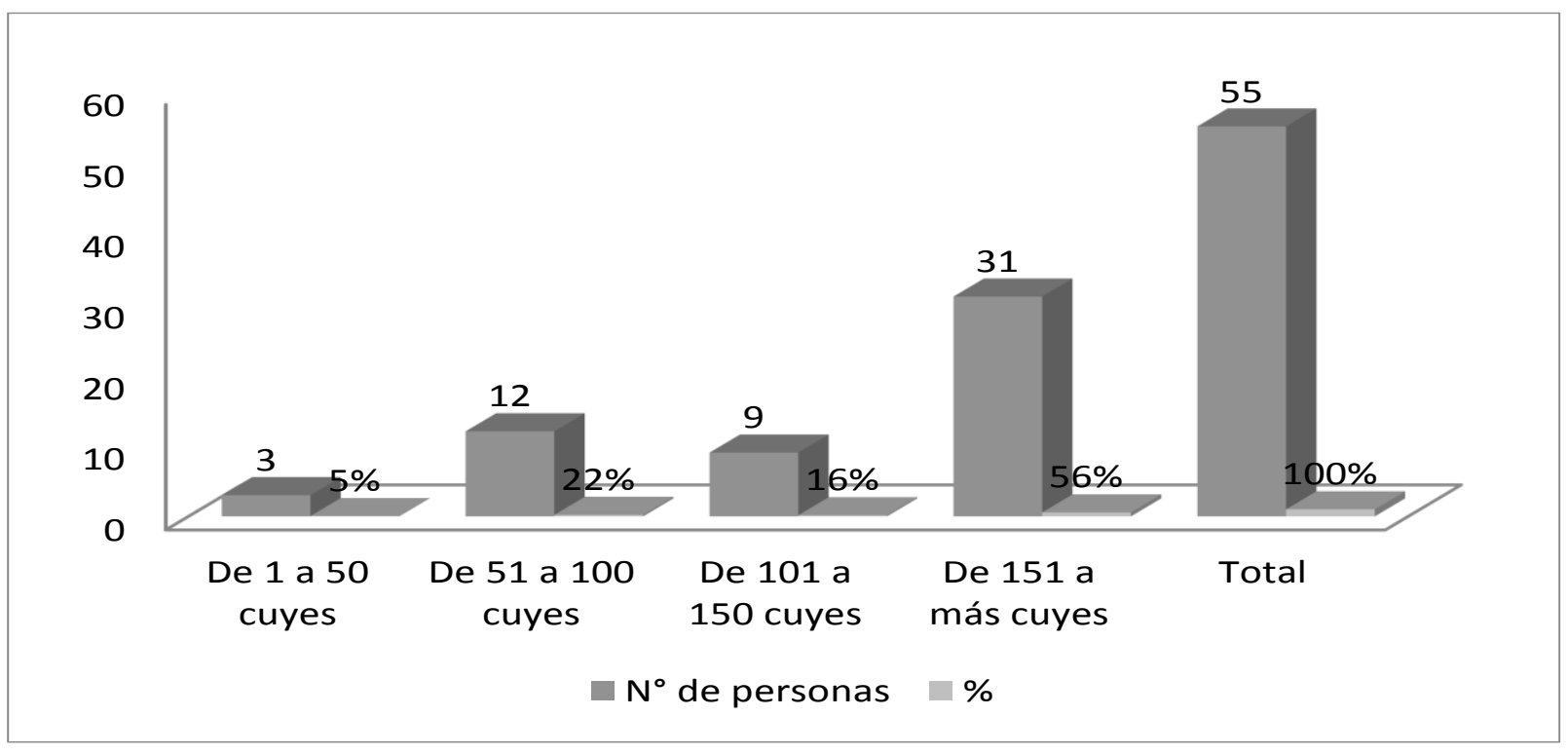

Figura 29.Cantidad de compra

A la interrogante de cuál es la cantidad de cuyes que compra para la venta en sus locales, el $56 \%$ manifiestan que compran entre 151 a más cuyes, seguido por un $22 \%$ que indican comprar entre 51 a 100 cuyes, por otro lado se aprecia que un $16 \%$ que adquiere de 101 a 150 cuyes, y solo y un $3 \%$ de los encuestados compran de uno a 50 cuyes.

\section{P13. ¿Cuál es el precio que paga según tipo de cuy que compra por unidad?}

Tabla 27

Precio que Paga según Tipo de Cuy

\begin{tabular}{cccccc}
\hline $\begin{array}{c}\text { Montos en } \\
\text { soles }\end{array}$ & Cuy Vivo & $\begin{array}{c}\text { Cuy } \\
\text { Sacrificado } \\
\text { eviscerado }\end{array}$ & $\begin{array}{c}\text { Cuy } \\
\text { empacado }\end{array}$ & Total & $\%$ \\
\hline s/15 a s/20 & 3 & 0 & 0 & 3 & $5 \%$ \\
s/ 21 a 25 & 15 & 25 & 0 & 40 & $73 \%$ \\
s/ 26 a s/ 30 & 0 & 12 & 0 & 12 & $22 \%$ \\
s/ 31 a más & 0 & 0 & 0 & 0 & $0 \%$ \\
Total & 18 & 37 & 0 & 55 & $100 \%$ \\
\hline Total $\%$ & $33 \%$ & $67 \%$ & $0 \%$ & $100 \%$ & \\
\hline
\end{tabular}


En cuanto al precio al que se compra los cuyes estos fluctúan entre a 15 a 30 soles, los cuales se distribuyen de la siguiente manera:

Un $73 \%$ adquiere el cuy entre 21 a 25 soles, seguido por el $22 \%$ cuyo precio de adquisición es de 26 a 30 soles y solo un cinco por ciento que lo adquieren a un precio de 15 a 20 soles. Ahora si consideramos la forma de comprar la carne se tiene que el $67 \%$ prefiere comprar el cuy ya sacrificado y eviscerado y el $33 \%$ manifiesta comprar el cuy vivo.

En este sentido la mayoría de los encuestados prefieren comprar el cuy ya sacrificado y eviscerado y a un precio que va desde los 21 a 25 soles; criterios que se tomaran en cuenta al momento de hacer la propuesta tanto de precio como de presentación del producto propuesto en el presente plan de negocios.

\section{P14. Marque la característica que considera su empresa determinante para adquirir carne}

\section{de este animal}

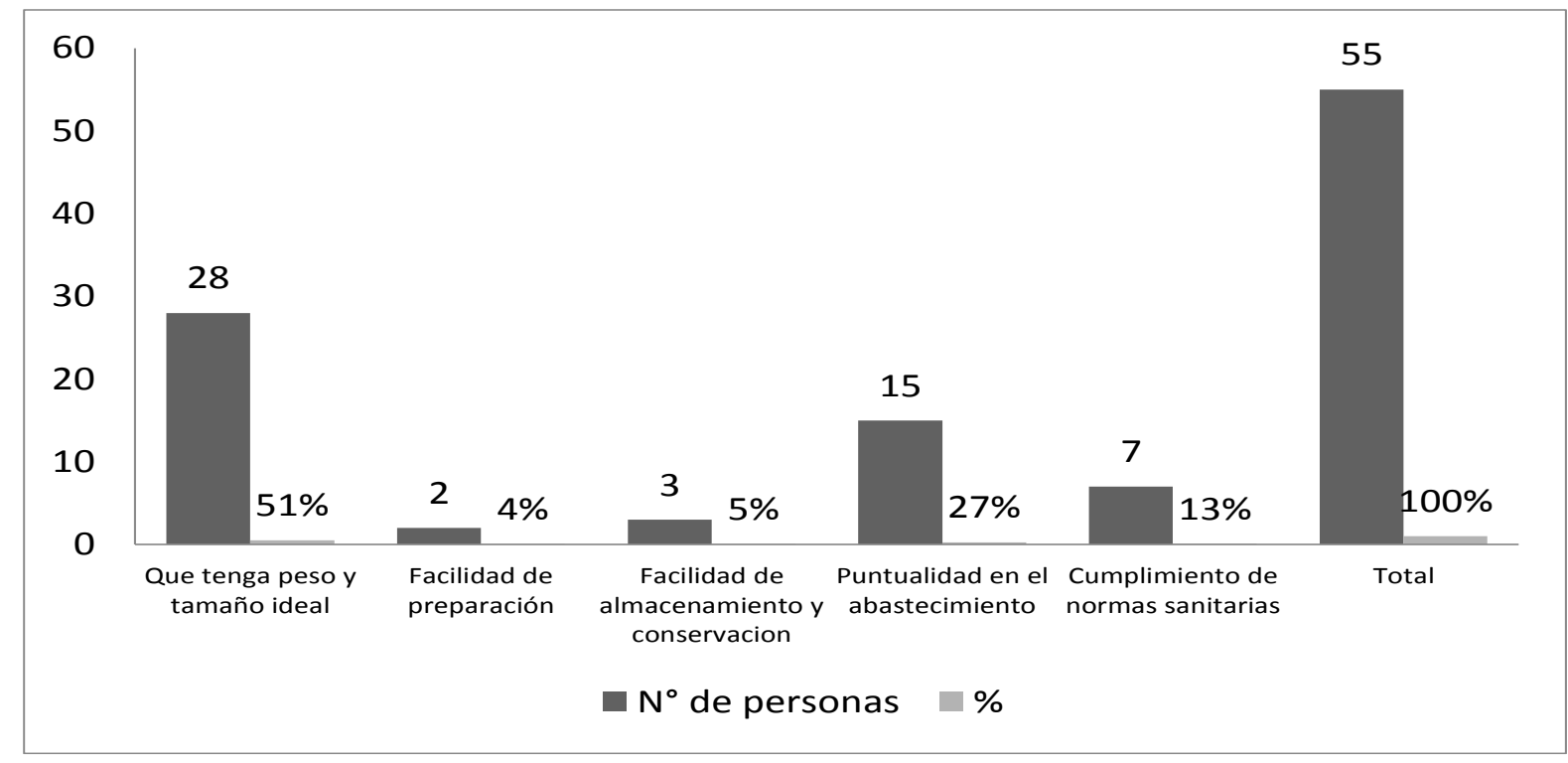

Figura 30.Caracteristica determinante

Como nos demuestra la figura que antecede un $51 \%$ de los encuestados toman en cuenta como aspecto principal para la adquisición el peso y tamaño ideal, el $27 \%$ se inclina a 
determinar por la puntualidad en la entrega pues si tienen retrasos tiene problemas para expender platos a base de esta carne, un $13 \%$ indican que el cumplimiento de las normas sanitarias es el factor más importante al momento de la compra; solo un 5 y $4 \%$ señalan que la facilidad de almacenamiento y facilidad en la preparación son las características más relevantes.

\section{P15. ¿Estaría dispuesto Ud. a comprar carne de cuy empacada al vacío?}

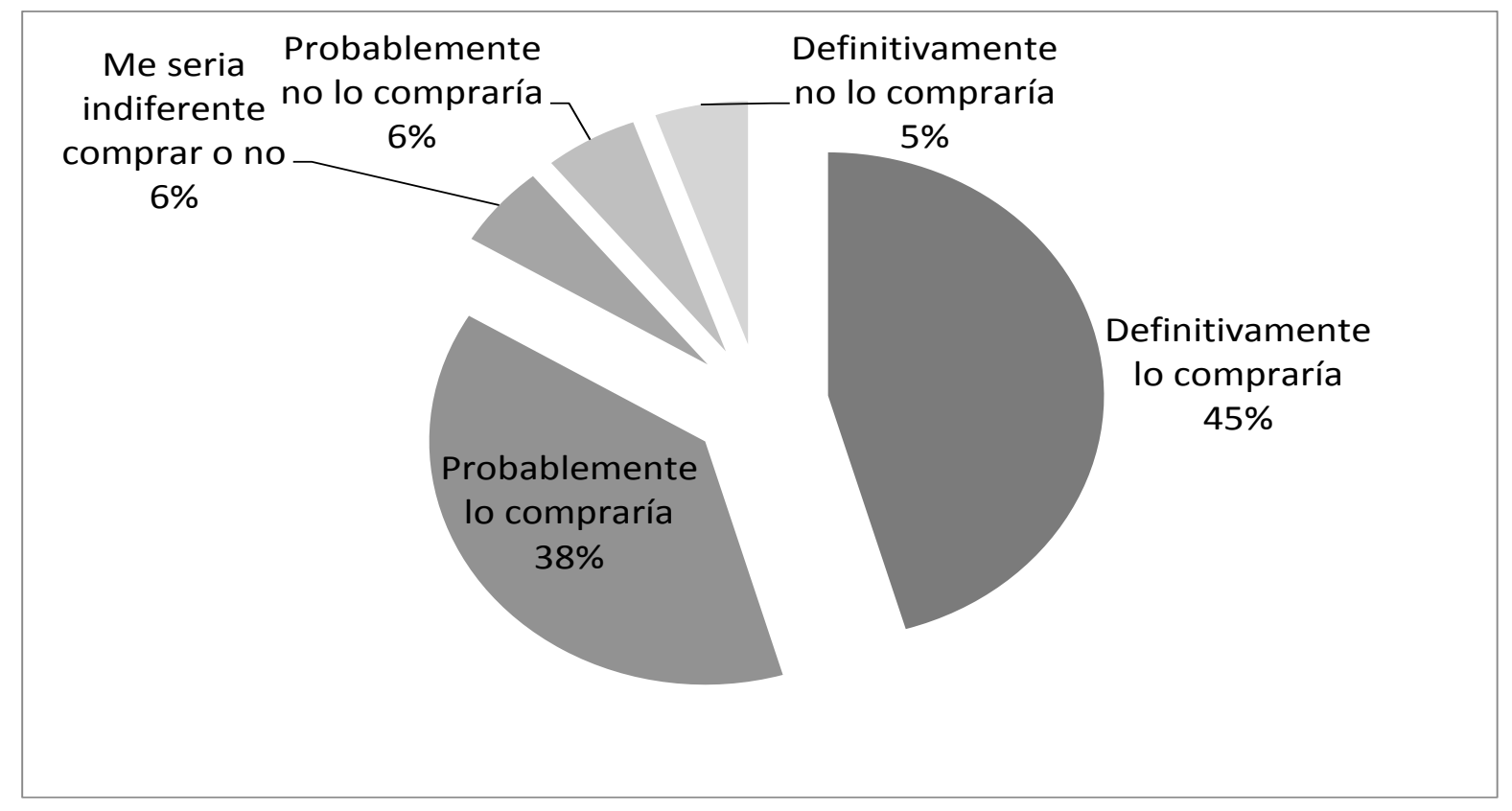

Figura 31.Disponibilidad de compra

En la figura se observa que del 100\% de dueños y administradores de restaurantes tradicionales el $45 \%$ definitivamente si comprarían la carne de cuy empacado al vacío producto propuesto en el plan de negocios, seguido por un $38 \%$ que a la explicación de la bondades del producto probablemente si comprarían el producto, un $6 \%$ de los encuestados les sería indiferente y probablemente no comprarían el producto y solo un 5\% en definitiva no comprarían el producto, esto va de la mano en que este porcentaje está acostumbrado a sacrificar el cuy. 
P16. ¿Conoce usted las ventajas de adquirir carne de cuy empacada al vacío?

Tabla 28

Conocimiento de Ventajas de Adquirir Carne de Cuy

\begin{tabular}{ccc}
\hline Ventajas & $\mathrm{N}^{\circ}$ de personas & $\%$ \\
\hline SI & 24 & $46 \%$ \\
NO & 28 & $54 \%$ \\
Total & 52 & $100 \%$ \\
\hline
\end{tabular}

Considerando a las personas que respondieron que consideran la posibilidad de adquirir el cuy empacado al vacío de las 52 que respondieron el 54\% no tiene un conocimiento claro de las ventajas de adquirir la carne de cuy empacada al vacío; sin embargo en contraposición a este porcentaje existe un $46 \%$ que si conocen las ventajas del empacado al vacío.

P17. ¿Dónde le gustaría adquirir carne de cuy empacada al vacío?

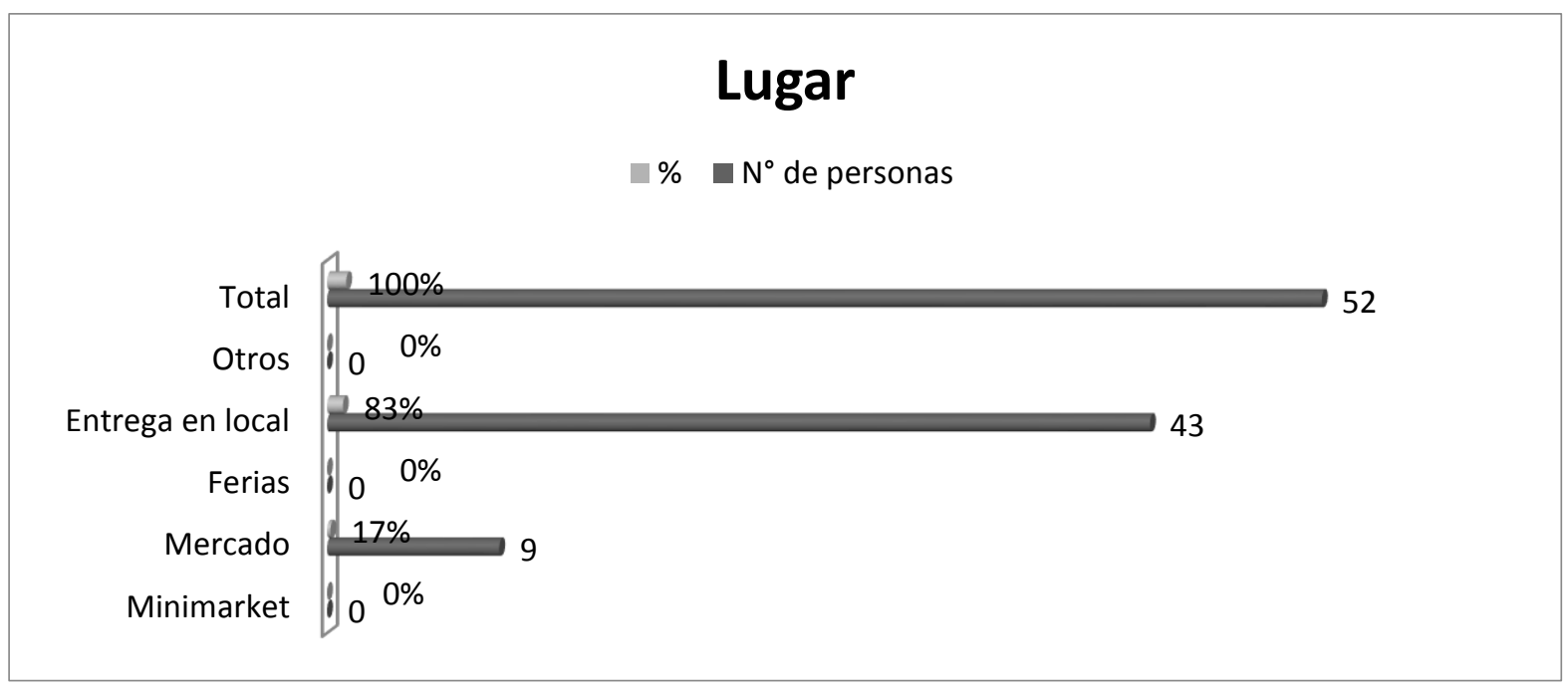

Figura 32.Lugar donde le gustaría adquirir

Las versiones vertidas por los encuestados demuestran que en su mayoría expresado por el $83 \%$ les gustaría que el producto sea llevado a su local, pues le facilitaría en temas de 
tiempo, un $17 \%$ preferiría adquirir el producto en el mercado aprovechando las compras que hacen de otros productos.

P18. ¿Cuánto estaría dispuesto a pagar por una unidad de cuy empacado al vacío?

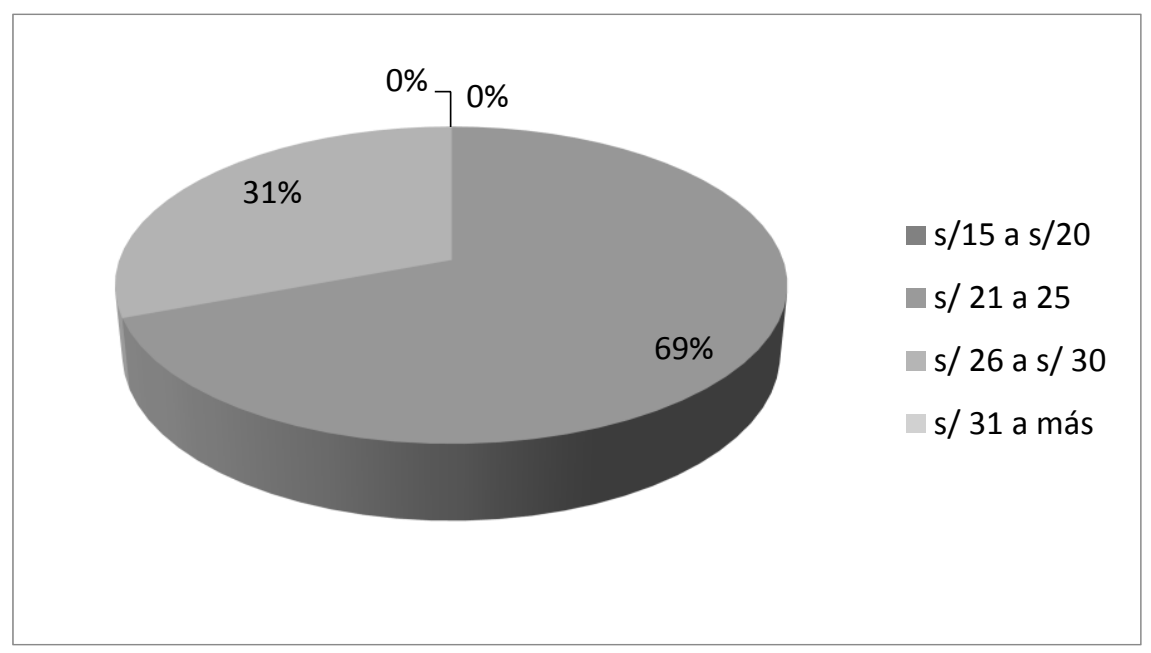

Figura 33.Precio que estaría dispuesto a pagar.

Como se aprecia en la figura que antecede existe un $69 \%$ de encuestados podrían pagar un margen que vaya desde 21 a 25 soles por esta nueva presentación, pareciéndole un precio bastante razonable debido a que le beneficiaría contar con mayor tiempo el producto en buenas condiciones, al no correr el riesgo que la carne se contamine rápidamente; mientras que el $31 \%$ prefiere pagar el precio que oscile entre 26 a 30 soles. Estos criterios nos ayudan a determinar el precio de venta del producto planteado en el plan de negocios. 
P19. ¿Por qué medio de comunicación recibe más publicidad en cuanto a productos alimenticios?

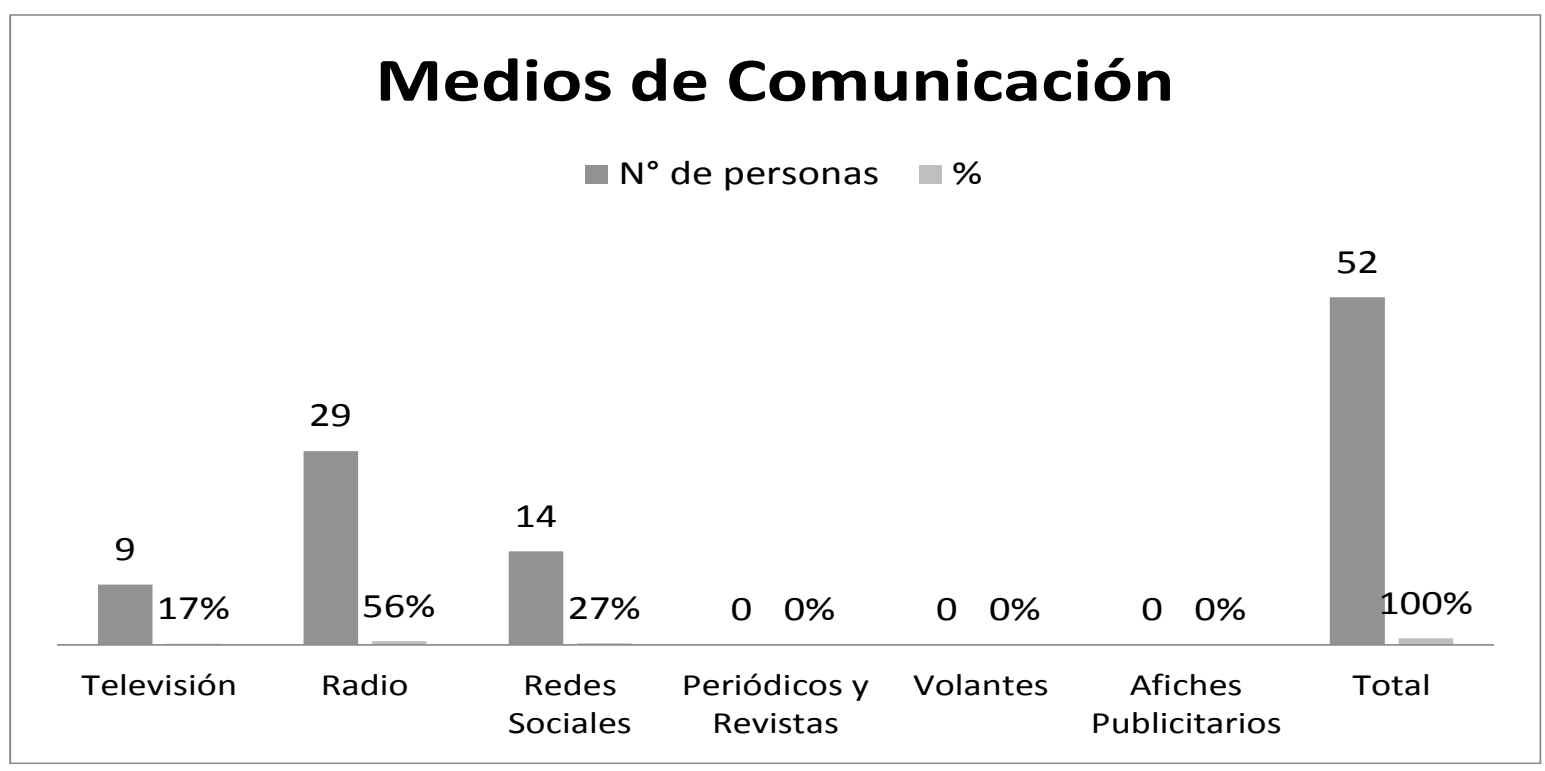

Figura 34.Medio de comunicación que recibe más publicidad.

A la pregunta se tiene que el $56 \%$ de los encuestados reciben información de productos alimenticios por medio de radio, seguido por el $27 \%$ que lo hacen por redes sociales y solo un $17 \%$ manifiesta recibir información por medio de la televisión.

\subsubsection{Encuesta dirigida a administradores de restaurante turísticos.}

Del mismo modo al haber determinado en la segmentación a los restaurantes de corte turístico en un número de 74, se responde a la pregunta número uno de este, prosiguiendo con el análisis de las demás preguntas. 
P2. ¿Cuál es el cargo que ocupa en el restaurante?

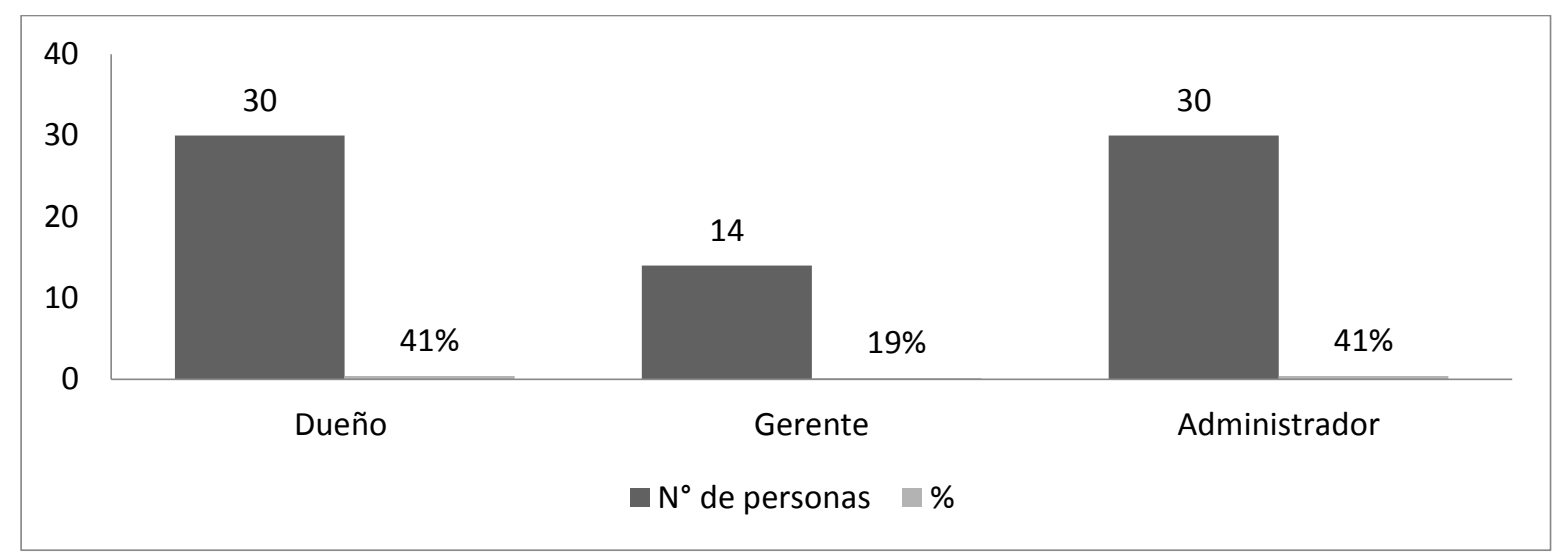

Figura 35.Cargo que ocupa en el restaurante

En la figura se puede apreciar que según refieren el $41 \%$ de los encuetados son dueños o administradores respectivamente, mientras que el 19\% de los entrevistados son gerentes los cuales tiene poder de decisión en varios temas relevantes de la gestión de estos establecimientos.

P3. ¿Este cargo le da la facultad de decidir las compras de alimentos para el restaurante? Tabla 29

¿Este Cargo le da la Facultad de Decidir las Compras de Alimentos para el Restaurante?

\begin{tabular}{ccc}
\hline Ítem & $\mathrm{N}^{\circ}$ de personas & $\%$ \\
\hline SI & 74 & $100 \%$ \\
NO & 0 & $0 \%$ \\
Total & 74 & $100 \%$ \\
\hline
\end{tabular}

Del total de encuestados se puede apreciar que el $100 \%$ de estos tienen la facultad de decidir las compras en los restaurantes, esto se da por el grado de confianza que tiene estas personas por parte de los propietarios. 


\section{P4. ¿En qué distrito del Cusco se encuentra su restaurante?}

Tabla 30

Distrito en que se Encuentra su Restaurante

\begin{tabular}{ccc}
\hline Distritos & $\begin{array}{c}\text { Nro de } \\
\text { Restaurantes }\end{array}$ & $\%$ \\
\hline Cusco & 47 & $64 \%$ \\
San Jerónimo & 2 & $3 \%$ \\
San Sebastián & 1 & $1 \%$ \\
Santiago & 1 & $1 \%$ \\
Wanchaq & 3 & $4 \%$ \\
Saylla & 1 & $1 \%$ \\
Calca & 5 & $7 \%$ \\
Urubamba & 14 & $19 \%$ \\
Total & 74 & $100 \%$ \\
\hline
\end{tabular}

Del total de los encuestados se puede apreciar que la mayor cantidad de restaurantes se encuentran en el distrito de Cusco representado por el $35 \%$ esto debido a que en la zona se concentra la mayor cantidad de restos arqueológicos de la región, seguido por un $19 \%$ que se encuentran en Urubamba sitio obligado donde los buses de turismo paran a la hora de almuerzo en la visita al Valle Sagrado de los Incas, también se tiene que considerar que existe un $7 \%$ que se concentran en las zona de Calca y en menor proporción en las zonas de San Sebastián, Santiago y Saylla que solo cuentan con $1 \%$ de restaurantes turísticos. 
P5. ¿Cuál es la capacidad de comensales con la que cuenta su local?

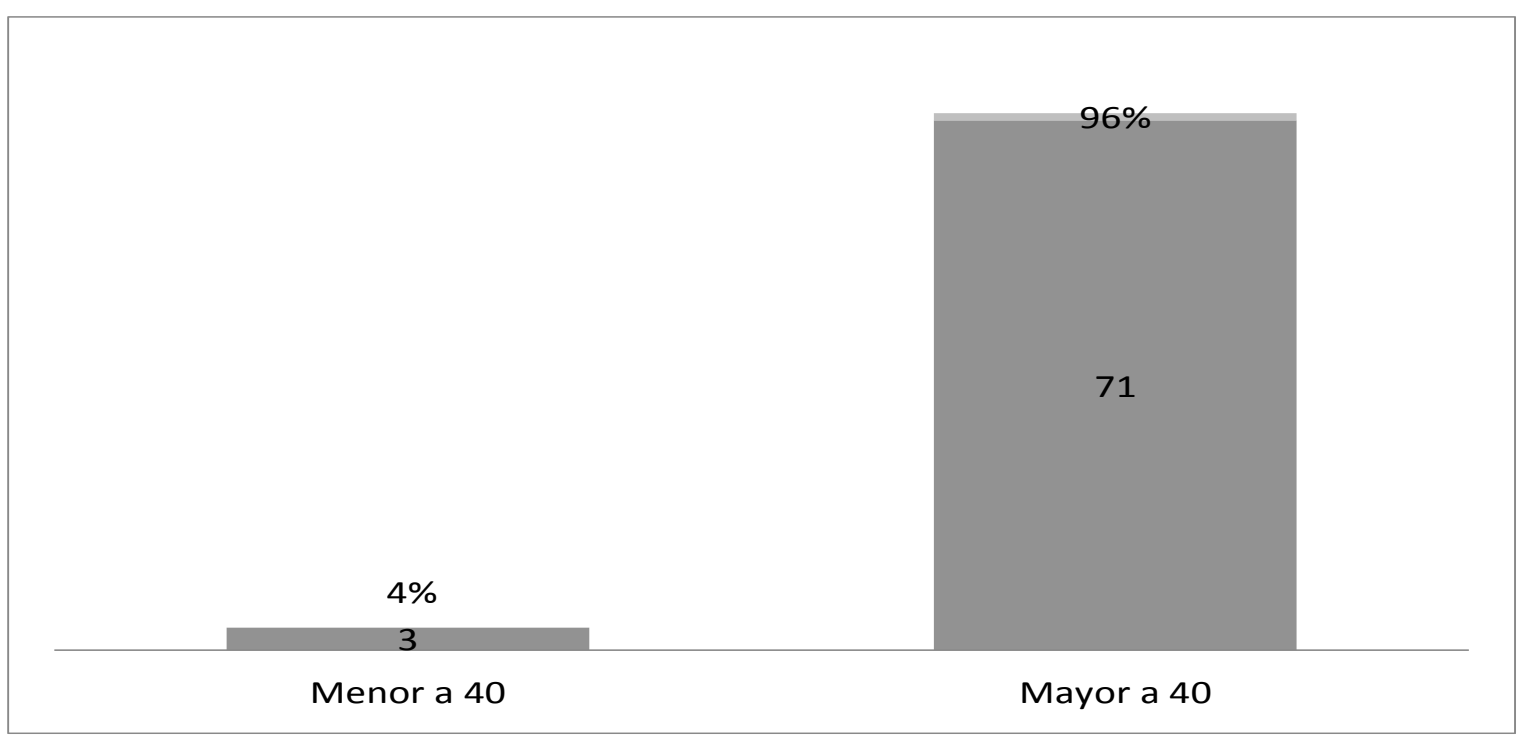

Figura 36.Capacidad de comensales

De la figura se puede apreciar que del total de estos, el 96\% están en la posibilidad de atender a más de 40 comensales a la vez y solo el $4 \%$ de los encuestados cuentan con locales que pueden atender a menos de 40 comensales de manera simultánea.

P6. ¿En su restaurante prepara platos a base de carne de cuy?

Tabla 31

En sus Locales se Preparan Platos a Base de Carne de Cuy

\begin{tabular}{ccc}
\hline Ítem & $\mathrm{N}^{\circ}$ de personas & $\%$ \\
\hline SI & 74 & $100 \%$ \\
NO & 0 & $0 \%$ \\
Total & 74 & $100 \%$ \\
\hline
\end{tabular}

Del total de los preguntados el $100 \%$ si preparan platos a base de cuy pero que lo hacen de manera especial cuando los turistas lo solicitan. 
P7. ¿Conoce usted proveedores de carne de cuy?

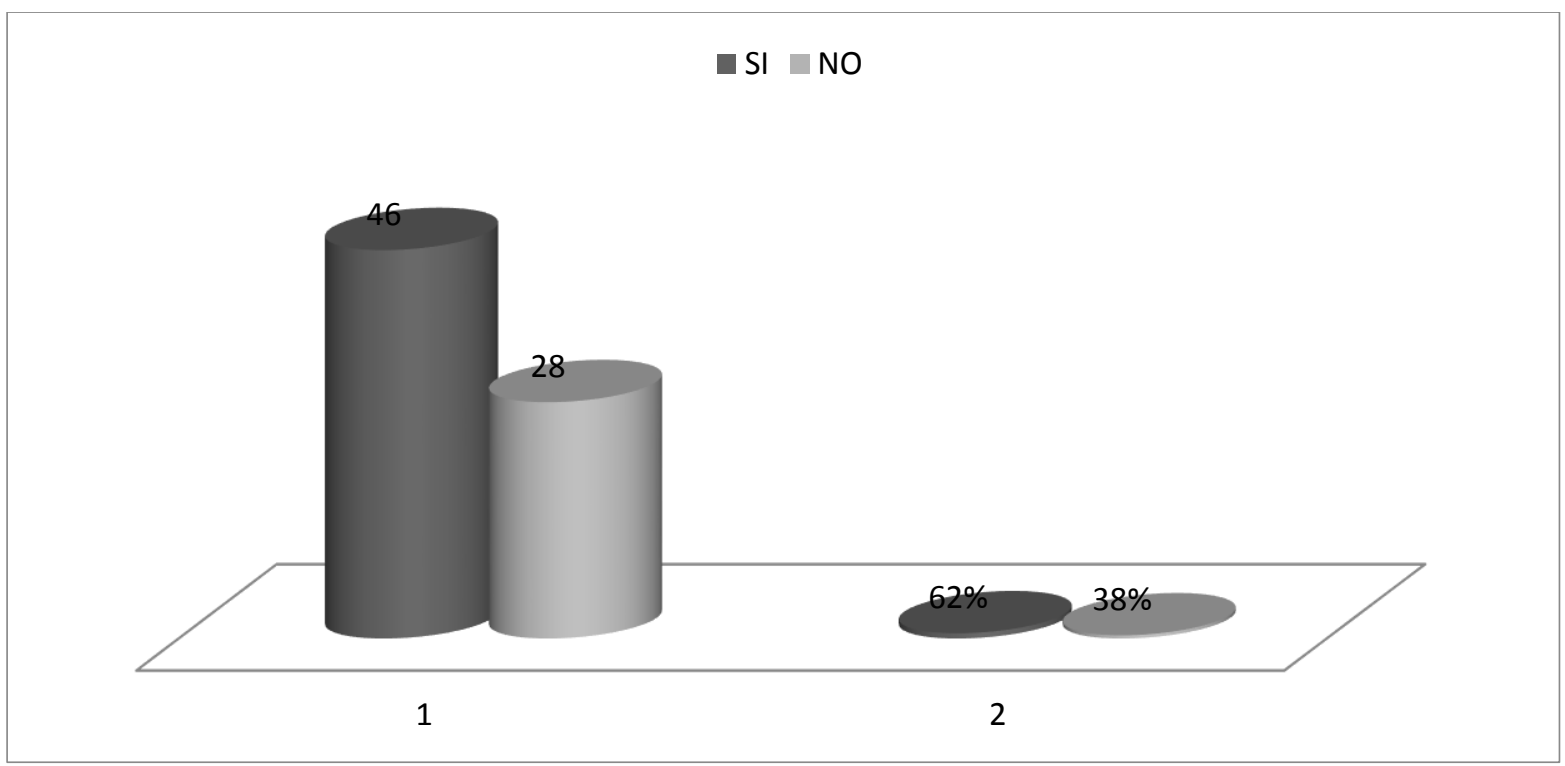

Figura 37.Conoce a su proveedor

En la figura se puede observar que el $62 \%$ de los encuestados manifiestan si conocer a su proveedor esto se debe a que estos traen los productos a sus locales, sin embargo existe un $38 \%$ que manifiestan no conocer a los sus proveedores, debido a que estos lo compran en mercados.

P8. ¿Cómo compra la carne cuy que prepara?

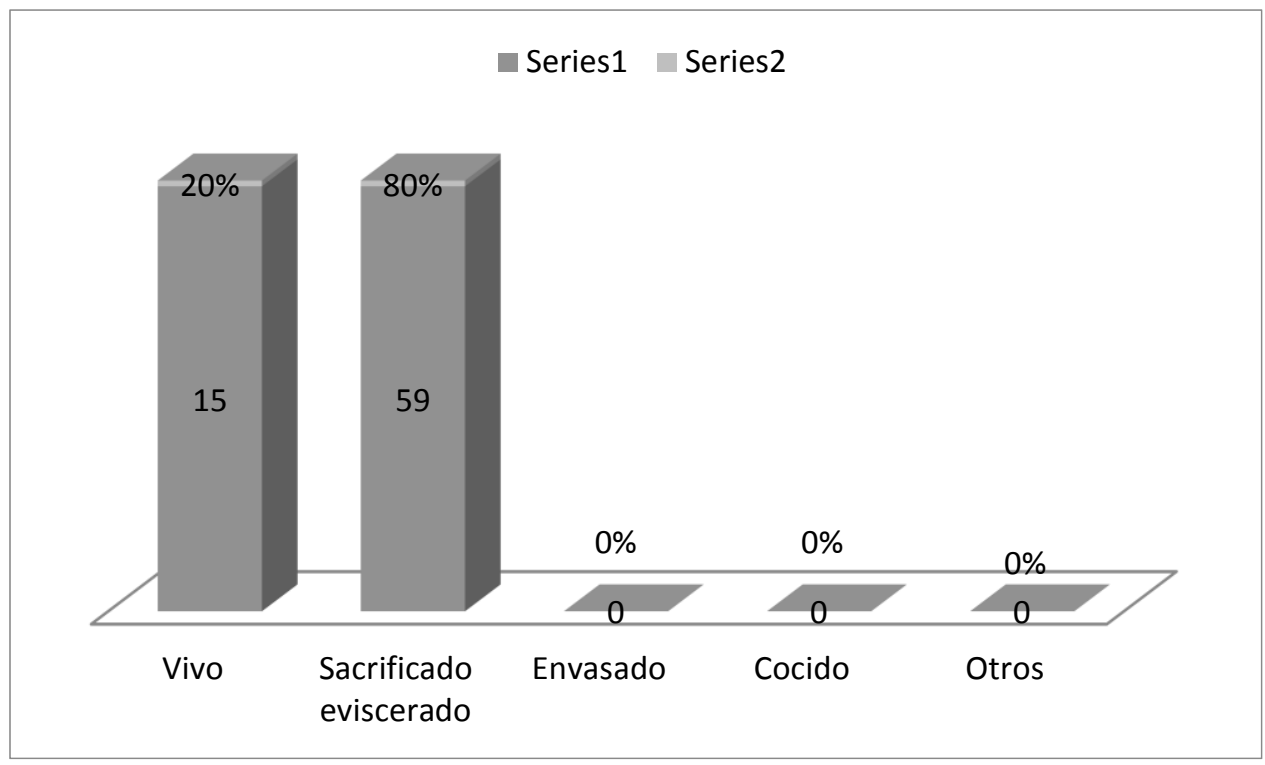

Figura 38.Como se compra 
Los resultados obtenidos indican que el $80 \%$ de los encuestados prefieren adquirir la carne de cuy ya sacrificada y eviscerada con lo que evitan el proceso engorroso de sacrificar, limpiar y eviscerar; sin embargo existe un $20 \%$ que manifiestan que por temas de demanda y manera de trabajar del chef lo adquieren el cuy vivo y por consiguiente tienen que hacer todo el proceso desde el sacrificio hasta el eviscerado.

\section{P9. ¿Dónde adquiere la carne de cuy que prepara?}

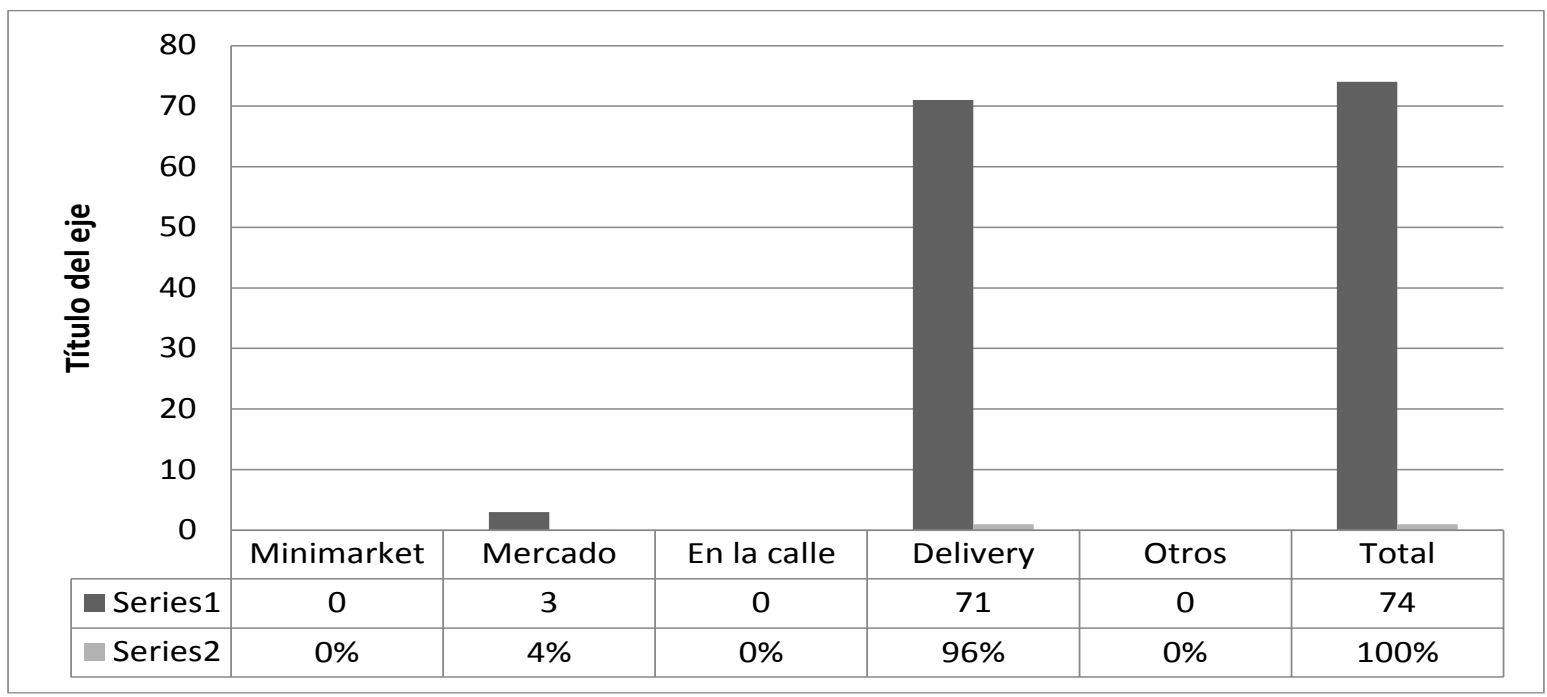

Figura 39.Lugar de compra

La figura que antecede refleja que el $96 \%$ se abastecen de cuy en el mismo lugar de su negocio, y un $4 \%$ mencionan que se abastecen de carne de cuy en mercados. 
P10. ¿Conoce las condiciones de crianza y de higiene del cuy que compra?

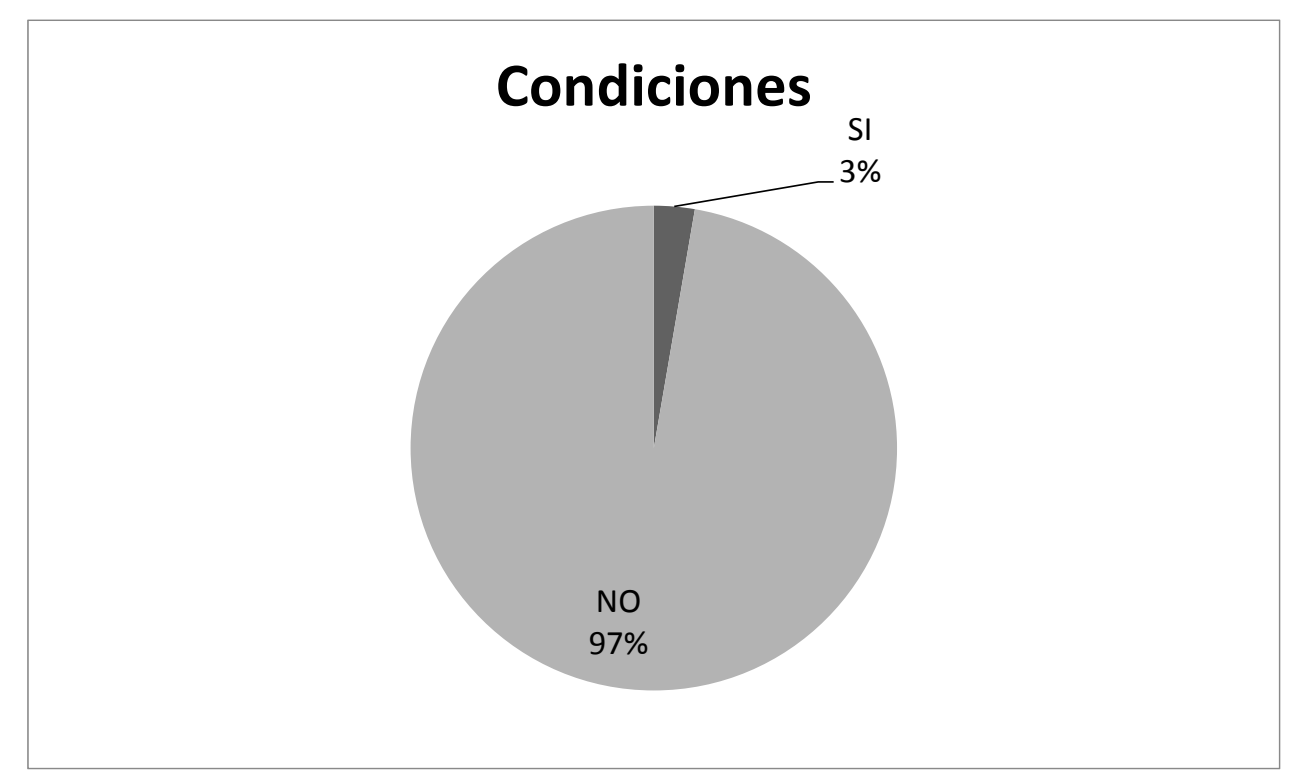

Figura 40.Condiciones de compra

Del $100 \%$ de los encuestados el $97 \%$ de estos manifiestan no conocer la condiciones en las que son criados los cuyes que compran para preparar en sus locales, solo un $3 \%$ indica si estar informados de esto.

P11. De manera mensual ¿con que frecuencia compra carne de cuy?

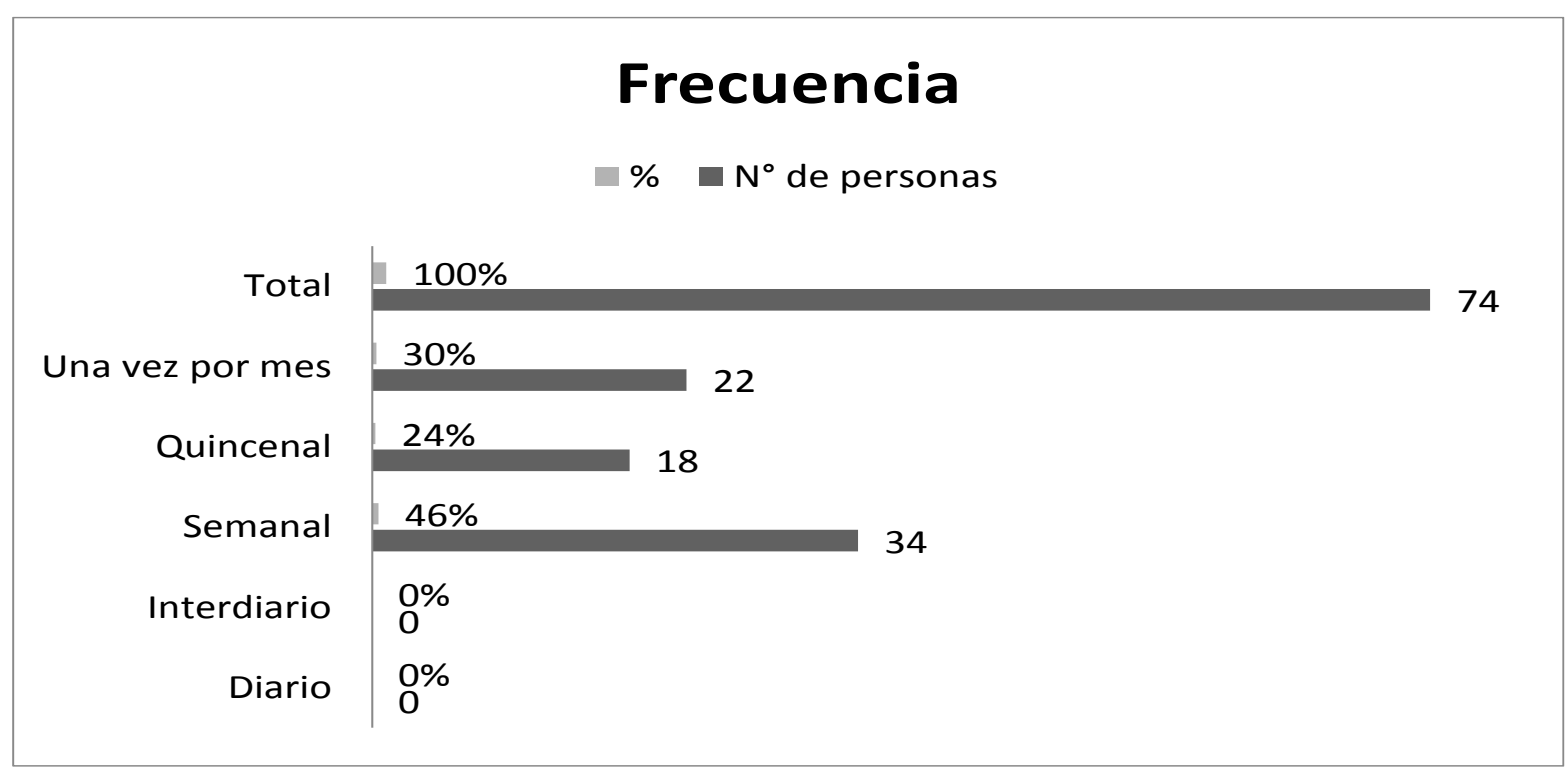

Figura 41.Frecuencia de compra 
De acuerdo a la investigación se encuentra que el $46 \%$ de la población encuestada se abastece del cuy semanalmente, el $30 \%$ compra esta carne mensualmente y el $24 \%$ compran este producto de manera quincenal de acuerdo a la demanda que tengan de turistas que quieran algún plato típico a base de carne de cuy.

\section{P12. ¿Qué cantidad de cuyes compra de manera mensual?}

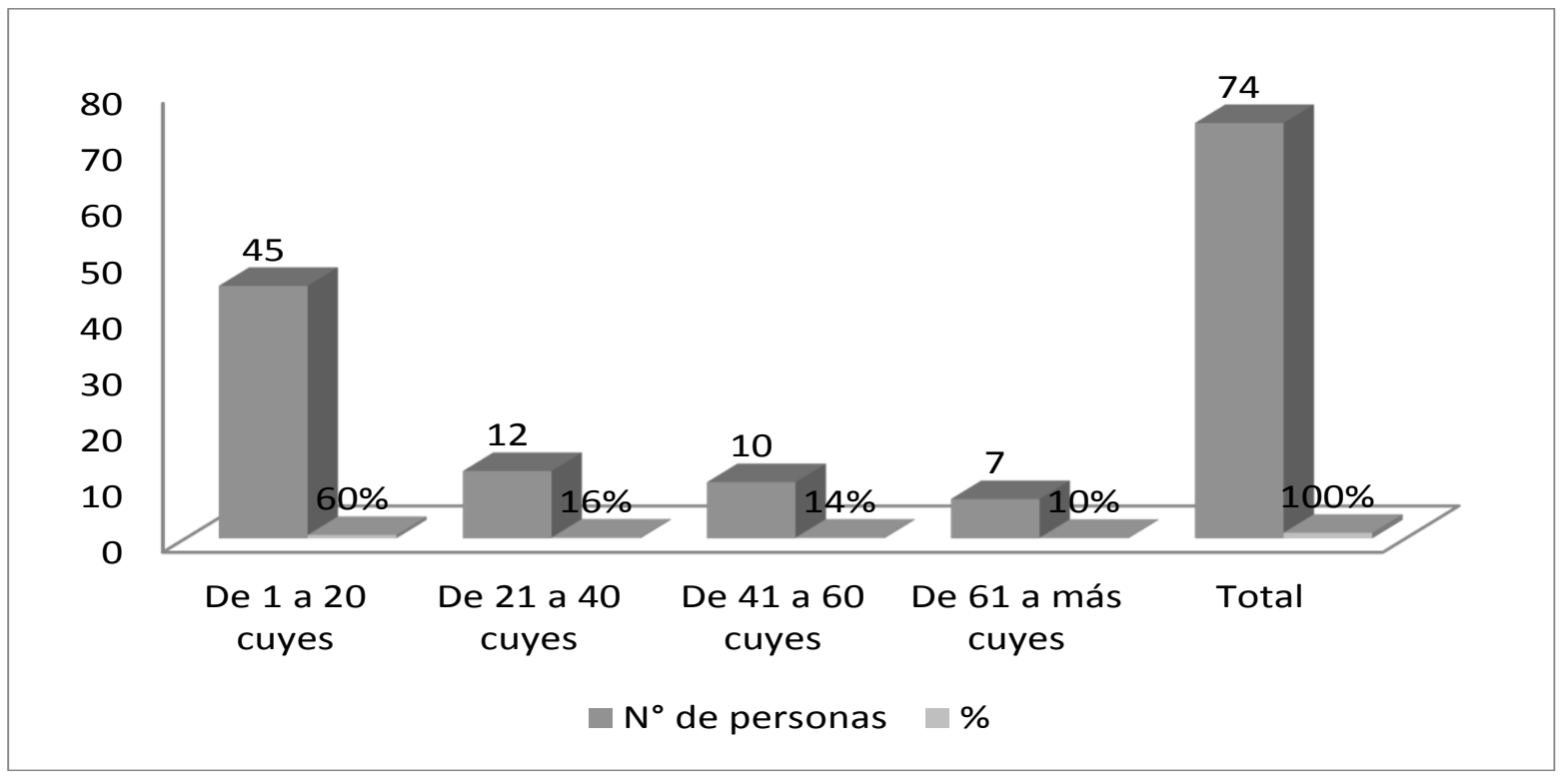

Figura 42.Cantidad de compra

A la pregunta acerca de la cantidad de cuyes que compra para sus restaurantes el $60 \%$ manifiestan que compran entre uno a 20 cuyes, seguido por el $16 \%$ que indican comprar entre 21 a 40 cuyes, por otro lado se aprecia que un 14\% que adquiere de 41 a 60 cuyes, y solo y un $10 \%$ de la los encuestados compran de 61 a más. 


\section{P13. ¿Cuál es el precio que paga según tipo de cuy que compra por unidad?}

Tabla 32

Precio que Paga Según Tipo de Cuy

\begin{tabular}{|c|c|c|c|c|c|}
\hline $\begin{array}{c}\text { Montos en } \\
\text { soles }\end{array}$ & Cuy Vivo & $\begin{array}{c}\text { Cuy } \\
\text { Sacrificado } \\
\text { eviscerado }\end{array}$ & $\begin{array}{c}\text { Cuy } \\
\text { empacado }\end{array}$ & Total & $\tilde{\mathrm{n}} \%$ \\
\hline $\mathrm{s} / 15$ a s/20 & 0 & 0 & 0 & 0 & $0 \%$ \\
\hline s/ 21 a 25 & 15 & 29 & 0 & 44 & $59 \%$ \\
\hline $\mathrm{s} / 26$ a s/ 30 & 0 & 30 & 0 & 30 & $41 \%$ \\
\hline s/ 31 a más & 0 & 0 & 0 & 0 & $0 \%$ \\
\hline Total & 15 & 59 & 0 & 74 & $100 \%$ \\
\hline Total \% & $20 \%$ & $80 \%$ & $0 \%$ & $100 \%$ & \\
\hline
\end{tabular}

En cuanto al precio al que se compra los cuyes estos fluctúan entre a 21 a 30 soles, los cuales se distribuyen de la siguiente manera:

Un 59\% adquiere el cuy entre 21 a 25 soles, seguido por el $41 \%$ cuyo precio de adquisición es de 26 a 30 soles. Ahora considerando la forma de compra se tiene que el $80 \%$ prefiere comprar el cuy ya sacrificado y eviscerado y el $20 \%$ manifiesta comprar el cuy vivo.

En este sentido la mayoría de los encuestados prefieren comprar el cuy ya sacrificado y eviscerado y a un precio que va desde los 21 a 25 soles; criterios que se ajusta al comportamiento de los restaurantes tradicionales y que ayudara a tomar los criterios adecuados para hacer la propuesta tanto de precio como de presentación del producto propuesto en el presente plan de negocios. 
P14. Marque la característica que considera su empresa determinante para adquirir carne de este animal

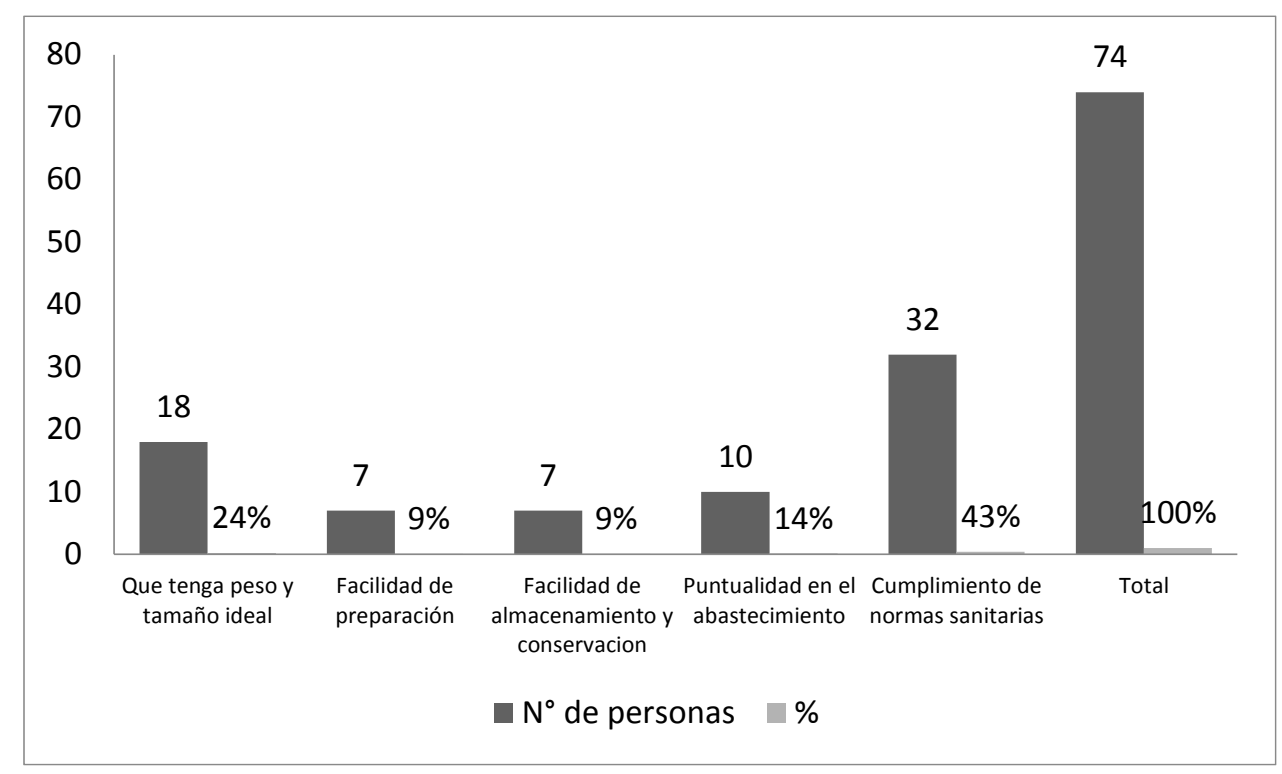

Figura 43.Caracteristica determinante

Como nos demuestra la figura el $43 \%$ toman en cuenta como aspecto principal para la adquisición el cumplimiento de normas sanitarias, el $24 \%$ se inclina a determinarla compra por el peso y tamaño, un $14 \%$ indican que la puntualidad en el abastecimiento es el factor más importante al momento de la compra; solo un $9 \%$ señalan que la facilidad de almacenamiento y facilidad en la preparación son las características más relevantes. 
P15. ¿Estaría dispuesto Ud. a comprar carne de cuy empacada al vacío?

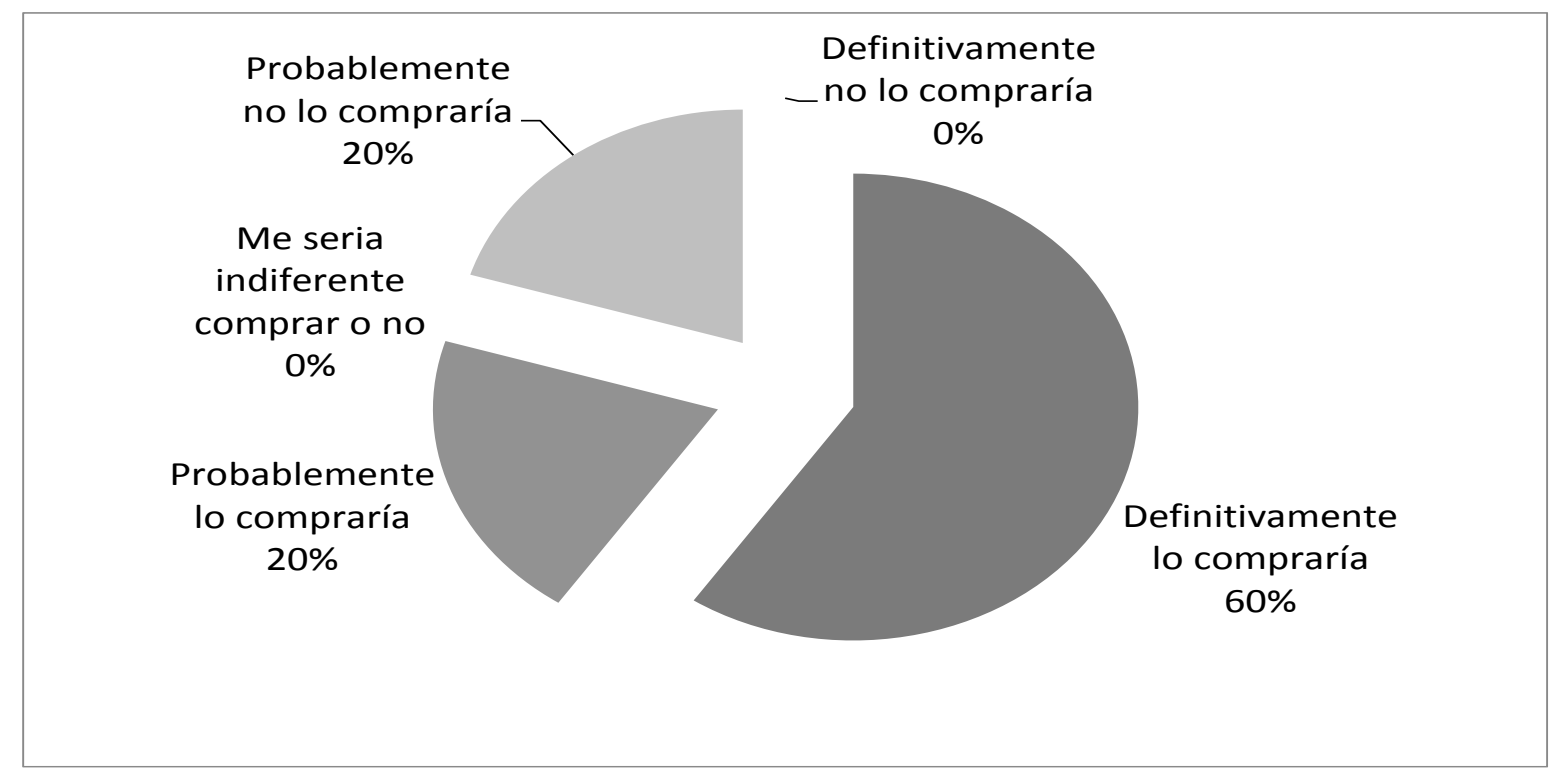

Figura 44.Disponibilidad de compra

Se observa que del $100 \%$ de los encuestados el $60 \%$ definitivamente si comprarían la carne de cuy empacado al vacío producto propuesto en el plan de negocios, seguido por un $20 \%$ que a la explicación de la bondades del producto probablemente si comprarían el producto, y también un $20 \%$ probablemente no comprarían el producto, en ningún caso se obtuvo una negativa al producto propuesto.

P16. ¿Conoce usted las ventajas de adquirir carne de cuy empacada al vacío?

Tabla 33

Conocimiento de Ventajas de Adquirir Carne de Cuy

\begin{tabular}{ccc}
\hline Ventajas & $\mathrm{N}^{\circ}$ de personas & $\%$ \\
\hline SI & 44 & $59 \%$ \\
NO & 30 & $41 \%$ \\
Total & 74 & $100 \%$ \\
\hline
\end{tabular}


Considerando a las personas que respondieron a la pregunta el 59\% tiene un conocimiento claro de las ventajas de adquirir la carne de cuy empacada al vacío; sin embargo existe un $41 \%$ que manifiestan no conocer las ventajas del empacado al vacío.

\section{P17. ¿Dónde le gustaría adquirir carne de cuy empacada al vacío?}

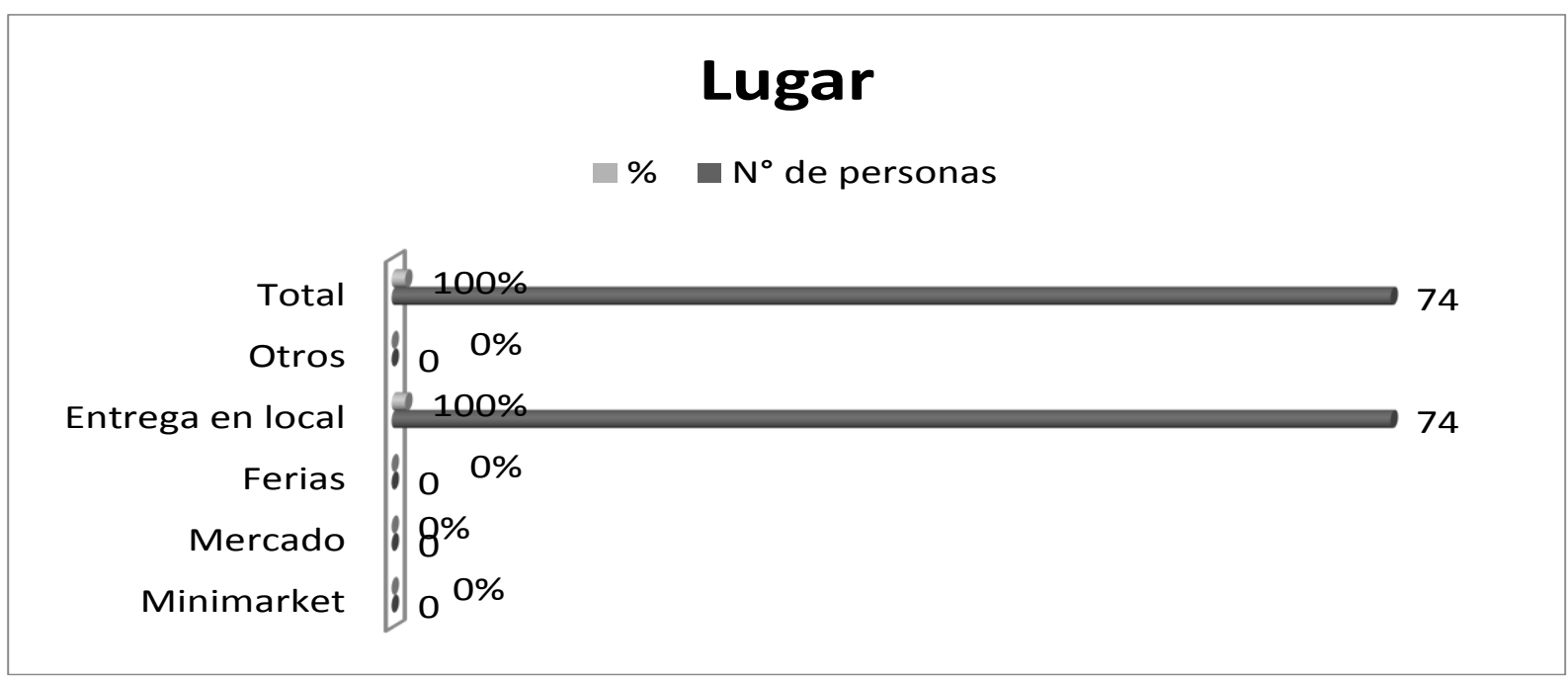

Figura 45.Lugar donde le gustaría adquirir

Del total de los encuestados el 100\% les gustaría que el producto sea llevado a su local, pues le facilitaría ahorro de tiempo y costos en tener que trasladarse al establecimiento de sus proveedores para adquirir el producto, además que es de esta manera que habitualmente se hace la entrega de los productos en esta clase de restaurantes.

\section{P18. ¿Cuánto estaría dispuesto a pagar por una unidad de cuy empacado al vacío?}

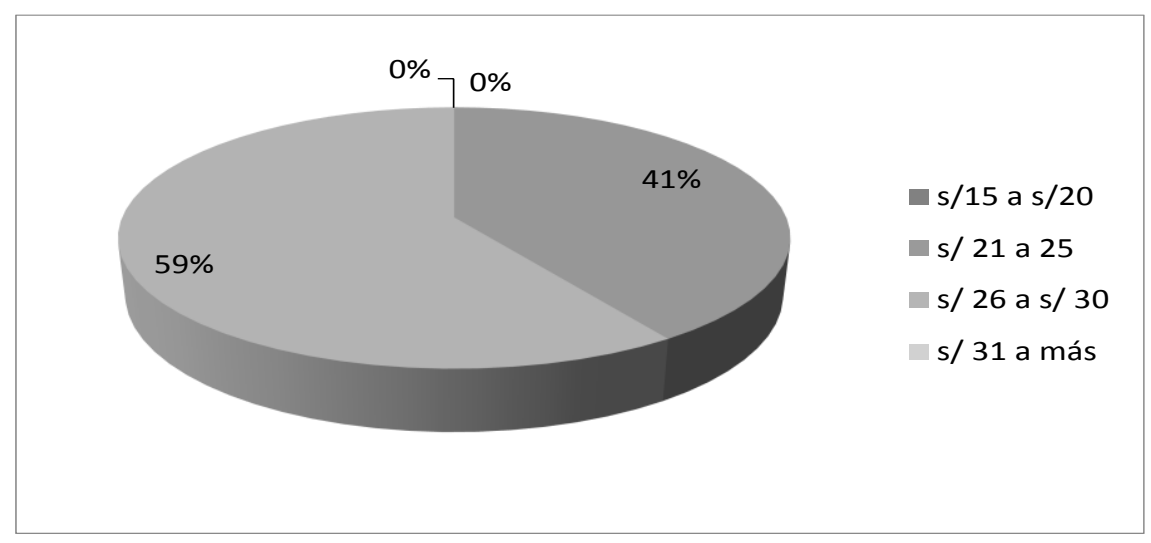

Figura 46.Precio que estaría dispuesto a pagar. 
Como se aprecia en la figura que antecede existe un 59\% de encuestados podrían pagar un margen que vaya desde 26 a 30 soles por ser conscientes de las bondades del empacado al vacío, pareciéndole un precio bastante razonable debido a que le beneficiara contar con mayor tiempo el producto en buenas condiciones al no correr el riesgo que la carne se contamine rápidamente y que guarde todas las condiciones de calidad, higiene y salubridad mientras que el $41 \%$ prefiere pagar el precio que oscile entre 21 a 25 soles.

P19. ¿Por qué medio de comunicación recibe más publicidad en cuanto a productos alimenticios?

\section{Medios de Comunicación}

$\square \mathrm{N}^{\circ}$ de personas $\quad \%$

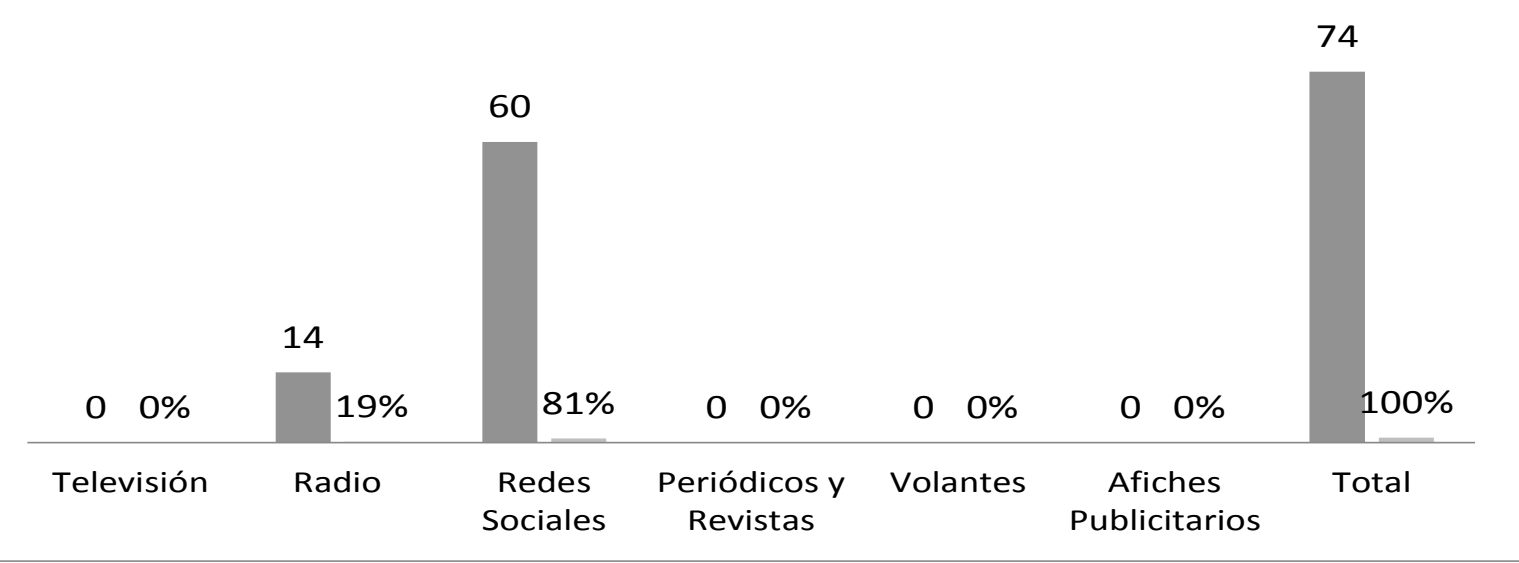

Figura 47.Medio de comunicación que recibe más publicidad.

A la pregunta se tiene que el $81 \%$ de los encuestados reciben información de productos alimenticios por medio de redes sociales, seguido por el $19 \%$ que lo hacen por radio. 


\subsection{Conclusiones y recomendaciones del estudio cualitativo y cuantitativo}

Del análisis cualitativo realizado a través de los focus group al público en general, restaurantes turísticos y tradicionales y a expertos en la cría, sacrificio y alimentación de este animal, se puede concluir:

- $\quad$ El consumidor objetivo conoce las cualidades que debe tener este animal al momento de realizar la adquisición.

- Los criadores o expertos en la producción de este tipo de carne conocen las exigencias que presenta el mercado para la adquisición del producto.

\section{Público en general}

- De la investigación cuantitativa se tiene que las personas que compran carne de cuy están entre los 18 a más años edad, que su unidad familiar está compuesta de dos a más personas y cuentan con ingresos mayores a los 2000 soles.

- También se puede indicar que los clientes están dispuestos a pagar por el producto entre 21 a 30 soles.

- Las personas compran el cuy sacrificado-eviscerado y vivo, con una frecuencia semanal, mensual, semestral y anual en cantidades de más de uno a cinco unidades, y mayor a 12 veces al año.

\section{Restaurantes Turísticos y Tradicionales}

- El 100\% de los encuestados definitivamente estaría dispuesto a comprar el cuy empacado al vacío, estando dispuesto a pagar entre 21 a 30 soles.

- Los restaurantes son de corte tradicional y turístico que en su mayoría tienen capacidad para atender a más de 40 comensales, los cuales preparan platos a base de carne de cuy. 
- La manera de adquirir el cuy es sacrificado-eviscerado y vivo con una preferencia de frecuencia semanal para hacer la compra y que lo adquieren en cantidades de más de 151 unidades en el caso de tradicionales y más de uno a 20 unidades en turísticos en su gran mayoría.

- El $45 \%$ de restaurantes tradicionales y $60 \%$ de turísticos definitivamente si estarían dispuestos a comprar el cuy envasado al vacío pues afirman conocer en gran mayoría las ventajas de esta técnica, pagando por el este producto entre los 21 a 30 soles.

Así mismo y de acuerdo con los resultados obtenidos tanto en el análisis cualitativo como cuantitativo se sugiere proseguir con el desarrollo del proyecto en vista que los resultados alientan a continuar con el proyecto propuesto.

\subsection{Perfil del consumidor tipo y sus variantes.}

De los estudios cualitativos y cuantitativos se definió que el consumidor al que está dirigido el producto reúne las siguientes características:

\section{a. Perfil del público en general.}

El perfil del público en general está determinado de acuerdo a: 
Tabla 34

Perfil Público en General

\begin{tabular}{|c|c|}
\hline Característica & Descripción \\
\hline Edad & De 18 a 75 años \\
\hline Genero & Masculino y Femenino \\
\hline NSE & $\begin{array}{l}\text { A,B y C con ingresos hasta más de los } 2000 \\
\text { soles }\end{array}$ \\
\hline Zona Geográfica & $\begin{array}{l}\text { Seis principales distrito de la provincia del } \\
\text { Cusco y las provincias de Calca y } \\
\text { Urubamba }\end{array}$ \\
\hline Estilo de vida & $\begin{array}{l}\text { - Conducta positiva al consumo de carne } \\
\text { de cuy } \\
\text { - El cuy es un alimento que se consume } \\
\text { desde la época inca. } \\
\text { - Consumo de la carne de cuy está } \\
\text { arraigada en la cultura popular de la } \\
\text { región del Cusco. } \\
\text { - Consumo de platos a base de carne de } \\
\text { cuy como el Chiri Uchu en ocasiones } \\
\text { especiales como fiestas religiosas y } \\
\text { otras ocasiones importantes. }\end{array}$ \\
\hline Cantidad de veces & Más de 12 veces al año \\
\hline $\begin{array}{l}\text { Costo a pagar por el } \\
\text { producto }\end{array}$ & Entre $\operatorname{los} 21$ a 30 soles \\
\hline
\end{tabular}

- El rango de edad está determinado entre los 18 a 75 años, de ambos sexos y dentro de un nivel socio económico A, B y C con ingresos que van hasta los 6379 de los principales distritos de la provincia de Cusco así como las provincias de Urubamba y Calca.

- El público consumidor de esta carne muestra aceptación por el producto, reconoce y se encuentra informado sobre el valor nutricional que posee este tipo de carne. 
- El consumo de este producto se da en fechas especiales y festivas así como en reuniones familiares, puesto que está arraigada en las costumbres, dispuestos a pagar entre los 21 a 30 soles por este producto y que lo consumen más de 12 veces al año.

\section{b. Perfil de restaurantes tradicionales.}

Del análisis se puede indicar que el perfil de los restaurantes tradicionales es:

Tabla 35

Perfil Restaurantes Tradicionales

\begin{tabular}{ll}
\hline \multicolumn{1}{c}{ Característica } & \multicolumn{1}{c}{ Descripción } \\
\hline Tipo de empresa & Naturales y Jurídicas \\
Sector & Comercio \\
Giro del negocio & Restaurantes \\
Tipo de restaurantes & $\begin{array}{l}\text { Tradicionales que atienden a público local } \\
\text { nacionales y extranjeros }\end{array}$ \\
Zona Geográfica & $\begin{array}{l}\text { Seis principales distrito de la provincia del } \\
\text { Cusco y las provincias de Calca y }\end{array}$ \\
Frecuencia de Compra & Semanal \\
Cantidad & 151 a mas \\
Característica & Peso y tamaño ideal \\
predominante para la & \\
compra & \\
Forma de entrega del \\
producto
\end{tabular}

- Empresas que se hallan en el sector comercio del giro restaurantes del tipo tradicional que se hallan en los principales distritos de la provincia de Cusco y las 
provincias de Calca y Urubamba, dedicados a expender comida a público local, nacional y extranjero.

- La frecuencia de compra de este tipo de carne es semanal con cantidades de compra que van más de las 151 unidades.

- La característica más predominante para adquirir este tipo de carne es que la de peso y tamaño ideal.

- Los propietarios de este tipo de restaurantes prefieren que la entrega y abastecimiento de este tipo de producto sea en sus locales.

\section{c. Perfil de restaurantes turísticos.}

Tabla 36

Perfil Restaurantes Turísticos

\begin{tabular}{ll}
\hline \multicolumn{1}{c}{ Característica } & \multicolumn{1}{c}{ Descripción } \\
\hline Tipo de empresa & Naturales y Jurídicas \\
Sector & Comercio \\
Giro del negocio & Restaurantes \\
Tipo de restaurantes & $\begin{array}{l}\text { Turísticos que atienden a visitantes } \\
\text { nacionales y extranjeros }\end{array}$ \\
Zona Geográfica & $\begin{array}{l}\text { Seis principales distrito de la provincia del } \\
\text { Cusco y las provincias de Calca y }\end{array}$ \\
$\begin{array}{ll}\text { Frecuencia de Compra } \\
\text { Cantidad }\end{array}$ & $\begin{array}{l}\text { Semanal } \\
\text { Característica } \\
\text { predominante para la } \\
\text { compra }\end{array}$ \\
$\begin{array}{l}\text { Forma de entrega del } \\
\text { producto }\end{array}$ & En uno a más 60 cuyes \\
\hline
\end{tabular}


- Empresas que se hallan en el sector comercio del giro restaurantes del tipo tradicional que se hallan en los principales distritos de la provincia de Cusco y las provincias de Calca y Urubamba, dedicados a expender comida a visitantes nacionales y extranjeros.

- La frecuencia de compra de este tipo de carne es semanal, con cantidades de compra que van desde uno a más de 60 unidades.

- La característica más predominante para adquirir este tipo de carne es que cumpla las condiciones sanitarias del producto y que les permita cumplir con los estándares de calidad requeridos para este sector.

- Los propietarios de este tipo de restaurantes prefieren que la entrega y abastecimiento de este tipo de producto sea en sus locales. 


\section{Capítulo IV: Proyección del Mercado}

\subsection{El Ámbito de la Proyección}

Para determinar el ámbito de proyección que se empleará en el proyecto se tomó como base a la población que habita en los distritos de Cusco, San Sebastián, San Jerónimo, Saylla, Wanchaq, Santiago de la provincia del Cusco y las provincias de Calca y Urubamba, lugares que pertenecen a la región de Cusco.

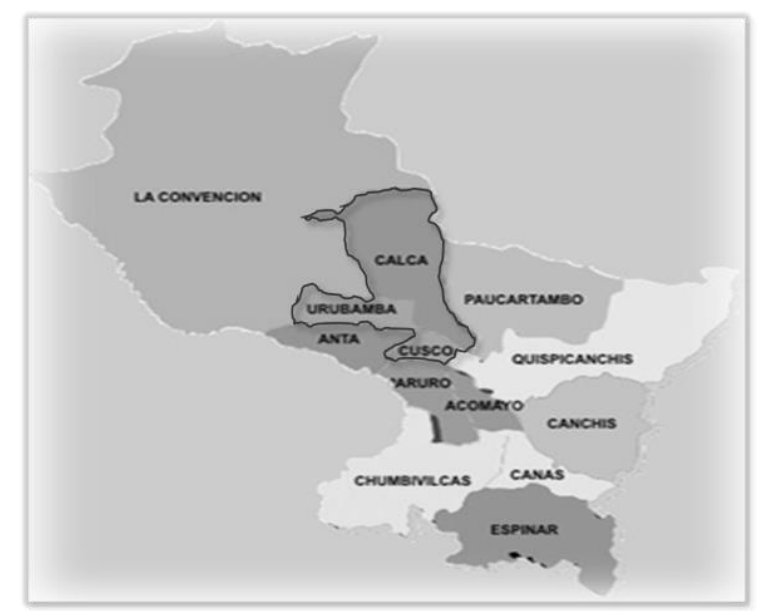

Figura 48. Ámbito de estudio.

\subsection{Selección del Método de Proyección}

El método utilizado para realizar la proyección en el caso del segmento de público en general fue el de Regresión Lineal, método que permitió sub dividir a la población; potenciales clientes, que habitan en los distritos y provincias antes mencionados, determinando las series de tiempo tomando en consideración que se trabajó con una población no mayor a cinco años (población desde el año 2012 al 2016). También mencionar que para proyectar la población al año 2016 se consideró la tasa de crecimiento por distrito y provincia, información recabada del Censo Nacional de Población del Instituto Nacional de Estadística e Informática del año 2007, la cual se puede apreciar en la tabla: 
Tabla 37

Población Proyectada en Base a la Tasa de Crecimiento por Distritos y Provincias

\begin{tabular}{cccccccccccc}
\hline Distritos & TC & 2007 & 2008 & 2009 & 2010 & 2011 & 2012 & 2013 & 2014 & 2015 & 2016 \\
\hline Cusco & $1.11 \%$ & 108,798 & 110008 & 111232 & 112469 & 113720 & 114985 & 116264 & 117557 & 118865 & 120187 \\
San Jeronimo & $5.40 \%$ & 31,687 & 33399 & 35204 & 37106 & 39111 & 41225 & 43453 & 45801 & 48276 & 50885 \\
San Sebastián & $6.21 \%$ & 74,712 & 79353 & 84282 & 89518 & 95079 & 100985 & 107258 & 113921 & 120998 & 128514 \\
Santiago & $0.97 \%$ & 83,721 & 84534 & 85355 & 86184 & 87021 & 87866 & 88719 & 89580 & 90450 & 91328 \\
Wanchaq & $0.98 \%$ & 59,134 & 59714 & 60299 & 60890 & 61487 & 62090 & 62699 & 63314 & 63935 & 64562 \\
Saylla & $8.34 \%$ & 2,934 & 3179 & 3444 & 3731 & 4042 & 4379 & 4744 & 5140 & 5569 & 6033 \\
Calca & $1.11 \%$ & 65,407 & 66133 & 66867 & 67609 & 68359 & 69118 & 69885 & 70661 & 71445 & 72238 \\
Urubamba & $1.16 \%$ & 56,685 & 57343 & 58008 & 58681 & 59362 & 60051 & 60748 & 61453 & 62166 & 62887 \\
Total & & 483,078 & 493663 & 504691 & 516188 & 528181 & $\mathbf{5 4 0 6 9 9}$ & $\mathbf{5 5 3 7 7 0}$ & $\mathbf{5 6 7 4 2 7}$ & $\mathbf{5 8 1 7 0 4}$ & $\mathbf{5 9 6 6 3 4}$ \\
\hline
\end{tabular}

Nota. Tomado en base a la información INEI-Censo Nacional de Población año 2007

Determinada las series de tiempo se empleando las siguientes ecuaciones

\begin{tabular}{c}
\hline Sy $=\mathrm{na}+\mathrm{bSx}$ \\
\hline $\mathrm{Sxy}=\mathrm{aSx}+\mathrm{bSx}^{2}$ \\
\hline
\end{tabular}

Tabla 38

Población en Serie Tiempo

\begin{tabular}{ccc}
\hline Años & X & POBLACION \\
\hline 2012 & -2 & 540699 \\
2013 & -1 & 553770 \\
2014 & 0 & 567427 \\
2015 & 1 & 581704 \\
2016 & 2 & 596634 \\
\hline
\end{tabular}


Enseguida se aplica la ecuación que permite obtener:

Tabla 39

Aplicación de la Ecuación

\begin{tabular}{ccccc}
\hline Año & $\mathrm{Y}$ & $\mathrm{X}$ & $\mathrm{YX}$ & $\mathrm{X}^{2}$ \\
\hline 2012 & 540,699 & -2.00 & $-1,081,398$ & 4.00 \\
2013 & 553,770 & -1.00 & $-553,770$ & 1.00 \\
2014 & 567,427 & 0.00 & 0 & 0.00 \\
2015 & 581,704 & 1.00 & 581,704 & 1.00 \\
2016 & 596,634 & 2.00 & $1,193,268$ & 4.00 \\
$\sum$ & $2,840,234$ & 0.00 & 139,804 & 10.00 \\
\hline
\end{tabular}

Siendo:

$$
\begin{array}{ll}
2,840,234=5 a & 139,804=10 b \\
a=568,047 & b=13,980
\end{array}
$$

Resultando la ecuación igual a:

$$
\mathbf{Y}=2840234+139804 X
$$

Obteniendo la proyección de demanda para un horizonte de 5 años de:

Tabla 40

Demanda Proyectada a Cinco Años

\begin{tabular}{llr}
\hline & \multicolumn{2}{c}{ Proyección de la Demanda } \\
\hline 2017 & 3 & 612,258 \\
2018 & 4 & 628,616 \\
2019 & 5 & 645,751 \\
2020 & 6 & 663,707 \\
2021 & 7 & 682,533 \\
\hline
\end{tabular}


En el caso de los restaurantes turísticos y tradicionales se realizó en base a la tasa de crecimiento anual en base a los estudios del Centro Peruano de Estudios Sociales anualmente (CEPES) del año 2012; que estima una tasa de crecimiento del $16.59 \%$ para este tipo de establecimientos, que de acuerdo a la Dirección Regional de Comercio Exterior y Turismo Cusco de un total de 144 al años 2016, se tiene registrado 84 restaurantes turísticos y 60 restaurantes tradicionales.

En este entender al estar trabajando la investigación de mercado en base de fuentes primarias se tiene que determinar los diferentes tipos de mercados, para esto se aplicará los filtros que brinda las fuentes secundarias como son datos estadísticos de INEI, APEIN, CEPES y DIRCETUR, para un mejor entendimiento en la siguiente figura se muestra los tipos de mercados:

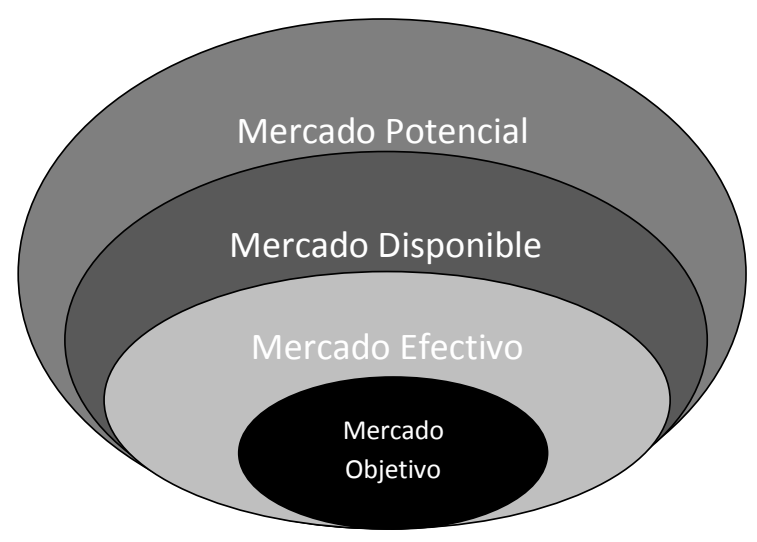

Figura 49. Tipos de mercado.

De la figura se puede desprender que existe cuatro tipos de mercados que va desde un mercado potencial, pasando por el disponible y efectivo los cuales son resultado de aplicar los filtros que brindan las encuestas hasta llegar al mercado objetivo o meta, en el que se planteará a través de las distintas estrategias captar parte de la participación de este. 


\subsubsection{Mercado potencial.}

Es definido como el universo de personas con necesidades que puedan ser satisfechas por la empresa y que además de desear el producto pueden adquirirlo (Maran, 2013).

Para esto se tomara los mercados potenciales para los tres segmentos los cuales se pretende atender.

\section{- Público en general.}

Como se mencionó en el capítulo anterior el plan de negocio está orientado a todas aquellas personas que se encuentran entre los 18 a 75 años de género masculino y femenino que están en los NSE A,B, C; que viven en los distritos de Cusco, San Sebastián, San Jerónimo, Saylla, Wanchaq, Santiago de la provincia del Cusco y las provincias de Calca y Urubamba.

Aplicando los filtros tanto de edad, zona geográfica y nivel socio económico, recurriendo a datos estadísticos de INEI y APEIN, que se puede observar a continuación:

Tabla 41

Población Urbana por Distritos

\begin{tabular}{cccccc}
\hline Distritos & 2017 & 2018 & 2019 & 2020 & 2021 \\
\hline Cusco & 121524 & 122876 & 124243 & 125625 & 127023 \\
San Jerónimo & 53635 & 56534 & 59589 & 62809 & 66203 \\
San Sebastián & 136497 & 144976 & 153982 & 163547 & 173706 \\
Santiago & 92215 & 93110 & 94014 & 94927 & 95849 \\
Wanchaq & 65195 & 65834 & 66479 & 67131 & 67789 \\
Saylla & 6536 & 7081 & 7672 & 8312 & 9005 \\
Calca & 73040 & 73851 & 74671 & 75500 & 76338 \\
Urubamba & 63616 & 64354 & 65101 & 65856 & 66620 \\
Total & $\mathbf{6 1 2 2 5 8}$ & $\mathbf{6 2 8 6 1 6}$ & $\mathbf{6 4 5 7 5 1}$ & $\mathbf{6 6 3 7 0 7}$ & $\mathbf{6 8 2 5 3 3}$ \\
\hline
\end{tabular}


Considerando los filtros tanto de edad como Nivel Socio Económico para lo cual se recurrió a los datos estadísticos de INEI y APEIN 2016 que se detalla en la taba:

Tabla 42

Filtros de Edad y Nivel Socio Económico

\begin{tabular}{crrrr}
\hline Rango de edad - Zona Urbana & \multicolumn{3}{c}{ Nivel Socioeconómico } \\
Entre 18 y 75 años & NSE AB & NSE C & Total \\
\hline Cusco & $72.61 \%$ & $15.60 \%$ & $21.70 \%$ & $37.30 \%$ \\
San Jerónimo & $68.03 \%$ & & & \\
San Sebastián & $70.00 \%$ & & & \\
Santiago & $68.95 \%$ & & \\
Wanchaq & $75.50 \%$ & & \\
Saylla & $67.74 \%$ & & \\
Calca & $62.92 \%$ & & \\
Urubamba & $66.63 \%$ & & \\
\end{tabular}

Al aplicar los filtros tanto de edad como de NSE se tiene un mercado potencial de: 
Tabla 43

Mercado Potencial para Público en General

\begin{tabular}{cccccc}
\hline \multicolumn{5}{c}{ Mercado Potencial } \\
Distritos & 2017 & 2018 & 2019 & 2020 & 2021 \\
\hline Cusco & 32915 & 33281 & 33651 & 34026 & 34404 \\
San Jerónimo & 13610 & 14346 & 15121 & 15938 & 16800 \\
San Sebastián & 35639 & 37853 & 40204 & 42701 & 45354 \\
Santiago & 23715 & 23945 & 24178 & 24413 & 24649 \\
Wanchaq & 18360 & 18540 & 18722 & 18905 & 19090 \\
Saylla & 1652 & 1789 & 1938 & 2100 & 2275 \\
Calca & 17141 & 17332 & 17524 & 17718 & 17915 \\
Urubamba & 15811 & 15994 & 16180 & 16368 & 16557 \\
\hline Total & 158843 & 163080 & 167518 & 172169 & 177044 \\
\hline
\end{tabular}

De la tabla se puede observar que el mercado potencial total para el año 2017 es de 158843 habitantes distribuidos en los distintos distritos y provincias consideradas, hasta llegar a 177044 personas que conforman el mercado potencial para el año 2021

\section{- Restaurantes turísticos.}

Para la determinación del mercado potencial para restaurantes turísticos se consideró a las empresas naturales y jurídicas pertenecientes al sector Comercio registradas y acreditadas en la Dirección Regional de Comercio y Turismo del Cusco, que se encuentran en los distritos de Cusco, Wanchaq, Santiago, San Sebastián, San Jerónimo, Saylla de la provincia del Cusco y las provincias de Calca y Urubamba que ofrecen platos a base de carne de cuy con una frecuencia y volumen de venta de este tipo de carne. 
Tabla 44

Total de Restaurantes Inscritos y Acreditados en DIRCETUR 2016

\begin{tabular}{cccccc}
\hline Ítem & 2017 & 2018 & 2019 & 2020 & 2021 \\
\hline $\begin{array}{c}\text { Restaurantes } \\
\text { Turísticos }\end{array}$ & 168 & 196 & 228 & 266 & 310 \\
Total & 168 & 196 & 228 & 266 & 310 \\
\hline
\end{tabular}

Considerando como filtro el porcentaje que representa este tipo de restaurante de acuerdo a DIRCETUR 2016 que se detalla en la taba:

Tabla 45

Filtros por Tipo de Restaurante

\begin{tabular}{ccc}
\hline & Nro. \\
Clase de restaurantes & restaurantes & $\%$ \\
\hline Turísticos & 84 & $58.00 \%$ \\
Tradicionales & 60 & $42.00 \%$ \\
Total restaurantes & 144 & $100 \%$ \\
\hline
\end{tabular}

Aplicando el filtro se tiene el mercado potencial para restaurantes turísticos de:

Tabla 46

Mercado Potencial para Restaurantes Turísticos

\begin{tabular}{cccccc}
\hline \multicolumn{7}{c}{ Mercado Potencial } & & \\
Ítem & 2017 & 2018 & 2019 & 2020 & 2021 \\
\hline Restaurante Turísticos & 97 & 114 & 132 & 154 & 180 \\
\cline { 2 - 6 } Total & 97 & 114 & 132 & 154 & 180 \\
\hline
\end{tabular}

De la tabla se puede considerar que para el año 2017 se tiene 97 restaurantes como mercado potencial hasta llega a 180 para el año 2021. 


\section{- Restaurantes tradicionales.}

Para la determinación del mercado potencial de restaurantes tradicionales se utilizó los mismos criterios que se empleó en el caso de restaurantes turísticos, del igual manera se recurrió a la misma información como fuente secundaria.

Tabla 47

Total de Restaurantes Inscritos y Acreditados en DIRCETUR 2016

\begin{tabular}{cccccc}
\hline Ítem & 2017 & 2018 & 2019 & 2020 & 2021 \\
\hline Restaurantes & 168 & 196 & 228 & 266 & 310 \\
Turísticos & 168 & 196 & 228 & 266 & 310 \\
Total & 168 & 196 \\
\hline
\end{tabular}

Considerando como filtro el porcentaje que representa este tipo de restaurante de acuerdo a DIRCETUR 2016 que se detalla en la taba:

Tabla 48

Filtros por Tipo de Restaurante

Nro.

\begin{tabular}{ccc} 
Clase de restaurantes & restaurantes & $\%$ \\
\hline Turísticos & 84 & $58.00 \%$ \\
Tradicionales & 60 & $42.00 \%$ \\
Total restaurantes & 144 & $100 \%$ \\
\hline
\end{tabular}


Aplicando el filtro se tiene el mercado potencial para restaurantes tradicionales de:

Tabla 49

Mercado Potencial para Restaurantes Tradicionales

\begin{tabular}{cccccc}
\hline \multicolumn{7}{c}{ Mercado Potencial } \\
Ítem & 2017 & 2018 & 2019 & 2020 & 2021 \\
\hline Restaurante & 71 & 82 & 96 & 112 & 130 \\
Total & 71 & 82 & 96 & 112 & 130 \\
\hline
\end{tabular}

De la tabla se puede considerar que para el año 2017 se tiene 71 restaurantes como mercado potencial hasta llega a 130 para el año 2021.

\subsubsection{Mercado disponible.}

El mercado disponible está definido como una porción del mercado potencial y está formado por el conjunto de consumidores que tienen la necesidad específica de comprar el producto o servicio que ofrece el nuevo negocio. Esto no quiere decir que todas estas personas comprarán el producto que ofrecerá el nuevo negocio. De este total, una parte podría comprar al nuevo negocio y otro no, por diferentes razones. Utilizando como filtro preguntas del cuestionario de la encuesta aplicada.

\section{- Público en general.}

El mercado disponible fue determinado de acuerdo al resultado de la encuesta aplicada al público en general donde se concluyó que el $87 \%$ de la población encuestada del mercado potencial responde afirmativamente a la pregunta número ocho del cuestionario acerca del sí consumen carne de cuy en el año. 
Tabla 50

Mercado Disponible Público en General Proyectado

\begin{tabular}{cccccc}
\hline \multicolumn{5}{c}{ Mercado Disponible } \\
Distritos & 2017 & 2018 & 2019 & 2020 & 2021 \\
\hline Cusco & 28636 & 28954 & 29276 & 29603 & 29931 \\
San Jerónimo & 11841 & 12481 & 13155 & 13866 & 14616 \\
San Sebastián & 31006 & 32932 & 34977 & 37150 & 39458 \\
Santiago & 20632 & 20832 & 21035 & 21239 & 21445 \\
Wanchaq & 15973 & 16130 & 16288 & 16447 & 16608 \\
Saylla & 1437 & 1556 & 1686 & 1827 & 1979 \\
Calca & 14913 & 15079 & 15246 & 15415 & 15586 \\
Urubamba & 13756 & 13915 & 14077 & 14240 & 14405 \\
Total & 138194 & 141879 & 145740 & 149787 & 154028 \\
\hline
\end{tabular}

Notándose que para el primer año se tiene 138194 personas que conforman el mercado disponible después de aplicado el filtro de las personas que si consumen carne de cuy en el año y para el año 2021 se tiene 154028 personas para el mercado disponible.

\section{- Restaurantes turísticos.}

A la pregunta, si en su restaurante prepara platos a base de carne de cuy, el 100\% de los encuestados respondieron que sí, con lo que el mercado disponible se mantiene igual que el potencial.

Tabla 51

Mercado Disponible Restaurantes Turísticos Proyectado

\begin{tabular}{cccccc}
\hline \multicolumn{7}{c}{ Mercado Potencial } & & \\
Ítem & 2017 & 2018 & 2019 & 2020 & 2021 \\
\hline Restaurante Turísticos & 97 & 114 & 132 & 154 & 180 \\
Total & 97 & 114 & 132 & 154 & 180 \\
\hline
\end{tabular}




\section{- Restaurantes tradicionales.}

A la pregunta, si en su restaurante prepara platos a base de carne de cuy, también el $100 \%$ de los encuestados respondieron que sí siendo un plato de mayor demanda en este tipo de negocios, con lo que el mercado disponible se mantiene igual que el potencial.

Tabla 52

Mercado Disponible Restaurantes Tradicionales

\begin{tabular}{cccccc}
\hline \multicolumn{7}{c}{ Mercado Potencial } \\
Ítem & 2017 & 2018 & 2019 & 2020 & 2021 \\
\hline Restaurantes & 71 & 82 & 96 & 112 & 130 \\
Total & 71 & 82 & 96 & 112 & 130 \\
\hline
\end{tabular}

\subsubsection{Mercado efectivo.}

El mercado efectivo está determinado por una parte del mercado disponible y está formado por el conjunto de consumidores que además de la necesidad específica, tienen la intención de comprar el bien o servicio que ofrece el nuevo negocio. Para la determinación de esta parte del mercado se recurrió a los filtros que se aplicaron en los cuestionarios de las encuestas, también al ser un negocio nuevo se aplicó el factor de ajuste de McDaniel y Gates considerando que sostienen que "en varias ocasiones, las compañías de investigación de mercados llevan a cabo estudios que contienen una escala de intención de compra, pero el cliente no cuenta con datos históricos sobre su uso para tomarlos como base a fin de sopesar los datos. Una estimación razonable pero conservadora sería que el 70 porciento de quienes indican que "van a comprar" el producto lo adquirirán, al igual que el 35 porciento de los que indican que "quizá lo compren", un 10 porciento de los que comentan que "quizá no lo compren" y un cero porciento de los que dicen que "no lo comprarán" (McDaniel y Gates 2011). 


\section{- Público en general.}

El resultado del mercado efectivo está determinado por el $52 \%$ de personas que definitivamente si estarían dispuesto a comprar carne de cuy empacada al vacío, además también se consideró un $88 \%$ de personas que estarían dispuestos a pagar un precio que va desde los 21 a más soles; considerando que se encuentra en el rango del precio de venta que se plantea en el proyecto que vendría a ser de 25 soles; además de la aplicación de estos filtros y considerando que se trata de un producto nuevo en el mercado se castiga este resultado aplicando el factor de ajuste de McDaniel y Gates, tomando como criterios para la aplicación de este factor:

Tabla 53

Factor de Ajuste de McDaniel y Gates para Público en General

\begin{tabular}{|c|c|c|c|}
\hline \multicolumn{2}{|c|}{$\begin{array}{c}\text { Estaría dispuesto Ud. a comprar carne } \\
\text { de cuy empacada al vacío }\end{array}$} & $\begin{array}{c}\% \text { de ajuste } \\
\text { de } \\
\text { McDaniel }\end{array}$ & $\begin{array}{c}\% \\
\text { castigado }\end{array}$ \\
\hline $\begin{array}{l}\text { Definitivamente lo } \\
\text { compraría }\end{array}$ & $52 \%$ & $70 \%$ & $37 \%$ \\
\hline $\begin{array}{c}\text { Probablemente lo } \\
\text { compraría } \\
\text { Me seria } \\
\text { indiferente } \\
\text { comprar o no }\end{array}$ & $36 \%$ & $35 \%$ & $13 \%$ \\
\hline $\begin{array}{l}\text { Probablemente no } \\
\text { lo compraría }\end{array}$ & $6 \%$ & $10 \%$ & $1 \%$ \\
\hline $\begin{array}{l}\text { Definitivamente no } \\
\text { lo compraría }\end{array}$ & $3 \%$ & $0 \%$ & $0 \%$ \\
\hline & de ajuste & & $50 \%$ \\
\hline
\end{tabular}

Aplicando el criterio propuesto por McDaniel y Gates se tomó el 70\% de las personas que definitivamente lo comprarían, el $35 \%$ de aquellos que probablemente lo comprarían, 
$10 \%$ de las personas probablemente no lo comprarían y en el caso de las personas que les es indiferente y definitivamente no lo comprarían se consideró el cero por ciento teniendo como resultado un 50\%, factor que se castigara de las personas que pasaron los filtros anteriormente mencionados, teniendo un mercado efectivo de:

Tabla 54

Mercado Efectivo Público en General

\begin{tabular}{cccccc}
\hline \multicolumn{5}{c}{ Mercado Efectivo } & \\
& 1 & 2 & 3 & 4 & 5 \\
Distritos & 2017 & 2018 & 2019 & 2020 & 2021 \\
\hline Cusco & 6525 & 6598 & 6671 & 6746 & 6820 \\
San Jerónimo & 2698 & 2844 & 2998 & 3160 & 3331 \\
San Sebastián & 7065 & 7504 & 7970 & 8465 & 8991 \\
Santiago & 4701 & 4747 & 4793 & 4840 & 4887 \\
Wanchaq & 3640 & 3676 & 3712 & 3748 & 3784 \\
Saylla & 327 & 355 & 384 & 416 & 451 \\
Calca & 3398 & 3436 & 3474 & 3513 & 3552 \\
Urubamba & 3135 & 3171 & 3208 & 3245 & 3282 \\
\hline Total & 31489 & 32331 & 33210 & 34133 & 35098 \\
\hline
\end{tabular}

Nótese que una vez aplicado los filtros y factor de ajuste se tiene un mercado efectivo de 31489 personas para el año 2017 hasta llegar a las 35098 personas de mercado efectivo para el año 2021. 


\section{- Restaurantes turísticos.}

El porcentaje de estos restaurantes que están dispuestos a adquirir este tipo de producto es del $60 \%$ y el $100 \%$ de los encuestado manifiestan poder pagar un precio que va desde los 21 a 30 soles rango en el que se encuentra el precio de venta que se propone, empero al ser un negocio nuevo es necesario aplicar el factor de ajuste de McDaniel y Gates determinando por:

\section{Tabla 55}

Factor de Ajuste de McDaniel y Gates para Restaurantes Turísticos

\begin{tabular}{|c|c|c|c|}
\hline \multicolumn{2}{|c|}{$\begin{array}{c}\text { Estaría dispuesto Ud. a comprar carne } \\
\text { de cuy empacada al vacío }\end{array}$} & $\begin{array}{l}\% \text { de ajuste } \\
\text { de McDaniel }\end{array}$ & $\begin{array}{c}\% \\
\text { castigado }\end{array}$ \\
\hline $\begin{array}{l}\text { Definitivamente lo } \\
\text { compraría }\end{array}$ & $60 \%$ & $70 \%$ & $42 \%$ \\
\hline $\begin{array}{l}\text { Probablemente lo } \\
\text { compraría }\end{array}$ & $20 \%$ & $35 \%$ & $7 \%$ \\
\hline $\begin{array}{l}\text { Me seria indiferente } \\
\text { comprar o no }\end{array}$ & $0 \%$ & $0 \%$ & $0 \%$ \\
\hline $\begin{array}{c}\text { Probablemente no lo } \\
\text { compraría }\end{array}$ & $20 \%$ & $10 \%$ & $2 \%$ \\
\hline $\begin{array}{l}\text { Definitivamente no } \\
\text { lo compraría }\end{array}$ & $0 \%$ & $0 \%$ & $0 \%$ \\
\hline Factor de & & & $51 \%$ \\
\hline
\end{tabular}

Aplicando el criterio propuesto por McDaniel y Gates se tomó el 70\% de las personas que definitivamente lo comprarían, el $35 \%$ de aquellos que probablemente lo comprarían, $10 \%$ de las personas probablemente no lo comprarían y en el caso de las personas que les es indiferente y definitivamente no lo comprarían se consideró el $0 \%$ teniendo como resultado un $50 \%$, factor que se castigara de los personas que pasaron los filtros anteriormente mencionados, teniendo un mercado efectivo de: 
Tabla 56

Mercado Efectivo Restaurantes Turísticos

\begin{tabular}{|c|c|c|c|c|c|}
\hline \multicolumn{6}{|c|}{ Mercado Efectivo } \\
\hline & 1 & 2 & 3 & 4 & 5 \\
\hline Ítem & 2017 & 2018 & 2019 & 2020 & 2021 \\
\hline Restaurante & 29 & 34 & 40 & 46 & 54 \\
\hline Total & 29 & 34 & 40 & 46 & 54 \\
\hline
\end{tabular}

Teniendo como mercado efectivo 29 restaurantes para el 2017 y 54 para el año 2021.

\section{- Restaurantes tradicionales.}

El porcentaje de estos restaurantes que están dispuestos a adquirir este tipo de producto es del $45 \%$ y el $100 \%$ de los encuestado manifiestan poder pagar un precio que va desde los 21 a 30 soles rango en el que se encuentra el precio de venta que se propone, empero al ser un negocio nuevo es necesario aplicar el factor de ajuste de McDaniel y Gates determinando por:

Tabla 57

Factor de Ajuste de McDaniel y Gates para Restaurantes Turísticos

\begin{tabular}{|c|c|c|c|}
\hline \multicolumn{2}{|c|}{$\begin{array}{c}\text { Estaría dispuesto Ud. a comprar carne } \\
\text { de cuy empacada al vacío }\end{array}$} & $\begin{array}{c}\% \text { de ajuste } \\
\text { de McDaniel }\end{array}$ & $\begin{array}{c}\% \\
\text { castigado }\end{array}$ \\
\hline $\begin{array}{l}\text { Definitivamente lo } \\
\text { compraría }\end{array}$ & $45 \%$ & $70 \%$ & $32 \%$ \\
\hline $\begin{array}{l}\text { Probablemente lo } \\
\text { compraría }\end{array}$ & $38 \%$ & $35 \%$ & $13 \%$ \\
\hline $\begin{array}{l}\text { Me seria indiferente } \\
\text { comprar o no }\end{array}$ & $6 \%$ & $0 \%$ & $0 \%$ \\
\hline $\begin{array}{l}\text { Probablemente no lo } \\
\text { compraría }\end{array}$ & $6 \%$ & $10 \%$ & $1 \%$ \\
\hline $\begin{array}{l}\text { Definitivamente no } \\
\text { lo compraría }\end{array}$ & $5 \%$ & $0 \%$ & $0 \%$ \\
\hline Factor de & & & $46 \%$ \\
\hline
\end{tabular}


Aplicando los mismos criterios anteriormente citados se tiene como resultado un $46 \%$, factor que se castigara de los personas que pasaron los filtros anteriormente mencionados, teniendo un mercado efectivo de

Tabla 58

Mercado Efectivo Restaurantes Tradicionales

\begin{tabular}{cccccc}
\hline \multicolumn{7}{c}{ Mercado Efectivo } & & \\
& 1 & 2 & 3 & 4 & 5 \\
Ítem & 2017 & 2018 & 2019 & 2020 & 2021 \\
\hline Restaurante & 15 & 17 & 20 & 23 & 27 \\
Total & 15 & 17 & 20 & 23 & 27 \\
\hline
\end{tabular}

Obteniendo 15 restaurantes para el año 2017 llegando a la cantidad de 27 para el quinto año.

\subsubsection{Mercado objetivo.}

Es una parte del mercado efectivo que la empresa espera atender, es decir la parte del mercado efectivo que se fija como meta a ser alcanzada por el negocio.

En otras palabras, al realizar los esfuerzos y acciones de marketing la empresa espera captar a esta cantidad de personas.

\section{Público en general}

El mercado objetivo fue determinado en función del porcentaje de participación que se pretende atender, para el primer año se trabajó en base a tres escenarios que van desde el más optimista que representaría captar un $15 \%$ del mercado creciendo anualmente un $1 \%$, un escenario conservador que plantea captar un $10 \%$ con una tasa de crecimiento anual del $1 \%$ 
y el pesimista que en las condiciones más adversas se pretende captar un $5 \%$ de mercado efectivo teniendo el mismo criterio de crecimiento de los anteriores escenarios.

Para determinar los porcentajes de la participación de mercado, se determinó en base a que existe un 52\% que definitivamente si compararían el cuy envasado al vacío con un precio acorde a sus posibilidades, existiendo una oportunidad de captar para el primer año solo un $10 \%$ de estos, en un escenario conservador con un crecimiento anual del $1 \%$ el cual va en relación al promedio de la tasa de crecimiento anual de la poblacional determinada al momento de realizar la proyección de la población.

Tabla 59

Mercado Objetivo Público en General para un Escenario Optimista con un 15\%

\begin{tabular}{|c|c|c|c|c|c|}
\hline \multicolumn{6}{|c|}{ Mercado Objetivo } \\
\hline & 1 & 2 & 3 & 4 & 5 \\
\hline Distritos & 2017 & 2018 & 2019 & 2020 & 2021 \\
\hline Cusco & 979 & 1056 & 1134 & 1214 & 1296 \\
\hline San Jerónimo & 405 & 455 & 510 & 569 & 633 \\
\hline San Sebastián & 1060 & 1201 & 1355 & 1524 & 1708 \\
\hline Santiago & 705 & 760 & 815 & 871 & 929 \\
\hline Wanchaq & 546 & 588 & 631 & 675 & 719 \\
\hline Saylla & 49 & 57 & 65 & 75 & 86 \\
\hline Calca & 510 & 550 & 591 & 632 & 675 \\
\hline Urubamba & 470 & 507 & 545 & 584 & 624 \\
\hline Total & 4724 & 5174 & 5646 & 6144 & 6670 \\
\hline
\end{tabular}


Tabla 60

Mercado Objetivo Público en General para un Escenario Conservador con un 10\%

\begin{tabular}{|c|c|c|c|c|c|}
\hline \multicolumn{6}{|c|}{ Mercado Objetivo } \\
\hline & 1 & 2 & 3 & 4 & 5 \\
\hline Distritos & 2017 & 2018 & 2019 & 2020 & 2021 \\
\hline Cusco & 653 & 726 & 801 & 877 & 955 \\
\hline San Jerónimo & 270 & 313 & 360 & 411 & 466 \\
\hline San Sebastián & 707 & 825 & 956 & 1100 & 1259 \\
\hline Santiago & 470 & 522 & 575 & 629 & 684 \\
\hline Wanchaq & 364 & 404 & 445 & 487 & 530 \\
\hline Saylla & 33 & 39 & 46 & 54 & 63 \\
\hline Calca & 340 & 378 & 417 & 457 & 497 \\
\hline Urubamba & 314 & 349 & 385 & 422 & 459 \\
\hline Total & 3151 & 3556 & 3985 & 4437 & 4913 \\
\hline
\end{tabular}

Tabla 61

Mercado Objetivo Público en General para un Escenario Pesimista con un 5\%

\begin{tabular}{|c|c|c|c|c|c|}
\hline \multicolumn{6}{|c|}{ Mercado Objetivo } \\
\hline & 1 & 2 & 3 & 4 & 5 \\
\hline Distritos & 2017 & 2018 & 2019 & 2020 & 2021 \\
\hline Cusco & 326 & 396 & 467 & 540 & 614 \\
\hline San Jerónimo & 135 & 171 & 210 & 253 & 300 \\
\hline San Sebastián & 353 & 450 & 558 & 677 & 809 \\
\hline Santiago & 235 & 285 & 336 & 387 & 440 \\
\hline Wanchaq & 182 & 221 & 260 & 300 & 341 \\
\hline Saylla & 16 & 21 & 27 & 33 & 41 \\
\hline Calca & 170 & 206 & 243 & 281 & 320 \\
\hline Urubamba & 157 & 190 & 225 & 260 & 295 \\
\hline Total & 1574 & 1940 & 2326 & 2731 & 3160 \\
\hline
\end{tabular}


Como se indicó se trabaja con un mercado objetivo proyectado en un escenario conservador es decir con una participación del 10\% para el primer año y un crecimiento del $1 \%$ para los próximos cuatro años.

\section{Restaurantes turísticos}

Como se indicó en el caso de público en general se determinará tres escenarios que van desde el más optimista que representaría captar un $15 \%$ del mercado creciendo año contra año alrededor del 1\%, un escenario conservador que plantea captar un $10 \%$ con una tasa de crecimiento anual del $1 \%$ y el pesimista que en las condiciones más adversas se pretende captar un 5\% de mercado efectivo teniendo el mismo criterio de crecimiento de los anteriores escenarios.

Para determinar los porcentajes participación de mercado en los tres escenarios, ha sido determinado en base a que existe un crecimiento del $16.59 \%$ de esta clase de restaurantes como señala el estudio del CEPES (Centro peruano de Estudios Sociales), existiendo una oportunidad de captar para el primer año solo un $10 \%$ de estos en un escenario conservador con un crecimiento anual del $1 \%$, porcentaje que está por debajo del crecimiento anual de estos.

Tabla 62

Mercado Objetivo para un Escenario Optimista con un $15 \%$

\begin{tabular}{cccccc}
\hline \multicolumn{7}{c}{ Mercado Objetivo } & & & \\
& 1 & 2 & 3 & 4 & 5 \\
Ítem & 2017 & 2018 & 2019 & 2020 & 2021 \\
\hline Restaurante & 4 & 5 & 7 & 8 & 10 \\
Total & 4 & 5 & 7 & 8 & 10 \\
\hline
\end{tabular}


Tabla 63

Mercado Objetivo para un Escenario Conservador con un 10\%

\begin{tabular}{cccccc}
\hline \multicolumn{7}{c}{ Mercado Objetivo } & & & \\
& 1 & 2 & 3 & 4 & 5 \\
Ítem & 2017 & 2018 & 2019 & 2020 & 2021 \\
\hline Restaurante & 3 & 4 & 5 & 6 & 8 \\
Total & 3 & 4 & 5 & 6 & 8 \\
\hline
\end{tabular}

Tabla 64

Mercado Objetivo para un Escenario Pesimista con un 5\%

\begin{tabular}{cccccc}
\hline \multicolumn{7}{c}{ Mercado Objetivo } & & \\
& 1 & 2 & 3 & 4 & 5 \\
Ítem & 2017 & 2018 & 2019 & 2020 & 2021 \\
\hline Restaurante & 1 & 2 & 3 & 4 & 5 \\
Total & 1 & 2 & 3 & 4 & 5 \\
\hline
\end{tabular}

Como se indicó se trabaja con un mercado objetivo proyectado en un escenario conservador es decir con una participación del $10 \%$ para el primer año y un crecimiento del $1 \%$ para los próximos cuatro años.

\section{Restaurantes tradicionales}

Como se mencionó en los dos casos anteriores se trabajará en base a tres escenarios que van desde el más optimista que representaría captar un $15 \%$ del mercado creciendo año contra año alrededor del 1\%, un escenario conservador que plantea captar un $10 \%$ con una tasa de crecimiento anual del $1 \%$ y el pesimista que en las condiciones más adversas se pretende captar un 5\% de mercado efectivo teniendo el mismo criterio de crecimiento de los anteriores escenarios. 
Los restaurantes tradicionales se caracterizan por comprar en grandes cantidades este tipo de carne por ser especialista en su preparación es por eso que el proyecto pretende tener una participación de mercado para el primer año solo un $10 \%$ de estos en un escenario conservador con un crecimiento anual del 1\%, criterio basado en los estudios del CEPES que indica que hay un crecimiento del $16.59 \%$ de esta clase de restaurantes, existiendo una oportunidad de captar este porcentaje que está por debajo del crecimiento anual de estos.

Tabla 65

Mercado Objetivo para un Escenario Optimista con un $15 \%$

\begin{tabular}{|c|c|c|c|c|c|}
\hline \multicolumn{6}{|c|}{ Mercado Objetivo } \\
\hline & 1 & 2 & 3 & 4 & 5 \\
\hline Ítem & 2017 & 2018 & 2019 & 2020 & 2021 \\
\hline Restaurante & 2 & 3 & 3 & 4 & 5 \\
\hline Total & 2 & 3 & 3 & 4 & 5 \\
\hline
\end{tabular}

Tabla 66

Mercado Objetivo para un Escenario Conservador con un 10\%

\begin{tabular}{cccccc}
\hline \multicolumn{7}{c}{ Mercado Objetivo } & & \\
& 1 & 2 & 3 & 4 & 5 \\
Ítem & 2017 & 2018 & 2019 & 2020 & 2021 \\
\hline Restaurante & 1 & 2 & 2 & 3 & 4 \\
Total & 1 & 2 & 2 & 3 & 4 \\
\hline
\end{tabular}


Tabla 67

Mercado Objetivo para un Escenario Pesimista con un 5\%

\begin{tabular}{cccccc}
\hline \multicolumn{7}{c}{ Mercado Objetivo } & & & \\
& 1 & 2 & 3 & 4 & 5 \\
Ítem & 2017 & 2018 & 2019 & 2020 & 2021 \\
\hline Restaurante & 1 & 1 & 1 & 2 & 2 \\
Total & 1 & 1 & 1 & 2 & 2 \\
\hline
\end{tabular}

Como se indicó se trabaja con un mercado objetivo proyectado en un escenario conservador es decir con una participación del $10 \%$ para el primer año y un crecimiento del $1 \%$ para los próximos cuatro años, además de considerar los volúmenes de compra para esta clase de restaurantes.

\subsection{Pronóstico de Ventas}

Para la determinación del pronóstico de ventas se ha toma en cuenta la frecuencia de compra y la cantidad de cuyes que compran en cada segmento, para esto se analizará estos dos factores por cada segmento.

\subsubsection{Público en general.}

En base a la información recabada del cuestionario de la encuesta realizada se determinó la frecuencia de compra anualizada para público en general teniendo como resultado: 
Tabla 68

Frecuencia de Compra

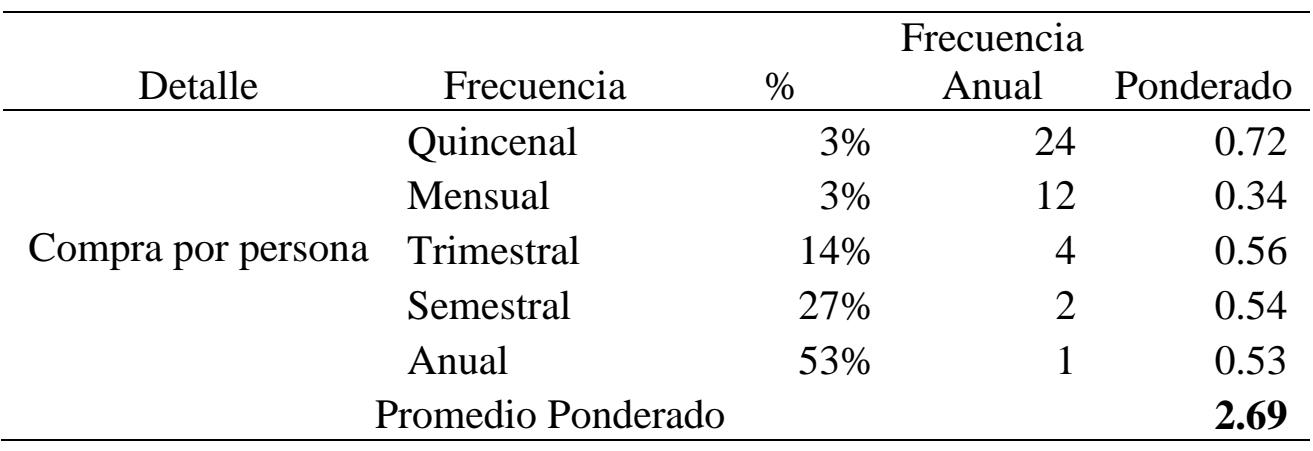

De la tabla de frecuencia se puede observar que el promedio de compra es de 2.69 veces por año esto se debe a que existe un porcentaje de personas que compran de manera anual y semestral.

De igual manera se determinó con el resultado del cuestionario el promedio ponderado para la compra de cuy por persona el cual se aprecia en la tabla siguiente:

Tabla 69

Ponderado de Compra por Familia

\begin{tabular}{|c|c|c|c|c|}
\hline Detalle & $\begin{array}{c}\text { Cantidad } \\
\text { Compra }\end{array}$ & $\%$ & Ponderado & $\begin{array}{c}\text { Promedio } \\
\text { compra }\end{array}$ \\
\hline \multirow{6}{*}{ Compra por persona } & De 1 a 5 & $61 \%$ & 1.83 & 3 \\
\hline & De 6 a 10 & $15 \%$ & 1.20 & 8 \\
\hline & De 11 a 15 & $8 \%$ & 1.04 & 13 \\
\hline & De 16 a 20 & $8 \%$ & 1.44 & 18 \\
\hline & De 21 a 25 & $5 \%$ & 1.15 & 23 \\
\hline & De 26 a más & $3 \%$ & 0.78 & 26 \\
\hline \multicolumn{2}{|c|}{ TOTAL } & $100.00 \%$ & 7.44 & \\
\hline
\end{tabular}


De la tabla se puede observar que la cantidad promedio de compra anual por persona es de 7.44 cuyes por año, concentrándose el mayor porcentaje en las personas que compra de uno a cinco cuyes de manera anual.

Para determinar la proyección de ventas se realizó en base al porcentaje de participación del mercado objetivo en un escenario conservador, frecuencia de compra y el ponderado de compra teniendo como resultado:

Tabla 70

Proyección de Ventas Público en General

\begin{tabular}{lccccc}
\hline & \multicolumn{5}{c}{ Proyección de Ventas por persona } \\
\multicolumn{1}{c}{ Ítem } & 2017 & 2018 & 2019 & 2020 & 2021 \\
\hline Cantidad de cuy anual & 62969 & 71063 & 79636 & 88668 & 98181 \\
Cantidad de cuy mensual & 5247 & 5922 & 6636 & 7389 & 8182 \\
\hline
\end{tabular}

Se puede observar que para el primer año se tiene proyectada una venta mensual de 5247 cuyes y que para el quinto año una producción y venta mensual de 8182 cuyes.

\subsubsection{Restaurante turístico.}

Para determinar la proyección de ventas para los restaurantes turísticos se realizó en base de información recogida de las encuestas realizadas a este segmento teniendo de forma anualizada: 
Tabla 71

Frecuencia de Compra

\begin{tabular}{cccrr}
\hline & & \multicolumn{3}{c}{ Frecuencia } \\
Detalle & Frecuencia & $\%$ & Anual & Ponderado \\
\hline & Diario & $0 \%$ & 360 & - \\
Compra por & Interdiario & $0 \%$ & 180 & - \\
restaurante & Semanal & $46 \%$ & 52 & 23.92 \\
& Quincenal & $24 \%$ & 24 & 5.76 \\
& Una vez por & & & \\
& mes & $30 \%$ & 12 & 3.60 \\
& Promedio Ponderado & & & $\mathbf{3 3 . 2 8}$ \\
\hline
\end{tabular}

De la tabla de frecuencia se puede observar que el promedio de compra es de 33.28 veces por año esto se debe a que estos restaurantes compran semanalmente, quincenalmente y de manera mensual.

De igual manera se determinó el promedio ponderado para la compra de cuy por restaurante el cual se puede apreciar:

Tabla 72

Ponderado de Compra por Restaurante Turístico

\begin{tabular}{cccrr}
\hline Detalle & $\begin{array}{c}\text { Cantidad } \\
\text { Compra }\end{array}$ & $\%$ & Ponderado & $\begin{array}{c}\text { Promedio } \\
\text { compra }\end{array}$ \\
\hline \multirow{4}{*}{$\begin{array}{c}\text { Compra por } 1 \text { a 20 cuyes } \\
\text { restaurante }\end{array}$} & $\begin{array}{c}\text { De 21 a 40 cuyes } \\
\text { De 41 a 60 cuyes }\end{array}$ & $16 \%$ & 6.30 & 10.5 \\
& De 61 a más & 5.04 & 31.5 \\
& cuyes & $10 \%$ & 7.21 & 51.5 \\
& & $100.00 \%$ & $\mathbf{2 4 . 6 5}$ & \\
\hline
\end{tabular}

Se observa que la cantidad promedio de compra por restaurante es de 24.65 cuyes, debido a que el mayor porcentaje se concentrándose en los que compra de uno a 20 cuyes. 
Para determinar la proyección de ventas se realizó en base al porcentaje de participación del mercado objetivo en un escenario conservador, frecuencia de compra y el ponderado de compra teniendo como resultado

Tabla 73

Proyección de Ventas Restaurantes Turístico

\begin{tabular}{cccccc}
\hline & \multicolumn{5}{c}{ Proyección Lineal de Ventas por Restaurante } \\
Ítem & 2017 & 2018 & 2019 & 2020 & 2021 \\
\hline Cantidad de cuy & 2461 & 3281 & 4102 & 4922 & 6563 \\
Cantidad de cuy mensual & 205 & 273 & 342 & 410 & 547 \\
\hline
\end{tabular}

Se puede observar que para el primer año se tiene proyectada una venta mensual de 205 cuyes y que para el quinto año una producción y venta mensual de 547 cuyes para este tipo de establecimientos.

\subsubsection{Restauran tradicional}

Para determinar la proyección de ventas para los restaurantes tradicionales se realizó en base de información recogida de las encuestas realizadas a este segmento teniendo:

Tabla 74

Frecuencia de Compra

\begin{tabular}{cccrr}
\hline & & & Frecuencia & \\
Detalle & Frecuencia & $\%$ & Anual & Ponderado \\
\hline & Diario & $11 \%$ & 360 & 39.27 \\
& Interdiario & $0 \%$ & 180 & - \\
Compra por & Semanal & $78 \%$ & 52 & 40.65 \\
restaurante & Quincenal & $5 \%$ & 24 & 1.31 \\
& Una vez por & & & \\
& mes & $5 \%$ & 12 & 0.65 \\
& Promedio Ponderado & & & $\mathbf{8 1 . 8 9}$ \\
\hline
\end{tabular}


De la tabla de frecuencia se puede observar que el promedio de compra es de 81.89 veces por año esto se debe a que estos restaurantes compran por lo general semanalmente debido a que tienen mayor demanda por platos en base a este tipo de carne.

De igual manera se determinó el promedio ponderado para la compra de cuy por restaurante el cual se aprecia:

Tabla 75

Ponderado de Compra por Restaurante Tradicional

\begin{tabular}{|c|c|c|c|c|}
\hline Detalle & Cantidad Compra & $\%$ & Ponderado & $\begin{array}{l}\text { Promedio } \\
\text { compra }\end{array}$ \\
\hline \multirow{4}{*}{$\begin{array}{l}\text { Compra por } \\
\text { restaurante }\end{array}$} & De 1 a 50 cuyes & $5 \%$ & 1.39 & 25.5 \\
\hline & $\begin{array}{l}\text { De } 51 \text { a } 100 \text { cuyes } \\
\text { De } 101 \text { a } 150\end{array}$ & $22 \%$ & 16.47 & 75.5 \\
\hline & $\begin{array}{l}\text { cuyes } \\
\text { De } 151 \text { a más }\end{array}$ & $16 \%$ & 20.54 & 125.5 \\
\hline & cuyes & $56 \%$ & 85.11 & 151 \\
\hline \multicolumn{2}{|c|}{ TOTAL } & $100.00 \%$ & 123.51 & \\
\hline
\end{tabular}

Se observa que la cantidad promedio de compra por restaurante es de 123.51 cuyes, ya que existe una gran parte de estos que compran de 151 cuyes a más de manera mensual.

Para determinar la proyección de ventas se realizó en base al porcentaje de participación del mercado objetivo en un escenario conservador, frecuencia de compra y el ponderado de compra teniendo como resultado.

Tabla 76

Proyección de Ventas Restaurante Tradicional

\begin{tabular}{cccccc}
\hline & \multicolumn{5}{c}{ Proyección Lineal por Restaurante Tradicional } \\
& 2017 & 2018 & 2019 & 2020 & 2021 \\
\hline Ítem & 10114 & 20229 & 20229 & 30343 & 40457 \\
Cantidad de Cuy anual & 843 & 1686 & 1686 & 2529 & 3371 \\
\hline
\end{tabular}


A continuación se muestra el cuadro resumen de las proyecciones de ventas por los segmentos de público en general, restaurante turístico y tradicional, cantidades que nos posibilitará proyectar la implementación de los cultivos de pastos, galpones de reproducción y crianza; así como las áreas de sacrificio y empacado, de la misma forma ayudará a determinar los costos que implicará esta proyección.

Tabla 77

Proyección de Ventas para los tres Segmentos en un Escenario Conservador de Participación del 10\% de mercado.

\begin{tabular}{cccccc}
\hline & \multicolumn{5}{c}{ PROYECCION LINEAL } \\
Ítem & 2017 & 2018 & 2019 & 2020 & 2021 \\
\hline Público en general & 62969 & 71063 & 79636 & 88668 & 98181 \\
Restaurantes Tradicionales & 10114 & 20229 & 20229 & 30343 & 40457 \\
Restaurantes Turísticos & 2461 & 3281 & 4102 & 4922 & 6563 \\
Total ventas Anual & 75544 & 94572 & 103966 & 123933 & 145201 \\
Total ventas Mensual & 6295 & 7881 & 8664 & 10328 & 12100 \\
\hline
\end{tabular}

De la tabla se puede observar que para el primer año se proyecta vender 6295 cuyes envasados al vacío de manera mensual y una venta anual de 75544 y para el quito año llegar a vender 12100 cuyes mensualmente y de manera anual 145201 cuyes considerando que anualmente se pretende captar el $1 \%$ de mercado a partir del segundo año. 


\section{Capítulo V: Ingeniería del Proyecto}

\subsection{Estudio de Ingeniería}

\subsubsection{Modelamiento y selección de procesos productivos.}

El presente plan de negocios "Crianza e Industrialización de la Carne de Cuy para su Comercialización en la Región Cusco", parte desde la instalación de pastos hasta el almacenamiento del producto final que es el empacado al vacío se detallan los Procesos de cada uno de ellos

\subsubsection{Proceso cultivos de alfalfa.}

El proceso para esta actividad abarca desde la limpieza de terreno para el cultivo de este alimento hasta la disposición final en los galpones de reproductores y engorde tal como se muestra.

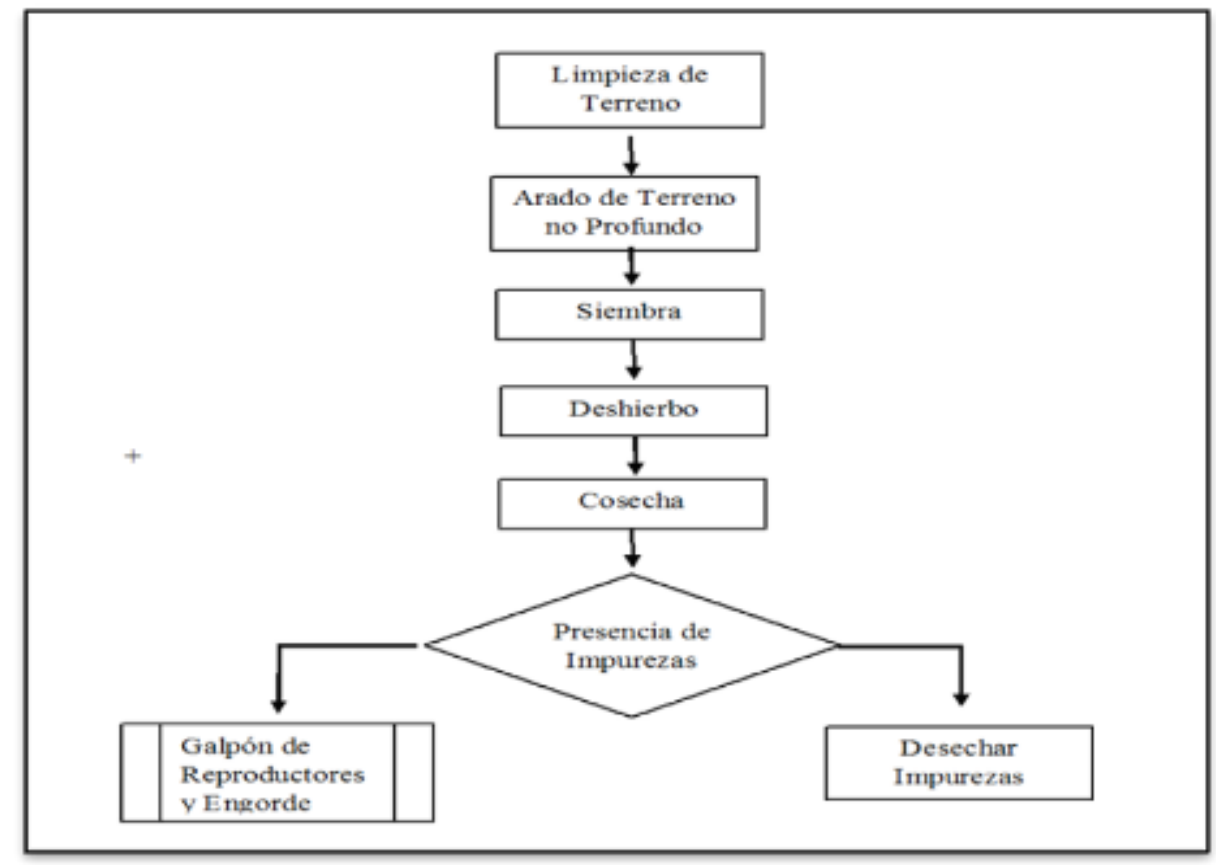

Figura 50. Diagrama proceso cultivo de alfalfa. 
La instalación de hectáreas de este cultivo está determinado por la producción de cuyes para ello se toma como referencia la tabla 70 que muestra cómo óptimo 06 cortes anuales con una producción de 12,000 kg por corte acumulando un total de 72,000 kg.

Tabla 78

Rendimiento de Alfalfa por Año

\begin{tabular}{cccc}
\hline Metros de Altura & $\begin{array}{c}\text { Nro de Cortes por } \\
\text { Año }\end{array}$ & $\begin{array}{c}\text { Kilos Alfalfa por } \\
\text { Corte }\end{array}$ & Total al Año \\
\hline $\mathbf{3 7 0 0}$ & 6 & 12000 & 72000 \\
\hline
\end{tabular}

Nota. Adaptado en base a la información Dirección Regional Agraria Cusco-Mejoramiento de la Competitividad de la Cadena Productiva de cuyes

La tabla siguiente nos muestra el consumo de alfalfa diario, mensual y por año de este animal, se considera un promedio de $20.70 \mathrm{~kg}(6.90 \mathrm{~kg}$. mensuales $* 3$ meses de engorde), de este alimento para obtener un cuy apto para el empacado al vacío .

Tabla 79

Consumo de Alfalfa por Cuy Diario, Mensual y Anual
Consumo por Día
Consumo por Mes
Consumo por Año

$230 \mathrm{gr} \quad 6.90 \mathrm{~kg} \quad 83 \mathrm{~kg}$.

Nota. Adaptado en base a la información Dirección Regional Agraria Cusco-Mejoramiento de la Competitividad de la Cadena Productiva de cuyes

Determinar la cantidad de alimento por año nos permitirá saber la instalación de alfalfa requerido en hectáreas, ponemos como ejemplo el cálculo para el periodo pre operacional de acuerdo al número de reproductores y crías. La adquisición de reproductores 
se realiza en dos lotes la primera en agosto de 2,878 (2,518 hembras y 360 machos) el mismo que después de dos meses de gestación en octubre se tendrá la cantidad de 6,295 crías que resulta de 2,518 (madres)*2.5 crías promedio por parto, este primer lote de gazapos luego de tres meses en enero se dispondrán para el sacrificio y empacado al vacío, proceso que se realizaran los cinco primeros días de cada mes el segundo lote se adquiere en el mes de setiembre de 2,878 reproductores para tener la disponibilidad de 6,295 cuyes en el mes de febrero para el proceso de sacrificio y empacado. Como se mencionó anteriormente el consumo de alfalfa por animal es de $6.9 \mathrm{~kg}$ por mes que multiplicado por el número de cuyes nos da el consumo total mensual, como nuestro cálculo es para el pre operacional sumamos los cinco meses que nos da un total de $395,901 \mathrm{~kg}$ de alfalfa que dividido entre el rendimiento por hectárea de este alimento 72,000 kg. Nos da un total de cinco ha. a instalar para sostenibilidad alimentaria de los cuyes, para detalle de instalación de pastos para los cinco próximos años (ver anexo 09)

Tabla 80

Estructura para Determinar la Cantidad de Hectáreas de Alfalfa Requeridos para el Proceso Pre Operacional

\begin{tabular}{|c|c|c|c|c|c|c|c|c|c|}
\hline & \multicolumn{9}{|c|}{ MESES 2016} \\
\hline & Abril & Mayo & Junio & Julio & Agosot & Setiembre & Octubre & Noviembre & Diciembre \\
\hline 1er Lote Reproductore & - & - & - & - & 2,878 & 2,878 & 2,878 & 2,878 & 2,878 \\
\hline Crias ler Lote & - & - & - & - & - & - & 6,295 & 6,295 & 6,295 \\
\hline 2do Lote Reproductores & - & - & - & - & - & 2,878 & 2,878 & 2,878 & 2,878 \\
\hline Crias 2do Lote & - & - & - & - & - & - & - & 6,295 & 6,295 \\
\hline Numero de Cuyes & & & & & 2,878 & 5,756 & 12,051 & 18,346 & 18,346 \\
\hline Consumo Mensual Alfalfa & & & & & 6.9 & 6.9 & 6.9 & 6.9 & 6.9 \\
\hline Consumo Total Alfalfa & & & & & 19,858 & 39,716 & 83,152 & 126,587 & 126,587 \\
\hline Total Consumo Periodo Pre Operacional Kg. & & & & & 395,901 & & & & \\
\hline Rendimiento por $\mathrm{Ha} . \mathrm{Kg}$. & & & & & 72,000 & & & & \\
\hline Total Instalacion Alfalfa Ha & & & & & 5 & & & & \\
\hline
\end{tabular}




\subsubsection{Proceso de crianza.}

Este proceso garantiza la obtención y estandarización de cuyes con el peso y tamaño ideal, además libre de todo tipo de enfermedades que hagan variar el color y aspecto de la carne al momento de su empaque y/o su comercialización.

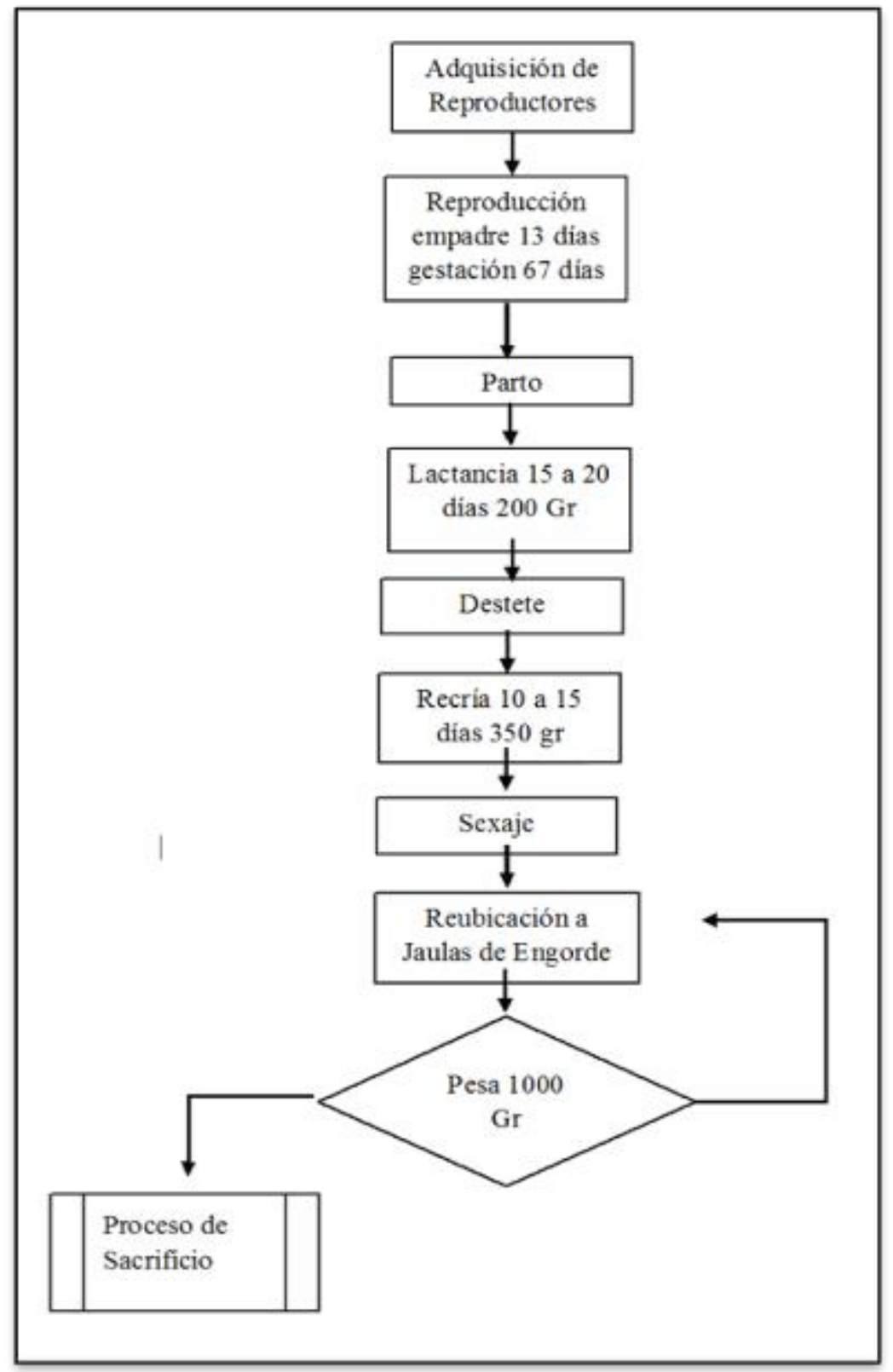

Figura 51. Diagrama proceso de crianza. 
Para este proceso de Crianza se tiene un programa de adquisición de reproductores y reemplazo de los mismos luego de 18 meses de producción, en la siguiente tabla se observa que las cantidades enmarcados en tono de grises representan la compra y a la vez el remplazo de los reproductores que concluyeron con su ciclo de reproducción

\section{Tabla 81}

Programa de Adquisición y Remplazo de Reproductores

\begin{tabular}{|c|c|c|c|c|c|c|c|c|c|c|c|c|c|c|c|c|c|c|c|c|c|c|c|}
\hline \multirow{2}{*}{ Lotes } & \multicolumn{2}{|c|}{ Pre Operacional } & \multicolumn{3}{|c|}{2017} & \multicolumn{3}{|c|}{2018} & \multicolumn{6}{|c|}{2019} & \multicolumn{4}{|c|}{2020} & \multicolumn{5}{|c|}{2021} \\
\hline & Ago. & Set. & Agot. & Set. & Oct. & Ene. & Feb. & Agot. Set. & Ene. & Feb. & Jun. & Jul. & 4got. & Set. & Ene. Feb. Jun. & Jul. Agot. Set. & Nov. & Dic. & Ene. & Feb. & Jun. & Jul. & Nov. \\
\hline 1er Lote Reproductore & 2,878 & & & & & 2,878 & & & & & 2,878 & & & & & & 2,878 & & & & & & \\
\hline 2do Lote Reproductores & & 2,878 & & & & & 2,878 & & & & & 2,878 & & & & & & 2,878 & & & & & \\
\hline 3er Lote Reproductores & & & 725 & & & & & & 725 & & & & & & 725 & & & & & & & & 725 \\
\hline 4to Lote Reproductore & & & & 725 & & & & & & 725 & & & & & & 725 & & & & & & & \\
\hline 5to Lote reproductore & & & & & & & & 358 & & & & & & & 358 & & & & & & 358 & & \\
\hline 6to Lote reproductores & & & & & & & & 358 & & & & & & & 358 & & & & & & & 358 & \\
\hline 7mo Lote reproductores & & & & & & & & & & & & & 761 & & & & & & 761 & & & & \\
\hline 8vo Lote reproductores & & & & & & & & & & & & & & 761 & & & & & & 761 & & & \\
\hline 9no Lote reproductores & & & & & & & & & & & & & & & & 810 & & & & & & & \\
\hline $10 \mathrm{mo}$ Lote reproductores & & & & & & & & & & & & & & & & 810 & & & & & & & \\
\hline
\end{tabular}

La siguiente tabla 73 muestra el sistema de reproducción (gestación dos meses y engorde tres meses). 
Tabla 82

\section{Sistema de Reproducción}

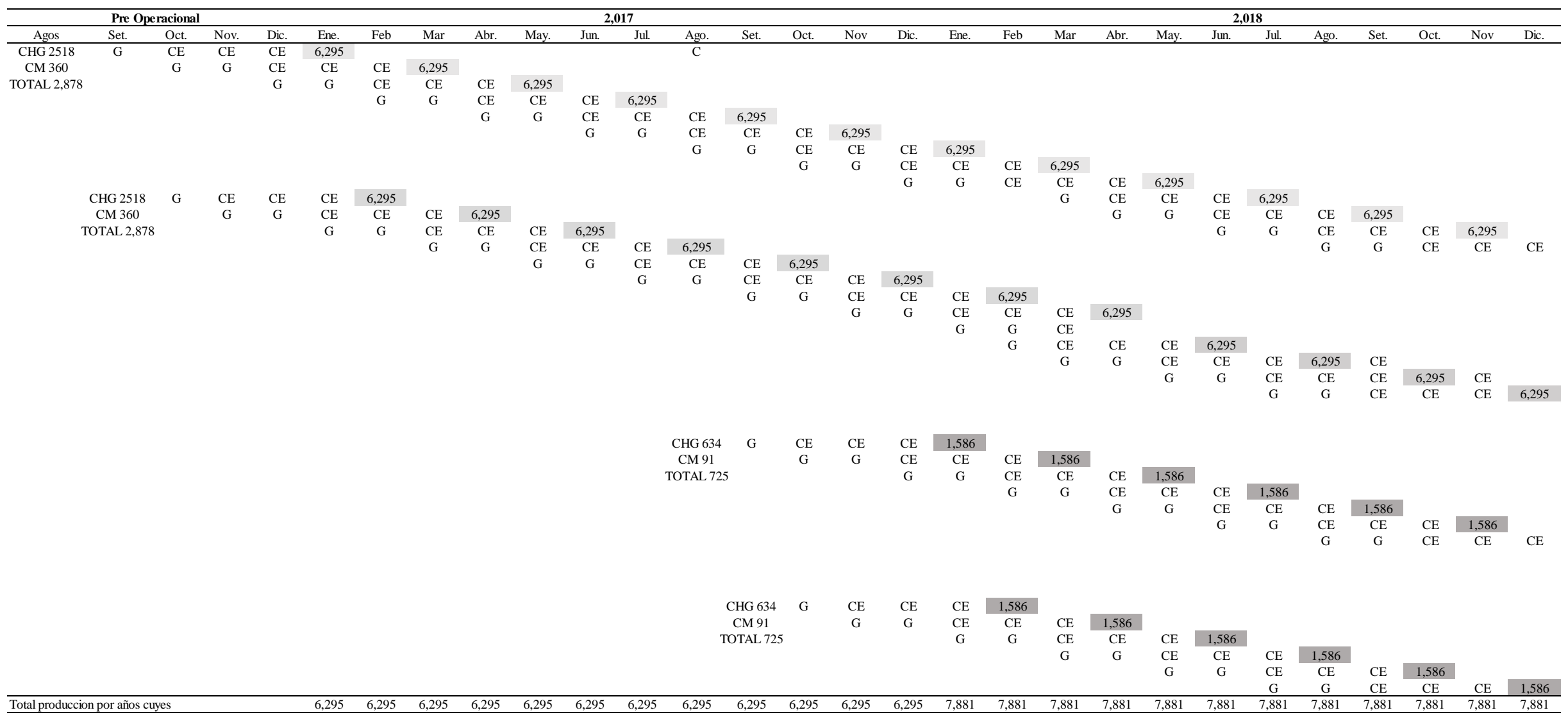


CHG Compra hembras y Gestación

CM Compra machos

G Gestación

CE Centro de Engorde

Cantidades enmarcado en gris producción del mes

\subsubsection{Proceso de sacrificio.}

En este proceso permite usar técnicas adecuadas para el sacrificio de estos animales que garanticen una presentación óptima para el empacado.

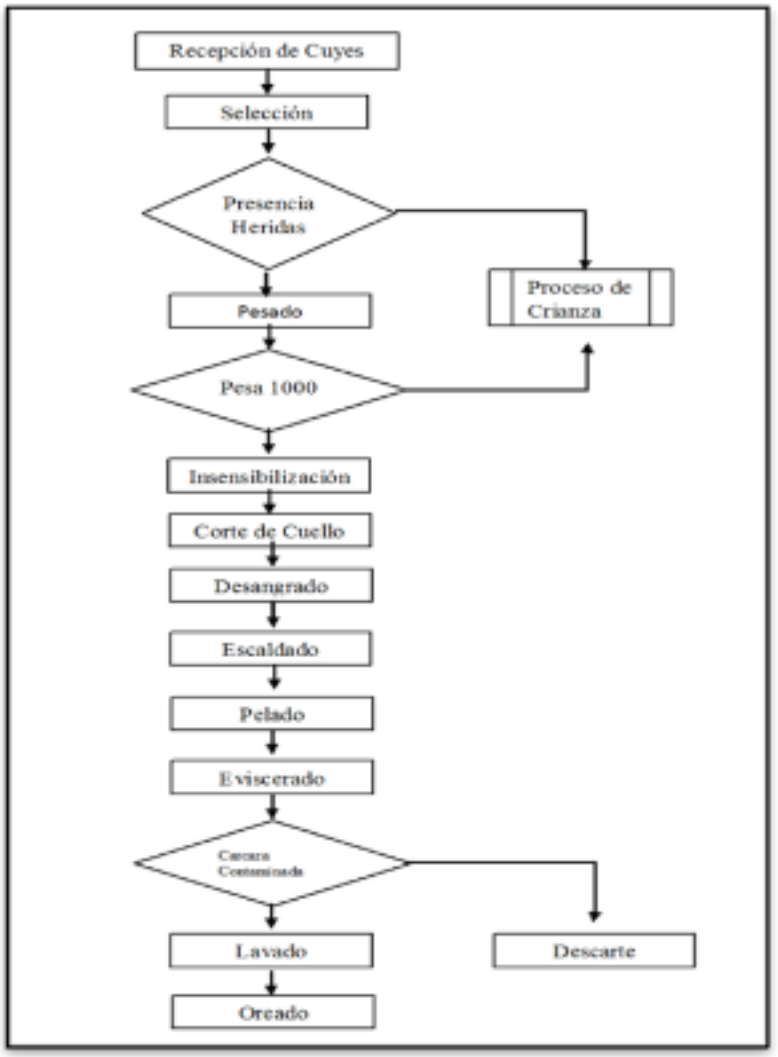

Figura 52. Diagrama proceso de sacrificio. 
En el proceso de sacrificio se determinó la cantidad de personal jornalero para llevar a cabo todo este procedimiento el mismo que se calculó por observación y toma de tiempos de otros centros similares en la provincia de Canas Información Dirección Regional Agraria Cusco - Mejoramiento de la Competitividad de la Cadena Productiva de Cuyes, este proceso se realizada en los cinco primeros días de cada mes

Tabla 83

Calculo para Cantidad de Personal jornalero

\begin{tabular}{lrrrrr}
\hline Año & $\mathbf{2 0 1 7}$ & $\mathbf{2 0 1 8}$ & $\mathbf{2 0 1 9}$ & $\mathbf{2 0 2 0}$ & $\mathbf{2 0 2 1}$ \\
Total Producción & $\mathbf{6 , 2 9 5}$ & $\mathbf{7 , 8 8 1}$ & $\mathbf{8 , 6 6 4}$ & $\mathbf{1 0 , 3 2 8}$ & $\mathbf{1 2 , 1 0 0}$ \\
\hline Sacrificio por Dia & $\mathbf{1 , 2 5 9}$ & 1,576 & 1,733 & 2,066 & 2,420 \\
Nro de Trabajadores & 27 & 34 & 37 & 44 & 51 \\
Cantidad de Cuyes por Trabajador & 47 & 47 & 47 & 47 & 47 \\
Sacrificio Tiempo Estimado Minutos & 1.5 & 1.5 & 1.5 & 1.5 & 1.5 \\
\hline Sub Total Minutos & $\mathbf{7 1}$ & $\mathbf{7 1}$ & $\mathbf{7 1}$ & $\mathbf{7 1}$ & $\mathbf{7 1}$ \\
\hline Pelado Tiempo Estimado Minutos & 3 & 3 & 3 & 3 & 3 \\
\hline Sub Total Minutos & $\mathbf{1 4 1}$ & $\mathbf{1 4 1}$ & $\mathbf{1 4 1}$ & $\mathbf{1 4 1}$ & $\mathbf{1 4 1}$ \\
\hline Eviserado y lavado Tiempo Minutos & 4 & 4 & 4 & 4 & 4 \\
\hline Sub Total Minutos & $\mathbf{1 8 8}$ & $\mathbf{1 8 8}$ & $\mathbf{1 8 8}$ & $\mathbf{1 8 8}$ & $\mathbf{1 8 8}$ \\
\hline Oreado Tiempo Estimado Minutos & 2 & 2 & 2 & 2 & 2 \\
\hline Sub Total Minutos & $\mathbf{9 4}$ & $\mathbf{9 4}$ & $\mathbf{9 4}$ & $\mathbf{9 4}$ & $\mathbf{9 4}$ \\
\hline Total Minutos & $\mathbf{4 9 4}$ & $\mathbf{4 9 4}$ & $\mathbf{4 9 4}$ & $\mathbf{4 9 4}$ & $\mathbf{4 9 4}$ \\
Minutos por Hora & 60 & 60 & 60 & 60 & 60 \\
\hline Total Horas & $\mathbf{8 . 2}$ & $\mathbf{8 . 2}$ & $\mathbf{8 . 2}$ & $\mathbf{8 . 2}$ & $\mathbf{8 . 2}$ \\
\hline
\end{tabular}

\subsubsection{Proceso de empacado al vacío.}

Producto final Empacado al vació técnica que cosiste en la eliminación total del aire existente en el envase, teniendo como característica principal la conservación de sus propiedades nutricionales y el incremento de tiempo en los anaqueles y/o conservadores. La no existencia de 
deshidratación en la carcasa del cuy en este tipo de presentación hace que este no pierda peso y evita la contaminación externa este producto está en un rango mayor o igual a 720 gr de peso.

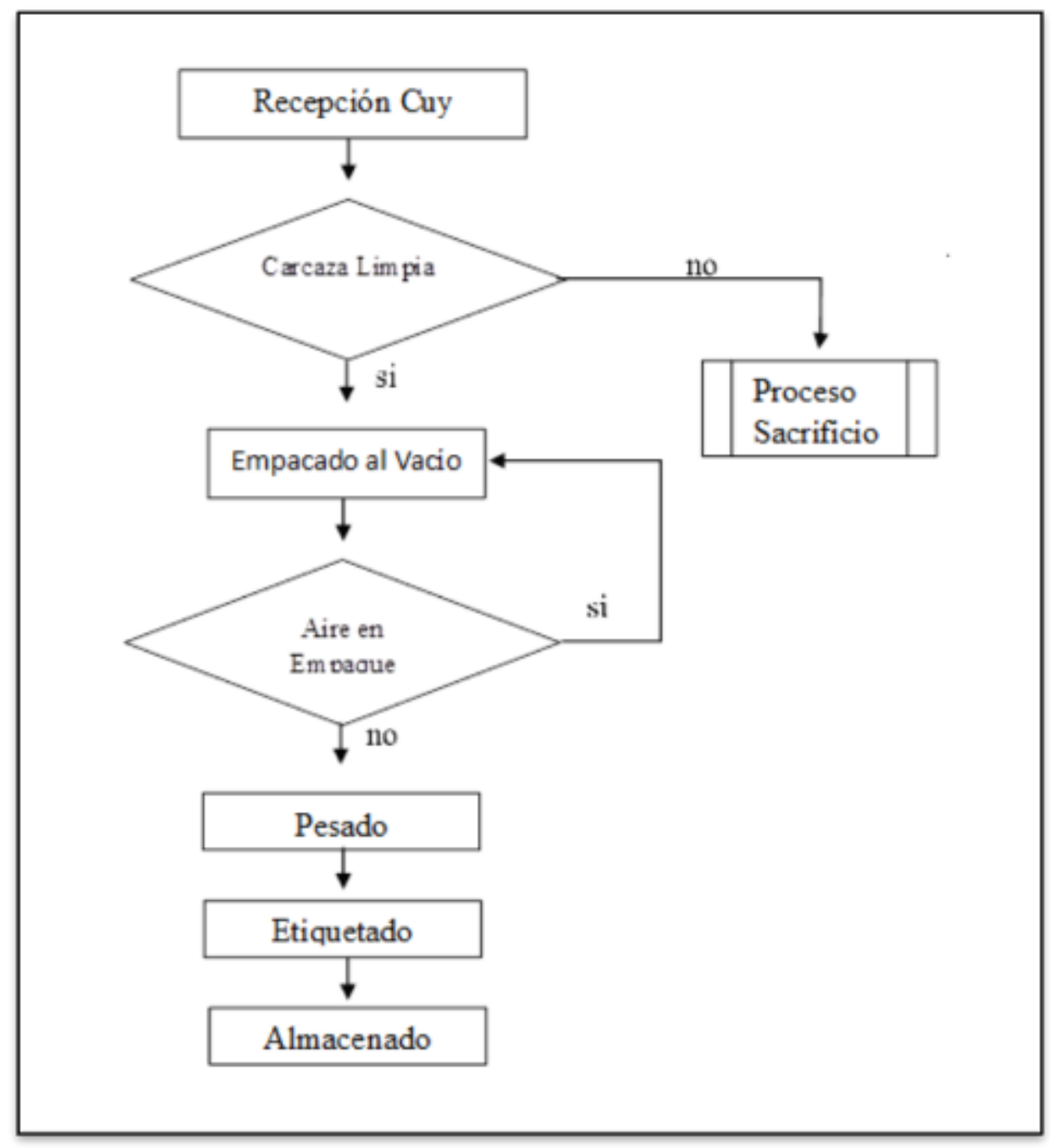

Figura 53. Diagrama proceso cultivo de empacado. 


\subsubsection{Selección y equipamiento}

\subsubsection{Proceso de pastos.}

Para este proceso se hará uso de terrenos de producción idóneos para este cultivo (alfalfa) en la modalidad de alquiler, con regadío durante todo el año y que garantice seis cortes al año

El alquiler de terreno según información de la Dirección regional de Agricultura Cusco Dirección de Información Agraria en marzo del año 2015 tiene un costo de s/1000 la ha. Teniendo en consideración dicha información y siendo conservadores se considera un alquiler de s/. 1,500

\subsubsection{Proceso de crianza.}

En este proceso se considerara equipamiento para el galpón de reproductores y para el galpón de engorde

\section{- Galpón de reproductores}

Este galpón está destinado para los reproductores y sus crías quienes permanecerán en las pozas por un periodo de 15 a 20 días 


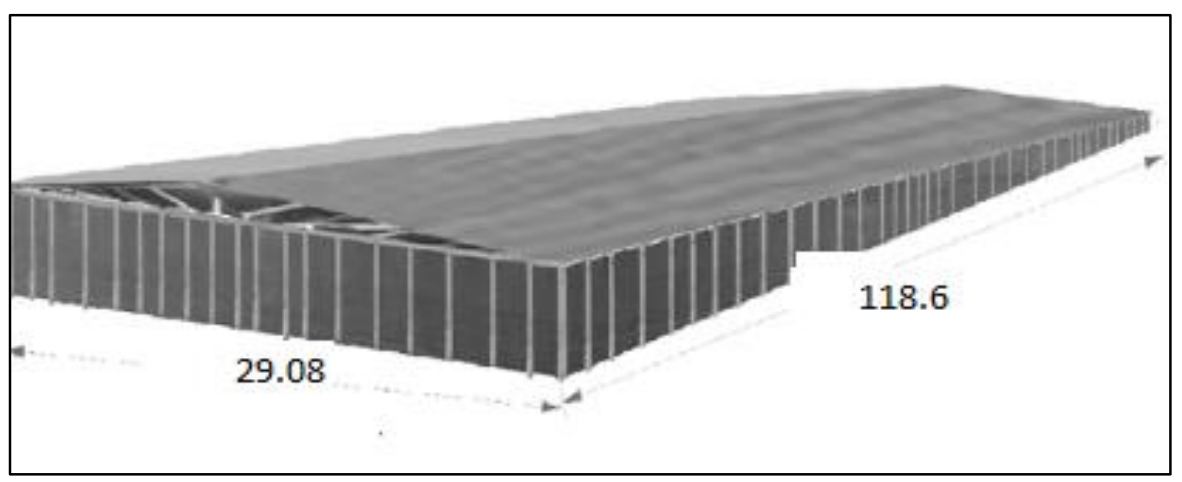

Figura 54 . Galpón de reproductores.

Las características físicas para este galpón, el cual tendrá un área de 3,449 metros cuadrados que albergará 1,383 pozas de reproductores al año cinco (12,100 producción quinto año / siete hembras por poza para albergar los lotes del uno al diez), estará construido con techo teja andina, como vigas de soporte se hará uso de rollizos de eucalipto y para cubrir los lados de la construcción se utilizará malla raschel ideal para el tipo de clima de la zona requerida, además de ello el piso será de tierra compactada. Para el albergue de estos animales se considera una poza de $1.5 \mathrm{~m}$ x $1.2 \mathrm{~m}$ x $0.45 \mathrm{~m}$ utilizando para su construcción malla y listones. Tal como se muestra a continuación siguiente

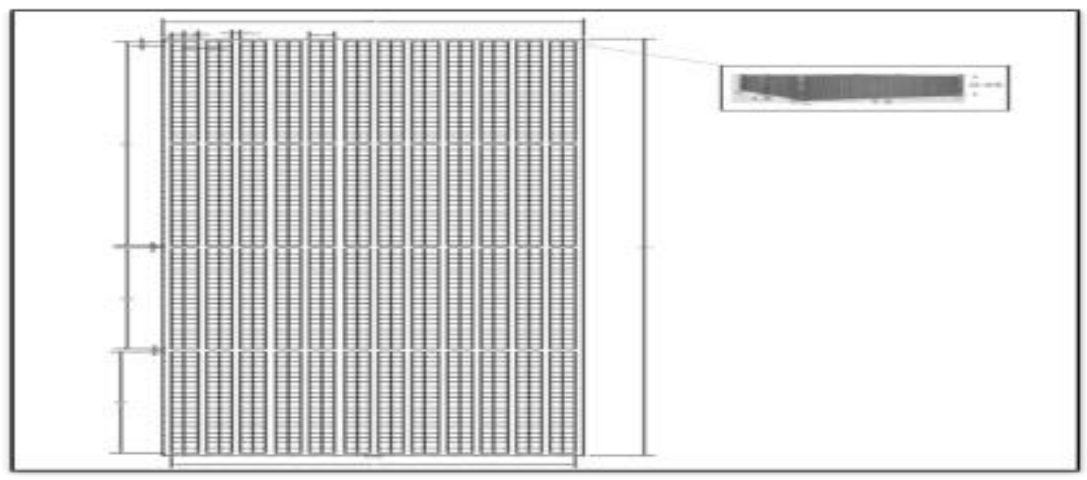

Figura 55. Distribución y diseño de pozas de galpón de reproductores. 


\section{- Galpón de engorde}

Este galpón está destinado para el engorde de las crías a partir de los 15 a 20 días de nacido por un periodo de dos meses

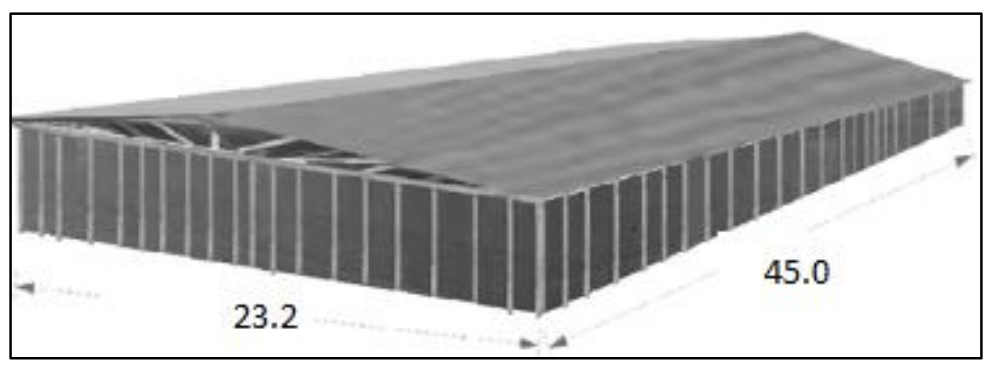

Figura 56 Galpón de engorde.

Tendrá un área de 1,046 metros cuadrados que albergara a 538 jaulas para engorde al año cinco (269 para crías del lote nueve 2269 para crías del lote diez). Teniendo las mismas características físicas que el galpón de reproductores la única diferencia radica en las dimensiones de las jaulas que son $1.3 \mathrm{~m}$ x $1 \mathrm{~m}$ x $0.6 \mathrm{~m}$ de tres pisos que albergara a 15 animales por piso con un total por módulo de 45 cuyes 


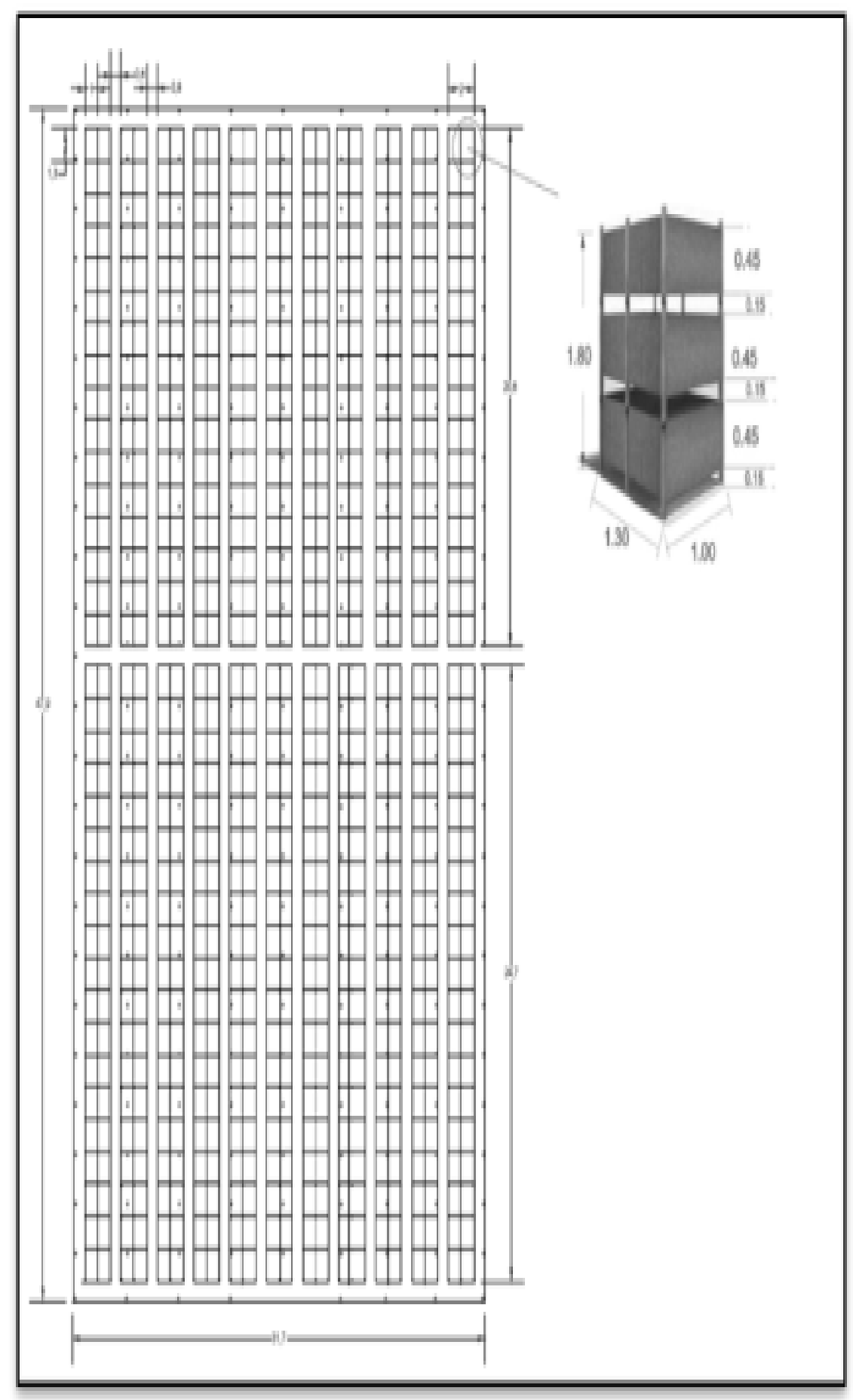

Figura 57. Distribución y diseño de jaulas del galpón de engorde 


\subsubsection{Proceso de sacrificio y empacado.}

Estos procesos al igual que el área de administración estarán distribuidos en un área de 180 metros cuadrados, la infraestructura será de material concreto con enchapado de mayólica en pisos y muros

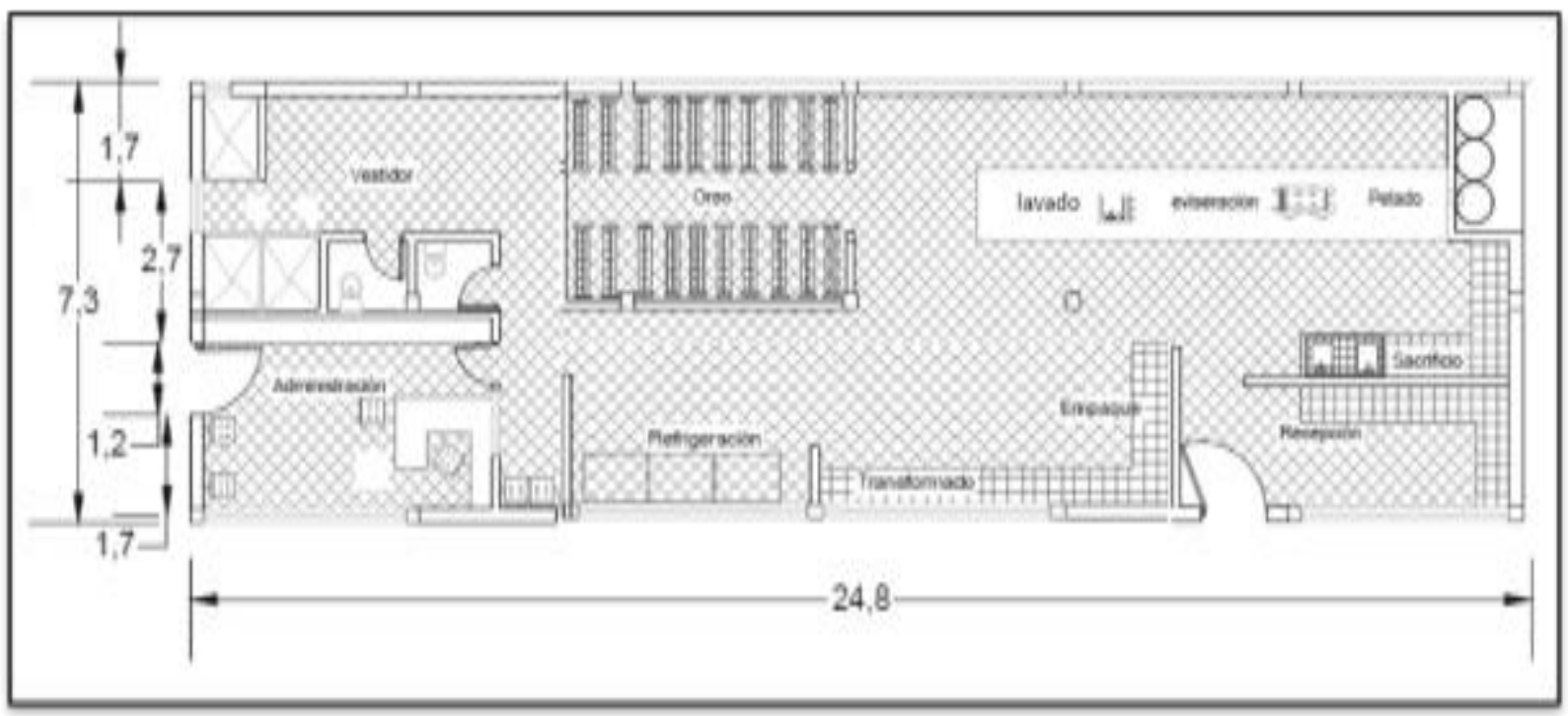

Figura 58. Distribución y diseño área de sacrificio, empacado y administrativo. 


\subsubsection{Lay out.}

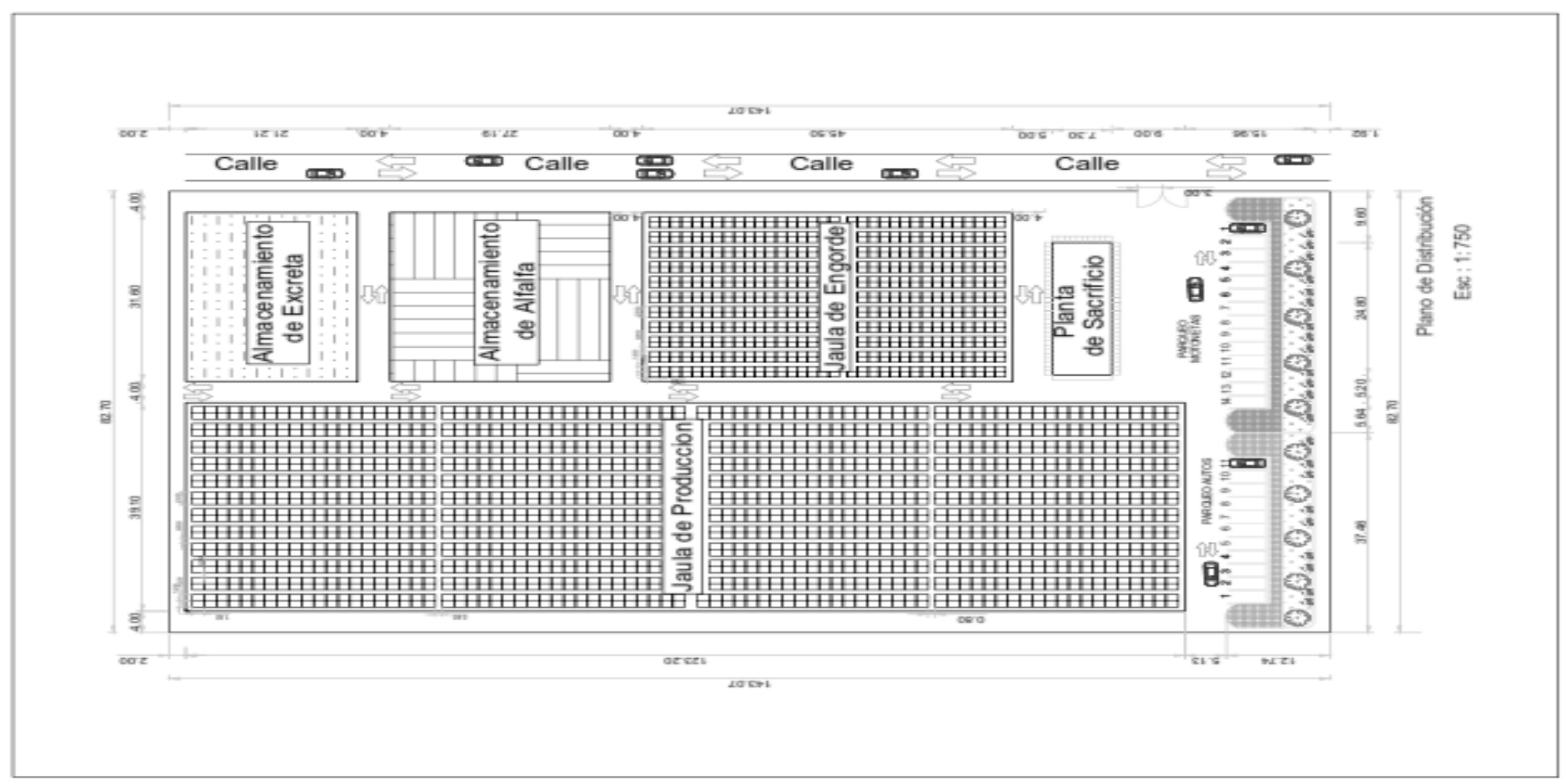

Figura 59. Distribución de Planta. 


\subsubsection{Distribución de equipos y maquinarias}

\subsubsection{Proceso pastos.}

Para este proceso que aprovisionara de alimento (alfalfa) a los cuyes de los galpones de reproductores y engorde se realizará el cultivo de este, en terrenos alquilados que dispongan de agua y aptos para el cultivo de alfalfa el mismo que será de forma anual.

Tabla 84

Equipo y Maquinaria

\begin{tabular}{cccc}
\hline Descripción & Cantidad & Precio Unitario & Total \\
\hline Motoneta & 03 & 6,102 & 18,306 \\
\hline & & & \\
\hline
\end{tabular}

Se realizara la compra de 04 motonetas al año 5 para el traslado de alfalfa de los centros de cultivo a los galpones de crianza y engorde los mismos que realizaran 06 viajes al mes ya que este forraje se puede almacenar por 04 días

\subsubsection{Proceso Crianza.}

Tabla 85

Equipo y Maquinaria

\begin{tabular}{lccc}
\hline \multicolumn{1}{c}{ Descripción } & Cantidad & Precio Unitario & Total \\
\hline Furgón & 01 & 24,890 & 24,890 \\
\hline
\end{tabular}


Tabla 86

Equipo y Maquinaria

\section{Descripción}

Figura

\section{Furgón para transporte}

Este vehículo tiene una capacidad de 1 tonelada el mismo que permitirá transportar nuestro producto a los puntos de expendio

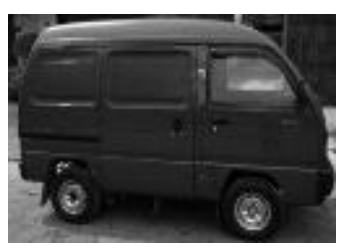

\subsubsection{Proceso Sacrificio.}

El proceso de sacrificio comprende desde la recepción, sacrificio, pelado, eviscerado, lavado y oreado tal como se muestra el plano adjunto los equipos y maquinarias que se requerirán en este proceso se tallan a continuación

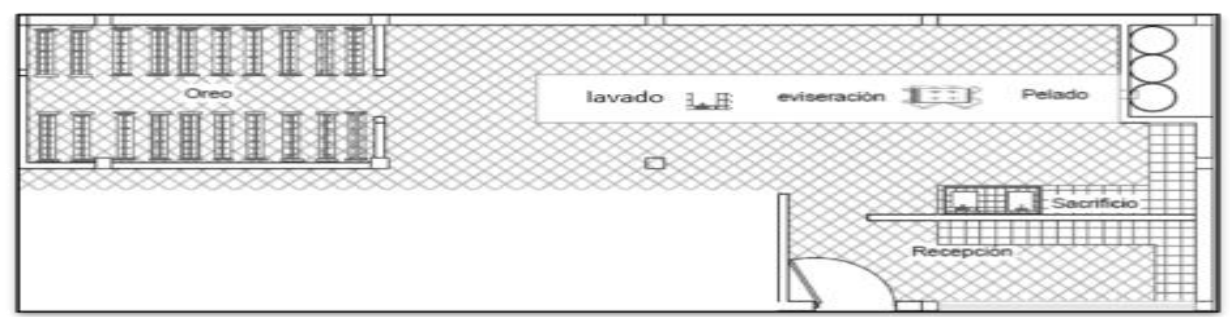

Figura 60. Plano distribución proceso de sacrificio. 
Tabla 87

Equipo y Maquinaria

\begin{tabular}{lccc}
\hline \multicolumn{1}{c}{ Descripción } & Cantidad & Precio Unitario & Total \\
\hline Cocina Industrial & 01 & 2,500 & 2,500 \\
Mesa inoxidable & 03 & 1,017 & 3,051 \\
Olla inoxidable & 04 & 190 & 760 \\
\hline
\end{tabular}

Tabla 88

Descripción Equipo y Maquinaria

\section{Descripción $\quad$ Figura}

\section{Cocina industrial 04 hornillas}

Esta se utilizara para el calentamiento del agua a una temperatura adecuada para sumergir a los cuyes para su posterior pelado la misma que se adquirirá de acero inoxidable

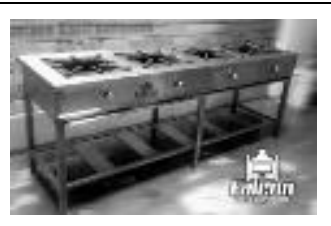

\section{Mesas de trabajo inoxidables}

Estas mesas permitirán realizar los actividades de pelado, eviscerado de los cuyes teniendo las siguientes dimensiones $1.10 * 0.55 * .90$

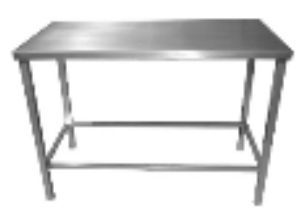

\section{Ollas}

Equipo de trabajo para el calentamiento del agua para el pelado de los cuyes sin tapa con material de acero inoxidable con triple

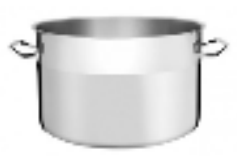
fondo de acero 


\subsubsection{Proceso de Empacado.}

El proceso de empacado es la última actividad para la obtención del producto final que es el cuy empacado al vacío para ello se requerirá

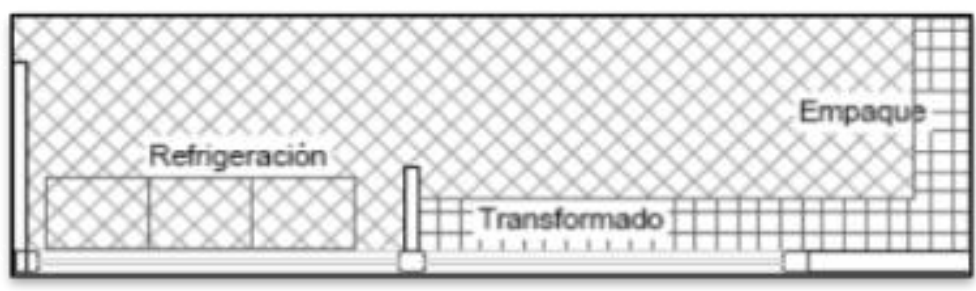

Figura 61. Distribución área de empacado.

Tabla 89

Equipo y Maquinaria

\begin{tabular}{lccc}
\hline \multicolumn{1}{c}{ Descripción } & Cantidad & Precio Unitario & Total \\
\hline Empacadora & 02 & 2.796 & 5,592 \\
Congeladora & 02 & 1,949 & 3,898 \\
Exhibidor & 01 & 2,712 & 2,712 \\
Computadora & 01 & 1,441 & 1,141 \\
\hline
\end{tabular}


Tabla 90

Descripción Equipo y Maquinaria

\section{Descripción Figura}

\section{Empacadora al vacío}

Se adquirirá una empacadora al vacío marca Liver modelo DZ300 frec. De 220v de potencia 300 watts sellado de $260 * 8 \mathrm{~mm}$,

\section{Congeladora}

Equipo que será utilizada para la conservación del producto terminado cuy empacado hasta su distribución a el centro de expendio
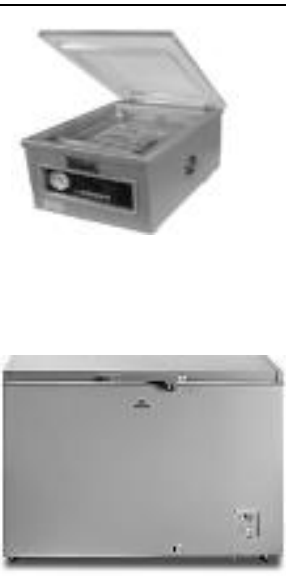

\section{Exhibidor}

Permitirá exhibir el cuy empacado al vacío en nuestra centro de distribución y a la vez su conservación

\section{Computadora}

Equipo que facilitara las tareas administrativas y de ventas

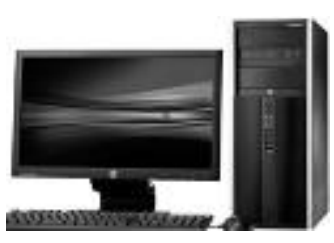




\subsection{Determinación del Tamaño}

La determinación del tamaño de la planta estará en función de la producción de cuyes empacados al vacío que determinara la cantidad de alfalfa que se instalara desde la pre operacional hasta el año 5, de igual manera la cantidad de metros cuadrados de construcción en el área de reproductores y engorde

\subsubsection{Proyección de crecimiento}

\subsubsection{Proceso de Pastos.}

La proyección de crecimiento para la instalación de cultivos de alfalfa parte desde las actividades per operacionales hasta el año 5 según detalle siguiente:

Tabla 91

Proyección de Crecimiento para Instalación de Alfalfa

\begin{tabular}{|c|c|c|c|c|c|c|}
\hline \multirow[t]{2}{*}{ Cultivo } & \multicolumn{6}{|c|}{ Instalación ha } \\
\hline & Pre operacional & Año 1 & Año 2 & Año 3 & Año 4 & Año 5 \\
\hline Alfalfa & 5 & 22 & 27 & 30 & 36 & 41 \\
\hline
\end{tabular}

\subsubsection{Proceso de Crianza.}

La proyección y crecimiento de este proceso está determinado básicamente por la construcción de los galpones de reproducción y engorde desde las actividades pre operacionales al año 5 según detalle siguiente. 
Tabla 92

Determinación de Pozas de Área de Reproducción

\begin{tabular}{|c|c|c|c|c|c|c|c|c|c|c|}
\hline & \multirow{2}{*}{\multicolumn{2}{|c|}{ Pre Operacional 2017}} & \multicolumn{8}{|c|}{ Años } \\
\hline & & & & 2018 & & 2019 & & 2020 & & 2021 \\
\hline Produccion & 6,295 & & & 7,881 & & 8,664 & & 10,328 & & 12,100 \\
\hline Aumento de Crias & & & 1,586 & & 783 & & 1,664 & & 1,772 & \\
\hline Parto & 2. & & 2.5 & 2.5 & 2.5 & 2.5 & 2.5 & 2.5 & 2.5 & 2.5 \\
\hline Total Hembra & 2,51 & & $634^{\prime}$ & 3,152 & $313^{\prime}$ & 3,466 & $666^{\prime}$ & 4,131 & 709 & 4,840 \\
\hline Siete $x$ poza & . & & 7 & 7 & 7 & 7 & 7 & 7 & 7 & 7 \\
\hline Sub total pozas & 36 & & 91 & 450 & 45 & 495 & 95 & 590 & 101 & 691 \\
\hline Dos Lotes & 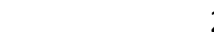 & & 2 & & 2 & & 2 & & 2 & \\
\hline Total Pozas & 71 & & 181 & & 89 & & 190 & & 203 & 1,383 \\
\hline
\end{tabular}

Para determinar el área de pozas se considera 1,383 pozas $* 1.2$ largo*1.5 ancho arrojando un área de 2,489 metros cuadrados de construcción en infraestructura, y las áreas de pasadizos se determinó por la cantidad de estos por su ancho y largo teniendo $(10 * 0.8 * 120$ = 960 metros cuadrados), lo que sumados nos da un total de 3,449 metros cuadrados

Tabla 93

Determinación de Pozas de Área de Engorde

\begin{tabular}{|c|c|c|c|c|c|c|}
\hline & \multirow[t]{2}{*}{ Pre operacional } & \multicolumn{4}{|c|}{ Años } & \multirow{2}{*}{$\begin{array}{l}\text { Total } \\
\text { Jaulas }\end{array}$} \\
\hline & & 2018 & 2019 & 2020 & 2021 & \\
\hline Produccion & 6,295 & 7,881 & 8,664 & 10,328 & 12,100 & \\
\hline Aumento de Crias & & 1,586 & 783 & 1,664 & 1,772 & \\
\hline 45 por Jaulas & 45 & 45 & 45 & 45 & 45 & \\
\hline Sub Total Jaulas & 140 & 35 & 17.4 & 37 & 39 & \\
\hline Dos Lotes & 2 & 2 & 2 & 2 & 2 & \\
\hline Sub Total Jaulas & 280 & 70 & 35 & 74 & 79 & 538 \\
\hline
\end{tabular}

Para determinar el área de las jaulas se considera 538 julas * 1 largo*1.3 ancho arrojando un área de 699 metros cuadrados de construcción en infraestructura, y las áreas de pasadizos se determinó por la cantidad de estos por su ancho y largo teniendo $(9 * 0.8 * 45.4=327$ metros 
cuadrados) teniendo un área libre dentro de este galpón de 20 metros cuadrados, lo que sumados nos da un total de 1,046 metros cuadrados

Tabla 94

Proyección de Crecimiento Infraestructura Galpones de Reproducción y Engorde

\begin{tabular}{|c|c|c|c|c|c|c|c|c|}
\hline \multirow{3}{*}{ Galpón } & \multicolumn{6}{|c|}{ Instalación Infraestructura Metros Cuadrados } & \multirow{3}{*}{$\begin{array}{c}\text { Pasadizos } \\
\text { y Area } \\
\text { Libre } \\
\end{array}$} & \multirow{3}{*}{$\begin{array}{c}\text { Total } \\
\text { Construcción }\end{array}$} \\
\hline & \multicolumn{6}{|c|}{ Años } & & \\
\hline & Pre Operacional & 2017 & 2018 & 2019 & 2020 & 2021 & & \\
\hline Reproducción metros & 1,295 & & 326 & 161 & 342 & 365 & 960 & 3,449 \\
\hline Engorde & 364 & & 92 & 45 & 96 & 102 & 347 & 1,046 \\
\hline
\end{tabular}

Para el área de reproducción se tiene un área total de 3,449 metros cuadrados y para el área de engorde se contara con 1,046 metros cuadrados, considerando que se comenzara con una área de 1295 para reproducción y 364 metros cuadrados en la etapa pre operacional. 


\subsubsection{Recursos}

\subsubsection{Proceso de Pastos.}

Los recursos necesarios para la instalación de pastos (alfalfa) son

Tabla 95

Recursos para Producción de Alfalfa

\begin{tabular}{lcc}
\hline \multicolumn{1}{c}{ Descripción } & $\begin{array}{c}\text { Unid. } \\
\text { Medida }\end{array}$ & Precio s/. \\
\hline Semilla alfalfa & Kg & 40 \\
Abonos Adherentes & Kg. & 4 \\
Fumigadora & Unid. & 99 \\
Segadora & Unid. & 12.9 \\
Aspersor & Unid. & 20 \\
Manguera aspersor & M & 2.10 \\
Botas & Par & 24.9 \\
\hline \multicolumn{1}{c}{ Descripción } & Unid. & Precio s/. \\
& Medida & \\
\hline Impermeable & Unid. & 29.9 \\
Alquiler Terreno & Ha & 1500 \\
Alquiler Tractor & Hora & 55 \\
Personal & Mes & 1340 \\
Jornalero & Día & 30 \\
\hline
\end{tabular}


Tabla 96

Descripción Recursos para Producción de Alfalfa

Descripción $\quad$ Figura

Semilla de alfalfa

Se realizara la compra de semilla de alfalfa a razón de $25 \mathrm{~kg}$ por ha. Según información Dirección regional de Agricultura Cusco

\section{Abonos y adherentes}

Se adquirirá Urea, Cloruro y adherente en promedio de $357 \mathrm{~kg}$. Por ha.

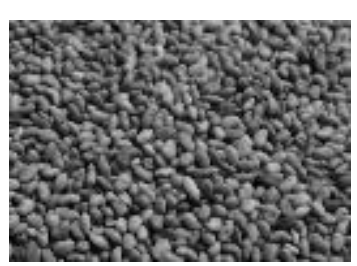

\section{Fumigadoras}

Cumplen la función de fumigación para la eliminación de agentes de puedan generar un deterioro o retardo en el crecimiento de la alfalfa

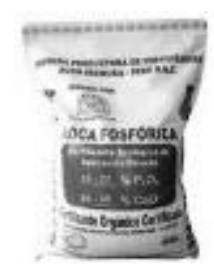

crecimiento de la alfalfa

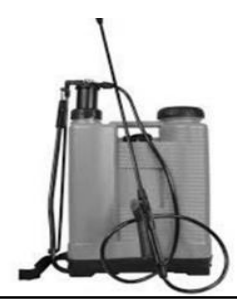


Descripción Recursos para Producción de Alfalfa

\section{Descripción $\quad$ Figura}

\section{Segadoras}

Herramienta de Trabajo que se utiliza para el corte de la alfalfa

\section{Aspersores}

Equipo útil para el regadío de las plantaciones de alfalfa

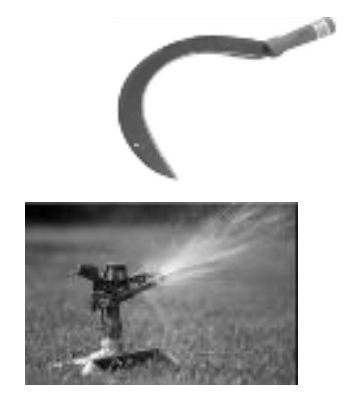

\section{Mangueras}

Se utilizara para el traslado del agua hasta los aspersores

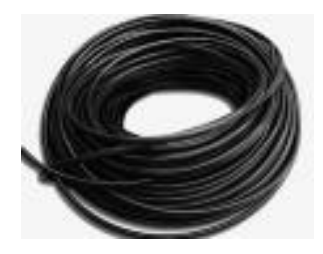

\section{Botas}

Equipo de protección que se proporcionara a los trabajadores estables para las labores encomendadas

\section{Guantes}

Equipo de protección que se proporcionara a los trabajadores estables para las labores encomendadas
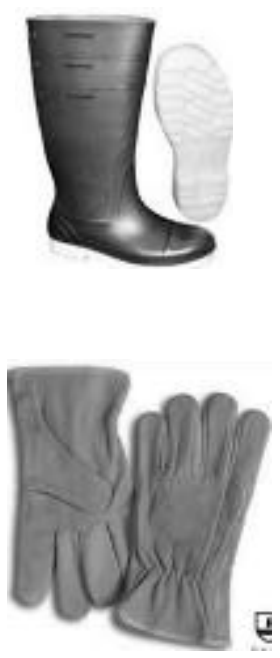


\section{Impermeables}

Equipo de protección para las labores encomendadas en época de lluvias

\section{Alquiler terreno}

El terreno para la instalación de alfalfa tiene un costo de s/. 1500. la ha por campaña

\section{Alquile de tractor}

Se alquilara tractores agrícolas para la preparación del terreno arado y rastrado es importante indicar cuando se realiza la siembra de este cultivo estas labores se realizan cada 3 a 4 años, la hora de este equipo se tomó de la información que maneja la dirección regional de Agricultura Cusco el mismo que los alquila en las diferentes provincias del Cusco

\section{Personal}

Se realizara la contratación de dos trabajadores en planillas por los nueve primeros meses a razón de s/. 1,000 para labores de corte selección de alfalfa y traslado de la misma al área de crianza.

\section{Jornaleros}

Se contratara jornaleros a razón de 30 soles con una frecuencia de 20 jornales por ha para labores de limpieza y deshierbo del terreno de cultivo 


\subsubsection{Proceso de Crianza.}

Los recursos para este proceso se destinaran a los galpones de reproductores y engorde

Tabla 97

Recursos para Proceso de Crianza

\begin{tabular}{llc}
\hline \multicolumn{1}{c}{ Descripción } & $\begin{array}{c}\text { Unid. } \\
\text { Medida }\end{array}$ & Precio \\
& s/. \\
\hline Productos Veterinarios & Cuy & 0.30 \\
Jaulas de Engorde & Unid. & 180 \\
Gazaperas de Fierro & Unid. & 12 \\
Jaba Transportadora & Unid. & 74 \\
Carretilla & Unid. & 129 \\
Fumigadora & Unid. & 99 \\
Reproductores & Unid. & 35 \\
Personal técnico & Mes & 1000 \\
Profesional & Mes & 3000 \\
Servicios & Mes & 95 \\
Botas & Par & 24.9 \\
Guantes & Par & 6.5 \\
Pala & Unid & 27.91 \\
\hline
\end{tabular}


Tabla 98

Descripción Recursos para Proceso de Crianza

\section{Descripción $\quad$ Figura}

\section{Jaulas para engorde}

Se realizara la compra de jaulas de engorde 03 pisos albergando cada uno de ellos la cantidad de 15 animales teniendo un total de 45 cuyes por jaula esta estará confeccionado de madera y malla como se muestra en la figura adjunta

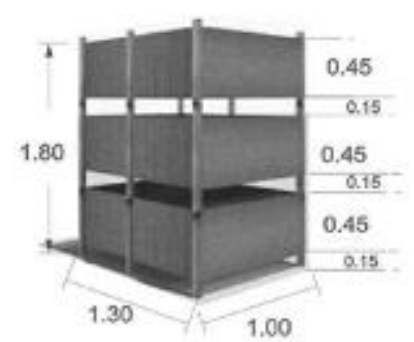

\section{Gazapera de fierro}

Este equipo evita que las crías recién nacidas sean aplastadas por los reproductores

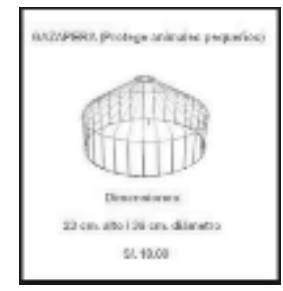

\section{Jaba transportadora de plástico}

Estas se utilizaran para transportar a las crías a la zona de engorde con una capacidad de 30 cuyes

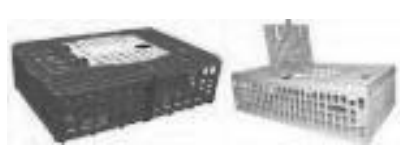

\section{Carretilla}

Herramienta que servirá para el retiro de excremento de las pozas instaladas

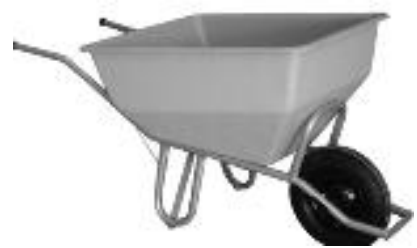




\section{Descripción}

\section{Fumigadora}

Equipo necesario para la fumigación del galpón de crianza y engorde

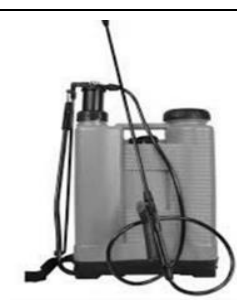

\section{Reproductores}

Según la clasificación tipo pelaje

\section{Tipo 1}

Según Instituto nacional de Investigación Agraria INIA estos animales se caracterizan por tener el pelo corto y lacio

Presenta como máximo un remolino

Están presente en más del 90\% de granjas comerciales

Mejor comportamiento en producción de carne

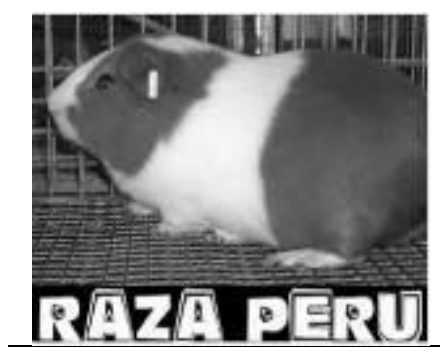

\section{Clasificación por raza}

Se seleccionó la raza mi Perú de Línea Mejorada

\section{Clasificación según la conformación}

Cuyes mejorados conformación enmarcada dentro de un paralepipedo clásico en las razas productoras de carne con mayor grado de desarrollo muscular de temperamento tranquilo responde eficientemente a un buen manejo y tiene buena conversión alimenticia 


\section{Pala}

Herramienta necesaria para el recojo de excretas y otros desperdicios de las pozas de crianza

\section{Personal}

Se tomaran los servicios de 03 trabajadores a razón de 1,000 los mismos que realizaran labores de limpieza de galpones, fumigación alimentación a reproductores y labores de sanidad

\section{Personal profesional zootecnista}

Profesional que estará encargado del manejo sanitario y alimentario de los animales y controles de reproducción 


\subsubsection{Proceso Sacrificio}

Para este proceso se requiere

Tabla 99

Recursos para Área de Sacrificio

\begin{tabular}{lcc}
\hline \multicolumn{1}{c}{ Descripción } & Unid. & Precio \\
& Medida & s/. \\
\hline Balanza & Unid. & 150 \\
Cuchillos & Unid. & 22 \\
Jabas & Unid. & 43.75 \\
Ganchos para oreado & Unid. & 10 \\
Tachos de desperdicio & Unid. & 52 \\
Escobas & Unid. & 10.5 \\
Guantes & Par & 0.5 \\
Buzo protector para todo tipo de trabajo & Unid & 15.9 \\
Protector Bucal & Unid. & 1 \\
Jornaleros & Día & 50 \\
Profesional & Par & 24.9 \\
Servicios & & 4169 \\
Botas & Mes & 95 \\
& & \\
\hline
\end{tabular}


Tabla 100

Descripción Recursos para Área de Sacrificio

\section{Descripción $\quad$ Figura}

\section{Balanza}

Se adquirirá balanzas para el pesado de los animales provenientes del galpón de engorde y para el peso final del empacado

\section{Cuchillo}

Herramienta necesaria para la evisceración del cuy, de acero inoxidable y para corte de carne

\section{Jabas}

Para el transporte de la carcasa oreada al área de empacado

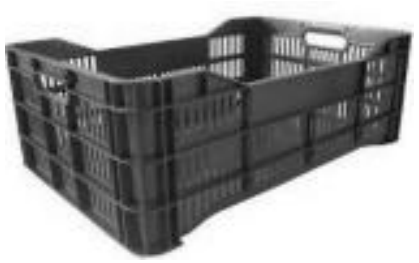

\section{Ganchos Para Oreado}

Estos ganchos serán utilizados para el oreado del producto antes de pasar al área de empacado se ha considerado ganchos de $12 \mathrm{~cm}$, de tamaño en material de acero inoxidable para evitar posibles contaminaciones 


\section{Tachos para Desperdicio}

Estos tachos cumplen la función de almacenamiento de las vísceras y pelo de los animales para su posterior disposición final

\section{Guantes}

Implemento que se utilizara para la manipulación de los animales

\section{Mandiles Blancos}

Ropa de Trabajo para evitar la contaminación de los cuyes en el proceso de sacrificio

\section{Protector Bucal}

Equipo de protección para la contaminación de los cuyes y del trabajador

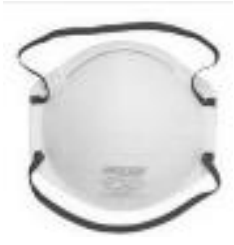

\section{Botas Blancas}

Este equipo de protección se utilizara para evitar la contaminación del ambiente de trabajo

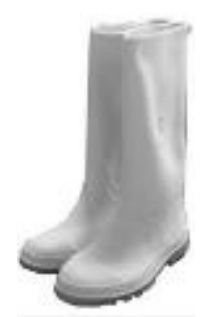

\section{Jornaleros}

El proceso de sacrificio se realizara con jornaleros los primeros 5 días de cada mes a razón de 50 soles por jornalero 


\subsubsection{Proceso de Empacado.}

El requerimiento para este proceso esta detallado en la tabla $\mathrm{N}^{\circ} 108$, que especifica la descripción, unidad de medida y precio unitario de cada artículo que será necesario en el proceso indicado, debemos tomar en cuenta que las estimaciones fueron consideradas en función de las cotizaciones realizadas a precio de mercado según los volúmenes de compra indicado.

Tabla $\mathrm{N}^{\circ} 101$

Recursos para Área de Empacado

\begin{tabular}{lcc}
\hline \multicolumn{1}{c}{ Descripción } & Unid. & Precio \\
& Medida & $\mathrm{s} /$. \\
\hline Bolsas para empaque & Unid. & 0.65 \\
Botas & Par & 24.90 \\
Guantes & Par & 6.5 \\
Buzo protector para todo tipo de trabajo & Unid & 15.90 \\
Protector Bucal & Unid. & 1 \\
Útiles de Escritorio & Varios & 1,500 \\
Escritorio & Unid. & 250 \\
Silla & Unid. & 59.9 \\
Mueble archivador & Unid. & 350 \\
Jornaleros & Día & 50 \\
Gerente & Mes & 6,093 \\
Administrador & Mes & 5,300 \\
Conductor & Mes & 1,566 \\
Vendedor & Mes & 1,566 \\
Servicios & Mes & 240 \\
Alquiler Comercial & Mes & 1,200 \\
\hline
\end{tabular}

El proceso de empacado se realizará mediante bolsas de polietileno de acuerdo a las especificaciones indicadas anteriormente, siendo descritas en la siguiente tabla: 
Tabla 102

Descripción Recursos para Área de Empacado

\section{Descripción}

\section{Figura}

\section{Bolsas para empaque al vacío}

Las bolsas ideales para empaque al vació para este tipo de producto son las que ofrecen una gran resistencia mecánica al rasgado y la punción de calibre recomendado entre 90 y 120, además de ello proporcionan una excelente barrera contra la humedad, gases y grasas y por supuesta la transparencia de los mismos que permite que el consumidor vea las características y color del producto permitiendo además la refrigeración y congelación.

\subsubsection{Tecnología}

La tecnología que se empleara en la implementación de este plan de negocios está basada en el empacado al vacío, la definición de vacío total es la presión atmosférica de 10 mbar en la tecnología de vacío total se extrae el aire del envase logrando esta presión

El empacado al vacío es un medio de conservación que constituye un avance sobre los métodos antiguos de venta de la carne desde el punto de vista microbiológico. Al adquirir carne fresca se observa que tenga la superficie un color rojo brillante. Por esta razón cuando se empaca la carne fresca al vacío se debe generar una atmosfera libre de oxígeno para retardar el actuar de las bacterias para así de esta manera conservar el color, sabor y aroma de la carne por largo tiempo, por ser un envase hermético evita la pérdida de peso ( $0 \%$ merma) 
asimismo evita que el producto se humedezca o pierda humedad evitando también el quemado por congelado facilita su almacenamiento y manipulación.

Por todo lo mencionado se adquirirá una empacadora al vacío marca Liver modelo DZ300 que garantizara las características mencionadas del producto final.

\subsubsection{Flexibilidad}

De acuerdo a Sapag (2011, P.344) se considera como los cambios que puede asumir el proyecto para hacer frente a posibles variaciones en cuanto a las condiciones del mercado.

EL presente plan de negocios contempla la adquisición total del terreno para la implementación de la planta de producción de cuy empacado al vacío, sin embargo se ha determinado que la construcciones de infraestructura de los centros de crianza y engorde conjuntamente con su implementación (jaulas y pozas), se ejecutará a medida que el proyecto vaya creciendo al igual que la instalación de pastos, la infraestructura para el proceso de sacrificio y empacado al vació se hará en su totalidad antes del inicio de la producción.

El proyecto para un posible aumento en su producción por requerimiento de sus clientes tendrá una flexibilidad para este incremento de cinco meses determinado uno por el ciclo reproductivo y de crianza de estos animales seguido por la producción de alfalfa de cuatro meses que es el tiempo que se espera para el primer corte, la construcción de infraestructura y su implementación por tener características rusticas en su arquitectura no lleva más de un mes en su implementación. Para un efecto contrario y por las características del proyecto se tiene la flexibilidad de comercializar las crías pasados los 30 días de nacimiento lo que ocasionara también se disponga del excedente de alfalfa en los mercados de la ciudad del cusco en el cual tienen mucha aceptación, Asimismo se cancelaran o 
retrasaran el incremento de las construcciones de los galpones de crianza y engorde como el alquiler de terrenos de cultivo.

\subsubsection{Selección del tamaño ideal}

El tamaño ideal para la planta proyectado hasta el año cinco, tiene la siguiente distribución

Tabla 103

Tamaño de la Planta

\section{Descripción de áreas $\quad$ Metros cuadrados}

Galpones de Reproducción $3,449.00$

Galpones de Crianza

$1,046.00$

Sacrificio y Empacado

180.00

Desechos Orgánicos

30.00

Almacén de Pastos

30.00

Pasadizos, Estacionamiento

200.00

Total

$4,935.00$

\subsection{Estudio de Localización}

Para determinar la localización para cultivos, crianza y sacrificio de estos animales se lograron identificar lugares potenciales que cumplen con los requisitos mínimos para la crianza de los mismos que se muestran en el siguiente cuadro 
Tabla 104

Localidades para la Ubicación de la Crianza de Cuyes

\begin{tabular}{lccccc}
\hline $\begin{array}{l}\text { Principales } \\
\text { Localidades }\end{array}$ & Altitud & $\begin{array}{c}\text { Disponibilidad } \\
\text { de Terreno para } \\
\text { Construcción }\end{array}$ & $\begin{array}{c}\text { Disponibilidad de } \\
\text { Terreno para } \\
\text { Cultivo }\end{array}$ & $\begin{array}{c}\text { Servicios } \\
\text { Básicos }\end{array}$ & $\begin{array}{c}\text { Distancia a } \\
\text { Cusco }\end{array}$ \\
\hline Cusco & 3,399 & Existe & No Existe & Existe & $5 \mathrm{~km}$ \\
Acomayo & 3,207 & Existe & Existe & Existe & $132 \mathrm{~km}$ \\
Anta & 3,337 & Existe & Existe & Existe & $79 \mathrm{~km}$ \\
Calca & 2,928 & Existe & No Existe & Existe & $51 \mathrm{~km}$ \\
Paruro & 3,051 & Existe & No Existe & Existe & $64 \mathrm{~km}$ \\
Paucartambo & 2,906 & Existe & No Existe & Existe & $110 \mathrm{~km}$ \\
Quispicanchi & 3,150 & Existe & Existe & Existe & $46 \mathrm{~km}$ \\
Urubamba & 2,871 & Existe & No Existe & Existe & $71 \mathrm{~km}$ \\
\hline
\end{tabular}

Del cuadro que antecede, se descartaron las Provincias de Calca y Urubamba por la falta de terrenos existentes para el cultivo de alfalfa siendo estas dos provincias productores de maíz blanco destinando su producción a la exportación y otra razón por la que se descartaron es el elevado costos de los terrenos.

Asimismo las provincias de Paruro y Paucartambo se descartaron por ser estos exclusivamente productores de papa y maíz según información de la Dirección regional de Agricultura Cusco

Las provincias más idóneas para la localización de la planta serian: 
Tabla 105

Lugares Potenciales para Localización de la Planta

\begin{tabular}{lccccc}
\hline \multicolumn{1}{c}{ Principales } & Altitud & $\begin{array}{c}\text { Disponibilidad } \\
\text { de Terreno para } \\
\text { Construcción }\end{array}$ & $\begin{array}{c}\text { Disponibilidad } \\
\text { de Terreno para } \\
\text { Cultivo }\end{array}$ & $\begin{array}{c}\text { Servicios } \\
\text { Básicos }\end{array}$ & $\begin{array}{c}\text { Distancia } \\
\text { a Cusco }\end{array}$ \\
\hline Acomayo & 3,207 & Existe & Existe & Existe & $132 \mathrm{~km}$ \\
$\begin{array}{l}\text { Anta } \\
\text { (Limatambo) }\end{array}$ & 3,337 & Existe & Existe & Existe & $79 \mathrm{~km}$ \\
Quispicanchi & 3,150 & Existe & Existe & Existe & $46 \mathrm{~km}$ \\
\hline
\end{tabular}

\subsubsection{Descripción de Lugares Potenciales}

\subsubsection{Provincia de Acomayo.}

\section{-Ubicación:}

Parte Central y oriental del departamento del Cusco con una extensión de $948.22 \mathrm{Km}$ cuadrados.

\section{-Relieve ecológico:}

Es accidentado presenta pequeños y profundos valles y una gran meseta donde se identifican las zonas ecológicas Quechua y Suni y sub dividida de la siguiente manera (clasificación Vidal Pulgar).

\section{-Quechua bajo}

Ubicada entre los 2,400 a 3,000 msnm. Clima templado con presencia de quebradas predomina el cultivo del maíz y frutales donde las tierras son mayormente con riego propicio para la crianza de animales. 


\section{-Quechua alta}

Comprendida entre los 3,000 a 3,500 msnm. Clima variado formada por laderas poco profundas de suelos delgados predomina el cultivo de papa, maíz, habas, trigo. etc. La producción ganadera de esta región está referida a ganado vacuno, equinos, caprino alpacas

\section{-Suni bajo}

Entre los 3,500 a 3,700 msnm clima frio con presencia de extensas mesetas pampas y llanuras predominan los cultivos de Mashua, quinua, haba y tarwi

\section{-Suni alto}

Oscila entre los 3,700 a 4,500 msnm clima frio se caracteriza por tener terrenos con pendientes profundas su producción más importante son las tuberosas con presencia de ganadería a pequeña escala

\section{-Clima}

La Ciudad de Acomayo presenta una temperatura medio anual de $13^{\circ} \mathrm{C}$ siendo los meses de mayo y junio que registran menores temperaturas

\subsubsection{Provincia de Anta (Limatambo).}

-Ubicación: Ubicada en el departamento del Cusco

-Relieve y ecología: Se observa el relieve

\section{-Yunga}

Esta región se encuentra comprendida en parte del distrito de Limatambo con valle profundos y cálidos donde prosperan cultivos de tomate, frijol, maíz amarillo duro dedicado a 
la crianza de animales menores como pollos, cuyes pavos con temperaturas que van desde los $16^{\circ}$ hasta $\operatorname{los} 20^{\circ} \mathrm{C}$

\section{-Quechua}

Comprende la llamada pampa de anta y valles interandinos llegando al límite de los 3500 msnm donde se realizan cultivos de papa, trigo cebada etc. Y tiene una ganadería complementaria

\section{-Suni}

Está por encima de los 3,500 m.n.s.m. con topografía irregular de laderas, quebradas y planicies donde se realizan cultivos de papa, trigo, cebada

\section{-Clima}

La temperatura promedio anuales de entre $11^{\circ}$ a $13^{\circ} \mathrm{C}$.

\subsection{Provincia de Quispicanchi.}

-Ubicación La provincia de Quispicanchi está situada al sur del Cusco

-Relieve y Ecología La provincia de Quispicanchi, abarca región sierra el 64\%, ceja de selva $32.5 \%$ y selva $3.5 \%$ según Vidal Pulgar lo clasifico

\section{-Región Omagua o Selva Baja}

Con una altitud de 200 a 600 msnm región netamente selva con temperaturas por encima de $\operatorname{los} 21^{\circ} \mathrm{c}$ 


\section{-Región Rupa Rupa}

Se ubica entre los 500 a 2,000 m.s.n.m. su relieve es muy variado muy rico para la explotación de madera castaña y productos propios de la región

\section{-Piso de valle}

Ubicado entre los 3,400 a 3,650 m.s.n.m. siendo esta zona apta para el desarrollo agropecuario y crianza de animales como

\section{-Puna o Baja}

Se halla entre los 3,650 a 4,000 m.s.n.m. presenta pendientes profundas y una topografía accidentada ideal para los cultivos de papa, quinua, cebada y crianza de animales vacunos y ovinos criollos

\section{-Clima}

De clima variado oscila entre los $13.6^{\circ}$ a $15.5^{\circ} \mathrm{C}$.

\subsubsection{Definición de factores de localización.}

Los factores para la localización de la planta se disgregaron en dos

\section{Factores cuantitativos}

\section{- $\quad$ Disponibilidad de terrenos de cultivo}

Es de suma importancia contar cerca al centro de producción con la disponibilidad de terrenos de cultivo para la producción de alfalfa con el cual se evitara el costo del transporte, mermas y marchites precoz, teniendo a la mano durante todo el año este alimento para los animales 


\section{- Distancia a centro de comercialización}

Es necesario que el centro de producción se encuentre cerca de la zona de comercialización del producto lo cual evitara costos de flete y tiempo de transporte

\section{- Mano de obra}

Esta deberá ser calificada según las labores y requerimientos de cada área teniendo experiencia básica y habilidades y con estructura salarial acorde al mercado

\section{- $\quad$ Disponibilidad de servicios agua, luz, telecomunicaciones}

Se evaluara la disponibilidad de contar con servicios de Luz, agua, desagüé, internet y comunicaciones en el área de producción durante las 24 horas

\section{- $\quad$ Precio de terreno}

Se evaluara el precio del metro cuadrado de terreno y alquiler de los mismos para la instalación de alfalfa

\section{Factores cualitativos}

\section{- Clima}

El hábitat de estos animales ha sido la sierra andina teniendo como requerimiento temperaturas que oscilen entre $\operatorname{los} 16^{\circ}$ a $18^{\circ} \mathrm{C}$.

\footnotetext{
Humedad

El grado de humedad para la crianza de cuy debe estar por debajo del $60 \%$
} 


\section{- Vías y accesos}

El centro de producción deberá tener acceso directo a las vías de comunicación terrestre para el fluido tránsito a los centros de expendio de nuestro producto

\section{$-\quad$ Terreno}

Deberá contar con una superficie plana, y con el área suficiencia para la instalación del centro de producción

\subsubsection{Consideraciones legales.}

Para el presente plan de negocio se tomará en cuenta normas que están relacionadas con aspectos de fomento y reactivación del sector agrario, reglamentos sanitarios, aspectos de calidad y certificaciones los cuales garanticen que el proyecto reúna todos los requerimientos por los órganos reguladores que intervienen directamente en nuestro proceso productivo.

De la misma manera se tomara en cuenta la ley de sociedades que nos ayude a organizar de mejor manera el ordenamiento jurídico de la empresa.

También será de gran apoyo tomar en cuenta la Ley de Micro y Pequeña empresa para realizar el dimensionar la empresa y saber a qué marco normativo poder acogerse.

\subsubsection{Identificación del Marco Legal.}

Como ya se mencionó el presente Plan de negocios está amparado en distintas leyes que estas directamente relacionados con aspectos que impactan en la producción, calidad, sanidad, certificaciones y leyes que coadyuvan a la promoción de la micro y pequeña empresa, es así que en este orden de ideas se ha considerado las siguientes normas que ayudarán a la consecución de proyecto: 
- Ley 29003, ley que modifica la conformación de los consejos regionales de concertación agraria para la reactivación del Sector Agropecuario promulgado el 19 de abril del 2007.

- Ley 28062, ley que promueve "Desarrollo y Fortalecimiento de Organizaciones Agrarias" las cuales pueden ser públicas o privadas promulgada el 22 de agosto del 2003.

- Reglamento Sanitario del Faenado de animales de Abasto, que es dictada por el SENASA Decreto Supremo n ${ }^{015-2012-A G ~ p r o m u l g a d o ~ e l ~ n u e v e ~ d e ~ n o v i e m b r e ~ d e l ~} 2012$.

- Normas Técnicas Peruanas del Ministerio de Agricultura

- Procesos implantados por el Instituto Nacional de Calidad (INACAL)

- Ley de Promoción de la competitividad, formalización y desarrollo de la micro y pequeña empresa, Ley $\mathrm{n}^{\circ} 28015$ modificatoria del artículo tres promulgada 27 de junio del 2008.

- $\quad$ Ley General de Sociedades n 26887 aprobada el cinco de diciembre de 1997.

\subsubsection{2 . Ordenamiento Jurídico de la Empresa.}

Se propone como nombre para la empresa el de Industrias Alimentarias del Sur SAC, cuyo objeto social es la de crianza, producción, beneficiado, comercialización, venta, compra, importación y exportación de todo tipo de animales y productos cárnicos, así como todo producto relacionado con esta actividad.

Estará constituida como una Sociedad Anónima Cerrada, que contará con un gerente general el cual podrá tomar las decisiones que sean necesarias para el buen funcionamiento de la empresa, podrá realizar las mismas funciones de la gerencia general en ausencia de este esto permitirá agilizar la toma de decisiones; además contará con un gerente comercial que tendrá funciones orientadas a generar nuevas alternativas de comercializar los productos que la empresa produzca de la misma forma podrá asumir las funciones del gerente general cuando este no esté presente, 
El capital estará conformado por acciones nominativas y será determinado por el aporte de los accionistas. Todas las acciones tendrán igual valor nominal, en cifras enteras (sin fracciones).

\subsection{Determinación de la Localización Óptima}

Para la determinación de esta actividad se empleó el método cualitativo por puntos que consiste en la asignación de pesos a los factores cualitativos y cuantitativos asignándoles una puntuación de importancia a cada lugar potencial que multiplicado por el peso nos determina la ponderación de este factor

Tabla 106

Método Cualitativo por Puntos

\begin{tabular}{lrrrrrrr}
\hline \multirow{2}{*}{ FACTORES } & \multirow{3}{*}{ PESO } & \multicolumn{2}{c}{ ACOMAYO } & \multicolumn{3}{c}{ ANTA } & \multicolumn{3}{c}{ QUISPICANCHI } \\
& & Punt. & Pond. & Punt. & Pond. & Punt. & Pond. \\
\hline Disponibilidad Terrenos de Cultivo & $15 \%$ & 3 & 0.45 & 4 & 0.6 & 2 & 0.3 \\
Distancia a Centro de Comercializacion & $11 \%$ & 1 & 0.11 & 3 & 0.33 & 3 & 0.33 \\
Mano de Obra & $5 \%$ & 3 & 0.15 & 3 & 0.15 & 3 & 0.15 \\
Disponibilidad de Servicios & $8 \%$ & 3 & 0.24 & 3 & 0.24 & 3 & 0.24 \\
Precio terrenos & $11 \%$ & 3 & 0.33 & 3 & 0.33 & 2 & 0.22 \\
Clima & $10 \%$ & 3 & 0.3 & 4 & 0.4 & 2 & 0.2 \\
Humedad & $10 \%$ & & 0 & 4 & 0.4 & 2 & 0.2 \\
Vias de Acceso & $10 \%$ & 3 & 0.3 & 3 & 0.3 & 3 & 0.3 \\
Terrenos & $15 \%$ & 3 & 0.45 & 3 & 0.45 & 3 & 0.45 \\
Seguridad y Marco Legal & $5 \%$ & 4 & 0.2 & 4 & 0.2 & 4 & 0.2 \\
Totales & $100 \%$ & & 2.53 & & 3.40 & & 2.59 \\
\hline
\end{tabular}

Según al resultado de cuadro de localización el mayor puntaje lo obtuvo la provincia de Anta (Limatambo) con 3.40\% sobre los otros dos es necesario indicar que esta distrito cumple con la mayoría de los factores cualitativos y cuantitativos ideales para la instalación de nuestro centro de producción y empacado al vacío. (Ver anexo 10) 


\section{Capítulo VI: Aspectos Organizacionales}

\subsection{Caracterización de la cultura organizacional deseada.}

La cultura organizacional, según lo define Robins (2013) representa las expresiones utilizadas para designar un determinado concepto de experiencias, hábitos, costumbres creencias y valores que caracteriza a la organización

Bajo ese entender se definió los lineamientos generales que deberán ser implementados y cumplidos dentro de la organización a fin de garantizar el resultado final como un producto apropiado que cumpla con las normas requeridas.

\subsubsection{Visión.}

La visión, según David (2013, p. 10) redacta una declaración, la cual responde a la pregunta ¿en que nos queremos convertir? O ¿Qué queremos ser?, recomienda considerar formular esta declaración como un primer paso para la determinación de las acciones a seguir y cumplir en el desarrollo de los proceso que involucre el proyecto y se direccione en satisfacer las necesidades de todos sus interesados.

Según Thompson y Strickland (2013), “el simple hecho de establecer con claridad lo que está haciendo el día de hoy no dice nada del futuro de la compañía, ni incorpora el sentido de un cambio necesario y de una dirección a largo plazo". (p. 113) En la tabla 113 se indica la descripción ideal a la cual el proyecto enfocará sus operaciones a fin de alcanzar estos objetivos en coherencia y orden. 
Tabla 107

Características y Descripción para Formular la Visión.

Característica Descripción

Visualizable Todas las personas de la organización deben tener una imagen mental de cómo estará la empresa en el futuro.

Deseable Debe generar motivación e interés en las personas que participaran del proyecto.

Alcanzable Debe contar con objetivos realistas y alcanzables.

Enfocada Debe ser clara y específica a fin que sirva de guía en la toma de decisiones.

Flexible Debe permitir el uso de criterio por parte de los participantes.

Comunicable Debe ser fácil de transmitir y explicar.

Nota: Adaptado de "Administración en teoría - visión estratégica para una empresa" por Janet Monica Thompson Baldivieso, 2009.

Bajo los criterios en que se formula el presente plan de negocios, se determinó que el proyecto debe cumplir con alcanzar la siguiente visión:

“Lograr ser la empresa especializada en la producción de productos cárnicos local con el producto de más alta calidad y mayor valor nutricional garantizado, con un alta reputación comercial". 


\subsubsection{Misión.}

Como lo define David (2013 p. 49) "la misión es un pronunciamiento de actitudes y perspectivas", por ello es que como describe el alcance que se asignará es amplio, debido a que cumplirá dos importantes razones:

a. Permitirá la generación y consideración de una variedad de estrategias y objetivos alternativos factibles, sin que la creatividad de la dirección se vea excesivamente reprimida.

b. Cumplirá con ser lo suficientemente amplia como para conciliar eficazmente entre las partes involucradas y grupos de interés participantes.

La misión comprenderá los siguientes nueve componentes característicos establecidos, los cuales están resumidos en la tabla 114 que especifica cada componente y su descripción, los cuales detallan cada uno de los factores que se involucrará para cumplir con los intereses de cada uno de los miembros intervinientes de la cadena productiva. 
Tabla 108

Características y Descripción para Formular la Misión

\begin{tabular}{ll}
\hline \multicolumn{1}{c}{ Componente } & \multicolumn{1}{c}{ Descripción } \\
\hline Clientes & $\begin{array}{l}\text { Satisfacción las necesidades de nuestro cliente } \\
\text { objetivo. }\end{array}$ \\
Producto & $\begin{array}{l}\text { Elaboración de un alimento garantizado apto para } \\
\text { el consumo humano. }\end{array}$ \\
& $\begin{array}{l}\text { En la Región Cusco, no existe un competidor } \\
\text { directo con las características del producto que } \\
\text { ofrece el presente plan }\end{array}$ \\
Mercado & $\begin{array}{l}\text { Diseño de procesos adecuados y equipamiento } \\
\text { apropiado. }\end{array}$ \\
Tecnología & Crecimiento con solides financiera. \\
Sostenibilidad y rentabilidad & Respeto a los valores sociales y tradicionales. \\
Filosofía & Producto innovador y de calidad certificada. \\
Valor agregado (auto & Repesáoslos de las preocupaciones sociales y \\
concepto) & ambientales. \\
Interesados & Valoración del trabajo del equipo. \\
Colaboradores &
\end{tabular}

Todos los procesos y tecnologías aplicadas en el desarrollo del producto por parte de la propuesta de plan de negocio estarán enfocados a cumplir con la siguiente misión:

“Abastecer al mercado local de un producto de alta calidad y garantía nutricional en base de un producto representativo que identifique nuestra historia y cultura".

El alcance que obtendrá está definido por los cuatro macro procesos que conforman el ciclo de producción del producto (Producción de pastos, crianza y reproducción, sacrificio y beneficio y empacado y comercialización) que permiten garantizar el cumplimiento de la misión establecida y así lograr la visión indicada anteriormente para el proyecto. 


\subsubsection{Principios.}

Conforme a lo descrito por D’alessio (2013) los principios, definidos como el conjunto de normas, creencias, y valores que orientan a la empresa y regulan su vida organizacional, son el soporte de la visión, la misión, las estrategias y los objetivos a alcanzar.

Cada uno de los procesos que forma el ciclo productivo cumplirá con los siguientes principios básicos que determinan los lineamientos a seguir para obtener el producto final.

- Cumplir con los procesos diseñados en cada uno de los niveles dentro del ciclo productivo.

- Mantener los niveles calidad indicados para la obtención del producto final esperado.

- $\quad$ No utilizar sustitutos que reemplacen los insumos identificados para la nutrición de cada uno de los animales a criar.

- Cumplir con los estándares diseñados para la obtención del producto esperado de forma permanente.

- Cumplir con los pedidos y despachos de manera puntual y coordinada con los clientes y proveedores.

\subsection{Formulación de estrategias del negocio}

De acuerdo a la Real Academia de la Lengua Española (RAE) se define una estrategia como "un proceso regulable, conjunto de reglas que aseguran una decisión optima en cada momento". Así entendiendo esta definición como lo indica David (2011) siendo una disciplina para coordinar acciones y recursos para conseguir los objetivos y la visión planteada, se proponen las siguientes estrategias del negocio: 
- Contar con una cadena de suministro integral en relación a los proveedores, que dote de todos los recursos necesarios para operar oportunamente a fin de garantizar el cumplimiento de los plazos y tiempos programados.

- Realizar supervisiones periódicas a cada macro proceso a fin de garantizar la calidad de estos procesos y asegurar que el producto final cumpla con todas las condiciones exigidas por los clientes.

- Generar reposiciones oportunas en cuanto a padres y madres reproductoras dentro de los tiempos programados.

- Contar con instrumental apropiado para garantizar la sanidad en el proceso de eviscerado y empacado de acuerdo a las condiciones indicadas.

\subsection{Determinación de las ventajas competitivas críticas}

Los factores críticos de éxito en los que se determinó que el proyecto podrá aprovechar como ventajas competitivas son los descritos en el tabla 115, donde se observa que al potenciar progresivamente cada uno de ellos se logrará superar a los que presenta la competencia directa por el valor agregado con el que se cuenta, siendo estos: 
Tabla 109

Ventajas Competitivas Críticas.

\begin{tabular}{llll}
\hline Factores críticos para el éxito & Ponderación & \multicolumn{2}{c}{ Proyecto } \\
& & Calificación & Puntuación \\
\hline Capacidad instalada & $15 \%$ & 3 & 0.45 \\
Tecnología y equipamiento & $15 \%$ & 4 & 0.60 \\
$\begin{array}{l}\text { Estandarización y calidad del } \\
\text { producto }\end{array}$ & $12 \%$ & 4 & 0.48 \\
Ubicación & $9 \%$ & 3 & 0.27 \\
Infraestructura & $9 \%$ & 3 & 0.27 \\
Estructura orgánica & $8 \%$ & 3 & 0.24 \\
Participación de mercado & $8 \%$ & 1 & 0.08 \\
Estrategias de comercialización & $7 \%$ & 4 & 0.28 \\
Competitividad de precios & $7 \%$ & 1 & 0.07 \\
Apoyo técnico & $5 \%$ & 1 & 0.05 \\
Administración & $5 \%$ & 4 & 0.20 \\
TOTAL & $100 \%$ & & 2.99 \\
\hline
\end{tabular}

\subsection{Diseño de la estructura organizacional deseada}

Para la definición de los puesto y asignación de responsabilidades específicas requeridas para cada macro proceso, se elaboró un organigrama funcional de acuerdo a los criterios definidos por Chiavenato (2015), quien define a la estructura orgánica formal según los criterios de división del trabajo, autoridad y responsabilidad así como la delegación de funciones unidad de mando, jerarquía, tramo de control, líneas de comunicación y equidad en la carga laboral. 


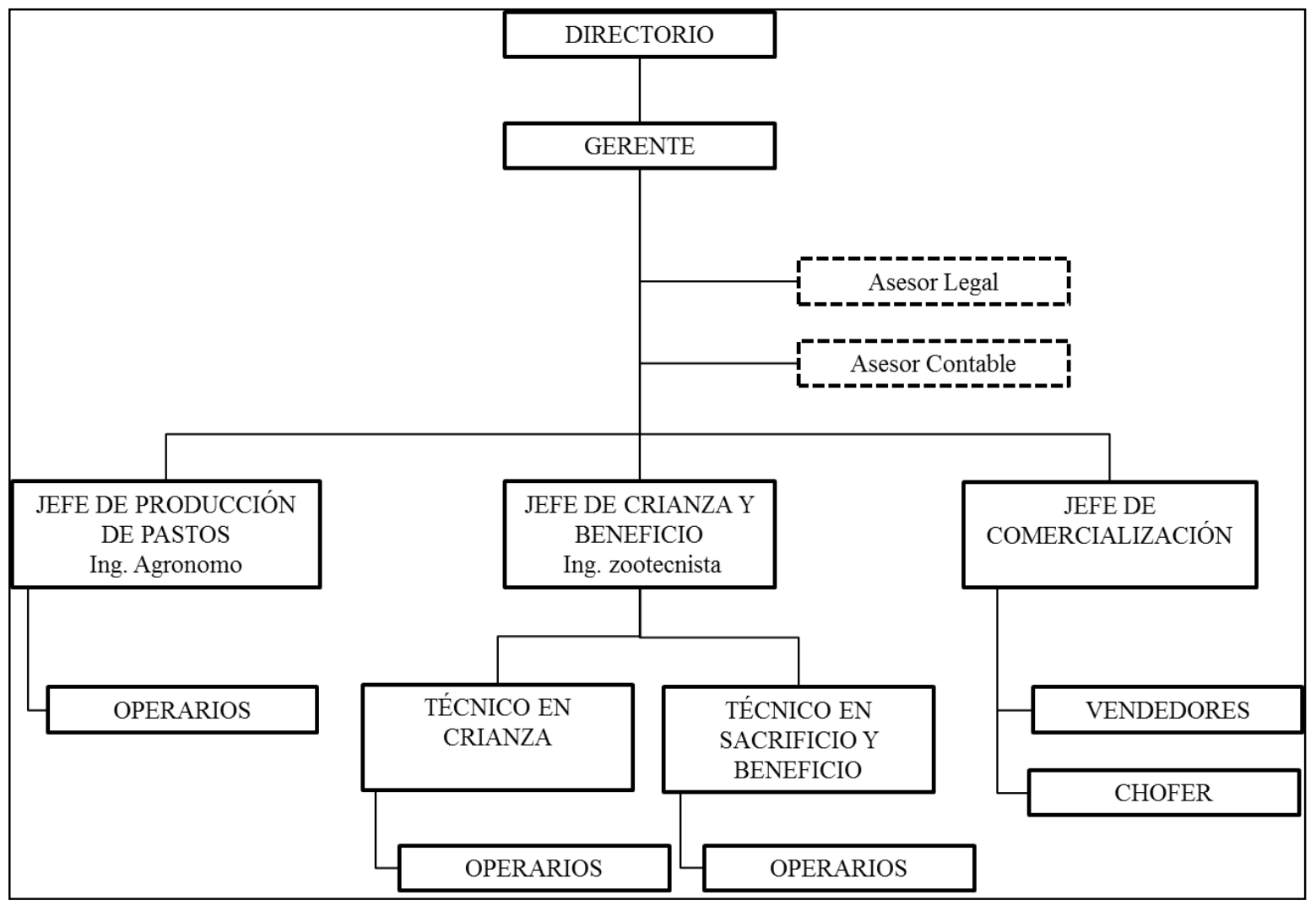

Figura 62. Estructura orgánica propuestas.

De acuerdo a los procesos identificados y conforme a las especificaciones de cada ciclo productivo y los requerimientos de conocimientos técnicos exigidos, la estructura orgánica identificada en la figura 19 refleja de manera funcional para cada proceso a cumplir según sus responsables y líneas de comunicación:

\subsection{Diseño de los perfiles de puestos clave}

Según Alles (2009) para el análisis de descripción de puestos (job description) se hace uso de formularios que contienen el título del puesto, resumen del puesto, relaciones y responsabilidades del puesto.

Los puestos claves deberán cumplir con las funciones específicas asignadas, siendo estos los siguientes: 


\section{- Gerente}

\section{Resumen.}

Será el responsable directo de la gestión integral para el funcionamiento y desempeño de todos los procesos bajo el cumplimiento de todas las directivas aprobadas por la junta de propietarios.

El perfil del puesto requiere de contar con estudios de administración, economía, ingeniería industrial o carreras afines, contar con título profesional y experiencia mayor a un año en el cargo.

\section{Responsabilidades.}

- Desarrollar el proceso administrativo integral de la empresa corroborando el cumplimiento de la normativa vigente aprobada por la junta de propietarios.

- Informar a la junta de propietarios de manera permanente sobre el logro de los resultados de manera periódica.

- Representar a la empresa ante proveedores, clientes y demás interesados con la finalidad de cumplir con las funciones asignadas.

- Firmar y contratar en representación de la junta de propietarios actos comerciales relacionados al desempeño comercial de la empresa.

- Otras que la junta de propietarios le asigne.

\section{- Asesor Contable}

\section{Resumen.}

Será responsable de la consultoría a la empresa en materia contable y tributaria, siendo el requerimiento de estos servicios de manera esporádica no se requiere 
disponer de un personal encargado de esta área de manera permanente en la empresa, por lo que se contratará los servicios de un contador público colegiado encargado de estas funciones.

El perfil del puesto requiere de un profesional independiente en contabilidad con colegiatura vigente y experiencia mayor a tres años en las funciones de asesoría contable.

\section{Responsabilidades.}

- Mantener los libros y registros contables al día con las operaciones realizadas.

- Declarar los estados financieros de la empresa de manera puntual y conforme los requerimientos de la SUNAT lo exija.

- Elaborar la planilla de remuneraciones de manera mensual y declarar los respectivos tributos y aportes del empleador conforme lo establece el ministerio de trabajo.

- Otras que sean encargadas por los organicismos supervisores y la junta de propietarios.

\section{- Asesor Legal}

\section{Resumen.}

Será responsable de la consultoría a la empresa en materia de temas legales, siendo el requerimiento de estos servicios de manera esporádica no se requiere disponer de un personal encargado de esta área de manera permanente en la empresa, por lo que se contratará los servicios de un contador público colegiado encargado de estas funciones. 
El perfil del puesto requiere de un profesional independiente en derecho con especialización en derecho comercial, civil y tributario y experiencia mayor a 05 años en el ejercicio de la abogacía.

\section{Responsabilidades.}

- Asesorar a la administración en temas legales que se presenten para el normal desarrollo de las actividades comerciales.

- Emitir opinión sobre temas de materia legal como apoyo a la gestión comercial que la Administración realice.

- Revisar, elaborar y modificar los contratos comerciales o laborales de acuerdo a los requerimientos que tenga la empresa, con la finalidad de ser suscritos por la empresa por medio de su representante legal.

- Otras que la junta de propietarios le asigne.

\section{- Ingeniero Agrónomo}

\section{Resumen.}

Será el responsable de cumplir con los procesos en materia de producción de alimento a base de pastos y productos naturales para los cuyes, el perfil del puesto exige de un profesional con experiencia y especialidad en el sembrío y cosecha de pastos de la variedad requerida para cumplir con las condiciones de alimentación requeridas para la obtención del producto final.

El perfil del puesto exige de un profesional en estudios de agronomía con habilitación vigente por el colegio de ingenieros del Perú, cuya experiencia laboral supere los dos años en el puesto. 


\section{Responsabilidades.}

- Elaborar el plan de producción de pastos mensual a fin de cubrir con los requerimientos de alimento necesario de manera permanente y eficiente.

- Supervisar las labores de los operarios encargados para garantizar la obtención de los productos alimenticios a requerimiento de las disposiciones exigidas por la administración.

- Informar sobre el estado de los terrenos y riesgos externos, conforme estos se presenten.

\section{Relaciones.}

Comunicación directa con los responsables de otras áreas operativas de manera horizontal y bajo supervisión del gerente general. Ejercerá supervisión sobre los operarios.

\section{- Ingeniero Zootecnista}

\section{Resumen.}

Será el encargado de cumplir con el proceso de cría, reproducción y sacrificio de cuyes siendo responsable de la correcta ganancia de peso en los plazos indicados para su posterior empacado y puesto en comercialización.

El perfil del puesto requiere de un profesional en zootecnia con habilitación vigente del colegio de ingenieros del Perú y presentar experiencia mayor a dos años en el puesto.

\section{Responsabilidades.}

- Elaborar el plan de producción de carne de cuy de manera mensual a fin de cubrir los lotes de producción requeridos. 
- Garantizar correcto cumplimiento del proceso productivo, velando por el cumplimiento de los estándares nutricionales exigidos.

- Elaborar los requerimientos de sanidad conforme a las situaciones lo exija.

- Informar sobre los requerimientos de mantenimiento de equipos y renovación de este conforme lo exija el proceso productivo.

- Supervisar las labores de los operarios en las diferentes etapas de producción a fin de garantizar el cumplimiento de los estándares exigidos por la empresa.

- Otras que la junta de propietarios le exija.

\section{Relaciones.}

Comunicación directa con los responsables de otras áreas operativas de manera horizontal y bajo supervisión del gerente general. Ejercerá supervisión sobre los técnicos de crianza y sacrificio.

\section{- Técnico en Crianza}

\section{Resumen.}

Será el responsable de garantizar que se cumplan los plazos de reproducción y apareamiento de los animales antes de pasar a beneficio, el perfil exige un personal técnico con amplia experiencia en la cría y conocimiento de las razas diversas que este animal presenta.

El perfil del puesto requiere de un bachiller en zootecnia experiencia no indispensable.

\section{Responsabilidades.}

- Desarrollar el proceso de cría y reproducción de este animal a fin de garantizar el lote de producción óptimo dentro de los plazos requeridos. 
- Supervisar la genética apropiada para un correcto apareamiento entre especímenes.

- Clasificar los especímenes de acuerdo a la edad, peso y sexo a fin de cumplir con los requerimientos exigidos para cubrir los lotes de producción esperados.

- Supervisar el desarrollo sanitario de y nutricional de los especímenes a fin de cumplir con los requerimientos nutricionales exigidos.

- Otras que la administración o la junta de propietarios le asigne.

\section{Relaciones.}

Comunicación directa vertical con el ingeniero Zootecnista. Ejercerá supervisión sobre los operarios.

\section{- Técnico en Sacrificio y Beneficio}

\section{Resumen.}

Será el responsable de cumplir con los procesos de sacrificio y empacado de los especímenes para la posterior comercialización, garantizando mediante un correcto desarrollo del proceso el empacado al vacío y puesta en comercialización del producto terminado.

El perfil requiere de un personal técnico especializado en técnicas de sacrificio y empacado así como conocedor de métodos de seguridad e higiene industrial.

\section{Responsabilidades.}

- Desarrollar el proceso de sacrificio cumpliendo con los procedimientos y técnicas apropiadas para garantizar la entrega de un producto terminado de calidad.

- Supervisar la labor de los operarios a fin de garantizar se cumplan con los procesos y exigencias requeridas para garantizar la entrega de un producto de calidad certificada. 
- Garantizar la higiene de los proceso de sacrificio.

- Garantizar la seguridad de los operarios en cada proceso.

- Velar por el cumplimiento de los requerimientos en cuanto a calidad exige el correcto empacado al vacío del producto final.

- Otras que la administración y la junta de propietarios le exija.

\section{Relaciones.}

Comunicación directa con el ingeniero zootecnista. Ejercerá supervisión sobre los operarios.

\section{- Operarios}

\section{Resumen.}

Serán los responsables de cumplir con el desarrollo operativo del proceso productivo en general dentro de la línea de producción específica asignada.

\section{Responsabilidades.}

- Cumplir con los procedimientos diseñados para el desarrollo de las actividades asignadas.

- Cumplir con el horario laboral de manera obligatoria a fin de garantizar el cumplimiento de os plazos de producción esperados.

- Cumplir con las normas de seguridad e higiene industrial requeridas en todos los procesos de producción desarrollados.

- Otros que la administración, junta de propietarios y personal de ingeniería les asignen. 


\section{Relaciones.}

Comunicación directa con los técnicos responsables de las áreas operativas de manera vertical.

\section{- Jefe de comercialización}

\section{Resumen.}

Encargado de coordinar las acciones de distribución y promoción del producto a los diferentes clientes y futuros clientes.

El perfil del puesto requiere de un profesional en carreras de administración de empresas, contabilidad,, economía, ingeniería industrial o carreras afines, con experiencia mayor a tres años en el cargo.

\section{Responsabilidades.}

- Elaborar el plan de ventas y promoción del producto en función del lote de producción determinado.

- Supervisar las acciones del equipo de ventas para la optimización de las ventas según el volumen de producción.

\section{Relaciones.}

Comunicación directa con los responsables de otras áreas operativas de manera horizontal y bajo supervisión del gerente general. Ejercerá supervisión sobre los vendedores.

\subsection{Remuneraciones y compensaciones}

Las partidas remunerativas serán establecidas de acuerdo a los presupuestos requeridos para el cumplimiento de los objetivos planteados a fin de satisfacer los lotes de producción esperados. 
La tabla 110 detalla la asignación de personal con las partidas remunerativas que deberá asignarse a cada trabajador a fin de cumplir con los requerimientos exigidos:

Tabla 110

Asignación de Remuneraciones y Compensaciones.

\begin{tabular}{|c|c|c|c|c|}
\hline $\mathrm{N}^{\circ}$ & Puesto & $\begin{array}{l}\text { Cantidad } \\
\text { Requerida }\end{array}$ & $\begin{array}{l}\text { Sueldo Básico } \\
\text { Unit. Mensual }\end{array}$ & $\begin{array}{l}\text { Costo Total } \\
\text { Anual }\end{array}$ \\
\hline 1 & Gerente & 1 & S/. 3,500.00 & S/. $\quad 49,000$ \\
\hline 2 & Ingeniero Agrónomo & 1 & S/. 2,000.00 & S/. $\quad 28,000$ \\
\hline 3 & Ingeniero Zootecnista & 1 & S/. 2,000.00 & S/. $\quad 28,000$ \\
\hline 4 & Técnico en Crianza & 1 & S/. 1,500.00 & S/. $\quad 21,000$ \\
\hline 5 & Técnico en Sacrificio & 1 & S/. $1,500.00$ & S/. $\quad 21,000$ \\
\hline 6 & Operarios & 7 & S/. $1,000.00$ & S/. $\quad 14,000$ \\
\hline 7 & Vendedores & 5 & S/. $1,500.00$ & S/. $\quad 21,000$ \\
\hline 8 & Chofer & 1 & S/. 750.00 & S/. $\quad 10,500$ \\
\hline 9 & Jefe de comercialización & 1 & S/. 2,000 & S/. 28,000 \\
\hline \multicolumn{2}{|c|}{ TOTAL } & 19 & $\mathrm{~S} / .24,250.00$ & $\mathrm{~S} / . \mathbf{3 3 9 , 5 0 0}$ \\
\hline
\end{tabular}

\subsection{Políticas de Recursos Humanos}

Las políticas laborales se consideraran dentro de las exigidas en la ley $\mathrm{N}^{\circ} 28381$ ley general del trabajo, la cual contempla todos los límites indicados en cuanto a jornada laboral, políticas de remuneraciones y compensaciones así como incentivos dentro de la ley de competitividad laboral.

Así mismo se identifican políticas contempladas dentro de la regulación exigida en cuanto a seguridad y salud en el trabajo conforme a la ley $\mathrm{N}^{\circ} 29783$. 
Estableciéndose los siguientes lineamientos generales de acuerdo al marco legal respectivo:

- La jornada laboral de todos los trabajadores contempla un total de 48 horas semanales, las mismas que serán distribuidas en turnos rotativos de acuerdo a los requerimientos de producción.

- El pago de remuneraciones será fijado el último día hábil de cada mes siempre y cuando sea un día laborable, el mismo que será abonado a la cuenta de remuneraciones que el trabajador indique.

- Todos los trabajadores tendrán derecho a 30 días de goce de vacaciones remuneradas una vez cumplidos el primer año de servicios las cuales serán programadas en función de un calendario de vacaciones.

- El personal a destajo recibirá una remuneración en efectivo al final de la jornada diaria de trabajo.

- El personal encargado del proceso de sacrificio deberá cumplir con los lineamientos requeridos para el correcto uso de instrumental necesario así como cumplir con las políticas de seguridad de la empresa.

- Se restringe el uso de alcohol y drogas dentro de la jornada de trabajo.

- La manipulación de objetos punzo cortantes deberá ser sujeta a las normas de seguridad laboral. 


\section{Capítulo VII: Plan de Marketing}

\subsection{Estrategias de Marketing}

Una de las estrategias a emplear para el presente plan de negocios será la de diferenciación la cual está orientada a brindar un servicio de calidad, estrategia que permitirá captar el porcentaje de mercado objetivo propuesto, para el logro de esto, se resaltaran los atributos y beneficios que tiene el producto y que en la actualidad no se encuentra en el mercado de la región del Cusco, siendo además uno de los objetivos que el público consumidor note y distinga las características del producto que están enmarcadas en la propuesta de valor de “ contar con un producto ecológico, de calidad, con carne tierna y que preste las garantías de salubridad".

Además de tener un producto el cual se diferencie del que actualmente se oferta en el mercado de la región del Cusco se empleara una estrategia de Penetración de Mercado, estrategia que nos permitirá incrementar la participación de la empresa en la región del Cusco con el propósito de atraer a los clientes de la competencia y a los clientes potenciales. Para el desarrollo de esta estrategia nos apoyaremos en la estrategia de empuje la cual es definida por Kotler y Armstrong como aquella que impulsa el producto a través de los canales distributivos, se aplicará esta estrategia con el fin de convertir la carne de cuy en un producto de consumo masivo.

También, se utilizará una estrategia de precios con el objetivo del segmento de mercado esperado, para esto se tendrá un precio competitivo, el cual permitirá captar de manera rápida un porcentaje del mercado objetivo, con esto los consumidores podrán percibir un producto de calidad con un precio diferenciado que actualmente no existe en el mercado regional. 


\subsubsection{Estrategia de Producto.}

El producto a ofrecer al cliente final ha de ser un producto de calidad que esté listo para su preparación, con lo que se evitará las molestias que habitualmente se tiene, tales como pelar, eviscerar, lavar; producto que, a través del proceso que se realizara, garantizara la higiene, fácil manejo y conservación por un periodo de 30 días refrigerado sin que la carne se descomponga u oxide.

Para esto se presentará el producto empacado al vacío en una envoltura de polivinilideno o pvdc, que en el interior no contendrá absolutamente nada de oxigeno (empacado al vacío) lo que garantizará la conservación del producto. En la parte superior del empaque se colocara una etiqueta que contendrá: El logotipo, la marca así como una breve descripción del valor nutricional de la carne de Cuy resaltando que el consumo de esta carne ayuda a la prevención del cáncer por contener Asparginasa, encima que actúa sobre tumores deteniendo el crecimiento de estos, peso del producto y edad (mes en el cual se hizo el sacrificio del animal 90 días).

En la inferior indicará la fecha de proceso y la fecha de vencimiento del producto, precio y un código de barra, un valor agregado que se le dará es el de anexar una receta para preparar un plato a base de cuy.(ver anexo 11)

\subsubsection{Estrategia de Precio.}

El precio del producto estará acorde a lo ofertado en el mercado, empleando el criterio de Fijación de precios basada en la competencia de límite superior, en este sentido actualmente se tiene un precio de venta de 25 a 30 soles en el mercado, hay que mencionar que este precio es competitivo en comparación al mercado informal que actualmente existe en la región. 
Sin embargo con el propósito de ganar participación de mercado de manera rápida se lanzará un precio de introducción de 25 soles, el cual permitirá posicionar a Industrias Alimentarias del Sur SAC no solo por diferenciación de producto sino por precio el cual será percibido por el mercado objetivo que se quiere ganar. Además de lograr una participación y posicionamiento en el mercado de la región de Cusco también se obligará a los potenciales competidores a bajar sus precios, tratar de mejorar su presentación; con esto sus márgenes bajaran por no tener el volumen de producción que tendrá Alimentos del Sur, no posibilitándoles continuar en el negocio, puesto que el cliente final percibirá la diferencia entre el producto propuesto por Industrias Alimentarias del Sur SAC. con el que actualmente existe en el mercado.

\subsubsection{Estrategia de distribución.}

En este sentido, Kotler y Armstrong (2012) señalaron que el canal directo no tiene niveles de intermediarios, la compañía vende directamente a los consumidores. Y para efecto del presente plan de negocios la empresa realizará la distribución del cuy ecológico empacado al vacío por un canal de marketing directo a través de una distribución masiva en mercados, bodegas, restaurantes tradicionales, especializados y turísticos, impulsado por una fuerza de venta de tres personas encargadas de la promoción, prospección y distribución del producto.

Paralelo a esta estrategia se contará con una tienda ubicada en inmediaciones del mercado de San Pedro principal centro de abastaos de Cusco, es importante contar con un punto de venta en esta zona debido a la gran concentración de clientes que requieren carne de cuy. Al contar con una tienda la cual preste las garantías de salubridad y calidad requeridas por los clientes y que este en la plaza donde interactúan todos los ofertantes y demandantes brinda a Industrias Alimentarias del Sur SAC una oportunidad de captar parte del mercado que requiere carne de cuy. (ver anexo 12) 


\subsubsection{Estrategia de promoción y publicidad.}

La estrategia de promoción que se empleará será través de la estrategia de empuje, considerando que se realizará en los distintos canales, para esto recurriremos a la fuerza de venta y promociones comerciales como ya se había mencionado en el punto 7.1.

En este sentido y tomando en cuenta a Kotler y Armstrong definiremos las herramientas que nos ayudaran a la promoción del producto:

- Venta personal; a través de una fuerza de venta se logrará la interacción directa con el público objetivo (dueños de restaurantes tradicionales, turísticos y público en general), el propósito es de lograr una mayor flexibilidad, atención personalizada y sobretodo fidelización con los clientes, si bien es cierto esta estrategia conlleva un costo de venta se ha analizado que es necesaria para lograr un posicionamiento efectivo del producto.

- Promoción de ventas, como se mencionó se plantea tener un precio de introducción el cual permitirá ganar a la empresa una porción del mercado y posicionar de manera rápida el producto, además se realizará acciones que incentiven la venta como visitas guiadas a las instalaciones de la planta donde se criará, sacrificará y envasará el producto a los principales dueños y administradores de restaurantes tradicionales y turísticos con el propósito de incrementar los ingresos de la empresa, entiéndase además que las promociones que se realizaran serán esporádicas y en épocas donde sea necesario garantizar los volúmenes de venta óptimos para cubrir los costos de producción, ventas y financieros así como la obtención de la utilidad esperada. Empero estas promociones no necesariamente impactaran en el precio de venta, también existen herramientas como el merchandicing, impulsadoras de degustación que ayudaran a incentivar la venta. 
La publicidad que se realizará será a través de Redes sociales, página web, volantes los cuales se detalla:

Facebook (Red social), a través de la creación de un fanpage, se difundirá los beneficios de nuestro producto, recetas a base de la carne de cuy y promociones logrando tener una comunicación directa con el público objetivo, considerando que el Facebook se está convirtiendo en un canal alternativo de promoción y ventas que bien gestionado ayuda promocionar y publicitar a la empresa.

Página Web de la empresa, se plantea una página web la cual ayudará a tener un canal de comunicación directo con los clientes, también permitirá consultar información relevante de la empresa, de los productos y servicios que se ofrece y trato directo con los clientes, permitiendo realizar pedidos en línea

Volantes, en estos se consignará información relevante de nuestro producto como valor nutritivo, dirección de la tienda, celulares de contacto y promociones que se tenga, estos volantes se distribuirán en lugares de alto transito aledaños a mercados de abasto, restaurantes, principales calles de la ciudad y provincias.

\subsection{Estrategia de ventas}

La estrategia de ventas se desarrollará de acuerdo a la proyección que se determinó a través del estudio de mercado realizado en el capítulo tres, el cual ha dado un mercado objetivo de 3151 personas, tres restaurantes turísticos y un restaurante tradicionales para el primer año de operación, que estará atendido por un vendedor que se concentrará en los restaurantes tanto tradicionales y turísticos, mientras que otro vendedor atenderá los principales mercados de abasto, plaza donde acuden las familias cusqueñas a comprar, y un tercero que atenderá en la 
tienda que se ubicará en inmediaciones del mercado de San Pedro donde atenderemos también al público en general.

\subsubsection{Plan de ventas.}

De acuerdo a las estimaciones realizadas y considerando la frecuencia de compra y consumo que se tiene, información obtenida del estudio de mercado realizado de los tres segmentos que se atenderá se ha determinado el siguiente plan de ventas para un horizonte de cinco:

Tabla 111

Plan de Ventas Proyectada para un Periodo de Cinco Años

\begin{tabular}{lrrrrr}
\hline \multirow{1}{*}{ Segmentos } & \multicolumn{5}{c}{ Años } \\
\cline { 2 - 6 } & 2017 & 2018 & 2019 & 2020 & 2021 \\
& Mensual & Mensual & Mensual & Mensual & \multicolumn{1}{c}{ Mensual } \\
\hline Público en general & 5,247 & 5,922 & 6,636 & 7,389 & 8,182 \\
Tradicionales & 843 & 1,686 & 1,686 & 2,529 & 3,371 \\
Turísticos & 205 & 273 & 342 & 410 & 547 \\
Total & 6,295 & 7,881 & 8,664 & 10,328 & 12,100 \\
\hline
\end{tabular}

De los resultados se tienen que el año 2017 se obtendrá una venta mensual de 6,295 cuyes, cantidad que se logrará a través de las estrategias planteadas para posicionar el producto, para los siguientes años con un producto ya posicionado se plantea un crecimiento del $1 \%$ para al final del proyecto se logre vender un promedio de 12,100 cuyes de manera mensual. 


\subsubsection{Políticas de servicios y garantías.}

Se implantará como política de servicio, la de establecer una relación de confianza con los clientes con los que garantizamos su fidelización, es así que se logrará la diferenciación con los posibles competidores mediante las siguientes acciones:

- Satisfacción del cliente, información oportuna, y control; garantizando el compromiso que la empresa tendrá mediante el cumplimiento de tiempos, servicios y sobretodo los estándares de calidad y salubridad exigidos para este negocio.

- Atención Personalizada, un trato personalizado con información oportuna y resolución de dudas y problemas garantizara la lealtad de los clientes.

Las garantías que se emplearan serán los permisos y registros exigidos para el expendio de alimentos de primera necesidad en este sentido el producto deben de contar con un registro sanitario expendido por el ministerio de Salud que esté acorde a las normas vigentes.

Otra medida es que todo el personal tiene que usar un vestuario adecuado que garantice una adecuada manipulación de los productos. 


\section{Capítulo VIII: Planificación Financiera}

\subsection{La Inversión}

El proyecto, al representar un esfuerzo a largo plazo, como lo define Hernandez, (2005), representa la salida considerable de dinero con la finalidad de obtener una ganancia futura. Así de acuerdo a los cálculos obtenidos para la estimación de las inversiones se identificaron las inversiones pre operativo con un periodo de nueve meses y las inversiones futuras en cinco años, los cuales están determinados por las cotizaciones realizadas en activos necesarios para la puesta en marcha y operatividad de los cuatro macro procesos que conforman el proyecto.

\subsubsection{Inversión pre operativa.}

De acuerdo con Sapag Chain (2011) "la mayoría de inversiones de un proyecto se concentra en aquellas que se deben realizar antes del inicio de la operación” (p. 180) por lo que de acuerdo a los requerimientos de cada macro proceso se procedió con las cotizaciones de cada detalle a incluir en esta etapa.

La inversión requerida para la etapa de implementación está definida por las asignaciones de salidas de dinero requeridas en la etapa de adquisición, implementación y acondicionamiento de cada uno de los procesos identificados en el presente plan de negocios de acuerdo a los tiempos estimados en producción, crianza y comercialización. 
La siguiente figura nos muestra el cronograma de inversión pre operativo:

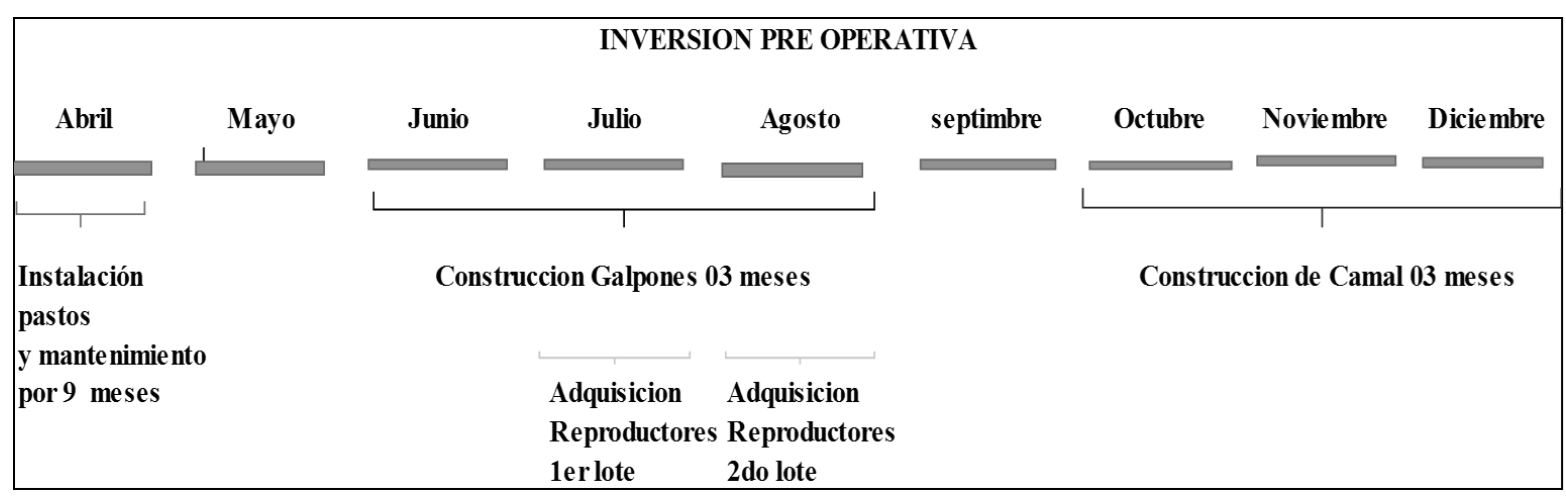

Figura 63: Programa de inversiones etapa pre operativa.

La inversión pre operativa estará conformada por los activos fijos, capital de trabajo y activos intangibles tal como se detallan en las siguientes tablas:

Tabla 112

Inversiones Pre Operativa Activo Fijo.

\begin{tabular}{lrr}
\hline \multicolumn{1}{c}{ Inversión Pre Operativa Activo fijo } & & \multicolumn{1}{c}{ S/. } \\
\hline Proceso de pastos & S/. & $6,726.00$ \\
Proceso de crianza & S/. & $451,798.00$ \\
Proceso de sacrificio & S/. & $114,619.00$ \\
Proceso de empacado y comercialización & S/. & $14,584.00$ \\
\hline Total Activo Fijo & S/. & $587,727.00$ \\
\hline
\end{tabular}

El activo fijo está determinado por la adquisición de todos los equipos, maquinarias, edificaciones y terrenos para los procesos que indica la tabla 112 para mayor detalle (ver anexos números $14,15,16,17)$ 


\subsubsection{Determinación del capital de trabajo.}

El capital de Trabajo son los recursos que requiere la empresa para desarrollar sus operaciones económicas. En ese sentido, el Capital de Trabajo viene a ser la diferencia existente entre los activos corrientes totales y los pasivos corrientes totales de la empresa. Tabla 113

Inversión Pre Operativa Capital de Trabajo.

\begin{tabular}{|c|c|c|c|c|c|c|}
\hline \multicolumn{7}{|c|}{ Cálculo de Capital de Trabajo (Metodo de MDA, Expresado en Nuevos Soles sin IGV) } \\
\hline & Mes 1 & Mes 2 & Mes 3 & Mes 4 & Mes 5 & Mes 6 \\
\hline Cuy evicerado empacado al vacio - & 5,351 & 5,351 & 5,351 & 5,351 & 5,351 & 5,351 \\
\hline Cuy evicerado empacado al vacio - & 20.50 & 20.50 & 20.50 & 20.50 & 20.50 & 20.50 \\
\hline Cuy evicerado empacado al vacio - & 109,696 & 109,696 & 109,696 & 109,696 & 109,696 & 109,696 \\
\hline Ingresos Totales Anuales & 109,696 & 109,696 & 109,696 & 109,696 & 109,696 & 109,696 \\
\hline \multicolumn{7}{|l|}{ Costos de Producción } \\
\hline Costos producción de pastos & 67,076 & 28,901 & 16,761 & 16,761 & 16,761 & 16,761 \\
\hline Costos de Producción Crianza y re] & 19,318 & 18,361 & 18,361 & 18,361 & 18,361 & 18,361 \\
\hline Costos de Producción Sacrificio y $€$ & 7,595 & 7,595 & 7,595 & 7,595 & 7,595 & 7,595 \\
\hline Costos de Producción Empacado & 6,343 & 6,343 & 6,343 & 6,343 & 6,343 & 6,343 \\
\hline Gastos administrativos & 5,892 & 5,892 & 5,892 & 5,892 & 5,892 & 5,892 \\
\hline Gastos de venta & 9,462 & 9,462 & 9,462 & 9,462 & 9,462 & 9,462 \\
\hline Egresos Totales & 115,686 & 76,554 & 64,414 & 64,414 & 64,414 & 64,414 \\
\hline Flujo Mensual (Ingresos - Egresos) & $-5,990$ & 33,141 & 45,281 & 45,281 & 45,281 & 45,281 \\
\hline Flujo Acumulado & $-5,990$ & 27,151 & 72,433 & 117,714 & 162,996 & 208,277 \\
\hline \multicolumn{7}{|c|}{ Variación del Capital de Trabajo - Expresado en Nuevos soles sin IGV } \\
\hline Año & Año 0 & Año 1 & Año 2 & Año 3 & Año 4 & Año 5 \\
\hline Ingresos & & $1,367,716$ & $1,711,242$ & $1,890,872$ & $2,246,678$ & $2,570,687$ \\
\hline Variación ingresos & & & $30.00 \%$ & $14.63 \%$ & $18.83 \%$ & $14.52 \%$ \\
\hline Capital de trabajo total & & $-5,990$ & $-7,787$ & $-8,926$ & $-10,607$ & $-12,147$ \\
\hline Capital de trabajo & $-5,990$ & $-1,797$ & $-1,139$ & $-1,681$ & $-1,540$ & \\
\hline
\end{tabular}


Tabla 114

Inversión Pre Operativa Activo Intangible

\begin{tabular}{|c|c|c|}
\hline DETALLE & CANT. & VALOR \\
\hline \multicolumn{3}{|l|}{ Constitución Empresa } \\
\hline Elaboracion de Minuta & 1 & $S / .1,271$ \\
\hline Inscripción registros públicos & 1 & $S / .59$ \\
\hline Escritura pública & 1 & $\mathrm{~S} / .110$ \\
\hline Registro de marca & 1 & $\mathrm{~S} / .297$ \\
\hline Licencia municipal e INDECI, Construccion y E & 1 & $\begin{array}{c}S / .1,525 \\
S / .0\end{array}$ \\
\hline Impresión boletas, facturas y guias & 1 & $\begin{array}{c}S / .233 \\
S / .0\end{array}$ \\
\hline Estudio plan de negocio & 1 & $S / .4,237$ \\
\hline Publicación en "El Peruano" & 1 & $S / .24$ \\
\hline \multicolumn{3}{|l|}{ Marketing Pre Operativo } \\
\hline Campaña de publicidad y difusión & 1 & $\mathrm{~S} / .3,390$ \\
\hline Diseño logo y etiqueta & 1 & $\mathrm{~S} / .492$ \\
\hline Publicidad exterior (volantes, letreros, etc.) & 1 & $S / .3,000$ \\
\hline \multicolumn{3}{|l|}{ Proceso de prod. de pastos } \\
\hline Alquiler terreno 5 ha. & 1 & $S / .6,356$ \\
\hline Semilla 5 siembras & 1 & $S / .4,100$ \\
\hline Abonos y adherentes 5 siembras & 1 & $\mathrm{~S} / .2,927$ \\
\hline Conocimiento actividades técnicas & 1 & $\mathrm{~S} / .9,963$ \\
\hline Conocimiento actividades productivas agricola & 1 & $S / .14,760$ \\
\hline Alquiler de tractor 5 ha & 1 & $S / .1,804$ \\
\hline Gasolina & 1 & $\mathrm{~S} / .126$ \\
\hline \multicolumn{3}{|l|}{ Proceso de prod. de crianza y reproducción } \\
\hline Conocimiento de actividades Tecnicas & 1 & $\mathrm{~S} / .12,300$ \\
\hline Conocimiento de actividades Pecuarias & 1 & $S / .12,300$ \\
\hline Luz & 1 & $\mathrm{~S} / .205$ \\
\hline Agua & 1 & $\mathrm{~S} / .185$ \\
\hline \multirow[t]{2}{*}{ Productos veterinarios } & 1 & $\mathrm{~S} / .16,327$ \\
\hline & TOTAL & $S / .95,991$ \\
\hline
\end{tabular}

Se incluyen como parte de la inversión pre operativo los costos de inversión intangible que representan las partidas asignadas a los gastos por servicios, derechos y licencias para implementación del proyecto, conocimiento de actividades técnicas agrícolas, pecuarias. 


\subsubsection{Costo inversión del proyecto.}

Como lo define Sapag Chain, (2011), son aquellas que deben de realizarse antes del inicio del proyecto se denomina calendario de inversiones previas a la puesta en marcha caracterizados por incluir todos los desembolsos anteriores

Tabla 115

Costos del Proyecto.

\begin{tabular}{|c|c|c|c|c|c|c|c|c|c|}
\hline \multicolumn{10}{|c|}{ Calendarizacion de Inversiones Pre Operativas S/. } \\
\hline Proceso & Mes 1 & Mes 2 & Mes 3 & Mes 4 & Mes 5 & Mes 6 & Mes 7 & Mes 8 & Mes 9 \\
\hline Pastos & & & & 6,726 & & & & & \\
\hline Crianza & 58,435 & & 77,973 & 60,260 & 115,120 & 115,120 & & 24,890 & \\
\hline Sacrificio & & & & & & & 114,619 & & \\
\hline Empacado & & & & & & & & 14,584 & \\
\hline TOTAL & 58,435 & & 77,973 & 66,986 & 115,120 & 115,120 & 114,619 & 39,474 & \\
\hline
\end{tabular}

En el proceso de pastos se considera la adquisición de una motoneta, el proceso de crianzas la compra del total de terrenos y construcción de infraestructura para reproductores y crianza, así como semovientes reproductores de igual manera para el proceso de sacrificio consideramos el desembolso para la construcción del camal y finalmente para el proceso de empacado la adquisición de empacadoras, conservadoras, exhibidoras y equipo de cómputo.

\subsubsection{Inversiones futuras.}

Las inversiones futuras, como lo define Pérez y Merino (2009) representa todos costos de implementación y acondicionamiento necesarios en un horizonte definido dentro del periodo de evaluación del proyecto, estos implican el re acondicionamiento de estructuras, reposición de activos fijos y la ampliación de capacidad instalada del proyecto de acuerdo a la necesidad de incremento de producción en cada etapa del proyecto.

Para ello es que se ha definido, dentro de cada macro proceso, la estimación necesaria de inversiones futuras a realizar según los requerimientos de producción programados en 
cada periodo de evaluación definido, detallándose en la tabla 116 que describe el importe necesario para el desarrollo de operaciones conforme sean estos requeridos.

Tabla 116

Flujo de Inversiones Proyectado por Años.

\begin{tabular}{|c|c|c|c|c|c|c|c|c|c|c|}
\hline Inversiones Futuras & & & & 02 & & 3 & & 104 & & \\
\hline Pastos & S/. & 6,102 & $\mathrm{~S} /$. & 6,102 & S/. & 6,102 & S/. & - & S/. & - \\
\hline Crianza y Reproduccion & S/. & - & $\mathrm{S} /$ & 19,646 & S/. & 9,682 & S/. & 20,586 & S/. & 21,949 \\
\hline Sacrificio & & & & & & & & & & \\
\hline Empacado y Comercializacion & & & & & & & & & & \\
\hline Total inversiones & S/. & 6,102 & $\mathrm{~S} /$. & 25,748 & S/. & 15,784 & S/. & 20,586 & S/. & 21,949 \\
\hline
\end{tabular}

Las inversiones futuras para el proceso de pastos este definido por la adquisición de motonetas para los años uno, dos y tres, para el proceso de crianza con la construcción de infraestructura para reproducción y crianza los años dos, tres, cuatro y cinco.

\subsection{Financiamiento comparativo de fuentes}

La estructura de financiamiento necesario para la implementación y puesta en marcha del proyecto está compuesta por la designación de recursos monetarios propios y de crédito que se destinaran al proyecto.

El proyecto demandará una inversión pre operativa por S/. 689,708. La tabla 117 nos permite conocer el movimiento económico pre-operativo (nueve meses) de los activos fijos, activos intangibles, se ha considerado cubrir estos gastos hasta el mes seis con inversión propia de S/, 522,744 que representa el 76.26\% del total de la inversión y para los tres siguientes meses un financiamiento bancario de S/. 166,964 que representa el $23.74 \%$ del total del costo pre-operativo. 
Esta decisión obedece en aprovechar tres meses de gracia que otorgan las entidades bancarias como máximo, para iniciar a pagar el financiamiento, a partir del primer mes de operaciones.

Tabla 117

Participación de Aporte.

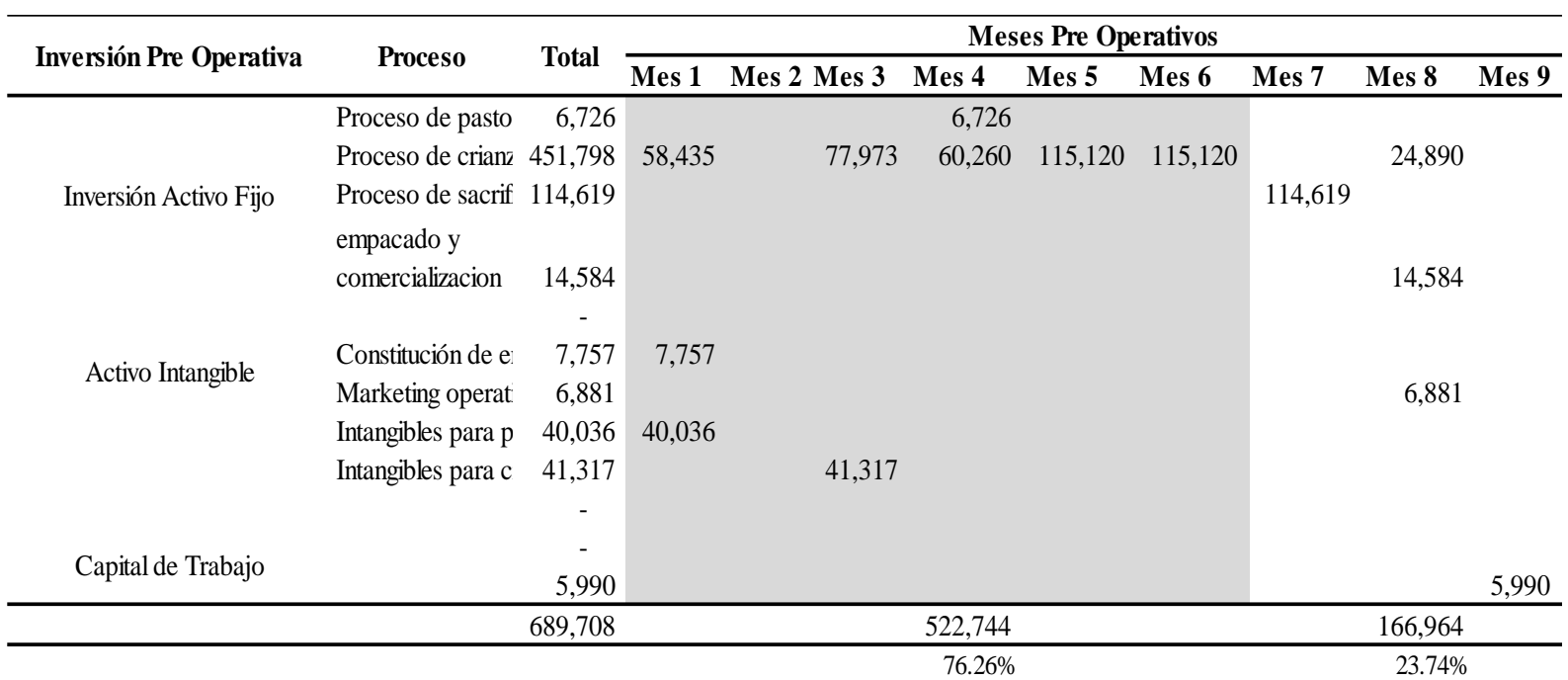

Considerando que el proyecto involucra un horizonte de evaluación proyectado por cinco años la solicitud de financiamiento requerido implica un acceso a un préstamo por ese plazo determinado.

Para lo cual se realizó una cotización referencial entre cuatro entidades bancarias a las cuales se solicitó las condiciones, requisitos y costos por el servicio de deuda de acuerdo al importe requerido según las condiciones indicadas en cuanto a plazo y monto a otorgar, obteniendo el detalle indicado en la tabla 118 donde se puede apreciar cada requerimiento. 
Tabla 118

Cotización Para Servicio de Deuda Requerido

\begin{tabular}{|c|c|c|c|}
\hline $\begin{array}{l}\text { Entidad } \\
\text { Bancaria }\end{array}$ & $\begin{array}{c}\text { TCEA } \\
\% *\end{array}$ & Valor de Cuota & Tipo de Garantía Requerida \\
\hline $\mathrm{BCP}$ & $14.38 \%$ & S/.3.974 & $\begin{array}{l}\text { 1. Real mediante constitución de } \\
\text { Hipoteca en primer rango y preferente. } \\
\text { 2. Carta fianza contra deposito por el } \\
10 \% \text { del valor del préstamo. }\end{array}$ \\
\hline Interbank & $13.98 \%$ & S/. 3,939 & $\begin{array}{l}\text { 1. Real mediante constitución de } \\
\text { Hipoteca en primer rango y preferente. } \\
\text { 2. Carta fianza por el importe del } 10 \% \\
\text { del valor del préstamo. }\end{array}$ \\
\hline Scotiabank & $16.50 \%$ & S/. 4,160 & $\begin{array}{l}\text { 1. Real mediante constitución de } \\
\text { Hipoteca en primer rango y preferente }\end{array}$ \\
\hline $\begin{array}{c}\text { BBVA } \\
\text { Continental }\end{array}$ & $12.28 \%$ & S/. 3,792 & $\begin{array}{l}\text { 1. Real mediante constitución de } \\
\text { Hipoteca en primer rango y preferente. }\end{array}$ \\
\hline
\end{tabular}

2. Estudio de factibilidad del proyecto.

Nota*: TCEA propuesta incluye costos por seguros, portes, comisiones entre otros.

De acuerdo a las estimaciones entre costos y condiciones planteadas por las entidades bancarias se optó por escoger la propuesta del BBVA Continental por ser la unida entidad bancaria que no exige una garantía colateral contra depósito para este financiamiento. 


\subsubsection{Endeudamiento y condiciones.}

En cumplimiento de las condiciones requeridas se cumple con los siguientes requisitos exigidos para el otorgamiento del préstamo indicado:

\section{Documentos de la empresa:}

- Testimonio de constitución de empresa.

- Vigencia de poderes de represéntate legal.

- Dni de cada uno de los socios integrantes de la empresa titular del proyecto.

- Perfil del proyecto.

\section{Documentos para la constitución de la garantía requerida:}

- Título de propiedad de inmueble el cual será materia de garantía del presente crédito.

- Último pago de autoevaluó.

- Informe de tasación emitido por un perito acreditado en REPEV.

Contando con la disponibilidad de estos es que se determinó la viabilidad de la inversión considerando las condiciones requeridas por la entidad bancaria, estableciendo una simulación del servicio de deuda a asumir detallado en la siguiente tabla mediante la estimación del factor de recuperación del capital: 
Tabla 119

Amortización de la Deuda por Años

\begin{tabular}{|c|c|c|c|c|c|}
\hline \multicolumn{6}{|c|}{ Cuadro Resumen de Amortización de la Deuda - Expresado en Nuevos soles } \\
\hline Periódo & Pago & Interés & Amortización & Saldo & Escudo Fiscal \\
\hline 0 & $\mathrm{~S} / .0$ & S/.4,905 & $\mathrm{S} / .0$ & S/.171,869 & $\mathrm{S} / .1,373$ \\
\hline 1 & $\mathrm{~S} / .45,502$ & S/.18,598 & $\mathrm{S} / .26,904$ & S/.144,966 & $\mathrm{S} / .5,207$ \\
\hline 2 & $\mathrm{~S} / .45,502$ & S/.15,294 & $\mathrm{S} / .30,208$ & $\mathrm{~S} / .114,758$ & $\mathrm{~S} / .4,282$ \\
\hline 3 & $\mathrm{~S} / .45,502$ & S/.11,585 & S/.33,917 & $\mathrm{S} / .80,841$ & S/.3,244 \\
\hline 4 & S/.45,502 & $\mathrm{S} / .7,420$ & $\mathrm{~S} / .38,082$ & S/.42,759 & S/.2,078 \\
\hline 5 & $\mathrm{~S} / .45,502$ & S/.2,743 & S/.42,759 & $\mathrm{S} / .0$ & S/.768 \\
\hline Total & $\mathrm{S} / .227,510$ & S/.55,640 & S/.171,869 & & S/.15,579 \\
\hline
\end{tabular}

Las condiciones de financiamiento incluyen tres meses como periodo de gracia los cuales se detallan en los (anexos nro 18, 19, 20)

\subsubsection{Capital y costo de oportunidad.}

Para determinar el costo de capital del proyecto se utilizó el método para la valoración del capital CPPC por sus siglas en inglés, el cual según Sapag (2011) se utiliza para definir el nivel de rentabilidad que obtendrá el proyecto según los indicadores de riesgo de los mercados similares. Habiendo está determinado en función de los indicadores de riesgo según el cálculo de la tasa de descuento que se obtuvo de la siguiente formula el valor de $14.98 \%$ más un aprovisionamiento de 5\% para el incremento del margen de rentabilidad obteniendo un valor de $19.98 \%$. Asimismo se realizó este cálculo en soles constantes durante el horizonte del proyecto

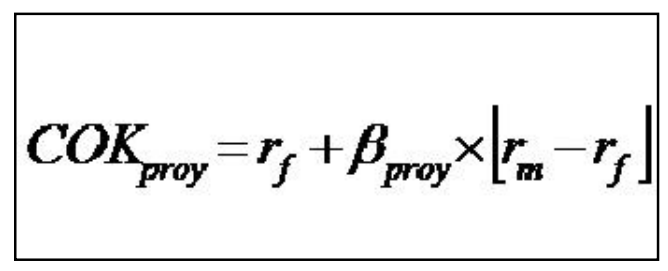


Tabla 120

Costo de Oportunidad de Capital.

\begin{tabular}{lc}
\hline \multicolumn{2}{c}{ Datos } \\
\hline Rf & $4.96 \%$ \\
Rm & $9.50 \%$ \\
Rm-Rf & $4.54 \%$ \\
Riesgo Perú & $1.52 \%$ \\
Inf. USA & $1.64 \%$ \\
Inf. Perú & $3.41 \%$ \\
Impuesto Renta & $28 \%$ \\
Deuda & $23.74 \%$ \\
Capital & $76.26 \%$ \\
\hline COK & $\mathbf{1 4 . 9 8 \%}$ \\
Prima negocio nuevo & $\mathbf{5 . 0 0 \%}$ \\
Tasa de descuento & \\
total & $\mathbf{1 9 . 9 8 \%}$ \\
\hline
\end{tabular}

$$
\begin{aligned}
& \text { COK }=4.96 \%+(1.46 \% * 4.54 \%) \\
& \text { COK }=4.96 \%+6.62 \\
& \text { COK }=11.60 \% \text { desapalancado } \\
& \text { COK proy }=\text { COK }+ \text { Inflación Perú } \\
& \text { COK proy. }=11.60 \%+3.41 \%+5 \%(\text { Negocio nuevo }) \\
& \text { COK proy }=19.98 \%
\end{aligned}
$$

Donde: 
Tabla 121

Crecimiento Promedio Geométrico

\begin{tabular}{clcc}
\hline \multicolumn{4}{c}{ Crecimiento Promedio Geometrico } \\
\hline Rango años & $\mathrm{rm}$ & $\mathrm{rf}$ & $\mathrm{rm}-\mathrm{rf}$ \\
$1928-2015$ & $9.50 \%$ & $4.96 \%$ & $4.54 \%$ \\
\hline
\end{tabular}

Nota. Tomado de http://www.damodaran.com

Tabla 122

Indicador Tasa Riesgo País Perú 2016.

\begin{tabular}{|c|c|c|c|}
\hline \multicolumn{3}{|c|}{ Tasa de Interés / Interest Rate } & \multirow[b]{2}{*}{ Date } \\
\hline $\begin{array}{c}\text { Tesoro de EUA } \\
5 \text { años / USA } \\
\text { Treasury } 5 \\
\text { years }\end{array}$ & $\begin{array}{c}\text { Tesoro de EUA } \\
10 \text { años / USA } \\
\text { Treasury } 10 \\
\text { years }\end{array}$ & $\begin{array}{c}\text { Tesoro de EUA } \\
30 \text { años / USA } \\
\text { Treasury } 30 \\
\text { years }\end{array}$ & \\
\hline$\underline{1}$ & $\underline{2}$ & $\underline{3}$ & $\underline{2016}$ \\
\hline 1.5 & 2.1 & 2.8 & Jan. \\
\hline 1.2 & 1.8 & 2.6 & Feb. \\
\hline 1.4 & 1.9 & 2.7 & Mar. \\
\hline 1.3 & 1.8 & 2.6 & Apr. \\
\hline 1.3 & 1.8 & 2.6 & May. \\
\hline 1.2 & 1.6 & 2.5 & Jun. \\
\hline 1.1 & 1.5 & 2.2 & Jul. \\
\hline 1.1 & 1.6 & 2.3 & Aug. \\
\hline 1.2 & 1.6 & 2.3 & Sep. \\
\hline 1.3 & 1.8 & 2.5 & Oct. \\
\hline 1.5 & 2.1 & 2.8 & Nov. $1-22$ \\
\hline
\end{tabular}

Nota. Tomado de Bloomberg y Reuters, indicador de tasa de riesgo país para países emergentes al 22 de noviembre del 2016. 
Tabla 123

Tasa de Inflación Estados Unidos a Octubre 2016.

\begin{tabular}{|c|c|c|c|c|c|c|}
\hline Períod & & $\begin{array}{r}\text { Tasa de } \\
\text { inflación U }\end{array}$ & & & & \\
\hline octubre 201 & & $1.636 \%$ & & & & \\
\hline septiembre & 2016 & $1,464 \%$ & & & & \\
\hline agosto 201 & & $1,063 \%$ & & & & \\
\hline julio 2016 & & $0,827 \%$ & & & & \\
\hline junio 2016 & & $0,997 \%$ & & & & \\
\hline mayo 2016 & & $1,019 \%$ & & & & \\
\hline abril 2016 & & $1,125 \%$ & & & & \\
\hline marzo 201 & & $0,853 \%$ & & & & \\
\hline febrero 20 & & $1,018 \%$ & & & & \\
\hline enero 2016 & & $1,373 \%$ & & & & \\
\hline Promedio & & $2.39 \%$ & & & & \\
\hline $\begin{array}{l}\text { Nota. Tomado } \\
\text { economicas/in }\end{array}$ & $\begin{array}{l}\text { o de Dia } \\
\text { nflacion }\end{array}$ & $\begin{array}{l}\text { Gestión http: } \\
\text { dice-de-precio }\end{array}$ & $\begin{array}{l}\text { /es.global-1 } \\
\text { s-al-consur }\end{array}$ & $\begin{array}{l}\text { tes.com/est } \\
\text { o/ipc/estad }\end{array}$ & $\begin{array}{l}\text { disticas- } \\
\text {-unidos.ast }\end{array}$ & \\
\hline Tabla 124 & & & & & & \\
\hline Tasa Inflación & n Perúf & tes Registro I & Iariación P & medio An & l de Inflac & In según $B C K$ \\
\hline Calendario & GMT & Referencia & Real & Anterior & Consenso & i xpectativa \\
\hline 01/09/2016 & 05:00 & m. Aug & $2.94 \%$ & $2.96 \%$ & $2.96 \%$ & $3 \%$ \\
\hline 01/10/2016 & 05:00 & m. Sep & $3.13 \%$ & $2.94 \%$ & & $3 \%$ \\
\hline 01/11/2016 & 05:00 & m. Oct & $3.41 \%$ & $3.13 \%$ & & $3 \%$ \\
\hline $01 / 12 / 2016$ & 05:00 & m. Nov & & $3.41 \%$ & & $3.40 \%$ \\
\hline
\end{tabular}

Nota. Boletín tasa de inflación Perú al 01 de diciembre del 2016 emitido por le BCRP. http://www.bcrp.gob.pe/estadisticas/cuadros-de-la-nota-semanal.html $B=$ Beta desapalancada del proyecto fuente Aswath Damodaran 
Tabla 125

Beta de Riesgo por Industria para Actividades "Business \% Consumer"

\begin{tabular}{|c|c|c|c|c|c|c|c|c|c|}
\hline Industry Name & $\begin{array}{c}\text { Number of } \\
\text { firms }\end{array}$ & Beta & D/E Ratio & Tax rate & $\begin{array}{c}\text { Unlevered } \\
\text { beta }\end{array}$ & $\begin{array}{c}\text { Cash/Firm } \\
\text { value }\end{array}$ & $\begin{array}{c}\text { Unlevered } \\
\text { beta } \\
\text { corrected } \\
\text { for cash }\end{array}$ & HiLo Risk & $\begin{array}{l}\text { Standard } \\
\text { deviation } \\
\text { of equity }\end{array}$ \\
\hline Advertising & 44 & 1.08 & $56.26 \%$ & $3.90 \%$ & 0.7 & $5.18 \%$ & 0.74 & 0.6415 & $71.03 \%$ \\
\hline Aerospace/Defense & 92 & 1.33 & $20.50 \%$ & $13.51 \%$ & 1.13 & $5.53 \%$ & 1.2 & 0.4706 & $46.90 \%$ \\
\hline Air Transport & 20 & 1.27 & $69.78 \%$ & $18.34 \%$ & 0.81 & $4.42 \%$ & 0.85 & 0.4583 & $51.95 \%$ \\
\hline Apparel & 63 & 1.06 & $27.86 \%$ & $13.84 \%$ & 0.85 & $3.43 \%$ & 0.88 & 0.5264 & $60.62 \%$ \\
\hline Auto \& Truck & 19 & 0.96 & $128.04 \%$ & $8.01 \%$ & 0.44 & $6.94 \%$ & 0.47 & 0.5315 & $33.71 \%$ \\
\hline Auto Parts & 65 & 1.29 & $32.91 \%$ & $9.64 \%$ & 0.99 & $8.65 \%$ & 1.08 & 0.506 & $55.06 \%$ \\
\hline Bank (Money Center) & 9 & 1.11 & $216.41 \%$ & $25.82 \%$ & 0.43 & $9.98 \%$ & 0.47 & 0.1576 & $32.77 \%$ \\
\hline Banks (Regional) & 644 & 0.51 & $78.59 \%$ & $24.11 \%$ & 0.32 & $11.86 \%$ & 0.36 & 0.1768 & $28.93 \%$ \\
\hline Beverage (Alcoholic) & 22 & 0.94 & $18.25 \%$ & $11.28 \%$ & 0.81 & $1.29 \%$ & 0.82 & 0.5431 & $58.51 \%$ \\
\hline Beverage (Soft) & 43 & 1.15 & $22.98 \%$ & $5.97 \%$ & 0.95 & $4.20 \%$ & 0.99 & 0.6125 & $54.55 \%$ \\
\hline Broadcasting & 29 & 1.29 & $94.73 \%$ & $21.20 \%$ & 0.74 & $1.90 \%$ & 0.75 & 0.4036 & $47.22 \%$ \\
\hline Brokerage \& Investment & 42 & 1.35 & $285.54 \%$ & $18.15 \%$ & 0.4 & $11.33 \%$ & 0.46 & 0.3991 & $48.05 \%$ \\
\hline Building Materials & 39 & 1.18 & $33.15 \%$ & $22.43 \%$ & 0.94 & $4.47 \%$ & 0.98 & 0.3619 & $44.27 \%$ \\
\hline Business \& Consumer Se & 159 & 1.19 & $35.33 \%$ & $13.76 \%$ & 0.91 & $4.04 \%$ & 0.95 & 0.5041 & $50.13 \%$ \\
\hline
\end{tabular}

Nota. Tomado de Last Updated in January 2016 - By Aswath Damodaran

Calculando Beta del proyecto:

Bproy. $=$ Beta despalancada $* 1+($ Aporte Financiado /Aporte Propio $) *(1-$ imp. A la Renta $)$

Bproy $=1.19 *(1+0.2374 / 0.7626) * 1-0.28$

Bproy $=1.457$

\subsubsection{Costo de capital promedio ponderado.}

De acuerdo a lo indicado por Sapag, 2011 el costo de capital está definido por el grado de certidumbre que genera el proyecto de acuerdo a las condiciones de riesgo indicadas, estas se definen de acuerdo a la tasa de riesgo establecida para la evaluación del comportamiento que presenta el mercado.

Según lo indicado por Sapag 2011 (p. 372) "El costo de capital representa la tasa de retorno exigida a la inversión realizada en un proyecto, para compensar el costo de oportunidad de los recursos destinados a él y el riesgo que deberá asumir" alcanzando un nivel de $13.53 \%$. 
WACC $=\frac{D}{D+E} \times \quad i \quad \times(1-\operatorname{tax})+\frac{E}{D+E} \times \operatorname{coK}$

Donde:

$\mathrm{D} / \mathrm{D}+\mathrm{E}=$ Participación deuda $=23.74 \%$

i: tasa de costo de deuda TCEA $=12.28 \%$

Tax: Tasa de impuesto a la renta Perú $=28 \%$

$\mathrm{E} / \mathrm{D}+\mathrm{E}=$ Participación aporte propio $=76.26 \%$

COK proy : $15 \%$

$\mathrm{WACC}=(0.2374 * 0.1228 * 0.73)+(0.7626 * 0.15)$

$\mathrm{WACC}=0.021+0.11$

$\mathrm{WACC}=0.1353$

$\mathrm{WACC}=13.53 \%$

\subsection{Presupuestos Base}

El presupuesto base del proyecto está definido por los programas de ventas, costos de producción programa de compras y costo de ventas que este incluye a través de los periodos de duración de estos, por lo que cada presupuesto se detalla a continuación.

Así mismo se detallan también los presupuestos que incluyen todos los gastos que asumirá el proyecto para la puesta en marcha y desarrollo de operaciones durante el periodo 
de vigencia de estos tales como son los gastos administrativos y de ventas, el servicio de deuda y gastos de marketing y constitución.

\subsubsection{Presupuesto de ventas.}

En el presupuesto de ventas se establecen todas las partidas que representan los ingresos de dinero por concepto de ventas del producto terminado a través de cada uno de los periodos de duración del proyecto y otros ingresos, para la determinación de estos se toma en consideración el volumen de producción estimado en función de la demanda. Del cual se considera un margen de holgura del $10 \%$ por la probabilidad de no de vender, asimismo se toma en consideración el 5\% de mortandad en la crianza Del 10\% de holgura se considera otorgar a trabajadores como bonos en carcasa o y/o la degustación en nuestra planta de crianza y transformación para pasantes de restaurantes y público en general.

De igual forma se ha visto por conveniente la comercialización de los sub productos en este caso de los reproductores que cumplieron su ciclo reproductivo (18 meses) esta venta se efectuara como cuy vivo.

Tabla 126

Programa de Ventas.

\begin{tabular}{|c|c|c|c|c|c|}
\hline Ventas & Año 1 & Año 2 & Año 3 & Año 4 & Año 5 \\
\hline Volumen de produccion $100 \%$ & 75,544 & 94,572 & 103,966 & 123,933 & 145,201 \\
\hline Margen de Holgura $10 \%$ & 7,554 & 9,457 & 10,397 & 12,393 & 14,520 \\
\hline Margen de Mortandad 5\% & 3,777 & 4,729 & 5,198 & 6,197 & 7,260 \\
\hline Volumen de comercializacion de $85 \%$ & 64,212 & 80,386 & 88,371 & 105,343 & 123,421 \\
\hline Valor de venta de S/ 20.50 sin IGV & $1,316,346$ & $1,647,917$ & $1,811,608$ & $2,159,533$ & $2,530,127$ \\
\hline \multicolumn{6}{|l|}{ Volumen de comercializacion venta } \\
\hline reproductores saca & & 5,756 & 7,206 & 7,922 & 3,688 \\
\hline Valor de venta de S/ $11 \sin$ IGV & & 63,316 & 79,266 & 87,142 & 40,568 \\
\hline $\begin{array}{l}\text { TOTAL VENTAS SIN IGV } \\
\end{array}$ & $1,316,346$ & $1,711,242$ & $1,890,872$ & $2,246,678$ & $2,570,687$ \\
\hline
\end{tabular}




\subsubsection{Presupuesto de costos de producción.}

En el presupuesto de costos de producción se establecen todos los costos que incluirá el proyecto a fin de obtener el producto propuesto con las condiciones establecidas que aseguren las cualidades descritas que demanda el mercado objetivo.

Se establecieron los costos de cada proceso: cultivo de pastos, reproducción y crianza, sacrificio, empacado y comercialización los cuales contemplan costos directos e indirectos de producción MOD. El resumen general de estos costos se puede ver en la tabla 127, y el detalle de los mismos (anexos números 21, 22, 23, 24).

Tabla 127

Estructura de Costos de Producción.

Estructura de Costos en Nuevos Soles Sin IGV.

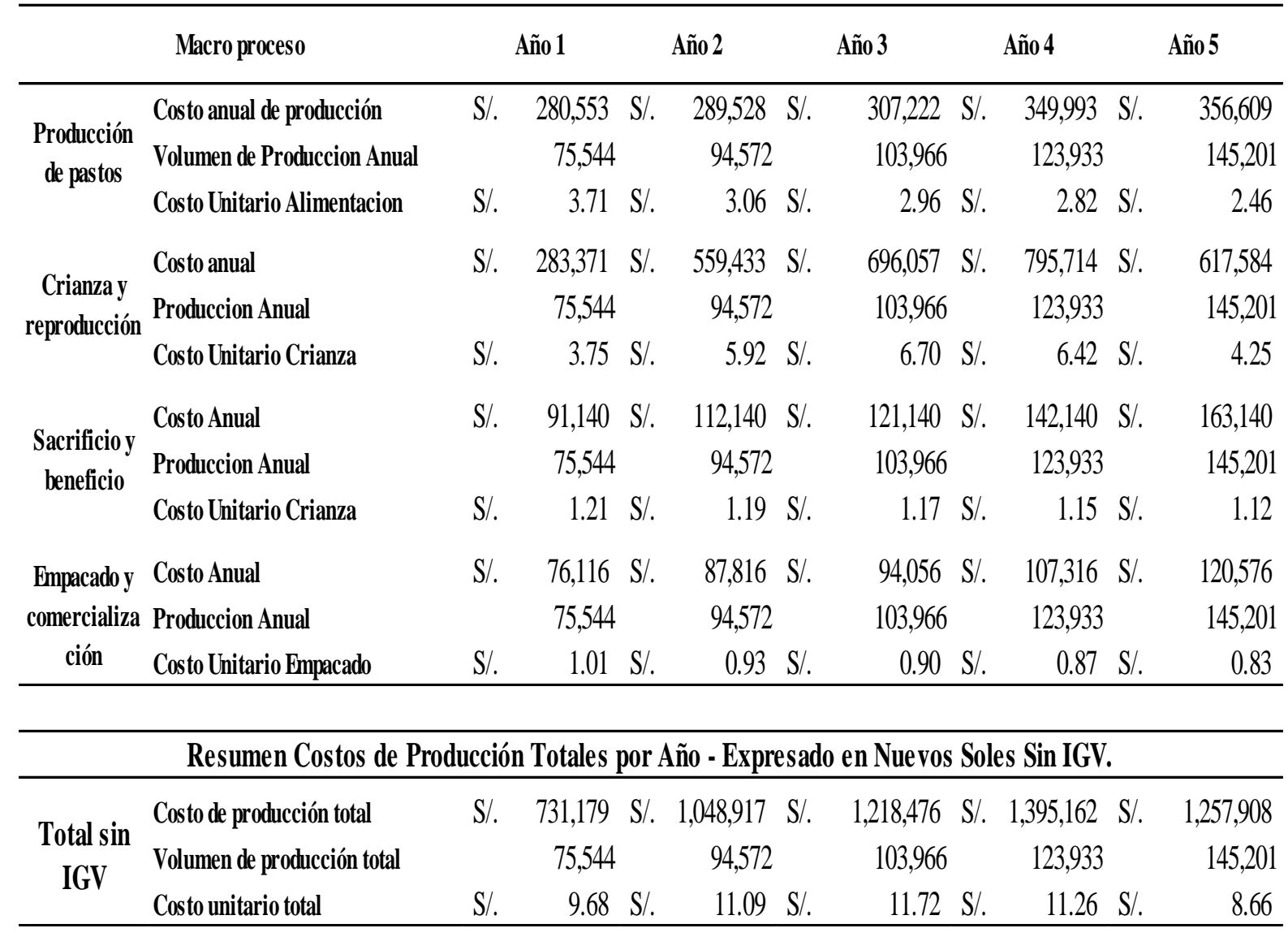




\subsubsection{Presupuesto de compras.}

El presupuesto de compras detalla las adquisiciones que se realizarán durante la duración del proyecto para cubrir los gastos varios, en los procesos ya mencionados anteriormente que se asumirán durante todo el horizonte del proyecto; así mismo se incluyen los gastos que componen las compras de materiales diversos

La tabla 128 detalla el resumen de compras por cada proceso (anexos números 21, 22, $23,24)$.

Tabla 128

Presupuesto de Compras Expresado.

\begin{tabular}{lccccc}
\hline \multicolumn{1}{c}{ Detalle } & Año 1 & Año 2 & Año 3 & Año 4 & Año 5 \\
\hline Proceso de Pastos & 67,114 & 64,744 & 62,949 & 71,774 & 71,835 \\
Proceso de Crianza y Reproduccion & 129,080 & 361,403 & 454,287 & 510,203 & 268,775 \\
proceso de Sacrificio & - & - & - & - & - \\
Proceso de Empacado y Comercializacion & 50,700 & 62,400 & 68,640 & 81,900 & 95,160 \\
Gastos de Comercializacion & 8,746 & 8,746 & 8,746 & 8,746 & 8,746 \\
Gastos de Administrativos & 3,166 & 3,166 & 3,166 & 3,166 & 3,166 \\
\hline
\end{tabular}

\subsubsection{Presupuesto de costo de ventas.}

Este presupuesto es el costo en el que se incurre para comercializar nuestro producto terminado (cuy empacado al vacío). Está determinado por la remuneración del personal encargado de las ventas, alquiler de local comercial en la ciudad del Cusco para la venta al público, combustible para el traslado del producto final de la planta de empacado al local comercial y a nuestros clientes finales.

La tabla 129, detalla las partidas indicadas dentro del proceso de comercialización. 
Tabla 129.

Presupuesto de Costo De Ventas

Gasto de Ventas (Expresado en Nuevos soles sin IGV)

\begin{tabular}{lccccc}
\hline \multicolumn{1}{c}{ Detalle } & Año 1 & Año 2 & Año 3 & Año 4 & Año 5 \\
\hline & & & & & \\
Remuneración de Ventas & S/. 90,396 & S/. 90,396 & S/. 90,396 & S/. 90,396 & S/. 90,396 \\
Alquiler de local comercial & S/. 14,400 & S/. 14,400 & S/. 14,400 & S/. 14,400 & S/. 14,400 \\
Combustible & S/. 8,746 & S/. 8,746 & S/. 8,746 & S/. 8,746 & S/. 8,746 \\
& & & & & \\
\hline TOTAL SIN IGV & S/. 113,542 & S/.113,542 & S/.113,542 & S/. 113,542 & S/. 113,542 \\
\hline
\end{tabular}

\subsubsection{Presupuesto de gastos administrativos.}

El presupuesto de gastos administrativos detalla cada partida que incluirá por concepto de remuneraciones del personal administrativo, artículos de oficina y servicios necesarios que interviene en los procesos de gestión administrativa del proyecto, durante los periodos de evaluación del proyecto, los cuales se describen en la tabla 130 para mayor detalle (anexo número 25).

Tabla 130

Gastos Administrativos.

Gastos Administrativos (Expresado en nuevos soles sin IGV)

\begin{tabular}{lccccc}
\hline \multicolumn{1}{c}{ Detalle } & Año 1 & Año 2 & Año 3 & Año 4 & Año 5 \\
\hline Remuneración administrativa & $\mathrm{S} / .58,320$ & $\mathrm{~S} / .58,320$ & $\mathrm{~S} / .58,320$ & $\mathrm{~S} / .58,320$ & $\mathrm{~S} / .58,320$ \\
Artículos de oficina & $\mathrm{S} / .3,166$ & $\mathrm{~S} / .3,166$ & $\mathrm{~S} / .3,166$ & $\mathrm{~S} / .3,166$ & $\mathrm{~S} / .3,166$ \\
Luz & $\mathrm{S} / .506$ & $\mathrm{~S} / .506$ & $\mathrm{~S} / .506$ & $\mathrm{~S} / .506$ & $\mathrm{~S} / .506$ \\
Agua & $\mathrm{S} / .203$ & $\mathrm{~S} / .203$ & $\mathrm{~S} / .203$ & $\mathrm{~S} / .203$ & $\mathrm{~S} / .203$ \\
Contador & $\mathrm{S} / .4,800$ & $\mathrm{~S} / .4,800$ & $\mathrm{~S} / .4,800$ & $\mathrm{~S} / .4,800$ & $\mathrm{~S} / .4,800$ \\
Asesor Legal & $\mathrm{S} / .2,160$ & $\mathrm{~S} / .2,160$ & $\mathrm{~S} / .2,160$ & $\mathrm{~S} / .2,160$ & $\mathrm{~S} / .2,160$ \\
Servicio de telefonía/internet & $\mathrm{S} / .1,548$ & $\mathrm{~S} / .1,548$ & $\mathrm{~S} / .1,548$ & $\mathrm{~S} / .1,548$ & $\mathrm{~S} / .1,548$ \\
TOTAL SIN IGV & $\mathrm{S} / . \mathbf{7 0 , 7 0 3}$ & $\mathrm{S} / . \mathbf{7 0 , 7 0 3}$ & $\mathrm{S} / . \mathbf{7 0 , 7 0 3}$ & $\mathrm{S} / . \mathbf{7 0 , 7 0 3}$ & S/. 70,703 \\
\hline
\end{tabular}




\subsubsection{Presupuesto de marketing y ventas.}

De acuerdo con Kotler y Armstrong (2012) el presupuesto de marketing que se aplicará fue definido como los gastos aplicables para la promoción y estudios del comportamiento del mercado y está determinado de acuerdo al método costeable para la fijación de las partidas que se asumirán para este proceso. Los conceptos por lo que se incurren en gastos son: Campaña de publicidad y difusión el mismo que servirá para pagos por servicio de red social facebook, publicidad web y elaboración de página web, anuncio en radio y diarios locales el concepto por publicidad exterior permitirá la elaboración de banner publicitarios, modelos para la impulsación de venta y merchardising.

La tabla 131 detalla los gastos que asumirá el proyecto para la promoción del producto en la etapa pre operativa.

Tabla 131

Presupuesto de Marketing

Concepto Precio Total sin IGV S/.

Campaña de publicidad y difusión

S/. 3,390

Diseño $\log$ y y etiqueta

Publicidad exterior (volantes, letreros, etc.)

\section{Total sin IGV}

S/. 6,882

\subsubsection{Presupuesto de gastos financieros.}

El presupuesto de gastos financieros detalla el importe a asumir por concepto de las obligaciones financieras que asumirá el proyecto requerido para iniciar con las pre operaciones los cuales están detallados en la tabla 132, que resume el cronograma indicado por el préstamo a obtener según las condiciones descritas que incluyen los periodos de gracia 
necesarios y los costos por intereses establecidos según cotización de financiamiento realizado.

El desembolso del financiamiento deberá realizarse a fines del sexto mes de la etapa pre operativo para iniciar los gastos de la etapa pre operativo correspondiente al mes siete.

Tabla 132

Presupuesto de Gastos Financieros.

Cuadro Resumen de Amortización de la Deuda - Expresado en Nuevos soles

\begin{tabular}{ccccccc} 
Periódo & Pago & Interés & Amortización & Saldo & Escudo Fiscal \\
\hline 0 & $\mathrm{~S} / .0$ & $\mathrm{~S} / .4,905$ & $\mathrm{~S} / .0$ & $\mathrm{~S} / .171,869$ & $\mathrm{~S} / .1,373$ \\
1 & $\mathrm{~S} / .45,502$ & $\mathrm{~S} / .18,598$ & $\mathrm{~S} / .26,904$ & $\mathrm{~S} / .144,966$ & $\mathrm{~S} / .5,207$ \\
2 & $\mathrm{~S} / .45,502$ & $\mathrm{~S} / .15,294$ & $\mathrm{~S} / .30,208$ & $\mathrm{~S} / .114,758$ & $\mathrm{~S} / .4,282$ \\
3 & $\mathrm{~S} / .45,502$ & $\mathrm{~S} / .11,585$ & $\mathrm{~S} / .33,917$ & $\mathrm{~S} / .80,841$ & $\mathrm{~S} / .3,244$ \\
4 & $\mathrm{~S} / .45,502$ & $\mathrm{~S} / .7,420$ & $\mathrm{~S} / .38,082$ & $\mathrm{~S} / .42,759$ & $\mathrm{~S} / .2,078$ \\
5 & $\mathrm{~S} / .45,502$ & $\mathrm{~S} / .2,743$ & $\mathrm{~S} / .42,759$ & $\mathrm{~S} / .0$ & $\mathrm{~S} / .768$ \\
\hline Total & $\mathrm{S} / . \mathbf{2 2 7 , 5 1 0}$ & $\mathrm{S} / . \mathbf{5 5 , 6 4 0}$ & $\mathrm{S} / . \mathbf{1 7 1 , 8 6 9}$ & & $\mathrm{S} / . \mathbf{1 5 , 5 7 9}$ \\
\hline
\end{tabular}

\subsection{Presupuestos de Resultados}

Los resultados de la planificación financiera describen los estados financieros del proyecto los cuales reflejan la situación económica y financiera del proyecto en cada uno de los periodos evaluados, al ser estos dinámicos se definen según la evaluación establecida de acuerdo a los cambios en cada uno de las cuentas detalladas.

\subsubsection{Estado de ganancias y pérdidas proyectado.}

El estado de ganancias y pérdidas, también conocido como estado de resultados, estados de ingresos y egresos o estado de rendimientos, es el informe que refleja la rentabilidad de la empresa durante un periodo de tiempo determinado.

El esquema de este estado de resultados está determinado por: 
Presupuestos de ventas información obtenida de la tabla 126.

Costo de producción información obtenida de la tabla 127.

Gasto de ventas información obtenida de la tabla 129

Presupuesto de gastos administrativos información obtenida de la tabla 130

Calculo de depreciaciones: se realizaron los cálculos de las depreciaciones de acuerdo al programa de inversiones pre operativas y futuras, según anexo 26 y, de las cuales su obtuvo los siguientes resultados para el primer año una depreciación de s/.19,038 para el segundo año s/.21,241 tercer año s/.22,945, cuarto año s/.23,975 y quito año s/. 25,072 asimismo el cálculo de valor de desecho se hizo según el método comercial obteniendo un resultado de S/ 194,812. , para mayor detalle ver anexo número 26.

Tabla 133

Estado de Resultados Proyectados

\begin{tabular}{|c|c|c|c|c|c|}
\hline \multicolumn{6}{|c|}{ Estado de Resultados - Expresado en Nuevos soles sin IGV } \\
\hline Resultados & Año 1 & Año 2 & Año 3 & Año 4 & Año 5 \\
\hline Ventas (Sin IGV) & S/.1,316,346 & $\mathrm{S} / .1,711,242$ & S/.1,890,872 & $\mathrm{S} / .2,246,678$ & $\mathrm{~S} / .2,570,687$ \\
\hline Costo de producción & S/.731,179 & S/.1,048,917 & S/.1,218,476 & S/.1,395,162 & S/.1,257,908 \\
\hline Utilidad Bruta & $\mathrm{S} / .585,167$ & $\mathrm{~S} / .662,325$ & S/.672,396 & $\mathrm{S} / . \mathbf{8 5 1 , 5 1 6}$ & $\mathrm{S} / .1,312,779$ \\
\hline Gasto de Administración & S/.70,703 & S/.70,703 & S/.70,703 & S/.70,703 & S/.70,703 \\
\hline Gasto de Ventas & S/.113,542 & S/.113,542 & S/.113,542 & S/.113,542 & S/.113,542 \\
\hline Depreciación & S/.19,038 & $\mathrm{S} / .21,241$ & S/.22,945 & S/.23,975 & $\mathrm{S} / .25,072$ \\
\hline Utilidad Operativa & S/.381,884 & $\mathrm{S} / . \mathbf{4 5 6 , 8 3 9}$ & S/.465,207 & $\mathrm{S} / .643,297$ & $\mathrm{~S} / .1,103,462$ \\
\hline Gasto Financiero & $\mathrm{S} / .45,502$ & $\mathrm{~S} / .45,502$ & $\mathrm{~S} / .45,502$ & $\mathrm{~S} / .45,502$ & $\mathrm{~S} / .45,502$ \\
\hline Utilidad Antes de impuestos & $\mathrm{S} / .336,382$ & $\mathrm{~S} / .411,337$ & S/.419,705 & $\mathrm{S} / . \mathbf{5 9 7 , 7 9 5}$ & $\mathrm{S} / .1,057,960$ \\
\hline Impuesto a la Renta & S/.94,187 & $\mathrm{S} / .115,174$ & S/.117,517 & S/.167,383 & $\mathrm{S} / .296,229$ \\
\hline Utilidad Neta & $\mathrm{S} / .242,195$ & $\mathrm{~S} / .296,163$ & $\mathrm{~S} / .302,187$ & $\mathrm{~S} / . \mathbf{4 3 0 , 4 1 2}$ & $\mathrm{S} / .761,731$ \\
\hline
\end{tabular}




\subsubsection{Balance general proyectado.}

El balance general, también conocido como el estado de situación patrimonial o balance patrimonial es el informe que refleja la situación patrimonial en un momento determinado, considera que el proyecto refleja el grado de patrimonio que posee al momento de finalizar el periodo evaluado y reflejo la evolución que este genera a través del tiempo de duración del proyecto.

El resultado de este informe está reflejado en la tabla 134, que detalla la situación patrimonial proyectada en cada periodo.

Tabla 134

Balance General

\begin{tabular}{|c|c|c|c|c|c|c|}
\hline \multicolumn{7}{|c|}{ Balance General Expresado en Nuevos Soles } \\
\hline Activo & Año 0 & Año 1 & Año 2 & Año 3 & Año 4 & Año 5 \\
\hline \multicolumn{7}{|l|}{ Activo corriente } \\
\hline Disponible (Efectivo, caja y bancos) & $\mathrm{S} / .0$ & $\mathrm{~S} / .279,181$ & $\mathrm{~S} / .342,459$ & $\mathrm{~S} / .353,090$ & S/.491,087 & $\mathrm{S} / .832,828$ \\
\hline Cuentas por cobrar & $\mathrm{S} / .0$ & $\mathrm{~S} / .0$ & $\mathrm{~S} / .0$ & $\mathrm{~S} / .0$ & $\mathrm{~S} / .0$ & $\mathrm{~S} / .0$ \\
\hline Existencias & S/.5,990 & S/.24,527 & $\mathrm{S} / .13,061$ & S/.6,454 & S/.7,329 & S/.7,329 \\
\hline Total Activo Corriente & $\mathrm{S} / .5,990$ & $\mathrm{~S} / .303,708$ & $\mathrm{~S} / . \mathbf{3 5 5 , 5 2 0}$ & $\mathrm{S} / .359,544$ & $\mathrm{~S} / .498,416$ & $\mathrm{~S} / .840,156$ \\
\hline \multicolumn{7}{|l|}{ Activo no corriente } \\
\hline Inmuebles, Maquinarias y equipos & S/.587,727 & S/.594,421 & $\mathrm{S} / .600,592$ & S/.616,445 & S/.637, 100 & S/.659,118 \\
\hline Intangibles & S/.95,991 & $\mathrm{S} / .0$ & $\mathrm{~S} / .0$ & $\mathrm{~S} / .0$ & $\mathrm{~S} / .0$ & $\mathrm{~S} / .0$ \\
\hline Depreciación & $\mathrm{S} / .0$ & $-\mathrm{S} / .21,241$ & $-S / .19,903$ & $-\mathrm{S} / .22,659$ & $-\mathrm{S} / .24,258$ & $-\mathrm{S} / .25,917$ \\
\hline Total Activo No Corriente & $\mathrm{S} / .683,718$ & $\mathrm{~S} / .573,180$ & $\mathrm{~S} / .580,689$ & $\mathrm{~S} / .593,786$ & $\mathrm{~S} / .612,842$ & $\mathrm{~S} / .633,201$ \\
\hline Activo Total & $\mathrm{S} / .689,708$ & $\mathrm{~S} / .876,888$ & $\mathrm{~S} / .936,208$ & $\mathrm{~S} / .953,329$ & S/.1,111,258 & S/.1,473,357 \\
\hline \multicolumn{7}{|l|}{ Pasivo } \\
\hline \multicolumn{7}{|l|}{ Pasivo corriente } \\
\hline Deudas tributarias & $\mathrm{S} / .0$ & $\mathrm{~S} / .0$ & $\mathrm{~S} / .0$ & $\mathrm{~S} / .0$ & $\mathrm{~S} / .0$ & $\mathrm{~S} / .0$ \\
\hline Cuentas por pagar & $\mathrm{S} / .0$ & $\mathrm{~S} / .0$ & $\mathrm{~S} / .0$ & $\mathrm{~S} / .0$ & $\mathrm{~S} / .0$ & $\mathrm{~S} / .0$ \\
\hline Deudas por pagar corrientes & $\mathrm{S} / .21,998$ & S/.30,208 & S/.33,917 & S/.38,082 & $\mathrm{S} / .42,759$ & $\mathrm{~S} / .0$ \\
\hline Total Pasivo Corriente & S/.21,998 & $\mathrm{S} / .30,208$ & $\mathrm{~S} / .33,917$ & $\mathrm{~S} / .38,082$ & $\mathrm{~S} / .42,759$ & $\mathrm{~S} / .0$ \\
\hline \multicolumn{7}{|l|}{ Pasivo no corriente } \\
\hline Deudas a largo plazo & S/.144,966 & S/.114,758 & S/.80,841 & S/.42,759 & $\mathrm{S} / .0$ & $\mathrm{~S} / .0$ \\
\hline Total Pasivo No Corriente & S/.144,966 & S/.114,758 & $\mathrm{S} / .80,841$ & S/.42,759 & $\mathrm{S} / .0$ & $\mathrm{~S} / .0$ \\
\hline Pasivo Total & S/.166,963 & S/.144,966 & $\mathrm{S} / . \mathbf{1 1 4 , 7 5 8}$ & $\mathrm{S} / .80,841$ & S/.42,759 & $\mathrm{S} / .0$ \\
\hline \multicolumn{7}{|l|}{ Patrimonio } \\
\hline Capital social & $\mathrm{S} / .522,744$ & $\mathrm{~S} / .452,741$ & S/.478,991 & $\mathrm{S} / .519,398$ & S/.577,412 & S/.640,530 \\
\hline Resultados acumulados & $\mathrm{S} / .0$ & $\mathrm{~S} / .279,181$ & $\mathrm{~S} / .342,459$ & $\mathrm{~S} / .353,090$ & S/.491,087 & $\mathrm{S} / .832,828$ \\
\hline Total Patrimonio Neto & $\mathrm{S} / .522,744$ & $\mathrm{~S} / .731,922$ & $\mathrm{~S} / .821,450$ & $\mathrm{~S} / .872,488$ & S/.1,068,499 & S/.1,473,357 \\
\hline Total Pasivo + Patrimonio Neto & S/.689,707 & $\mathrm{S} / .876,888$ & $\mathrm{~S} / .936,208$ & $\mathrm{~S} / .953,329$ & $\mathrm{~S} / .1,111,258$ & $\mathrm{~S} / . \mathbf{1 , 4 7 3 , 3 5 7}$ \\
\hline
\end{tabular}




\subsubsection{Flujo de caja proyectado.}

El flujo de caja proyectado es el informe que presenta el detalle de los flujos en ingresos y salidas de dinero que tiene el proyecto en un periodo determinado.

El flujo de caja fue estructurado de acuerdo a la metodología definida por Sapag, 2011, quien indica que a fin de medir la rentabilidad del proyecto, la rentabilidad de los recursos propios invertidos y la capacidad de pago que presenta para asumir los medios de financiamientos indicados.

La tabla 135, refleja estos periodos de modo tal que se puede determinar el nivel de ingresos que este refleja durante el tiempo de duración del proyecto.

En este flujo se aplicó el valor de desecho comercial (Nassir Sapag 2012, p 232 p.233), donde el porcentaje de valor comercial de activos al año cinco se estimó considerando el mercado actual de estos bienes (segunda mano) y de establecimientos de venta de estos activos de los cuales se obtuvieron información de los valores que pudieran tener estos al primer, segundo, tercer, cuarto y quinto año de uso, de esta manera se ha llegado a determinar que los activos que cumplieron 5 años de uso dentro de la empresa tenga un porcentaje comercial menor frente a los que tuvieron de cuatro a un año de uso (véase anexo 26) 
Tabla 135

Flujo de Caja Proyectado con Crecimiento Anual

\begin{tabular}{|c|c|c|c|c|c|c|}
\hline \multicolumn{7}{|c|}{ Flujo de Caja Proyectado - Expresado en Nuevos soles sin IGV } \\
\hline Flujo de Caja & Año 0 & Año 1 & Año 2 & Año 3 & Año 4 & Año 5 \\
\hline Ingresos & & S/.1,367,716 & S/.1,711,242 & S/.1,890,872 & $S / .2,246,678$ & $\mathrm{~S} / .2,570,687$ \\
\hline Costo de producción & & 731,179 & $1,048,917$ & $1,218,476$ & $1,395,162$ & $1,257,908$ \\
\hline Gastos Administrativos & & 70,703 & 70,703 & 70,703 & 70,703 & 70,703 \\
\hline Gastos de Ventas & & 113,542 & 113,542 & 113,542 & 113,542 & 113,542 \\
\hline Utilidad Operativa & & 452,292 & 478,080 & 488,151 & 667,271 & $1,128,534$ \\
\hline Depreciación(-) & & 19,038 & 21,241 & 22,945 & 23,975 & 25,075 \\
\hline Utilidad Antes de Impuestos & & 433,254 & 456,839 & 465,206 & 643,296 & $1,103,459$ \\
\hline Impuesto a la Renta & & 121,311 & 127,915 & $130,258^{\prime}$ & $180,123^{\circ}$ & 308,969 \\
\hline Flujo de Caja Operativo & & 311,943 & 328,924 & 334,949 & 463,173 & 794,491 \\
\hline Depreciación (+) & & 19,038 & 21,241 & 22,945 & 23,975 & 25,075 \\
\hline Activos Fijos Tangibles & 587,727 & 6,102 & 25,748 & 15,784 & 20,586 & 21,949 \\
\hline Activos intangibles & 95,991 & - & - & - & - & - \\
\hline Capital de Trabajo & 5,990 & - & - & - & - & - \\
\hline Valor de Deshecho & & & & & & 194,812 \\
\hline Flujo Económico & $-689,708$ & 324,879 & 324,417 & 342,110 & 466,562 & 992,429 \\
\hline Préstamo & 166,964 & 45,502 & 45,502 & 45,502 & 45,502 & 45,502 \\
\hline Flujo Financiero & $-522,744$ & 279,377 & 278,915 & 296,608 & 421,060 & 946,927 \\
\hline
\end{tabular}

Se considera una segunda alternativa del flujo de caja con una producción estándar para el cual se toma en consideración la producción del primer año para todo el horizonte del proyecto, asimismo la inversión pre operativa constituida por activo, fijo, intangible y trabajo es la misma a la alternativa que se trabajó con crecimiento anual al igual que la participación de aportes, tal como se muestra en la tabla 136. 
Tabla 136

Participación de Aportes Producción Estándar

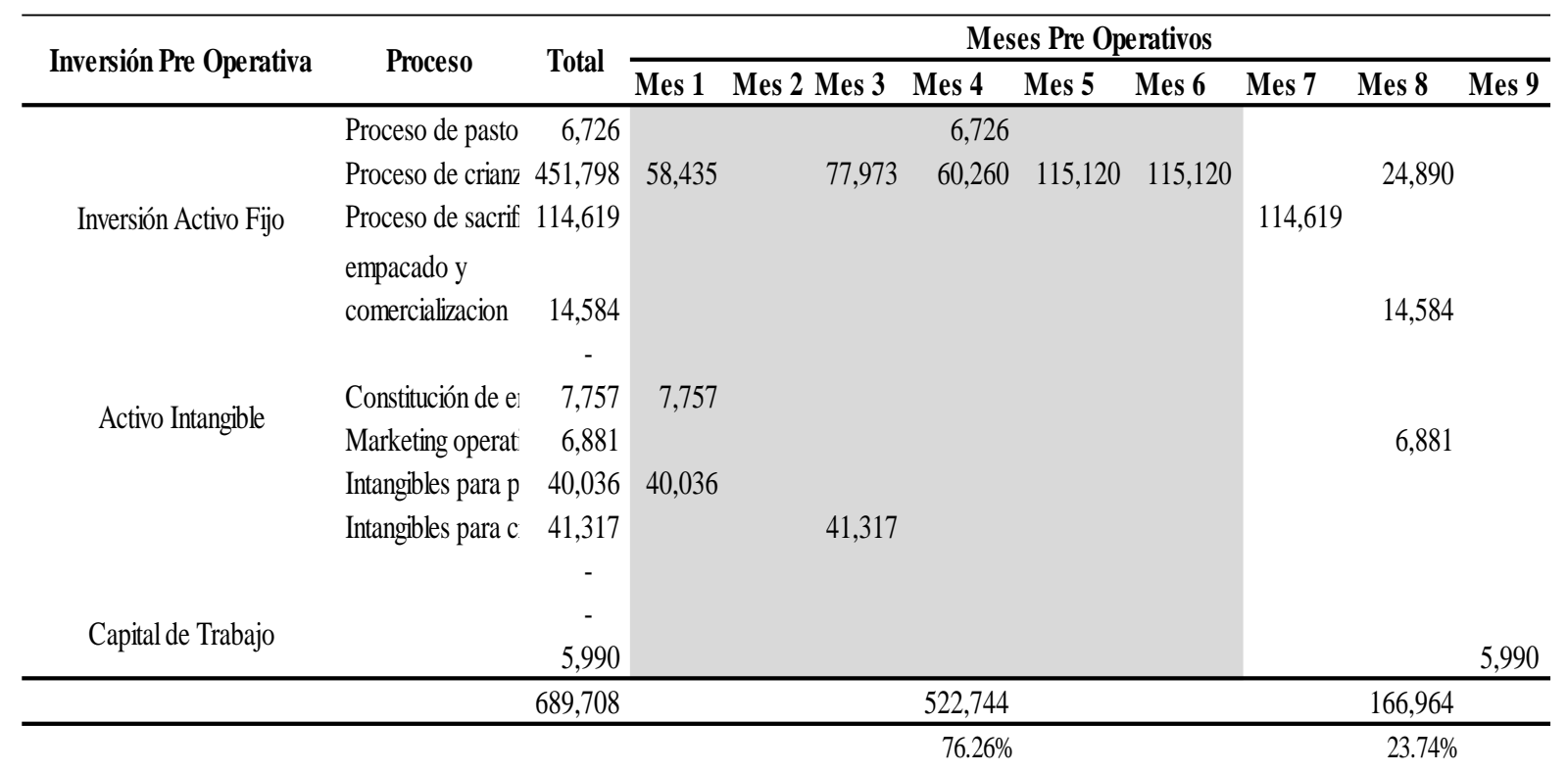

En el flujo de caja se muestra un valor de producción de S/. 731,179 para los cinco años, sin embargo debido al reemplazo de los reproductores estos son vendidos como sub productos o cuy de saca, en los años dos, tres y cinco lo que hace que el valor de venta total sea diferente cada año. Asimismo, este flujo de caja refleja que ya no se consideran reinversiones futuras en todo el horizonte del proyecto y por ende las depreciaciones son iguales para todos los años, el capital de trabajo es el mismo que se calculó para el modelo de crecimiento anual. La tabla 137 muestra lo mencionado. 
Tabla 137

Flujo de Caja con Producción Estándar Cinco Años.

\begin{tabular}{|c|c|c|c|c|c|c|}
\hline \multicolumn{7}{|c|}{ Flujo de Caja Proyectado - Expresado en Nuevos soles sin IGV } \\
\hline Flujo de Caja & Año 0 & Año 1 & Año 2 & Año 3 & Año 4 & Año 5 \\
\hline Ingresos & & $\mathrm{S} / .1,367,716$ & $\mathrm{~S} / \mathbf{1 , 4 3 1 , 0 3 2}$ & $\mathrm{S} / \mathbf{. 1 , 4 3 1 , 0 3 2}$ & $\mathrm{S} / .1,431,032$ & $\mathrm{~S} / .1,367,716$ \\
\hline Costo de producción & & 731,179 & 731,179 & 731,179 & 731,179 & 731,179 \\
\hline Gastos Administrativos & & 70,703 & 70,703 & 70,703 & 70,703 & 70,703 \\
\hline Gastos de Ventas & & 113,542 & 113,542 & 113,542 & 113,542 & 113,542 \\
\hline Utilidad Operativa & & 452,292 & 515,608 & 515,608 & 515,608 & 452,292 \\
\hline Depreciación(-) & & 19,038 & 19,038 & 19,038 & 19,038 & 19,038 \\
\hline Utilidad Antes de Impuestos & & 433,254 & 496,570 & 496,570 & 496,570 & 433,254 \\
\hline Impuesto a la Renta & & 121,311 & $139,040^{\prime}$ & $139,040^{\prime}$ & $139,040^{\circ}$ & 121,311 \\
\hline Flujo de Caja Operativo & & 311,943 & $\mathbf{3 5 7 , 5 3 0}$ & $\mathbf{3 5 7 , 5 3 0}$ & 357,530 & 311,943 \\
\hline Depreciación (+) & & 19,038 & 19,038 & 19,038 & 19,038 & 19,038 \\
\hline Activos Fijos Tangibles & 587,727 & - & - & - & - & - \\
\hline Activos intangibles & 95,991 & - & - & - & - & - \\
\hline Capital de Trabajo & 5,990 & - & - & - & - & - \\
\hline Valor de Deshecho & & & & & & 145,495 \\
\hline Flujo Económico & $-689,708$ & 330,981 & 376,568 & 376,568 & 376,568 & 476,476 \\
\hline Préstamo & 166,964 & 45,502 & 45,502 & 45,502 & 45,502 & 45,502 \\
\hline Flujo Financiero & $-522,744$ & 285,479 & 331,066 & 331,066 & 331,066 & 430,974 \\
\hline
\end{tabular}

El cálculo del valor de desecho estimado para el escenario de proyección de flujo de caja en una situación estándar fue determinado mediante el método de valor de deshecho comercial de acuerdo a lo definido por Sapag, 2012, p. 232 p. 233

Tabla 138

Cálculo del Valor de Deshecho Comercial para Flujo de Caja Estándar.

\begin{tabular}{lr}
\hline & Monto \\
\hline Valor comercial activos & 149,573 \\
Valor en Libros contable (-) & 135,010 \\
Utilidad antes del impuesto & 14,563 \\
Impuesto 28\% & 4,078 \\
Utilidad neta & 10,485 \\
Valor en Libros contable (+) & 135,010 \\
Flujo Neto & $\mathbf{1 4 5 , 4 9 5}$ \\
\hline
\end{tabular}




\section{Capítulo IX: Evaluación Económico Financiera}

\subsection{Evaluación Financiera.}

De acuerdo a Sapag (2011), la etapa de evaluación financiera del proyecto comprende el análisis e interpretación de los resultados obtenidos en la estimación de las partidas asignadas descritas en la planificación financiera con relación al comportamiento del mercado según los indicadores macroeconómicos que los componen.

Para esta evaluación se aplicó la metología planteada por Sapag (2011) considerando los resultados obtenidos detallados en cada anexo para la estimación de los estados financieros respectivos.

Estos indicadores fueron determinados en función de la tasa de descuento calculada descrita en el capítulo octavo, según los indicadores de mercado como referencia a la tasa de actualización estimada siendo estos un COK de $19.98 \%$ y WACC de 13,53\%.

\subsubsection{Tasa interna de retorno (TIR).}

Sapag (2011) define la tasa interna de retorno (TIR) como un segundo criterio de evaluación que mide la rentabilidad como porcentaje, es decir la máxima tasa exigible que haga que el valor actual neto (VAN) sea cero, interpretándose también como la sensibilización de la tasa de descuento ya que mide el máximo costo que se podría pagar por el capital.

El porcentaje fue calculado tomando en cuenta los flujos generados en el proyecto, considerando que se cuenta con financiamiento, este flujo debe considerar dos tipos de tasa interna de retorno, una económica de $49.62 \%$ y otra financiera de $58.55 \%$. 


\subsubsection{Valor actual neto (VAN).}

Sapag (2011) define e valor actual neto (VAN) como el método para medir el excedente resultante después de obtener la rentabilidad deseada exigida y después de recuperar toda la inversión. Para ello calcula el valor actual de todos los flujos futuros de caja, proyectados a partir del primer periodo de operación, y le resta la inversión total expresada en el momento cero (pg. 300). La tabla 139 y 140 detallan los resultados obtenidos tanto en la evaluación económica y financiera del proyecto, donde se puede apreciar que frente a las inversiones por S/. 689,708 en etapa pre operativa se obtiene un rendimiento de S/. 628,832 con relación a los flujos según los resultados proyectados dentro de la evaluación económica. Sin embargo al hacer la evaluación financiera se tiene un rendimiento de S/. 1, 435,230 des pues de haber cubierto S/.522, 744 producto del financiamiento.

Tabla 139

Valor Actual Neto Económico y Tasa Interna de Retorno Económico.

\begin{tabular}{lcccccc}
\hline \multicolumn{7}{c}{ Cálculo del VANE - Expresado en Nuevos soles sin IGV } \\
\multicolumn{1}{c}{ Flujo Económico } & Año 0 & Añ 0 1 & Año 2 & Año 3 & Añ 0 4 & Añ 0 5 \\
\hline Flujo Económico & $-689,708$ & 324,879 & 324,417 & 342,110 & 466,562 & 992,429 \\
Flujo Económico Descontado & $-689,708$ & 270,777 & 225,365 & 198,079 & 225,151 & 399,167 \\
VANE & 628,832 & & & & & \\
\hline
\end{tabular}

$\overline{\text { TIRE }} 49.62 \%$

Lo cual refleja que la inversión realizada genera una recuperación de esta en función al crecimiento de la demanda y los volúmenes de producción constantes proyectados. 
Tabla 140

Valor Actual Neto Financiero y Tasa Interna de Retorno Financiera

\begin{tabular}{lcccccc}
\hline \multicolumn{7}{c}{ Cálculo del VANF - Expresado en Nuevos soles sin IGV } \\
\multicolumn{1}{c}{ Flujo Financiero } & Año 0 & Año 1 & Año 2 & Año 3 & Año 4 & Año 5 \\
\hline Flujo Financiero & $-522,744$ & 279,377 & 278,915 & 296,608 & 421,060 & 946,927 \\
Flujo Financiero Descontado & $-522,744$ & 246,082 & 245,676 & 261,259 & 370,880 & 834,076 \\
VANF & $1,435,230$ & & & & & \\
\hline
\end{tabular}

\begin{tabular}{l} 
TIRF $58.55 \%$ \\
\hline
\end{tabular}

En un escenario de producción estándar se obtuvo un resultado de VANE S/. 439,146 y TIRE de $45.06 \%$ así como un VANF S/.983, 159 y TIRF de 54.19\%. lo cual se interpreta como un índice de recuperación de capital más lento dentro del periodo de evaluación bajo condiciones de ingresos y demanda sin crecimiento, esto debido a que las inversiones pre operativas presupuestadas frente a los ingresos proyectados estándar representan una capacidad instalada mayor, los cuales se detallan en las tablas 141 y 142.

Tabla 141

Valor Actual Neto Económico y Tasa Interna de Retorno Económico para Flujo Estándar.

\begin{tabular}{lcccccc}
\hline \multicolumn{7}{c}{ Cálculo del VANE - Expresado en Nuevos soles sin IGV } \\
\multicolumn{1}{c}{ Flujo Económico } & Año 0 & Año 1 & Año 2 & Año 3 & Año 4 & Año 5 \\
\hline Flujo Económico & $-689,708$ & 330,981 & 376,568 & 376,568 & 376,568 & 476,476 \\
Flujo Económico Descontado & $-689,708$ & 275,863 & 261,593 & 218,030 & 181,722 & 191,645 \\
VANE & 439,146 & & & & & \\
\hline \multicolumn{7}{l|}{} \\
\hline TIRE & $45.06 \%$ & & & & \\
\hline
\end{tabular}


Tabla 142

Valor Actual Neto Financiero y Tasa Interna de Retorno Financiero para Flujo Estándar.

\begin{tabular}{lcccccc}
\hline \multicolumn{7}{c}{ Cálculo del VANF - Expresado en Nuevos soles sin IGV } \\
\multicolumn{1}{c}{ Flujo Financiero } & Año 0 & Año 1 & Año 2 & Año 3 & Año 4 & Año 5 \\
\hline Flujo Financiero & $-522,744$ & 285,479 & 331,066 & 331,066 & 331,066 & 430,974 \\
Flujo Financiero Descontado & $-522,744$ & 251,457 & 291,611 & 291,611 & 291,611 & 379,612 \\
VANF & 983,159 & & & & & \\
\hline
\end{tabular}

\begin{tabular}{l} 
TIRF $54.19 \%$ \\
\hline
\end{tabular}

\subsubsection{Rentabilidad sobre el patrimonio (ROE).}

Sanchez (2012) define el la rentabilidad financiera (ROE) por sus siglas en inglés como la relación entre los recursos para obtener beneficio económico, este muestra el retorno de la inversión del accionista como proveedores de capital y esta expresada entre la relación utilidad neta después de impuestos sobre el patrimonio o los fondos propios.

La evaluación económica financiera arrojó un índice de rentabilidad sobre los activos del $46 \%$, que se puede interpretar como un nivel alto de utilidad por las inversiones registradas al inicio del proyecto frente al resultado obtenido durante el periodo de evaluación aplicada.

\subsubsection{Ratios.}

Gropelli (2012), define los ratios financieros también llamados razones financieras a los cocientes que proporcionan unidades contables y financieras de medida y comparación a través de los cuales permiten analizar estos datos a fin de conocer el estado actual del proyecto en función de niveles y resultados esperados. 
Las razones evaluadas corresponden a las categorías de razones financieras de liquidez y mercado, actividad o gestión y endeudamiento o solvencia. Los cuales se detallan en la tabla 143 que describe los resultados obtenidos según los estados financieros elaborados.

Tabla 143

Ratios Financieros.

\begin{tabular}{|c|c|}
\hline \multicolumn{2}{|l|}{ Indicadores Financieros } \\
\hline Indicadores de Liquidez & \\
\hline Prueba Acida & 0.00 \\
\hline $\begin{array}{l}\text { Capital de Trabajo / Fondo de maniobra S } \\
\text { Indicadores de Gestión }\end{array}$ & 236,514 \\
\hline ROA & $35 \%$ \\
\hline $\mathrm{ROE}$ & $46 \%$ \\
\hline Margen de Utilidad & $18 \%$ \\
\hline Rotacion de inv. & 12.24 \\
\hline Indicadores de Solvencia & \\
\hline Apalancamiento & $32 \%$ \\
\hline
\end{tabular}

Los índices de gestión presentan niveles que reflejan la rentabilidad del proyecto en el largo plazo, asimismo la solvencia está reflejada en la capitalización del proyecto en el tiempo.

Lawrence (2012), indica que la información contenida en los estados financieros es importante por ser de interés para los inversionistas conocer los niveles de riesgo presentes y futuros así como el rendimiento del proyecto. 


\subsection{Análisis de Riesgo}

En la evaluación de riesgo del proyecto el análisis del riesgo, como lo establece Sapag el 2011 define lo siguiente:

Los resultados que se obtienen al aplicar los criterios de evaluación no miden con exactitud la rentabilidad del proyecto, sino solo la de uno de los tantos escenarios futuros posibles. Los cambios que casi con certeza se producirán en el comportamiento de las variables del entorno harán que sea prácticamente imposible esperar que la rentabilidad calculada sea la que efectivamente tenga el proyecto implementado (pg. 331)

Por lo tanto al obtener los resultados corresponde identificar todos los factores que representen una probabilidad de que ocurran diferentes eventos que impacten directamente los resultados en el proyecto.

Al aplicar un análisis de punto críticos, de acuerdo a la metodología definida por Sapag (2011) determina hasta donde se puede modificar el valor de una o más variables para que el proyecto tenga mínimo un valor actual neto de cero.

\subsubsection{Análisis de punto de equilibrio.}

El análisis del punto de equilibrio, de acuerdo a Lawrence y Zutter (2012) determina el nivel de operaciones que se requiere para cubrir todos los costos y evaluar la rentabilidad relacionada con diversos niveles de ventas.

La tabla 144 resume el detalle del punto de equilibrio y está representado por el nivel de ventas que se requiere para cubrir todos los costos en el proyecto intereses e impuestos. 
Tabla 144

Punto de Equilibrio

\begin{tabular}{|c|c|c|c|c|c|c|c|c|c|c|}
\hline \multicolumn{11}{|c|}{ Punto de Equilibrio Promedio - Expresado en Nuevos Soles sin IGV } \\
\hline Concepto & & $\tilde{\mathbf{n}} \mathbf{0} 1$ & & Año 2 & & Año 3 & & Año 4 & & Año 5 \\
\hline Total Ventas & & 367,716 & & $1,711,242$ & & $\mathbf{8 9 0 , 8 7 2}$ & & ,246,678 & & $, 570,687$ \\
\hline Total Costos Fijos & S/. & $184,245^{\prime}$ & $\mathrm{S} /$. & 184,245 & $\mathrm{~S} /$. & $184,245^{\prime}$ & S/. & $184,245^{\prime}$ & S/. & 184,245 \\
\hline Total Costos Variables & $\mathrm{S} /$. & 731,179 & S/. & $1,048,917$ & $\mathrm{~S} /$. & $1,218,476$ & S/. & $1,395,162$ & S/. & $1,257,908$ \\
\hline Punto de Equilibrio Promedi & & 17,026 & & 19,582 & & 20,984 & & 19,934 & & 15,565 \\
\hline Total Costos de Producción & $\mathrm{S} /$ & 915,424 & $\mathrm{~S} /$. & $1,233,162$ & $\mathrm{~S} /$ & $1,402,721$ & $\mathrm{~S} /$. & $1,579,407$ & S/. & $1,442,153$ \\
\hline Total Unid. Producción & & 75,544 & & 94,572 & & 103,966 & & 123,933 & & 145,201 \\
\hline Precio de Venta sin IGV. & $\mathrm{S} /$. & 20.50 & $\mathrm{~S} /$. & 20.50 & $\mathrm{~S} /$. & 20.50 & $\mathrm{~S} /$. & 20.50 & $\mathrm{~S} /$. & 20.50 \\
\hline Costo Var. Unit. De Prod. & $\mathrm{S} /$. & 9.68 & S/. & 11.09 & $\mathrm{~S} /$. & 11.72 & S/. & 11.26 & S/. & 8.66 \\
\hline Margen de Contribución & $\mathrm{S} /$. & 10.82 & S/. & 9.41 & $\mathrm{~S} /$. & 8.78 & S/. & 9.24 & S/. & 11.84 \\
\hline
\end{tabular}

Considerando esta relación se observa que para cubrir el nivel de costos totales (costos fijos y variables) en proporción a la proyección de ingresos estimado, es necesarios la producción de 17,026 cuyes como producto terminado para el primer año, volumen que sería cubierto el cuarto mes de producción según las estimaciones definidas en el anexo de niveles de producción detallado.

\subsubsection{Análisis de sensibilidad.}

El análisis de sensibilidad se considera las variaciones que afecta el VAN del proyecto en consideración de los incrementos y reducciones al que puede estar afecto las variables determinantes de la evaluación financiera.

Considerando la definición de Sapag (2011) como la variabilidad relativa del retorno esperado respecto al retorno medio en cuanto a la magnitud de la variación. Los procesos de simulación a los que el proyecto fueron sometidos se detallan en la tabla donde se puede apreciar los resultados frente a seis niveles diferentes que representan condiciones de cambios crecientes y decrecientes a los que podría someterse el proyecto en diferentes puntos críticos que intervienen en el proceso de producción y comercialización. 
Tabla 145

Variaciones en el Costo de la Deuda.

\begin{tabular}{lccccccccc}
\hline \multirow{2}{*}{$\begin{array}{c}\text { Costo de Deuda } \\
\text { Resultado }\end{array}$} & VANE & VANF & TIRE & TIRF & $\begin{array}{c}\text { Variación } \\
\text { \% VANE }\end{array}$ & Variación \\
\% VANF \\
\hline Escenario
\end{tabular}

Como se puede observar de los resultados obtenidos se puede reflejar que el proyecto mantiene índices de rentabilidad y retorno aceptables inclusive bajo las condiciones de financiamiento más altas.

Tabla 146

Variaciones en el Costo de Producción

\begin{tabular}{|c|c|c|c|c|c|c|c|c|c|c|}
\hline \multirow{3}{*}{$\hat{y}^{e^{v^{v^{5}}}}$} & \multicolumn{10}{|c|}{ Analisis de Sensibilidad Unidimensional - Costo de Producción } \\
\hline & \multicolumn{3}{|c|}{ Costo de Producción } & \multirow{2}{*}{\multicolumn{2}{|c|}{ VANE }} & \multirow{2}{*}{ VANF } & \multirow{2}{*}{ TIRE } & \multirow{2}{*}{ TIRF } & \multirow{2}{*}{$\begin{array}{l}\text { Variación } \\
\text { \% VANE }\end{array}$} & \multirow{2}{*}{$\begin{array}{l}\text { Variación } \\
\text { \% VANF }\end{array}$} \\
\hline & Variación & & sultado & & & & & & & \\
\hline \multirow{3}{*}{$\begin{array}{l}\text { Escenario } \\
\text { Pesimista }\end{array}$} & $30 \%$ & S/. & 563,230 & S/. & 247,022 & S/. 820,894 & $32.33 \%$ & $37.07 \%$ & $-60.72 \%$ & $-42.69 \%$ \\
\hline & $20 \%$ & $\mathrm{~S} /$. & 519,904 & $\mathrm{~S} / \mathrm{s}$ & 374,292 & S/. $1,024,745$ & $38.28 \%$ & $44.40 \%$ & $-40.48 \%$ & $-28.46 \%$ \\
\hline & $10 \%$ & S/. & 476,579 & $\mathrm{~S} / \mathrm{s}$ & 501,562 & S/. $1,228,595$ & $44.03 \%$ & $51.51 \%$ & $-20.24 \%$ & $-14.23 \%$ \\
\hline Actual & $0 \%$ & $\mathrm{~S} /$. & 433,254 & $\mathrm{~S} /$. & 628,832 & S/. $1,432,446$ & $49.62 \%$ & $58.43 \%$ & - & - \\
\hline \multirow{3}{*}{$\begin{array}{l}\text { Escenario } \\
\text { Optimista }\end{array}$} & $-10 \%$ & S/. & 389,928 & S/. & 513,132 & S/. $1,247,127$ & $44.55 \%$ & $52.15 \%$ & $-18.40 \%$ & $-12.94 \%$ \\
\hline & $-20 \%$ & $\mathrm{~S} /$. & 346,603 & S/. & 416,716 & S/. 1,092,695 & $40.22 \%$ & $46.79 \%$ & $-33.73 \%$ & $-23.72 \%$ \\
\hline & $-30 \%$ & $\mathrm{~S} /$. & 303,278 & $\mathrm{~S} /$. & 335,132 & S/. 962,021 & $36.48 \%$ & $42.17 \%$ & $-46.71 \%$ & $-32.84 \%$ \\
\hline
\end{tabular}

Como se puede observar en el detalle, el proyecto arroja resultados aceptables hasta el punto de variación y sensibilización del 30\% de incremento en los costos directos de producción, a partir de ello el retorno esperado ya se encuentra fuera de los límites de éxito del proyecto. 
Tabla 147

Variaciones en Precio de Venta.

\begin{tabular}{|c|c|c|c|c|c|c|c|c|c|c|}
\hline \multirow{3}{*}{$\hat{y}^{v^{v^{v^{5}}}}$} & \multicolumn{10}{|c|}{ Analisis de Sensibilidad Unidimensional - Precio de Venta } \\
\hline & \multicolumn{3}{|c|}{ Precio de Venta } & \multirow{2}{*}{\multicolumn{2}{|c|}{ VANE }} & \multirow{2}{*}{ VANF } & \multirow{2}{*}{ TIRE } & \multirow{2}{*}{ TIRF } & \multirow{2}{*}{$\begin{array}{l}\text { Variación } \\
\% \text { VANE }\end{array}$} & \multirow{2}{*}{$\begin{array}{l}\text { Variación } \\
\text { \% VANF }\end{array}$} \\
\hline & Variación & & tado & & & & & & & \\
\hline \multirow{3}{*}{$\begin{array}{l}\text { Escenario } \\
\text { Optimista }\end{array}$} & $15 \%$ & $\mathrm{~S} /$. & 23.58 & S/. & $1,227,332$ & S/. $2,363,493$ & $75.17 \%$ & $90.54 \%$ & $95.18 \%$ & $65.00 \%$ \\
\hline & $10 \%$ & $\mathrm{~S} /$. & 22.55 & $\mathrm{~S} /$. & $1,027,832$ & S/. $2,053,144$ & $66.84 \%$ & $80.03 \%$ & $63.45 \%$ & $43.33 \%$ \\
\hline & $5 \%$ & $\mathrm{~S} /$. & 21.53 & S/. & 828,332 & S/. $1,742,795$ & $58.34 \%$ & $69.34 \%$ & $31.73 \%$ & $21.67 \%$ \\
\hline Actual & $0 \%$ & $\mathrm{~S} /$. & 20.50 & S/. & 628,832 & S/. 1,432,446 & $49.62 \%$ & $58.43 \%$ & - & - \\
\hline \multirow{3}{*}{$\begin{array}{l}\text { Escenario } \\
\text { Pesimista }\end{array}$} & $-5 \%$ & $\mathrm{~S} /$. & 19.48 & S/. & 429,332 & S/. 1,122,097 & $40.63 \%$ & $47.25 \%$ & $-31.73 \%$ & $-21.67 \%$ \\
\hline & $-10 \%$ & $\mathrm{~S} /$. & 18.45 & $\mathrm{~S} /$. & 229,832 & S/. $\quad 811,748$ & $31.29 \%$ & $35.70 \%$ & $-63.45 \%$ & $-43.33 \%$ \\
\hline & $-15 \%$ & $\mathrm{~S} /$. & 17.43 & S/. & 30,332 & S/. $\quad 501,400$ & $21.51 \%$ & $23.67 \%$ & $-95.18 \%$ & $-65.00 \%$ \\
\hline
\end{tabular}

De acuerdo a los resultados obtenidos se observa que el proyecto mantiene índices de rentabilidad y retorno tolerables dentro del margen de disminución hasta el -10\%, a partir de este el proyecto ya representaría un nivel de retorno muy bajo lo que representaría poco beneficio sobre la inversión.

Los incrementos superiores en el precio de venta significarían mayores beneficios y retornos más acelerados de la recuperación de la inversión realizada, sin embargo se debe indicar que esto haría que el mercado reduzca el consumo del producto.

Tabla 148

Variación en Participación de Mercado.

\begin{tabular}{|c|c|c|c|c|c|c|c|c|c|}
\hline \multirow{3}{*}{$\hat{y}^{e^{v^{0^{0}}}}$} & \multicolumn{9}{|c|}{ Analisis de Sensibilidad Unidimensional - Participación de Mercado } \\
\hline & \multicolumn{2}{|c|}{ Participación } & \multirow{2}{*}{\multicolumn{2}{|c|}{ VANE }} & \multirow{2}{*}{ VANF } & \multirow{2}{*}{ TIRE } & \multirow{2}{*}{ TIRF } & \multirow{2}{*}{$\begin{array}{l}\text { Variación } \\
\text { \% VANE }\end{array}$} & \multirow{2}{*}{$\begin{array}{l}\text { Variación } \\
\text { \% VANF }\end{array}$} \\
\hline & Variación & Resultado & & & & & & & \\
\hline \multirow{3}{*}{$\begin{array}{l}\text { Escenario } \\
\text { Optimista }\end{array}$} & $15 \%$ & $11.50 \%$ & S/. & 828,332 & S/. $1,742,795$ & $58.34 \%$ & $69.34 \%$ & $31.73 \%$ & $21.67 \%$ \\
\hline & $10 \%$ & $11.00 \%$ & $\mathrm{~S} /$. & 748,532 & S/. $1,618,655$ & $54.88 \%$ & $65.01 \%$ & $19.04 \%$ & $13.00 \%$ \\
\hline & $5 \%$ & $10.50 \%$ & $\mathrm{~S} /$. & 668,732 & S/. $1,494,516$ & $51.38 \%$ & $60.64 \%$ & $6.35 \%$ & $4.33 \%$ \\
\hline Actual & $0 \%$ & $10.00 \%$ & S/. & 628,832 & S/. 1,432,446 & $49.62 \%$ & $58.43 \%$ & - & - \\
\hline \multirow{3}{*}{$\begin{array}{l}\text { Escenario } \\
\text { Pesimista }\end{array}$} & $-5 \%$ & $9.50 \%$ & $\mathrm{~S} /$. & 509,132 & S/. $1,246,237$ & $44.26 \%$ & $51.76 \%$ & $-19.04 \%$ & $-13.00 \%$ \\
\hline & $-10 \%$ & $9.00 \%$ & $\mathrm{~S} /$. & 429,332 & S/. 1,122,097 & $40.63 \%$ & $47.25 \%$ & $-31.73 \%$ & $-21.67 \%$ \\
\hline & $-15 \%$ & $8.50 \%$ & $\mathrm{~S} /$. & 229,832 & S/. 811,748 & $31.29 \%$ & $35.70 \%$ & $-63.45 \%$ & $-43.33 \%$ \\
\hline
\end{tabular}

Los resultados obtenidos sobre las variaciones en cuanto a la participación del mercado reflejan que el proyecto representa resultados favorables aun cuando el porcentaje 
de participación de mercado disminuya en un $-10 \%$, esto debido a factores de competencia y el margen de utilidad que presenta el producto, variaciones inferiores a $-10 \%$ representan que el valor actual neto de la inversión a realizar sería inferior a la inversión inicial del proyecto.

\subsubsection{Análisis de escenarios.}

Los procesos de simulación a los que el proyecto fue sometido se detallan en las tablas siguientes, donde se puede apreciar los resultados frente a seis niveles diferentes que representan condiciones pesimistas y optimistas a los que podría someterse el proyecto.

Según Sapag (2011) describe que estos escenarios reflejan lo que pasa con el valor actual neto si se modifica el valor de una o más variables. Los modelos de simulación de probabilidades se aplican a fin de poder evaluar las condiciones de riesgo al que podría someterse el proyecto.

El detalle estos escenarios se reflejan en las tablas que a continuación muestran los resultados de los escenarios optimistas y pesimistas en las siguientes variables:

- Variaciones en el costo de la deuda.

- Variaciones en el costo de producción.

- Variaciones en el precio de venta.

- Variaciones en la participación de mercado. 
Tabla 149

Variaciones en el Costo de Deuda

\begin{tabular}{lcc}
\hline \multirow{2}{*}{ Escenarios } & \multicolumn{2}{c}{ Costo de la deuda } \\
& $5 \%$ & $12.89 \%$ \\
& Variación & Resultado \\
\hline \multirow{2}{*}{ Escenario } & $3 \%$ & $12.65 \%$ \\
pesimista & $1 \%$ & $12.40 \%$ \\
Actual & $0 \%$ & $12.28 \%$ \\
& $-1 \%$ & $12.16 \%$ \\
Escenario & $-3 \%$ & $11.91 \%$ \\
optimista & $-5 \%$ & $11.67 \%$ \\
\hline
\end{tabular}

Como se refleja en las variaciones indicadas, cambios determinados como pesimistas representa a los incrementos en el la tasa de costo efectivo que asumiría el proyecto por el acceso al financiamiento requerido.

Tabla 150

Variaciones en el Costo de Producción.

Costo de producción

Escenarios

Variación Resultado

$30 \% \quad$ S/. $\quad 563,230$

Escenario pesimista

$20 \% \quad$ S/. $\quad 519,904$

$10 \% \quad$ S/. $\quad 476,579$

Actual

$0 \% \quad$ S/. $\quad 433,254$

Escenario optimista

$-10 \% \quad$ S/. 389,928

$-20 \% \quad$ S/. 346,603

$-30 \% \quad$ S/. 303,278 
Como se detalla se considera un escenario optimista a los cambios decrecientes en los costos de producción que intervienen directamente en los macro procesos requeridos para la elaboración, producción y comercialización del producto, sin embargo de acuerdo a las tendencias inflacionarias los principales riesgos a asumir por el proyecto están focalizados en los incrementos considerados como escenario pesimista, ya que estos son muy propensos a sufrir alzas en los precios de mercado.

Tabla 151

Variaciones en Precio de Venta.

\begin{tabular}{llll}
\hline \multirow{2}{*}{ Escenario } & \multicolumn{3}{c}{ Precio de venta } \\
& VAR. & \multicolumn{2}{c}{ Resultado } \\
\hline \multirow{2}{*}{ Escenario optimista } & $15 \%$ & $\mathrm{~S} /$. & 23.58 \\
& $10 \%$ & $\mathrm{~S} /$. & 22.55 \\
& $5 \%$ & $\mathrm{~S} /$. & 21.53 \\
Actual & $0 \%$ & $\mathrm{~S} /$. & 20.50 \\
& $-5 \%$ & $\mathrm{~S} /$. & 19.48 \\
& $-10 \%$ & $\mathrm{~S} /$. & 18.45 \\
Escenario pesimista & $-15 \%$ & $\mathrm{~S} /$. & 17.43 \\
\hline
\end{tabular}

Como se puede apreciar los escenarios pesimistas representan las reducciones en el precio de venta del producto, ya que este al generar una reducción implica menor rentabilidad y un retorno más lento de la inversión realizada.

Por otro lado se considera escenario optimista al incremento del precio de venta, sin embargo al tratarse este de un producto elástico cuya cantidad demandada está directamente 
relacionada al precio de venta determinado por el ofertante considerando que se trata de un producto de baja frecuencia de compra y con diferentes sustitutos.

Tabla 152

Variación en Participación de Mercado

\begin{tabular}{lcc}
\hline \multirow{2}{*}{ Escenario } & \multicolumn{2}{c}{ Participación promedio } \\
& Variación & Resultado. \\
\hline \multirow{2}{*}{ Escenario optimista } & $15 \%$ & $11.50 \%$ \\
& $10 \%$ & $11.00 \%$ \\
Actual & $5 \%$ & $10.50 \%$ \\
& $0 \%$ & $10.00 \%$ \\
Escenario pesimista & $-5 \%$ & $9.50 \%$ \\
& $-10 \%$ & $9.00 \%$ \\
& $-15 \%$ & $8.50 \%$ \\
\hline
\end{tabular}

Como se puede observar se considera escenario pesimista a los cabios decrecientes en la participación del mercado, puesto que la disminución de estos representa la pérdida de utilidades que generen la rentabilidad del proyecto.

Los escenarios optimistas están representados por el incremento de la participación en el mercado, sin embargo se debe tomar en cuenta que para elevar el lote de producción es necesario también elevar la capacidad instalada de planta, la cual representa un incremento en el costo de producción, así mismo de acuerdo al estudio de mercado realizado la participación y preferencia del mercado por este producto es limitada y está definida por la frecuencia, hábitos de consumo y estacionalidad por parte del público objetivo. 


\section{Conclusiones}

De la investigación efectuada en el presente plan de negocio se colige:

1. Que el plan de negocio elaborado en el presente trabajo de investigación demuestra que a través del estudio de mercado, localización y análisis financiero es viable, ya que permite la crianza, industrialización y comercialización de la carne de cuy en la región Cusco, siendo el producto ecológico propuesto del cuy empacado al vacío para consumo de forma masiva, lo que brindará el desarrollo económico y social en la zona donde se implementara el proyecto y por ende en la región del Cusco; así mismo este proyecto es sustentable económicamente para los inversionistas como demuestra los indicadores financieros.

2. Del estudio de mercado elaborado para el presente Plan de Negocio, se desprende que el 52\% del público en general acepta adquirir el cuy en la forma propuesta por presentar características de calidad, garantía y precio. Por otro lado un $45 \%$ de restaurantes tradicionales y el $60 \%$ de turísticos argumentan que este producto les garantiza la manipulación adecuada de esta carne, con tiempo de conservación aceptable, así como un peso y precio adecuado.

3. Se concluye que la planta para el presente proyecto estará localizada en la provincia de Anta; distrito de Limatambo, zona que reúne las condiciones de disponibilidad de terrenos, mano de obra por reunir este distrito características geográficas y ambientales propicias para la crianza e implementación de la planta de producción facilitando la aplicación de las técnicas y métodos propuestos, teniendo esta zona costos tanto en terrenos como mano de obra y servicios accesibles lo que permitirá proponer un precio de venta competitivo.

4. El canal de distribución se ajusta a los requerimientos del público objetivo, en este entender se empleara el marketing directo, siendo necesario contar con un centro de 
expendio que tenga las prácticas necesarias de salubridad y calidad, el cual debe estar ubicado cerca de la plaza donde actualmente se oferta este producto en condiciones inadecuadas, que a pesar de esto se viene convirtiendo en la plaza donde ofertantes y demandantes se reúnen para realizar la compra y venta de la carne de cuy, por lo que en el plan de negocio elaborado se desprende que una de las estrategias de distribución es la de empuje la cual contribuirá a atender de manera oportuna a los restaurantes turístico y tradicionales que requieren del producto propuesto en el presente plan.

5. Finalmente se concluye que en cuanto respecta la viabilidad económica y financiera los ratios tanto de liquidez, rentabilidad arrojan que el proyecto es rentable a corto plazo, los que fueron determinados en función de las expectativas de inversión y utilidad esperada para el proyecto, obteniendo un valor actual neto económico de 628, 832 soles que demuestra que el proyecto es viable desde el punto de vista económico, la tasa interna de retorno económica de $49.62 \%$ define la recuperación de capital favorable para los inversionistas al ser superior al costo de oportunidad promedio de capital, reflejando que, una vez iniciado la puesta en marcha, el proyecto contará con la capacidad de generar recursos propios para reinversión, producción y comercialización sin comprometer la utilidad esperada y cumplir con las obligaciones financieras y comerciales en el corto y largo plazo. En cuanto al impacto ambiental este no ha de generar ninguna alteración en la zona donde se implemente el proyecto. 


\section{Recomendaciones}

De la investigación efectuada en el presente plan de negocios se recomienda:

1. Implementar el proyecto propuesto en el plan de negocios referido a la crianza e industrialización y comercialización de carne de cuy ecológico en la Región del Cusco por ser viable en todos los aspectos estudiados y requeridos para proyectos de inversión.

2. Se recomiendo efectuar estudios de mercado en otras provincias como Quillabamba y Canchis por ser zonas que presentan características similares al ámbito estudiado, lo que ha de permitir ampliar la oferta del producto planteado en el presente proyecto.

3. Reducir el tamaño de las instalaciones de pastos con la implementación de la técnica alternativas como la de hidroponía método de cultivo industrial; el mismo que permitiría realizar una localización de la planta de producción más cercana al punto de venta en la ciudad de Cusco, previo estudio de costos.

4. Posicionar el producto prepuesto del presente plan en las cadenas de supermercados de la ciudad del cusco teniendo como estrategia la aplica en el presente proyecto a través de la degustación e impulsación del mismo, así como la difusión a través de medios de comunicación de las bondades del producto.

5. Ser recomienda controlar las variaciones de los costos de producción y baja de precio de venta, pues un incremento de los precios de materias primas mayores al $30 \%$ y la reducción del precio de venta de un $10 \%$ ocasionarían que el proyecto no sea atractivo ni rentable para los inversionistas. 


\section{Índice De Tablas.}

Pg.

Tabla 1 Raza de Cuy Mejorada con Mayores Índices de Ganancia de Peso, Número de Crías

Tabla 2 Producción Nacional por Región Natural

Tabla 3 Distribución de la Producción Nacional por Región.

$\begin{array}{llll}\text { Tabla } 4 & \text { Segmentación de Criadores y Consumidores } & 14\end{array}$

$\begin{array}{llll}\text { Tabla } 5 & \text { Principales Empresas que Exportan Carne de Cuy al Exterior } & 16\end{array}$

$\begin{array}{llll}\text { Tabla } 6 & \text { Interrogantes Formuladas } & 23\end{array}$

$\begin{array}{lll}\text { Tabla } 7 & \text { Interrogantes Formuladas } & 24\end{array}$

$\begin{array}{llll}\text { Tabla } 8 & \text { Interrogantes Formuladas } & 25\end{array}$

Tabla 9 Matriz de Atractividad de las Cinco Fuerzas de Porter 27

Tabla 10 Asociaciones de Productores de la Región Cusco 30

Tabla 11 Matriz del Perfil Competitivo Sector Venta Carne de Cuy en 35

Tabla 12 Perfil de la Segmentación del Público en General 48

Tabla 13 Perfil de la Segmentación de Restaurantes 49

Tabla 14 Distribución Población Proyectada por Estratos de Cusco, 53

Tabla 15 Distribución Población Proyectada Según Proporción: 55

Tabla 16 Distribución Población Proyectada Según Proporción: 55

Cusco, Calca y Urubamba 2016

Tabla 17 Número de Encuestas por Distrito 57

Tabla 18 Distrito en los que se Encuentran Viviendo $\quad 61$

Tabla 19 Manera de Comprar la Carne de Cuy 65

Tabla 20 Cuantas veces y Frecuencia de Compra 67

Tabla 21 Características que Considera Determinante 70

Tabla 22 Donde le Gustaría Adquirirlo $\quad 72$

Tabla 23 ¿Este Cargo le da la Facultad de Decidir las Compras de 74

Alimentos para el Restaurante?

Tabla 24 Distrito en que se Encuentra su Restaurante 75

Tabla 25 En sus Locales se Preparan Platos a Base de Carne de Cuy 76

Tabla 26 Condiciones de Crianza y de Higiene del Cuy que Compra 79

Tabla 27 Precio que Paga Según Tipo de Cuy 80

Tabla 28 Conocimiento de Ventajas de Adquirir Carne de Cuy 83 
Tabla 29 ¿Este Cargo le da la Facultad de Decidir las Compras de Alimentos para el Restaurante?

$\begin{array}{lll}\text { Tabla } 30 & \text { Distrito en que se Encuentra su Restaurante } & 87\end{array}$

Tabla 31 En sus Locales se Preparan Platos a Base de Carne de Cuy 88

Tabla 32 Precio que Paga según Tipo de Cuy 93

Tabla 33 Conocimiento de Ventajas de Adquirir Carne de Cuy 95

Tabla 34 Perfil Público en General 100

$\begin{array}{lll}\text { Tabla } 35 & \text { Perfil Restaurantes Tradicionales } & 101\end{array}$

$\begin{array}{lll}\text { Tabla } 36 & \text { Perfil Restaurantes Turísticos } & 102\end{array}$

Tabla 37 Población Proyectada en Base a la Tasa de Crecimiento por 105 Distritos y Provincias

Tabla 38 Población en Serie Tiempo 105

Tabla 39 Aplicación de la Ecuación 106

$\begin{array}{ll}\text { Tabla } 40 & \text { Demanda Proyectada a Cinco Años }\end{array}$

$\begin{array}{lll}\text { Tabla } 41 & \text { Población Urbana por Distritos } & 108\end{array}$

$\begin{array}{lll}\text { Tabla } 42 & \text { Filtros de Edad y Nivel Socio Económico } & 109\end{array}$

Tabla 43 Mercado Potencial para Público en General 110

Tabla 44 Total de Restaurantes Inscritos y Acreditados en DIRCETUR 111 2016

Tabla 45 Filtros por Tipo de Restaurante 111

Tabla 46 Mercado Potencial para Restaurantes Turísticos 111

Tabla 47 Total de Restaurantes Inscritos y Acreditados en DIRCETUR 112 2016

Tabla 48 Filtros por Tipo de Restaurante 112

Tabla 49 Mercado Potencial para Restaurantes Tradicionales 113

Tabla 50 Mercado Disponible Público en General Proyectado 114

Tabla 51 Mercado Disponible Restaurantes Turísticos Proyectado 114

Tabla 52 Mercado Disponible Restaurantes Tradicionales 115

Tabla 53 Factor de Ajuste de McDaniel y Gates para Público en 116 $\begin{array}{ll}\text { General } & \\ \text { Mercado Efectivo Público en General } & 117\end{array}$

$\begin{array}{lll}\text { Tabla } 54 & \text { Mercado Efectivo Público en General } & 117 \\ \text { Tabla } 55 & \text { Factor de Ajuste de McDaniel y Gates para Restaurantes } & 118\end{array}$

Tabla 56 Mercado Efectivo Restaurantes Turísticos 119

Tabla 57 Factor de Ajuste de McDaniel y Gates para Restaurantes 119

Tabla 58 Mercado Efectivo Restaurantes Tradicionales 120

Tabla 59 Mercado Objetivo Público en General para un Escenario 121 optimista con un $15 \%$ 
Tabla 60 Mercado Objetivo Público en General para un Escenario

Conservador con un $10 \%$

Tabla 61 Mercado Objetivo Público en General para un Escenario

Pesimista con un $5 \%$ o

Tabla 62 Mercado Objetivo para un Escenario Optimista con un 15\%

Tabla 63 Mercado Objetivo para un Escenario Conservador con un

Tabla 64 Mercado Objetivo para un Escenario Pesimista con un 5\%

Tabla 65 Mercado Objetivo para un Escenario Optimista con un 15\%

Tabla 66 Mercado Objetivo para un Escenario Conservador con un

Tabla 67 Mercado Objetivo para un Escenario Pesimista con un 5\%

Tabla 68 Frecuencia de Compra

Tabla 69 Ponderado de Compra por Familia

Tabla 70 Proyección de Ventas Público en General

Tabla 71 Frecuencia de Compra

Tabla 72 Ponderado de Compra por Restaurante Turístico

Tabla 73 Proyección de Ventas Restaurantes Turístico

Tabla 74 Frecuencia de Compra

Tabla 75 Ponderado de Compra por Restaurante Tradicional

Tabla 76 Proyección de Ventas Restaurante Tradicional

Tabla 77 Proyección Ventas Tres Segmentos en un Escenario

Tabla 78 Rendimiento de Alfalfa por Año

Tabla 79 Consumo de Alfalfa por Cuy Diario, Mensual y Anual

Tabla 80 Estructura para Determinar la Cantidad de Hectáreas de

Tabla 81 Programa de Adquisición y Remplazo de Reproductores

$\begin{array}{lll}\text { Tabla } 82 & \text { Sistema de Reproducción } & 138\end{array}$

$\begin{array}{lll}\text { Tabla } 83 \text { Calculo para Cantidad de Personal Jornalero } & 140\end{array}$

$\begin{array}{lll}\text { Tabla } 84 & \text { Equipo y Maquinaria } & 148\end{array}$

$\begin{array}{lll}\text { Tabla } 85 & \text { Equipo y Maquinaria } & 148\end{array}$

$\begin{array}{lll}\text { Tabla } 86 & \text { Equipo y Maquinaria } & 149\end{array}$

$\begin{array}{lll}\text { Tabla } 87 & \text { Equipo y Maquinaria } & 150\end{array}$

Tabla 88 Descripción Equipo y Maquinaria $\quad 150$

$\begin{array}{lll}\text { Tabla } 89 & \text { Equipo y Maquinaria } & 151\end{array}$

Tabla 90 Descripción Equipo y Maquinaria $\quad 152$

Tabla 91 Proyección de Crecimiento para Instalación de Alfalfa 153 
Tabla 92 Determinación de Pozas de Área de Reproducción 154

Tabla 93 Determinación de pozas de Área de Engorde 154

Tabla 94 Proyección de Crecimiento Infraestructura Galpones de 155

Tabla 95 Recursos para Producción de Alfalfa 156

Tabla 96 Descripción Recursos para Producción de Alfalfa 157

Tabla 97 Recursos para Proceso de Crianza 160

Tabla 98 Descripción Recursos para Proceso de Crianza 161

Tabla 99 Recursos para Área de Sacrificio 164

Tabla 100 Descripción Recursos para Área de Sacrificio 165

Tabla 101 Recursos para Área de Empacado 167

Tabla 102 Descripción Recursos para Área de Empacado 168

$\begin{array}{lll}\text { Tabla } 103 & \text { Tamaño de la Planta } & 170\end{array}$

Tabla 104 Localidades para la Ubicación de la Crianza de Cuyes 171

Tabla 105 Lugares Potenciales para Localización de la Planta 172

$\begin{array}{ll}\text { Tabla } 106 \text { Método Cualitativo por Puntos } & 179\end{array}$

Tabla 107 Características y Descripción para Formular la Visión 181

Tabla 108 Características y Descripción para Formular la Misión 183

Tabla 109 Ventajas Competitivas Críticas 186

Tabla 110 Asignación de Remuneraciones y Compensaciones 196

Tabla 111 Plan de Ventas Proyectada para un Periodo de 5 Años 203

Tabla 112 Inversiones Pre Operativa Activo Fijo. 206

Tabla 113 Inversión Pre Operativa Capital de Trabajo. 207

Tabla 114 Inversión Pre Operativa Activo Intangible 208

Tabla 115 Costos del Proyecto 209

Tabla 116 Flujo de Inversiones Proyectado por Años. 210

Tabla 117 Participación de Aporte. 211

Tabla 118 Cotización para Servicio de Deuda Requerido 212

Tabla 119 Amortización de la Deuda por Años 214

Tabla 120 Costo de Oportunidad de Capital. 215

Tabla 121 Crecimiento Promedio Geométrico 216

Tabla 122 Indicador Tasa Riesgo País Perú 2016.

Tabla 123 Tasa de Inflación Estados Unidos a Octubre $2016 \quad 217$

Tabla 124 Tasa Inflación Perú Fuentes Registro Variación Promedio 217

Tabla 125 Beta de Riesgo por Industria para Actividades "Business \% 218 Consumer" 
Tabla 126 Programa de Ventas. 220

Tabla 127 Estructura de Costos de Producción. 221

Tabla 128 Presupuesto de Compras Expresado 222

Tabla 129 Presupuesto de Costo de Ventas 223

Tabla 130 Gastos Administrativos 223

$\begin{array}{lll}\text { Tabla } 131 & \text { Presupuesto de Marketing } & 224\end{array}$

Tabla 132 Presupuesto de Gastos Financieros. 225

Tabla 133 Estado de Resultados Proyectados 226

Tabla 134 Balance General 227

Tabla 135 Flujo de Caja Proyectado con Crecimiento Anual 229

Tabla 136 Participación de Aportes Producción Estándar 230

Tabla 137 Flujo de Caja con Producción Estándar Cinco Años. 231

Tabla 138 Cálculo del Valor de Deshecho Comercial para Flujo de Caja 231 Estándar.

Tabla 139 Valor Actual Neto Económico y Tasa Interna de Retorno 233

Tabla 140 Valor Actual Neto Financiero y Tasa Interna de Retorno 234 Financiera

Tabla 141 Valor Actual Neto Económico y Tasa Interna de Retorno 234 Económico para Flujo Estándar.

Tabla 142 Valor Actual Neto Financiero y Tasa Interna de Retorno 235 Financiero para Flujo Estándar.

Tabla 143 Ratios Financieros. 236

$\begin{array}{lll}\text { Tabla } 144 & \text { Punto de Equilibrio } & 238\end{array}$

Tabla 145 Variaciones en el Costo de la Deuda 239

Tabla 146 Variaciones en el Costo de Producción 239

Tabla 147 Variaciones en Precio de Venta 240

Tabla 148 Variación en Participación de Mercado 240

Tabla 149 Variaciones en el Costo de Deuda 242

Tabla 150 Variaciones en el Costo de Producción. 242

Tabla 151 Variaciones en Precio de Venta. 243

Tabla 152 Variación en Participación de Mercado 244 


\section{Índice De Figuras}

Pg.

Figura 1 Análisis de La industria: análisis del entorno competitivo de La 19 industria del cuy de acuerdo a las cinco

Figura 2 Participación de Mercado de los Productores Región Cusco 31

Figura 3 Comparación de Procesos Productivos Actuales y Propuesto en el 33 Plan de Negocio

Figura 4 Evolución mensual de la producción. nacional” sección Economía” 39 Crecimiento en el PBI 2015 de los restaurantes

Figura 5 Carne de Cuy en carcasa y envasado al vacío 45

$\begin{array}{llll}\text { Figura } & 6 & \text { Etiqueta del producto } & 46\end{array}$

Figura 7 Número de Encuestas por Distrito $\quad 59$

$\begin{array}{lll}\text { Figura } 8 \text { Genero } & 60\end{array}$

$\begin{array}{lll}\text { Figura } 9 & \text { Número de familias } & 60\end{array}$

Figura 10 Ingreso mensual $\quad 62$

Figura 11 Consumo de carne $\quad 62$

$\begin{array}{lll}\text { Figura } 12 & \text { Ventajas de comer carne de cuy } & 63\end{array}$

$\begin{array}{lll}\text { Figura } 13 \text { Consume carne de cuy } & 64\end{array}$

Figura 14 Consume carne de cuy $\quad 64$

$\begin{array}{lll}\text { Figura } 15 & \text { Lugar de compra } & 66\end{array}$

Figura 16 Ocasión de compra. 66

$\begin{array}{lll}\text { Figura } 17 \text { Cantidad de cuyes que compra } & 68\end{array}$

$\begin{array}{lll}\text { Figura } 18 \text { Precio que paga. } & 69\end{array}$

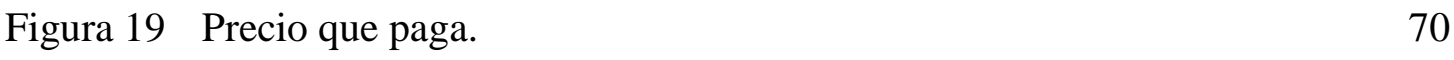

Figura 20 Conoce algún lugar.

$\begin{array}{lll}\text { Figura } 21 \text { Precio } & 72\end{array}$

Figura 22 Medios de comunicación $\quad 73$

$\begin{array}{ll}\text { Figura } 23 \text { Cargo que ocupa en el restaurante } & 74\end{array}$

$\begin{array}{ll}\text { Figura } 24 \text { Capacidad de comensales } & 76\end{array}$

$\begin{array}{lll}\text { Figura } 25 \text { Conoce a su proveedor } & 77\end{array}$

$\begin{array}{lll}\text { Figura } 26 & \text { Como se compra } & 77\end{array}$

$\begin{array}{lll}\text { Figura } 27 & \text { Lugar de compra } & 78\end{array}$

$\begin{array}{lll}\text { Figura } 28 & \text { Frecuencia de compra } & 79\end{array}$

$\begin{array}{ll}\text { Figura } 29 \text { Cantidad de compra } & 80\end{array}$

$\begin{array}{lll}\text { Figura } 30 & \text { Característica determinante } & 81\end{array}$

Figura 31 Disponibilidad de compra $\quad 82$

$\begin{array}{lll}\text { Figura } 32 & \text { Lugar donde le gustaría adquirir } & 83\end{array}$

$\begin{array}{ll}\text { Figura } 33 \text { Precio que estaría dispuesto a pagar. } & 84\end{array}$

Figura 34 Medio de comunicación que recibe más publicidad 85

Figura 35 Cargo que ocupa en el restaurante 86

$\begin{array}{lll}\text { Figura } 36 & \text { Capacidad de comensales } & 88\end{array}$ 
$\begin{array}{lll}\text { Figura } 37 & \text { Conoce a su proveedor } & 89\end{array}$

$\begin{array}{lll}\text { Figura } 38 \text { Como se compra } & 89\end{array}$

$\begin{array}{ll}\text { Figura } 39 \text { Lugar de compra } & 90\end{array}$

$\begin{array}{lll}\text { Figura } 40 \text { Condiciones de compra } & 91\end{array}$

Figura 41 Frecuencia de compra $\quad 91$

$\begin{array}{lll}\text { Figura } 42 \text { Cantidad de compra } & 92\end{array}$

Figura 43 Característica determinante $\quad 94$

Figura 44 Disponibilidad de compra $\quad 95$

$\begin{array}{lll}\text { Figura } 45 & \text { Lugar donde le gustaría adquirir } & 96\end{array}$

Figura 46 Precio que estaría dispuesto a pagar 96

Figura 47 Medio de comunicación que recibe más publicidad 97

$\begin{array}{ll}\text { Figura } 48 \text { Ámbito de estudio } & 104\end{array}$

$\begin{array}{lll}\text { Figura } 49 & \text { Tipos de mercado } & 107\end{array}$

$\begin{array}{lll}\text { Figura 50 Diagrama proceso cultivo de alfalfa } & 133\end{array}$

$\begin{array}{ll}\text { Figura 51 Diagrama proceso de crianza } & 136\end{array}$

$\begin{array}{lll}\text { Figura 52 Diagrama proceso de sacrificio } & 139\end{array}$

$\begin{array}{ll}\text { Figura } 53 \text { Diagrama proceso cultivo de empacado } & 141\end{array}$

$\begin{array}{ll}\text { Figura } 54 \text { Galpón de reproductores } & 143\end{array}$

Figura 55 Distribución y diseño de pozas de galpón de reproductores. 143

$\begin{array}{ll}\text { Figura } 56 \text { Galpón de engorde } & 144\end{array}$

Figura 57 Distribución y diseño de jaulas del galpón de engorde 145

Figura 58 Distribución y diseño área de sacrificio, empacado y administrativo 146

$\begin{array}{ll}\text { Figura } 59 \text { Distribución de Planta } & 147\end{array}$

$\begin{array}{lll}\text { Figura } 60 & \text { Plano distribución proceso de sacrificio } & 149\end{array}$

Figura 61 Distribución área de empacado 151

$\begin{array}{lll}\text { Figura } 62 & \text { Estructura orgánica propuestas } & 187\end{array}$

Figura 63 Programa de inversiones etapa pre operativa 206 
ANEXOS 


\section{Anexo 01}

Criadores de cuyes de la Región Cusco.

Criadores de Cuyes de la Region Cusco

\begin{tabular}{|c|c|c|c|c|}
\hline \multirow{2}{*}{ NRO } & \multirow{2}{*}{ NOMBRE DE LA AGRUPACION } & \multirow{2}{*}{ DIRECCION } & \multicolumn{2}{|c|}{ UBICACION } \\
\hline & & & PR OVINCIA & DISTRITO \\
\hline & Asociacion de Productores Agrto pecuarios Licenciados & C.C. Compone & ANTA & Antax \\
\hline 2 & Asociacion do Productores Pecuarios L.AS FLORES & C.C. Compons & ANTAL & Anta \\
\hline 3 & Asociacion de Pro duc tores de Cuy Union Sima & C.C. Simaseucho & ANTA & Cachimayo \\
\hline 4 & Asociacion de Productores Asgro pecuarios do $\mathrm{C}$ uy Lhion Rosar: & C.C.Cachimayo & ANTAL & Cachimayo \\
\hline 5. & Associacion de Pro ductores A_zto pecuarios de Cuy Ricchari Wa & C.C Compons & ANTA & Cachimayo \\
\hline 6 & Asociacion de Productores Azg to pecuarios de $\mathrm{Cuy} 15$ de Mayo & C.C Cachimayo & ANTA & Cachimayo \\
\hline 7 & Asociacition de Productores de Cuy Tinlicuy & C.C. Cachimayo & ANTA & Cachimayo \\
\hline 8 & Asociacion de Animates Menores Sr de in Senrencia & C.C. Juan Volasco Alvaradc & ANTA & Pucyura \\
\hline 9 & Asociacion do Productores Virgen de la Natividad & C.C. Juan Volageo A.tvaradc & ANTA & Pucyura \\
\hline 10 & Asociacion de Productores S an Bartolome & C.C. Tambo Roa 1 & ANTAL & Zurits \\
\hline 11 & Asociacion de Productores Nueva Esperana & C.C. San Nicolas de Bati & ANTA & Zurits \\
\hline 12 & Asociacion do Productores Antasayac & C.C. Uringaya Anangaya & ANTA & Anta \\
\hline 13 & Asociacion de Productores de Cuyes Cuy de oro & C.C. Conchacalla & ANTA & Anta \\
\hline 14 & Asociacion de Productores do Cuyos andino & c.c. Conchacalla & ANTA & Anta \\
\hline 15 & Asociacion de Criadores de Cuyos Cristo Rey & C.C. Ayarmaca & ANTA & Pucyura \\
\hline 16 & Asociacion de Productores Qaly Causay & C.C. Katafitay & ANTA & Ancalunasi \\
\hline 17 & Associacion de Criadores do Cuyes Cisolo. Antefilo & C.C. Juan Volageo A.tvaradc & ANTA & Pucyura \\
\hline 18 & Asoociacion de Productores Killa Rumizoc & C.C. Chaquilecasa & ANTA & Ancaluasi \\
\hline 19 & Grupe Org anizado S anta Ines & C.:C Pacea & ANTAL & Anta \\
\hline 20 & Grupo Organizado ol gigants & C.C. Conchacalla & ANTA & Anta \\
\hline 21 & Grupo Organizado Nuevo Amanecer & C.C. Ccaccahuara & ANTA & Acahuasi \\
\hline 22 & Grupo organiado Santa Inos & C.C. Ceacoshuara & ANTA & Acahuasi \\
\hline 23 & Grupo Org anizado Manay California & C.C. Circa Kajya & ANTA & Acahusasi \\
\hline 24 & Grupo organi-a do S anta Inos & C.C. Curamba & ANTA & Zuxits \\
\hline 25 & Grupo Organimado Seflor do Qoytloriti & C.C. Kohuar & ANTA. & Antax \\
\hline 26 & Asociacion San Juasn do Ureo & c.C. Uroo & CALCA & Calea \\
\hline 27 & Asociacion de Pro ductores L lankati Huqqui & Calea & CALCA & Calca \\
\hline 28 & Asaciacion de Criadores de Cuyes V alb Sagrado do los Ineas & Calea & C.ALCA_ & Calea \\
\hline 29 & Associacion do Pro duc tores A.llin L larileani & Calea & C.ALCA. & Calea \\
\hline 30 & Asociacion de Productores S ayhua & C.C. Sayhux & C.ALCA & Lamay \\
\hline 31 & Asociacion de Productores Chumpe & C.C. Clmumpe & C.ALCA & Lamay \\
\hline 32 & Asociacion do Gana deros Sacca & C.C. Sacea & CALCA & Pisac \\
\hline 33 & Associacion de Productores Individuales & San Salvador & CAALCA & San Sakador \\
\hline 34 & Asociacion do Criadores de Cuyos So1 Naciente & C.C. Suiga & C ALCA & San Sakador \\
\hline 35 & Asociacion de Crial dores de Cuyes Apu Nugta & C.C. Oocoturo & CALCA & San Sakador \\
\hline 36 & Asociacion Nubva Generacion Ellapa & C.C. Siuga & C.ALCA A & San Sakador \\
\hline 37 & Asociacion Yuraq qaqa & C.C. Pacor Aita & CALCA. & San Sakador \\
\hline 38 & Asociacion Santa Monica & Miraflores & CALCA & San Sakador \\
\hline 39 & Asociacion Hiatun Qoo de Coya & c.C. Coya & C.ALCAA & Coya \\
\hline 40 & Asociacion de Pro ductores Nueva Generacion & C.C. Sivos & C.ALCA & San Sakador \\
\hline 41 & Asociacion de Cuyes los Descalinos & Calea & CAICA & Calea \\
\hline 42 & Asociacion de Criadores de Cuyes Appu Hiatun C & Calea & C.ALCA & Coya \\
\hline 43 & Grupo Organimado los Luceros & c.c. uringaya & C.ANCHIS & Combapata \\
\hline 44 & Grupe de Jovones Solid arios & C.C. Mamuera & CANCHIS & Marangani \\
\hline 45 & Asociacion de Pro duc tores de Huicachani & C.C. Huicachani & CANCHIS & Marangani \\
\hline 46 & Asociacion do jovenas Productorses de CC Cuyo & C.C. Cyyo & C.ANCHIS & Marangani \\
\hline 47 & Asociacion des Productores S umac Coos & C.C. Cuyo & CANCFIS & Marangani \\
\hline 48 & Asociacion de Productores los Garapos & C.C. Cuyo & C.ANCHIS & Marangani \\
\hline 49 & Asociacion de Productores Nueva Esperana & C.C. Totorani & CANCHIS & Combapata \\
\hline 50 & Asociacion de anima les monores de Cuyos Canchis & Sicuani & C.ANCHIS & Sicuani \\
\hline 51 & Associacion de Criadores de Cuyos Seflor del Filuerto & Trapiche & C.ANCHIS & S icuani \\
\hline 52 & Asociacion de Criadores de Cuyos Canchinos & Sicuani & C.ANCHIS & Sicuani \\
\hline & Grupo Organizado de Cuyes los Cuturos del Vallecito & Vallocito & CANCFIS & Sicuani \\
\hline 54 & Associacion de Criadores de Cuyos los Mavuitos & C.C. Tiquifta & C.ANCHIS & Choc acupes \\
\hline 55 & Asociacion de Productores S ol Naciente & Tinta & C.ANCHIS & Chacacupo \\
\hline 56 & Associacion do Criadores do Cuy Lideres de Saytla & Say tha & cusco & Say $11 \mathrm{a}$ \\
\hline 57 & Associacion do Criadores do Cuy Sumaq Cos & C.C. Corao & cusco & San Sobastian \\
\hline 58 & Asociacion de Productores las Dalias & Zons Norts & $\operatorname{cusco}$ & San Sobascian \\
\hline 59 & Asociacion de Criadores de Huastla cocha & C.C. Huaytlac ocha & $\operatorname{cusco}$ & Cusco \\
\hline 60 & Associacion de Criadores de Cuyes de Mayrasco & C.C. Mayraseo & cusco & Santia go \\
\hline 61 & Asociacion do Criadores de Cuyos Retamalos do Ceachona & C.C. Cachona & cusco & Sancia go \\
\hline 62 & $\begin{array}{l}\text { Asociacion de Pro ductores A.gropecuarios y de anima bs } \\
\text { menores Nueva Generacion }\end{array}$ & C.C Oc0opata & cusco & S antis go \\
\hline 63 & Asociacion de Criadoroes de CuYEsere tha de Chitapampa & C.C Chitapampa & Cusco & S suntix go \\
\hline 64 & Comits de Cria dores de Cuy Ccateca & C.C. Coatoca & QUISPIC.ANCHI & Ceatcos \\
\hline 65 & Comits de Cria dores de Cuy Antisuyso & C.C. C caluraya A.lto & QUIS PIC.ANCHI & Quiquijana \\
\hline 66 & Comits do Criadores do Cuy Hua co aytaki & C.C. Hua co aytaki & QUISPICANCHI & Quiquijana \\
\hline 67 & Comite do Criadores do Cuy Carhuayo & c.C. Carhuayo & QUISPICANCFI & Carlurayo \\
\hline & Comits de Criadores de Cuy Pigpita & C.C: Pispita & QUISPICANCHI & Ocongate \\
\hline 69 & Comits de Criadores de Cuy Chacachimpa & C.C. Chacachimpa & QUIS PICANCHI & Ocongate \\
\hline 70 & Comits do Criadores do Cuy Pucabamba & C.C. Pucabamba & QUIS PICANCFI & Ocongate \\
\hline 71 & Comits de Criadores de CuyMarjugata & C.C Marjugata & QUISPICANCHI & Ocongate \\
\hline 72 & Comits de Criadores de Cuy Parcacolla & C.C. Parcacolla & QUISPICANCANI & Ocongate \\
\hline 73 & Comits do Criadores do CuyLa Providoncin & Quiquijana & QUISPICANCHI & Quiquijana \\
\hline 74 & Associacion Provincial de Criadores de Cuy & Unubamba & URLBAAMBA.A & Unubamba \\
\hline 75 & Asociacion do Dosarrollo $\mathrm{Y} S$ istematimacion & Chinchero & URTIB_AMBA. & Chinchero \\
\hline 76 & Asociacion de Criadores y rePro duc tores Mo $90 \mathrm{q}$ W ayna & Chinchero & URTEBAMBA. & Chinchero \\
\hline 77 & Associacion $\mathrm{S}$ an Isidro do Urquitlo & Urquillo & URTBAMBA. & Huaytlabamba \\
\hline
\end{tabular}




\section{Anexo 02}

\section{Programa de inversiones 2013-Gobierno Regional del Cusco.}

\begin{tabular}{|c|c|c|c|}
\hline $\mathrm{N}^{\circ}$ & Cód. SNIP & Nombre del Proyecto / Unidades Ejecutoras & PRESUPESTO 2013 \\
\hline 1 & 214833 & MEJORAM IENTO DE LA CADENA PRODUCTIVA DE CUYES EN LOS DISTRITOS DE LA PROVINCIA DE CANAS-CUSCO & $997,892.40$ \\
\hline 2 & 234625 & MEJORAMIENT O DE LA PRODUCCION Y COMERCIALIZACION DE CUYES EN LA C.C DE ACOS ACOMAYO & $76,482.00$ \\
\hline 3 & 234626 & INCREMENTO DE LA PRODUCCION Y COMERCIALIZACION DE CUYES EN LA C.C DE MARCACONG A - SANGARARA & $49,560.00$ \\
\hline 4 & 234627 & MEJORAM ENTO DE LA PRODUCTIVAD DE CUYES EN LA C.C DE KUÑUTAMBO - RONDOCAN - ACOMAYO - CUSCO. & $55,504.00$ \\
\hline 5 & 234628 & MEJORAMIENTO DE LA PRODUCTIVAD Y COMERCIALIZACION DE CUYES EN LA C.C DE COYA - CALCA - CUSCO. & $91,000.00$ \\
\hline 6 & 234629 & MEJORAMIENTO DE LA PRODUCCIÓN DE CUYES EN LA COMUNID AD DE TARAY, DISTRITO DE TARAY, CALCA, CUSCO. & $76,328.00$ \\
\hline 7 & 234630 & MEJORAMIENTO DE LA CRIANZA DE CUYES EN LA COMUNIDAD DE HUARAN DISTRITO DE CALCA - CUSCO. & $29,291.20$ \\
\hline 8 & 234631 & MEJORAMIENTO DE PRODUCTIVAD Y COMERCIALIZACION DE CUYES EN LA C.C DE TARAY - CALCA & $62,152.00$ \\
\hline 9 & 234632 & MEJORAMIENTO DE LA CRIANZA DE CUYES EN LA C.CDE CHIM PAPALPA - DISTRITO DE CALCA-CALCA CUSCO. & $20,894.00$ \\
\hline 10 & 234633 & INCREMENTO DE LA PRODUCCION DE LA CRIANZA DE CUYES EN LA C.C DE SIUSA - SAN SALVADOR CALCA CUSCO. & $49,164.00$ \\
\hline 11 & 234634 & TO DE LA PRODUCCION Y CRIANZA DE CUYES DE LA ASOCIACIÓN APU ÑUUSTA EN LA C.CDE OCCORURO - SAN SALVADOR CA & $58,637.40$ \\
\hline 12 & 234635 & ENTO DE LA PRODUCCION Y PRODUCTIVID AD DE LA CRIANZA DE CUYES EN LA C.C DE TIRACANCHA - SAN SALVAD OR CALCA & $65,000.00$ \\
\hline 13 & 234636 & MEJORAMIENTO PRODUCCIÓN DE CUYES Y COMERCIALIZACION CONJUNTA EN ANGOSTURA - SAYLLA CUSCO. & $89,506.00$ \\
\hline 14 & 234637 & MEJORAMIENTO DE LA CAPACDAAD PRODUCTIVA DE LA CRIANZA DE CUYES EN LA C.CDE HUATACALLA -PARURO & $90,000.00$ \\
\hline 15 & 234638 & MEJORAM IENTO DE LA CRIANZA DE CUYES EN LA C.C DE M OLLEMOLLE - HUANOQUITE PARURO. & $77,507.00$ \\
\hline 16 & 234639 & MEJORAMIENTO DE LA CRIANZA DE CUYES EN LA C.C DE ARAYCALLA DISTRITO DE & $41,745.00$ \\
\hline 17 & 234640 & MEJORAM IENTO DE LA CRIANZA DE CU YES EN LA C.C DE ANYARATE DISTRIT O DE YAURISQUI PARURO, CUSCO. & $41,709.00$ \\
\hline 18 & 234641 & MEJORAMIENTO DE LA CRIANZA DE CUYES EN LA COMUNIDAD DE ARAYPALLPA COLCHA PARURO CUSCO. & 47,529.00 \\
\hline 19 & 234642 & MEJORAMIENTO DE LA PRODUCTIVIDAD DE C & $52,920.00$ \\
\hline 20 & 234643 & MEJORAMIENTO DE LA PRODUCTIVIDAD DE LA CRIANZA DE CUYES EN LA C.C DE PAMPACUCHO - COLCHA - PARURO & $42,000.00$ \\
\hline 21 & 234644 & MEJORAMIENTO DE LA CRIANZA Y COMERCIALIZACION DE Cl & $35,910.00$ \\
\hline 22 & 234645 & MEJOR. LA CRIANZA DE CUYES EN LA CC DE KALLACANCHA, DISTRITO DE PAUCARTAMBO -PAUCART AMBO CUSCO. & $88,208.00$ \\
\hline 23 & 234646 & LLA CRIANZA DE CUYES PARA INCREMENT AR LA F & $50,780.00$ \\
\hline 24 & 234647 & $\begin{array}{l}\text { MEJ. DE LA PRODUCTIVIDAD DE CUYES EN LA CC. DE PARPACALLA - DISTRITO DE PAUCARTAMBO - CUSCO. } \\
\end{array}$ & $80,000.00$ \\
\hline 25 & 234648 & MEJ. DE LA PRODUCCION DE CUYES EN LA CC. DE TOCRA, DISTRITO DE COLQUEPATA - PAUCARTAMBO CUSCO. & $79,000.00$ \\
\hline 26 & 234649 & DE LA CRIANZA Y COMERCIALIZACION DE CUYES EN LA CC DE INCA PAUCAR DISTRITO DE COLQUEPATA PAUCARTAMBOC & $69,966.00$ \\
\hline 27 & 234650 & MEJ. DE LA PRODUCTIVIDAD DE CUYES EN LA CC DE LLULLUCHA DISTRITO DE PAUCARTAMBO CUSCO. & $29,610.00$ \\
\hline 28 & 234651 & IMPLEMENTACION Y MEJ. DE LA CRIANZA DE CUYES EN LA C.C. DE PHUYUCALLA - DISTRITO DE PAUCART AMBO & $47,648.00$ \\
\hline 29 & 234652 & MEJ. DE LA PRODUCTIVIDAD DE CUYES EN LA C.C DE SIHUAYPAMPA -DISTRITO DE PAUCARTAMBO - CUSCO. & $31,240.00$ \\
\hline 30 & 234653 & MEJ. DE LA PRODUCCIÓN DE CUY ENLA CC DE OCONGATE, DISTRITO DE OCONGATE - QUISPICANCHI CUSCO. & $90,000.00$ \\
\hline 31 & 234654 & IPLIACION DE LA PRODUCCION TECNIFICADA DE CUYES EN LA CC DE HUASA O - DISTRITO DE OROPEZA QUISPICANCHI & $93,425.20$ \\
\hline 32 & 234655 & MEJ. DE LA PRODUCCION Y COMERCIALIZACION DE CUYES EN LA C.C. DE CHIMPA QUIQUIJANA - QUISPICANCHI & $44,800.00$ \\
\hline 33 & 234656 & MEJ. DE LA PRODUCCION Y COMERCIALIZACION DE CUYES EN LA C.C. DE HUACCAYTAQUI - DIST.QUISPICANCHI & $38,439.00$ \\
\hline 34 & 234657 & MEJ. DE LA PRODUCCION Y COMERCIALIZACION DE CUYES EN LA C.C DE TTIO - DISTRITO DE QUISPICANCHI & $43,448.40$ \\
\hline 35 & 234658 & MEJ. DE LA CRIANZA DE CUYES ENEL C.C. CAMPESINA DE SALLAC-DISTRITO URCOS QUISPICANCHI CUSCO. & $51,000.00$ \\
\hline 36 & 234659 & MEJ. DE LA CRIANZA DEL CUY EN LA CC. DE UMUTO DISTRITO DE URCOS QUISPICANCHI CUSCO. & $55,640.00$ \\
\hline 37 & 210438 & DE LOS PROCESOS DE INDUSTRIALIZACION Y ADIESTRAMIENTO DE LA CARNE DE CUY EN LAS PROVINCIASDE CUSCO Y CAN & $450,000.00$ \\
\hline \multicolumn{3}{|r|}{ TOTAL DE INVERSION } & $3,493,935.60$ \\
\hline
\end{tabular}


Anexo 03

Estudio cualitativo entrevista a expertos.

Entrevista:

Expertos Criadores Ministerio de Agricultura Proyecto "Mejoramiento de la competitividad de la cadena productiva de cuyes"

Propuesta Crianza e Industrialización de la Carne de Cuy Ecológico para su Comercialización en la región Cusco.

Lugar : Oficina del Proyecto Cadena Productiva de Cuyes del Ministerio de Agricultura Fecha: viernes 15 de julio del 2016.

Hora: 9:00 a 11:00 am

\section{Presentación del Moderador:}

El moderador de esta entrevista fue Sr Erick Bocangel, quien dio inicio al mismo agradeciendo la participación de los profesionales y técnicos del proyecto quien dio a conocer los objetivos

\section{Objetivo:}

Recabar información con respecto a producción de alfalfa, crianza de cuyes, sacrificio y empacado de los mismos para una producción industrializada de cuy ecológico empacado al vacío,

Para ello se pidió el aporte de todo los integrantes del focus a cada pregunta planteada sugirió que este reunión se haga por etapas la primera todo lo referente al proceso de pastos, 
seguido del proceso de crianza y finalmente la de sacrificio y empacado. Seguidamente pidió a cada participante su presentación.

\section{Presentación de Participantes:}

Inicio la presentación el $\mathrm{Ing}^{\circ}$ Nilo Gerente del Proyecto cuyes quien manifestó su vasta experiencia en el conocimiento de este tipo de proyectos de profesión $\operatorname{Ing}^{\circ}$ Zootecnista con más de 15 años en ejercicio profesional y que el proyecto que actualmente dirige en las zonas alto andina de la Región comprende desde la producción de pastos hasta el sacrificio y empacada.

Seguidamente hizo su presentación el $\mathrm{Ing}^{\circ}$ Sandro Coordinador del Proyecto Cuyes quien indico que aparte de trabajar para este proyecto se dedica a la crianza de cuyes de forma independiente por más de seis años.

Luego fue turno del técnico Agropecuario Alfredo quien también trabaja en el proyecto cuyes como especialista y que también se dedica a la crianza de cuyes de forma independiente.

También hizo su presentación el técnico Roger Técnico Agropecuario especialista del proyecto cuyes, dedicado también a la crianza de cuyes.

El Sr Antonio Técnico Agropecuaria especialista del proyecto dedicado de forma particular a la crianza de cuyes y a la fabricación de jaulas y pozas para cuyes.

El Técnico Agropecuario Miguel manifiesta ser especialista también del proyecto dedicado a la producción de pastos. 


\section{Preguntas para el Proceso de Cultivo de alfalfa.}

\section{1. ¿Cuánto es el consumo promedio de pasto de un cuy y riesgos en la producción} de pastos?

A la pregunta realizada tomo la palabra el Ing. Nilo quien aseguro que un cuy requiere un promedio de 230 gr. De alfalfa más o menos la cuarta parte de su peso vivo entendiendo que el pasto verde contiene un $20 \%$ de materia seca y el $80 \%$ restante es agua.

El ing. Sandro identificó los riesgos que generan la baja producción de pastos señalando que un inadecuado tratamiento de estos vale decir deshierbo, abono retrasaría la producción prolongando el ciclo de crecimiento y obtención de alimento.

\section{2. ¿Qué tipo de pastos es el adecuado para una alimentación con alto valor} nutricional para los cuyes?

A la pregunta realizada todo el grupo técnico participante indicó de manera unánime que la Alfalfa es el alimento con mayor cantidad de nutrientes para estos animales.

3. ¿Cuál es el mejor tipo de concentrado que se le puede administrar a un cuy para una mejor ganancia de peso?

El ing ${ }^{\circ}$ Sandro coordinador del Proyecto cuyes y criador de estos animales indica que el clima cálido favorece a un desarrollo más rápido con mayor ganancia de peso considerando no recurrir a estos concentrados y criarlos únicamente con alfalfa.

Asimismo se identificó que la alimentación de cuyes con harinas concentradas puede presentar toxinas nocivas para el animal como hongos, gorgojos o paracitos que afectan al estómago del cuy. 
Se concluyó que, si la zona donde se pretende cultivar los pastos cuenta con riego además de las época marcada de lluvias garantizaría la cantidad de alimento para estos animales, no siendo indispensable los concentrados.

Se dejó como recomendación recurrir solo a estos suplementos solo como un recurso contingente ya que se debe tomar en cuenta la optimización de costos de producción.

\section{4. ¿La administración de concentrados cambia el sabor de la carne de cuy?}

Tomo la palabra el Técnico Alfredo, quien indicó que si varia el sabor de la carne de cuy entre un animal alimentado solo a base de forraje y uno que recibió alimentación complementada.

Tomo la palabra el Ing. Nilo, quien indicó que se han creado muchos mitos acerca de la alimentación concentrada como lo sucedido con la producción de huevos.

El Ing. Sandro Molina afirmó que aún no se conoce de manera exacta este efecto ya que en la industria del cuy no existe una empresa que se especialice en el desarrollo de alimento exclusivo para este animal, por lo que no es habitual la alimentación de cuyes con concentrados sustitutos del forraje.

Tomo la palabra el técnico Roger quien señalo que existen otros factores que afectan el sabor de la carne de cuy, como por ejemplo el stress del animal a causa de un mal transporte, ya que el stress en estos animales genera deshidratación y secreción de bilis.

\section{5. ¿El valor nutricional de la carne depende de la calidad de los pastos y} suplementos que se disponga?

Todo el grupo concluyó con que un cuy alimentado netamente de forraje desarrolla un valor nutricional optimo esperado dentro de los estándares, sin embargo 
estos complementos son necesarios si es que se desea optimizar tiempos y costos de producción y cría de cuyes.

6. ¿Cuánto es el tiempo aproximado para obtener un cuy con el peso ideal para sacrificio con una alimentación solo de pasto y/o alfalfa?

De manera unánime todo el grupo concluyo que con los factores de alimentación y clima adecuados el tiempo esperado para ganancia de peso ideal es de 03 meses en la raza Mi Perú.

7. ¿Dónde seria la localización recomendable para el sembrío y cosecha de estos pastizales?

A la pregunta planteada se obtuvo el consenso de recomendación de la zona de Limatambo ya que presenta características climatológicas y disponibilidad de agua que favorecen la permanente producción de alfalfa, con respaldo de un buen tratamiento de tierras y abonado a base de roca fosfórica.

Se tomó la intervención del técnico Antonio Barrientos Miranda, quien indicó que la producción de alfalfa en zonas de mayor altura y friaje complica el corte por alcanzar una menor altura y tamaño.

El ing. Nilo indicó que en una zona cálida como Limatambo se puede obtener hasta 6 cortes de alfalfa al año.

8. ¿Cuán recomendable es la utilización de chuponeras de agua en la dieta del cuy?

A la pregunta realizada tomo la palabra el Ing. Nilo quien indico que solo sería recomendable cuando se complemente la alimentación con otros recursos como suplementos o concentrados ya que estos generan deshidratación. 
El Técnico Antonio indicó que es recomendable en temporada de secas la instalación de una chuponera Adlivitum en época de sacas con una dosis de $100 \mathrm{ml}$ de agua diaria.

De manera consensual se concluyó que mientras se mantenga una dieta a base de pastos no es necesaria la dosificación de agua ya que el pasto contiene un $80 \%$ de agua que cubre las necesidades de hidratación del animal de manera diaria.

\section{Para la implementación de cultivos de pastos, ¿qué es lo más importante a tener} en cuenta?

En la Intervención el técnico Alfredo indica: la disponibilidad de un terreno con presencia de agua para riego y un clima cálido que permita hasta 06 cortes al año dependiendo del mantenimiento que se haga al terreno lo cual fue corroborado por demás integrantes del equipo, $\mathrm{el} \mathrm{Ing}^{\circ}$ Sandro manifiesta que para tener un excelente rendimiento es necesario considerar labores agrícolas (limpieza de terreno, deshierbo, fumigación) considerando por la experiencia que tienen en el proyecto cuyes un promedio de 20 jornales por ha. Así mismo en la participación del Técnico Antonio Barrientos toma como muy importante el tema del abono de los terrenos de cultivo a base de roca fosfórica y nitratos que garanticen un óptimo rendimiento por hectárea teniendo un promedio de $357 \mathrm{~kg}$ entre adherentes y abonos a razón de s $/ .2 .00$ por cada ha

\section{Preguntas para el proceso de Crianza:}

\section{1. ¿Qué raza de cuy es recomendable de criar para este tipo de proyecto?}

A la pregunta realizada se concluyó de manera unánime que para este fin es recomendable la raza Perú en el tipo 1 lacio en colores claros o castaños, ya que el mercado exige que la presentación del cuy sea de carne blanca. 
2. ¿Dónde es posible conseguir esta raza de cuy?

A la pregunta planteada se tomó la participación del Ing. Nilo quien indicó que esta variedad de cuy es escaza siendo los mayores lugares de cría en las zonas de Anta, Limatambo, Marangani, Ocongate y Ccatca. Distritos de la Región Cusco.

3. ¿Cuál es el precio aproximado de esta raza de cuy en el mercado?

El Ing. Sandro Colque indicó que el promedio de venta de estos reproductores a va entre los S/. 25 a S/. 30 en hembras y S/. 35 los machos.

4. ¿Cada cuánto tiempo es recomendable el cruce de estos animales?

Manera general todos los miembros del grupo indicaron que es posible mantener periodos de cruce constante mejorando la alimentación cada vez que la hembra se encuentre en periodo de lactancia periodo aproximado por 14 días.

5. ¿Cuánto es el tiempo que puede aparearse un reproductor?

El total de los miembros índico que la vida útil de un reproductor tanto macho como hembra es de máximo 18 meses periodo en que se debe dar hasta 3 a 4 partos.

6. ¿Qué tipo de instalaciones recomendaría implementar para una apropiada cría y reproducción de cuyes?

El total de miembros del grupo indicó que es recomendable implantar pozas en suelo para el desarrollo de cuyes, destinado un área de 1.50x1.20 mt2 para reproducción.

El técnico Roger recomendó jaulas para recría en jaulas de cuatro pisos.

7. ¿Cada cuánto tiempo se debe realizar un control sanitario?

De manera unánime se recomendó que el control debe ser de manera permanente ya que se debe estar atento a cualquier problema que se pueda identificar. 
Tomo la palabra el ing. Nilo quien además de los controles recomendó que se deban tomar medidas preventivas rigurosas ya que el cuy es un animal muy delicado y la cría de estos animales en gran escala es muy propensa a sufrir diferentes plagas. Indicando que costo promedio mensual en temas de sanidad por cuy es de s/. 0.30.

\section{8. ¿Cuál es el peso ideal que debe alcanzar un espécimen para el ingreso a} beneficio?

Tomó la palabra el ing. Nilo quien indico que se debe alcanzar el peso de 1,200 gr. Para sacrificio y empacado.

Bajo el siguiente estándar:

Peso Vivo 1200 gr.

Beneficiado sin viseras 700 gr.

Sin cabeza y sin patas 550 gr.

Deshuesado 350 gr. De carne magra para empacado.

Tomó la palabra el Ing. Sandro quien indicó que la tendencia del mercado actual en la zona de Lima es la de pedir cuy de 1200 gr. Ya que de esta manera se puede obtener fracciones de este para servir al plato.

\section{9. ¿Qué cantidad de desecho orgánico produce 1000 cuyes y con qué frecuencia?}

Tomó la palabra el técnico Roger que señalo que en promedio un adulto de peso aproximado 1000 gr. Produce un aproximado de 40gr de desecho por día, por ende se puede determinar que un lote de 1000 cuyes generaría un total de 400 gr. De desecho diario. 
10. ¿De cuántas personas debe estar compuesto el equipo de trabajo para generar un volumen de producción de 6,000 a 10,000 cuyes mensuales y con qué especialidad deben contar?

Tomo la palabra el ing. Sandro quien indicó que es necesario contar con mínimamente un total de ocho colaboradores, de los cuales es necesario que tres estén encargados del área de pastizales y cinco en la parte operativa de cría y sacrificio.

El personal encargado de la sanidad debe ser a requerimiento.

\section{Preguntas para el proceso de Sacrificio:}

1. ¿Cuáles son las técnicas de beneficio más apropiadas para obtener un cuy pelado listo para empacar?

Tomó la palabra el técnico Antonio quien indicó que la mejor técnica para el sacrificio de los cuyes es la del desangrado ya que esta técnica evita que la sangre se concentre en el estómago del cuy.

Además de esta técnica existen otras técnicas como son por asfixia y desnucado los cuales no son muy recomendables ya que estas técnicas pueden acarrar en enfermedades como la linfadenitis.

Asimismo se mencionó que no se recomienda estas técnicas por malograr la presentación del cuy al momento de entregarlo al cliente final ya que genera rechazo de presentar cortes o cicatrices en el cuerpo.

2. ¿Cuantos metros cuadrados debe contar el área de sacrificio si se espera contar con un promedio de 6,000 a 10,000 cuyes beneficiados mensualmente?

De manera unánime se indicó que el área de sacrifico para este volumen de cuyes mensual es de 120 a $180 \mathrm{mt} 2$.

3. ¿Qué tipo de equipos de equipos se emplea para para el proceso de sacrificio, empacado al vacío y conservación de la carne de cuy? 
Tomó la palabra el Ing. Nilo quien indicó que es necesario siempre contar con una cocina industrial y ollas para el hervido de agua. Una peladora de cuyes, lavaderos con cañerías de agua para lavado, un espacio con ganchos para oreado y una empacadora al vacío con selladora.

Además es importante contar con cadenas de frio para conservación.

Se mencionó que la peladora presenta inconvenientes ya que la velocidad que cuenta no es la óptima para un volumen de cuyes a gran escala.

\section{4. ¿Cuál es el tiempo estimado para el sacrificio, empacado y almacenado para su} comercialización?

El ingeniero Sandro mencionó que el proceso de sacrificio tomando en consideración los tiempos estimados en el camal piloto del proyecto Cuyes es:

Aturdimiento minuto y medio minutos, pelado tres minutos, eviscerado cuatro minutos, oreado dos minutos tiempo que se toma en colocar un cuy en los ganchos de oreado.

La empacadora actual con la que cuenta la planta del ministerio de agricultura cuenta con una capacidad de tres cuyes por cada dos minutos.

\section{Preguntas para el Proceso de empacado:}

\section{1. ¿Cuánto tiempo se puede conservar la carne de cuy empacada al vacío sin que} esta pierda el valor nutricional obtenido?

Se concluyó que de manera unánime que el periodo en que se puede conservar no debe superar los 30 días congelados, ya que posterior a este plazo se compromete el valor nutricional de la carne.

El técnico Roger indicó que es posible obtener un mayor periodo de conservación si es que el empacado se realiza con la adición de otros gases 
conservantes, sin embargo no es recomendable ya que afecta el sabor del producto final.

El ing. Nilo Delgado dejo indicado que al momento de morir* cualquier animal genera una encina llamada "cadaverina" que deteriora la carne de manera permanente, sin embargo se han presentado experiencias que muestran que es posible conservar hasta por tres meses la carne en estado congelado.

El técnico Alfredo indicó que de conservar la carne por un periodo mayor a 30 días esta pierde el sabor y valor nutricional sin embargo no existe estudios que sostengan esta teoría. 
Anexo 04

Estudio cualitativo focus group restaurantes turísticos.

Propuesta Crianza e Industrialización de la Carne de Cuy Ecológico para su Comercialización en la región Cusco.

Lugar : Urb. Ingenieros Larapa B1 9D San Jerónimo Cusco.

Fecha: 01 de Julio del 2016.

Hora : 8:00 a 9:00 am

Presentación del Moderador:

El moderador de este Focus fue el Sr Helmut Escobar, quien dio inicio al mismo agradeciendo la participación de los asistentes.

\section{Objetivo:}

Recabar información respecto a las preferencias de los propietarios y chef de los restaurantes turísticos al momento de adquirir carne de cuy.

\section{Presentación de Participantes:}

Lounge Bar La Retama Scrl Rep. Legal: Julio Dirección: calle Procuradores 320.

Jimmy Jaimes Cheff Restaurant Paititi SCRL.

Inversiones Pucara EIRL Rep. Legal Susuki Dirección: Calle Plateros 309.

Restaurant Nuna Raymi EIRL Rep. Legal: Victor Dirección: Calle Triunfo 356.

Luis Cheff Restaurante Palacio Nazarenas.

Restaurante Mayo Nombre Representante Legal: Carlos.

Preguntas para el Proceso de Decisión de Compra. 


\section{1 ¿En su carta Ofrecen Platos a Base de Carne de Cuy?}

La respuesta de los integrantes de este Focus fue unánime indicando que todos ofrecen platos a base de esta carne.

\section{2 ¿Qué es lo Más Importante para adquirir esta Carne y donde le Gustaría}

\section{Comprarlo?}

Los participantes indicaron que sus restaurantes por ser turísticos cumplen con ciertos estándares para la adquisición de materia prima para la preparación de la carta que presentan a sus comensales coincidiendo todos ellos en los siguientes aspectos.

La carcaza debe ser impecable que no presente heridas de ningún tipo en ella ni presencia de pelos

La coloración de la misma debe ser rojiza, sin presencia de vísceras.

Todas deben tener un tamaño y peso estándar y la edad del animal debe ser relativamente joven tres a cuatro meses que garantice la suavidad de la carne.

Que la manipulación de este producto al momento de hacer la compra no se contamine.

Este animal debe ser alimentado lo más naturalmente posible para garantizar el sabor de su carne.

La exigencia de estos restaurantes se hizo reflejar en la presentación de la carcasa el mismo que lo prefieren empacado al vacío para poder almacenarlos y utilizar en el momento que lo soliciten y que la compra lo realizan de forma semanal en los alrededores del mercado de Cascaparo. 
Solicitaron que este producto sea entregado en sus restaurantes y que en algún momento estarían interesados en hacer una visita a la planta de producción lo cual les garantizaría saber que la carne que compran cumple con los estándares de sus establecimiento.

\section{3 ¿Cuánto Estaría Dispuesto a Pagar por este Producto Empacado al Vacío y que}

\section{Cumpla con todos sus Estándares?}

Manifiestan que actualmente compran este producto pelado, lavado y eviscerado a s/. 24 en los locales del mercado de Cascaparo pero estarían dispuestos a pagar entre s/. 24 y s/. 25 pero que cumplan con sus exigencias antes mencionadas. 
Anexo 05

Estudio cualitativo focus group restaurantes tradicionales.

Propuesta Crianza e Industrialización de la Carne de Cuy Ecológico para su Comercialización en la región Cusco.

Lugar : Tipon.

Fecha: 06 de Julio del 2016.

Hora : 8:00 a 9:30 am

Presentación del Moderador:

El moderador de este Focus fue el Sr Erick Bocangel, quien dio inicio al mismo agradeciendo la participación de los asistentes.

\section{Objetivo:}

Recabar información respecto a las preferencias de los propietarios de los restaurantes tradicionales al momento de adquirir carne de cuy.

\section{Presentación de Participantes:}

Restaurante Quinta La Cusqueñita propietario Jaime.

Restaurante El Rancho propietario Vicente.

Restaurante La Encantada propietario Irene.

Restaurante La Escondida propietario Eudocia.

Restaurante El Moqueguano propietario Marco.

Restaurante Sol Moquehuano propietario Romell.

Preguntas para el Proceso de Decisión de Compra. 


\section{1¿Qué es lo Más Importante para adquirir esta Carne y donde le Gustaría}

\section{Comprarlo?}

Los propietarios manifestaron que lo más importante para comprar esta carne es:

El tamaño de la carcasa que este en un rango de 750 a 800 gr.

Que sean maltones (no muy viejos, tres meses de edad).

Que la carne no tenga olor a concentrados al igual que el sabor.

Que los vendedores de este producto tengan suficiente stock al momento que realicen su compra, pues ellos compran semanalmente entre 50 a 300 cuyes.

Y que en la actualidad lo adquieren vivo y los traen a sus establecimientos desde las provincias de Calca, Ocongate, Acomayo.

Sería una buena alternativa que se venda pelado, lavado y eviscerado siempre y cuando el precio este dentro del promedio al que adquieren actualmente vivo, ya que les ahorraría bastante tiempo y adquirirlo empacado les ayudaría a conservarlos siempre y cuando no varié el sabor de esta carne.

\section{2 ¿Cuánto Estaría Dispuesto a Pagar por este Producto Empacado al Vacío y que}

\section{Cumpla con sus Exigencias?}

Manifiestan que actualmente lo compran vivo y que les traen de diferentes lugares a un promedio de s/. 23.00.

Anexo 06

Estudio cualitativo focus group público en general. 


\section{Propuesta Crianza e Industrialización de la Carne de Cuy Ecológico para su Comercialización en la Región Cusco.}

Lugar : Urb. Ingenieros Larapa B1 9D San Jerónimo Cusco.

Fecha: Miércoles 03 de julio del 2016.

Hora : 9:00 a 11:00 am.

\section{Presentación del Moderador:}

El moderador de este Focus fue el Sr Ingmar Aparicio Gutiérrez, quien dio inicio al mismo agradeciendo la participación de los asistentes.

\section{Objetivo:}

Recabar información respecto a las preferencias del público al momento de adquirir carne de cuy en los establecimientos existentes en la ciudad del Cusco.

\section{Presentación de Participantes:}

Inicio la presentación la Sra. Ricardina, quien manifestó ser profesora cesante con domicilio en el distrito de San Jerónimo Cusco.

Seguidamente hizo su presentación la sra. Caroll, comunicadora trabaja actualmente en la Beneficencia del Cusco con domicilio en el distrito de San Jerónimo - Cusco.

Luego fue turno de la señora Graciela cesante del hospital Regional del Cusco con domicilio en la Urb. San Luis del distrito de San Sebastián - Cusco.

Seguidamente se presentó el Sr Miguel Trabajador de la constructora DIPOL con domicilio en el distrito de Santiago - Cusco. 
También hizo su presentación la sra. Hipatya profesora en ejercicio domiciliada en el distrito del Cusco.

Y finalmente la sra Mirelle trabajadora del Hospital regional domiciliada en el distrito de San Sebastián - Cusco.

\section{Preguntas para el Proceso de Decisión de Compra.}

\section{Cuándo compra carne de cuy ¿qué es en lo que más se fija?}

A la pregunta planteada respondió en primer lugar la Sra. Graciela, quien manifiesta que primeramente se fija en la condiciones higiénicas del punto de expendio que si no reúne lo mínimo en salubridad busca otro local, luego en la frescura de la carne vale decir color y olor de la misma y que este sea tierno es decir un cuy malton (joven), asimismo la sra. Hypatia remarco que generalmente busca esta carne ya sacrificada para evitar la tediosa labor de sacrificar pelar y lavar y que las condiciones de higiene es más importante también para ella que sino halla un lugar de venta con las condiciones necesarias ya no realiza la compra, y que esta carne debe ser fresca y suave, la Sra Myrelle manifiesta también que en muchos de estos centros de expendio venden la carne de este animal con distinto sabor aduciendo que ya no era como antes esto por rumores que son alimentados con otro tipo de alimentos distintos al pasto. La sra. Ricardina expone que esta carne que se vende en la Calle Cascaparo muchas veces es dura debido a que son animales viejos por eso dudan en adquirirlos para prepararlos en sus casas y prefieren ir a restaurantes que les garanticen una carne suave ya preparado en sus diferentes presentaciones. 


\section{2 ¿Cómo le Gustaría que sea esta Carne y donde le Gustaría Comprarlo?}

La sra. Caroll indica que esta carne en primer lugar debería ser suave y que mantenga el sabor tradicional como cuando este animal era alimentado con pastos, que el lugar de expendio garantice que este animal haya sido sacrificado con todas las normas de salubridad y que el local preste todas las garantías para su conservación.

El Sr Miguel indica también que la textura, color de la carne es muy importante y que no presenten ningún tipo de coloración diferente en la carne puesto esto limita su compra y le gustaría comprarlo en un lugar limpio e higiénico como por ejemplo supermercados.

La sr Hypatya manifiesta que todo entra por los ojos que primeramente se fija en el lugar donde lo venden que este tenga todos los permisos y condiciones higiénicas seguidamente en el aspecto de la carne si está fresca y que sea tierno que garantice la suavidad de la carne.

La sra. Graciela indica que el sacrificio, pelado y lavado de esta carne tiene que ser en un lugar garantizado y supervisado por que en anteriores ocasiones que adquirió le toco carcazas con presencia de pelos y que el lugar de expendio sea siempre en un lugar limpio además manifiesta que antes lo compraba vivo por razones de seguridad pero todo este proceso de sacrificar, pelarlo y lavarlo era muy fastidioso.

\section{3 ¿Está de Acuerdo con la Presentación en la que Actualmente lo Adquiere o como}

\section{lo Desea?}

La sra. Mirelly indica que lo compra pelado y eviscerado y observa que esta carne está en contacto directo con el medio ambiente y que una y otra persona lo manipula sin ningún tipo de protección en sus manos, lo que realmente desea es que este dentro de un plástico o algún otro empaque que evite todo lo antes mencionado. 
La sra. Hypatya coincide con todo lo antes mencionado pero si aporta que debería existir presentaciones de carne de cuy empacado al vacío y que vio poco en la ciudad del Cusco.

Mientras tanto la señora Graciela indica que si compraría con más garantía si este producto no estaría expuesto a tantos agentes contaminantes y que este en una presentación que lo proteja.

\section{4. ¿Si en el Mercado Existiera esta Carne empacado al Vacío que haya sido}

\section{Alimentado Solamente con Pastos y Sacrificado con todas las Normas de Salubridad lo Adquiriría y Cuanto Estaría Dispuesto a Pagar?}

La respuesta de cuatro de los miembros de este focus manifestaron que si lo adquirían que sería una garantía este tipo de empaque ya que en la actualidad es una limitante este aspecto para poder adquirirlos, mientras tanto las señoras Graciela y Ricardina dicen no conocer mucho del empacado al vacío pero con la información necesaria y viendo las ventajas quizá decidan adquirirlo. Con relación al precio al que estarían dispuesto a pagar manifestaron que en la actualidad el cuy eviscerado y lavado lo adquieren entre s/. 23.00 y s/. 24.00 y que lo ideal sería adquirir este nuevo producto en ese mismo rango de precios. 
Anexo 07

Encuesta para público en general.

\section{IDUSTRIALIZACIÓN DE LA CARNE DE CUY}

\section{ENCUESTA PARA PÚBLICO EN GENERAL}

Buenos días/tardes. Mi nombre es : y soy encuestador(a) de la empresa Industrias

Alimentarias del Sur. En este momento nos encontramos haciendo una investigación sobre la carne de Cuy Por favor responda a las siguientes preguntas de la manera más sincera posible, ya que sus comentarios y opiniones nos ayudarán a mejorar los productos y servicios que Ud. recibe. Muchas gracias por su colaboración.

P1. Edad: (si es menos de 18 años agradecer y terminar).
$18-30$
$31-45$
$46-60$
61 a mas

P2. Sexo:

\section{Hombre \\ Mujer}

P3. ¿Por cuantas personas está compuesta su unidad familiar?

Solo una.

Dos a cuatro.

Más de cinco.

P4. ¿En qué distrito del Cusco se encuentra viviendo actualmente?

CUSCO

SAN JERONIMO

SAN SEBASTIAN

SANTIAGO

- WANCHAQ

SAYLLA

- CALCA 


\section{URUBAMBA}

Otros:

P5. ¿Cuál es el ingreso mensual que actualmente percibe como familia?

Menos de 850 soles.

Entre 851 y 2,000 soles.

Mayor 2,001 soles

P6. ¿Ud., consume carne en su menú diario?

SI.

NO ¿Por qué? . Fin de la encuesta.

P7 ¿Conoce usted las ventajas de comer cuy?

$\mathrm{Si}$

No ¿Por qué?:

P8. ¿En el año usted consume carne de cuy?

$\mathrm{Si}$

No ¿Por qué?: fin de la encuesta.

P9. ¿Alguna persona en su familia compra carne de cuy para preparar en casa?

$\mathrm{Si}$

No ¿Por qué? Fin de la encuesta.

P10. ¿Cómo lo compra? Puede marcar más de una.

Vivo

Sacrificado eviscerado

Envasado

$\square$ Cocido

$\square$ Otros

P11. ¿Dónde lo adquiere? Puede marcar más de una alternativa.
Minimarket
$\square$ Mercados
$\square$ En la Calle
Ferias
$\square$ Otro 
P12. ¿Para qué ocasiones lo compra?

Fines de semana.

Aniversarios / Cumpleaños.

Eventos u ocasiones especiales.

$\square$ Otro

P13. ¿Cuantas veces y con qué frecuencia al año en su casa compran carne de cuy?

Semanal

Quincenal

Mensual

Trimestral

Semestral

Anual

Veces

P14. ¿Qué cantidad de cuyes compra para su consumo familiar al año?

Unidades.

P15. ¿Cuál es el precio que paga por cada cuy?

s/. 15 a s/ .20

s/. 21 a s/. 25

$\square$ s/. 26 a s/. 30

s/. 31 a mas

P16. Marque la característica que considera usted determinante para adquirir este animal como alimento

\begin{tabular}{ll}
\hline ORDEN & \multicolumn{1}{c}{ Características para la decisión de compra } \\
\hline Que tenga peso y tamaño ideal \\
Facilidad de preparación \\
Valor nutricional \\
Precio \\
Presentación del producto
\end{tabular}


P17. ¿Estaría dispuesto Ud. a comprar carne de cuy empacada al vacío?

Definitivamente lo compraría

Probablemente lo compraría

Me seria indiferente comprar o no

Probablemente no lo compraría

Definitivamente no lo compraría (concluye encuesta)

P18. ¿Conoce usted algún establecimiento en el que vendan carne de cuy empacada.

Si ¿dónde?:

$\square$ No

P19. ¿Dónde le gustaría adquirirlo? Puede marcar varias alternativas.

Minimarket

Mercados

Ferias

tiendas

Otro:

P20. ¿Cuánto estaría dispuesto a pagar por unidad de este producto?

s/. 15 a s/. 20

s/. 21 a s/. 25

$\square$ s/. 26 a s/. 30

s/. 31 a mas

P21. ¿Por qué medio de comunicación recibe usted más publicidad de productos alimenticios?

Televisión

Radio

Redes sociales

Periódicos y revistas

$\square$ Volantes

$\square \quad$ Afiches publicitarios 
DATOS DE CONTROL

Nombre:

Teléfono:

Dirección:

Distrito:

Encuestador: Fecha:

Supervisor: Fecha: 
Anexo 08

Encuesta para restaurantes turísticos y tradicionales.

\section{IDUSTRIALIZACIÓN DE LA CARNE DE CUY}

\section{ENCUESTA PARA RESTAURANTES TRADICIONALES Y TURÍSTICOS}

\section{PARA PERSONAL CON DECISIÓN DE COMPRA}

Buenos días/tardes. Mi nombre es : y soy encuestador(a) de la empresa Industrias

Alimentarias del Sur. En este momento nos encontramos haciendo una investigación sobre la carne de Cuy Por favor responda a las siguientes preguntas de la manera más sincera posible, ya que sus comentarios y opiniones nos ayudarán a mejorar los productos y servicios que Ud. recibe. Muchas gracias por su colaboración.

P1. ¿Qué tipo de restaurante es?

\section{Tradicional}

Turístico

P2. ¿Cuál es el cargo que ocupa en el restaurante?

Especifique:

P3. ¿Este cargo le da la facultad de decidir las compras de alimentos para el restaurante?
SI
NO (Fin de la encuesta)

P4. ¿En qué distrito del Cusco se encuentra su restaurante?

CUSCO

SAN JERONIMO

SAN SEBASTIAN

SANTIAGO

WANCHAQ

SAYLLA

CALCA

URUBAMBA 
Otro:

P5. ¿Cuál es la capacidad de comensales con la que cuenta su local?

Menor a 40

Mayor a 40

P6. ¿En su restaurante prepara platos a base de carne de cuy?

$\mathrm{Si}$

No (fin de la encuesta)

P7. ¿Conoce usted proveedores de carne de cuy?

Si ¿Cuáles?

No

P8. ¿Cómo compra la carne cuy que prepara? Puede indicar más de una.

$\square$ Vivo

$\square$ Sacrificado eviscerado

$\square \quad$ Envasado

$\square$ Otros:

P9. ¿Dónde adquiere la carne de cuy que prepara? Puede indicar más de una.

Minimarket

$\square \quad$ Mercados

$\square \quad$ En la Calle

$\square$ Entrega Delivery

$\square$ Otros:

P10. ¿Conoce las condiciones de crianza y de higiene del cuy que compra?

$\square \mathrm{Si}$

$\square$ No

P11. De manera mensual ¿con que frecuencia compra carne de cuy?

Diaria

Interdiaria

Semanal

Quincenal

Una vez por mes. 
P12. ¿Qué cantidad de cuyes compra? Indicar número de unidades.

Unidades.

P13. ¿Cuál es el precio que paga según tipo de cuy que compra por unidad?

\begin{tabular}{|c|c|c|c|}
\hline Monto en soles & Cuy vivo & $\begin{array}{l}\text { Cuy Sacrificado } \\
\text { eviscerado }\end{array}$ & Cuy empacado \\
\hline \multicolumn{4}{|l|}{$\mathrm{s} / .15 \mathrm{a} \mathrm{s} / .20$} \\
\hline \multicolumn{4}{|l|}{$\mathrm{s} / .21$ a s/. 25} \\
\hline \multicolumn{4}{|l|}{ s/. 26 a s/. 30} \\
\hline $\mathrm{s} / .31$ a mas & & & \\
\hline
\end{tabular}

P14. Marque la característica que considera su empresa determinante para adquirir carne de este animal

\begin{tabular}{ll}
\hline ORDEN & \multicolumn{1}{c}{ Características para la decisión de compra } \\
\hline & Peso y tamaño apropiado \\
& Facilidad de preparación y manipulación \\
& Facilidad de almacenamiento y conservación \\
& Puntualidad en abastecimiento \\
& Cumplimiento de normas sanitarias \\
\hline
\end{tabular}

P15. ¿Estaría dispuesto Ud. a comprar carne de cuy empacada al vacío?

Definitivamente lo compraría

Probablemente lo compraría

Me seria indiferente comprar o no

Probablemente no lo compraría

Definitivamente no lo compraría (concluye encuesta) 
P16. ¿Conoce usted las ventajas de adquirir carne de cuy empacada al vacío?

Si ¿Cuáles?:

No

P17. ¿Dónde le gustaría adquirir carne de cuy empacada al vacío? Puede indicar más de uno.

Minimarket

Mercados

Ferias

Entrega en local

Otro:

P18. ¿Cuánto estaría dispuesto a pagar por una unidad de cuy empacado al vacío?

s/. 15 a s/. 20

$\mathrm{s} / .21$ a $\mathrm{s} / .25$

s/. 26 a s/. 30

s/. 31 a mas

P19. ¿Por qué medio de comunicación recibe más publicidad en cuanto a productos alimenticios?

Televisión

Radio

Redes Sociales

$\square$ Periódicos / revistas

$\square$ Catálogos de proveedores

$\square$ Afiches publicitarios / volantes

$\square$ Publicidad exterior

$\square$ Otros:

\section{DATOS DE CONTROL}

Nombre:

Teléfono:

Dirección:

Distrito:

Encuestador: Fecha:

Supervisor: Fecha: 
Anexo 09

Instalación de pastos por cantidad de reproductores y crías.

\begin{tabular}{|c|c|c|c|c|c|c|c|c|c|c|c|c|}
\hline \multirow{2}{*}{$\begin{array}{c}\text { Reproductores } \\
\text { Crias }\end{array}$} & \multicolumn{12}{|c|}{ MESES 2017} \\
\hline & Enero & Febrero & Marzo & Abril & Mayo & Junio & Julio & Agosto & ieptiembrt & Octubre & Noviembre & Diciembre \\
\hline 1er Lote Reproductore & 2,878 & 2,878 & 2,878 & 2,878 & 2,878 & 2,878 & 2,878 & 2,878 & 2,878 & 2,878 & 2,878 & 2,878 \\
\hline Crias 1er Lote & 6,295 & 6,295 & 6,295 & 6,295 & 6,295 & 6,295 & 6,295 & 6,295 & 6,295 & 6,295 & 6,295 & 6,295 \\
\hline 2do Lote Reproductores & 2,878 & 2,878 & 2,878 & 2,878 & 2,878 & 2,878 & 2,878 & 2,878 & 2,878 & 2,878 & 2,878 & 2,878 \\
\hline Crias 2do Lote & 6,295 & 6,295 & 6,295 & 6,295 & 6,295 & 6,295 & 6,295 & 6,295 & 6,295 & 6,295 & 6,295 & 6,295 \\
\hline 3er Lote Reproductores & & & & & & & & 725 & 725 & 725 & 725 & 725 \\
\hline Crias 3er Lotes & & & & & & & & & & 1,586 & 1,586 & 1,586 \\
\hline 4to Lote Reproductore & & & & & & & & & 725 & 725 & 725 & 725 \\
\hline Crias 4to Lotes & & & & & & & & & & & 1,586 & 1,586 \\
\hline Numero de Cuyes & 18,346 & 18,346 & 18,346 & 18,346 & 18,346 & 18,346 & 18,346 & 19,071 & 19,796 & 21,382 & 22,968 & 22,968 \\
\hline Consumo Mensual Alfalfa & 7 & 7 & 7 & 7 & 7 & 7 & 7 & 7 & 7 & 7 & 7 & 7 \\
\hline Consumo Total Alfalfa & 126,587 & 126,587 & 126,587 & 126,587 & 126,587 & 126,587 & 126,587 & 131,590 & 136,592 & 147,536 & 158,479 & 158,479 \\
\hline Total Consumo Periodo Pre Operacional Kg. & & & & & $1,618,788$ & & & & & & & \\
\hline Rendimiento por Ha. Kg. & & & & & 72,000 & & & & & & & \\
\hline Total Instalacion Alfalfa $\mathrm{Ha}$ & & & & & 22 & & & & & & & \\
\hline
\end{tabular}

\begin{tabular}{|c|c|c|c|c|c|c|c|c|c|c|c|c|}
\hline \multirow{2}{*}{$\begin{array}{c}\text { Reproductores } \\
\text { Crias }\end{array}$} & \multicolumn{12}{|c|}{ MESES 2018} \\
\hline & Enero & Febrero & Marzo & Abril & Mayo & Junio & Julio & Agosto ; & ieptiembre & Octubre & Noviembre & Diciembre \\
\hline 1er Lote Reproductore & 2,878 & 2,878 & 2,878 & 2,878 & 2,878 & 2,878 & 2,878 & 2,878 & 2,878 & 2,878 & 2,878 & 2,878 \\
\hline Crias 1er Lote & 6,295 & 6,295 & 6,295 & 6,295 & 6,295 & 6,295 & 6,295 & 6,295 & 6,295 & 6,295 & 6,295 & 6,295 \\
\hline 2do Lote Reproductores & 2,878 & 2,878 & 2,878 & 2,878 & 2,878 & 2,878 & 2,878 & 2,878 & 2,878 & 2,878 & 2,878 & 2,878 \\
\hline Crias 2do Lote & 6,295 & 6,295 & 6,295 & 6,295 & 6,295 & 6,295 & 6,295 & 6,295 & 6,295 & 6,295 & 6,295 & 6,295 \\
\hline 3er Lote Reproductores & 725 & 725 & 725 & 725 & 725 & 725 & 725 & 725 & 725 & 725 & 725 & 725 \\
\hline Crias 3er Lotes & 1,586 & 1,586 & 1,586 & 1,586 & 1,586 & 1,586 & 1,586 & 1,586 & 1,586 & 1,586 & 1,586 & 1,586 \\
\hline 4to Lote Reproductore & 725 & 725 & 725 & 725 & 725 & 725 & 725 & 725 & 725 & 725 & 725 & 725 \\
\hline Crias 4to Lotes & 1,586 & 1,586 & 1,586 & 1,586 & 1,586 & 1,586 & 1,586 & 1,586 & 1,586 & 1,586 & 1,586 & 1,586 \\
\hline 5to Lote reproductore & & & & & & & & 358 & 358 & 358 & 358 & 358 \\
\hline Crias 5to Lote & & & & & & & & & & 783 & 783 & 783 \\
\hline 6 Lote reproductores & & & & & & & & & 358 & 358 & 358 & 358 \\
\hline Crias 6to Lote & & & & & & & & & & & 783 & 783 \\
\hline Numero de Cuyes & 22,968 & 22,968 & 22,968 & 22,968 & 22,968 & 22,968 & 22,968 & 23,326 & 23,684 & 24,467 & 25,250 & 25,250 \\
\hline Consumo Mensual Alfalfa & 7 & 7 & 7 & 7 & 7 & 7 & 7 & 7 & 7 & 7 & 7 & 7 \\
\hline Consumo Total Alfalfa & 158,479 & 158,479 & 158,479 & 158,479 & 158,479 & 158,479 & 158,479 & 160,949 & 163,420 & 168,822 & 174,225 & 174,225 \\
\hline Total Consumo Periodo Pre Operacional Kg. & & & & & $1,950,996$ & & & & & & & \\
\hline Rendimiento por Ha. Kg. & & & & & 72,000 & & & & & & & \\
\hline Total Instalacion Alfalfa Ha & & & & & 27 & & & & & & & \\
\hline
\end{tabular}

\begin{tabular}{|c|c|c|c|c|c|c|c|c|c|c|c|c|}
\hline \multirow{2}{*}{$\begin{array}{c}\text { Reproductores } \\
\text { Crias } \\
\end{array}$} & \multicolumn{12}{|c|}{ MESES 2019} \\
\hline & Enero & Febrero & Marzo & Abril & Mayo & Junio & Julio & Agosto & ieptiembrt & Octubre & Noviembre & Diciembre \\
\hline 1er Lote Reproductore & 2,878 & 2,878 & 2,878 & 2,878 & 2,878 & 2,878 & 2,878 & 2,878 & 2,878 & 2,878 & 2,878 & 2,878 \\
\hline Crias 1er Lote & 6,295 & 6,295 & 6,295 & 6,295 & 6,295 & 6,295 & 6,295 & 6,295 & 6,295 & 6,295 & 6,295 & 6,295 \\
\hline 2do Lote Reproductores & 2,878 & 2,878 & 2,878 & 2,878 & 2,878 & 2,878 & 2,878 & 2,878 & 2,878 & 2,878 & 2,878 & 2,878 \\
\hline Crias 2do Lote & 6,295 & 6,295 & 6,295 & 6,295 & 6,295 & 6,295 & 6,295 & 6,295 & 6,295 & 6,295 & 6,295 & 6,295 \\
\hline 3er Lote Reproductores & 725 & 725 & 725 & 725 & 725 & 725 & 725 & 725 & 725 & 725 & 725 & 725 \\
\hline Crias 3er Lotes & 1,586 & 1,586 & 1,586 & 1,586 & 1,586 & 1,586 & 1,586 & 1,586 & 1,586 & 1,586 & 1,586 & 1,586 \\
\hline 4to Lote Reproductore & 725 & 725 & 725 & 725 & 725 & 725 & 725 & 725 & 725 & 725 & 725 & 725 \\
\hline Crias 4to Lotes & 1,586 & 1,586 & 1,586 & 1,586 & 1,586 & 1,586 & 1,586 & 1,586 & 1,586 & 1,586 & 1,586 & 1,586 \\
\hline 5to Lote reproductore & 358 & 358 & 358 & 358 & 358 & 358 & 358 & 358 & 358 & 358 & 358 & 358 \\
\hline Crias 5to Lote & 783 & 783 & 783 & 783 & 783 & 783 & 783 & 783 & 783 & 783 & 783 & 783 \\
\hline 6 Lote reproductores & 358 & 358 & 358 & 358 & 358 & 358 & 358 & 358 & 358 & 358 & 358 & 358 \\
\hline Crias 6to Lote & 783 & 783 & 783 & 783 & 783 & 783 & 783 & 783 & 783 & 783 & 783 & 783 \\
\hline 7 Lote reproductores & & & & & & & & 761 & 761 & 761 & 761 & 761 \\
\hline Crias 7to Lote & & & & & & & & & & 1,664 & 1,664 & 1,664 \\
\hline 8 Lote reproductores & & & & & & & & & 761 & 761 & 761 & 761 \\
\hline Crias 8to Lote & & & & & & & & & & & 1,664 & 1,664 \\
\hline Numero de Cuyes & 25,250 & 25,250 & 25,250 & 25,250 & 25,250 & 25,250 & 25,250 & 26,011 & 26,772 & 28,436 & 30,100 & 30,100 \\
\hline Consumo Mensual Alfalfa & 7 & 7 & 7 & 7 & 7 & 7 & 7 & 7 & 7 & 7 & 7 & 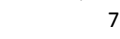 \\
\hline Consumo Total Alfalfa & 174,225 & 174,225 & 174,225 & 174,225 & 174,225 & 174,225 & 174,225 & 179,476 & $6 \quad 184,727$ & 196,208 & 207,690 & 207,690 \\
\hline Total Consumo Periodo Pre Operacional Kg. & & & & & $2,195,366$ & & & & & & & \\
\hline Rendimiento por Ha. Kg. & & & & & 72,000 & & & & & & & \\
\hline Total Instalacion Alfalfa Ha & & & & & 30 & & & & & & & \\
\hline
\end{tabular}




\begin{tabular}{|c|c|c|c|c|c|c|c|c|c|c|c|c|}
\hline \multirow{2}{*}{$\begin{array}{c}\text { Reproductores } \\
\text { Crias }\end{array}$} & \multicolumn{12}{|c|}{ MESES 2020} \\
\hline & Enero & Febrero & Marzo & Abril & Mayo & Junio & Julio & Agosto ; & jeptiembrt & Octubre & Noviembre & Diciembre \\
\hline 1er Lote Reproductore & 2,878 & 2,878 & 2,878 & 2,878 & 2,878 & 2,878 & 2,878 & 2,878 & 2,878 & 2,878 & 2,878 & 2,878 \\
\hline Crias 1er Lote & 6,295 & 6,295 & 6,295 & 6,295 & 6,295 & 6,295 & 6,295 & 6,295 & 6,295 & 6,295 & 6,295 & 6,295 \\
\hline 2do Lote Reproductores & 2,878 & 2,878 & 2,878 & 2,878 & 2,878 & 2,878 & 2,878 & 2,878 & 2,878 & 2,878 & 2,878 & 2,878 \\
\hline Crias 2do Lote & 6,295 & 6,295 & 6,295 & 6,295 & 6,295 & 6,295 & 6,295 & 6,295 & 6,295 & 6,295 & 6,295 & 6,295 \\
\hline 3er Lote Reproductores & 725 & 725 & 725 & 725 & 725 & 725 & 725 & 725 & 725 & 725 & 725 & 725 \\
\hline Crias 3er Lotes & 1,586 & 1,586 & 1,586 & 1,586 & 1,586 & 1,586 & 1,586 & 1,586 & 1,586 & 1,586 & 1,586 & 1,586 \\
\hline 4to Lote Reproductore & 725 & 725 & 725 & 725 & 725 & 725 & 725 & 725 & 725 & 725 & 725 & 725 \\
\hline Crias 4to Lotes & 1,586 & 1,586 & 1,586 & 1,586 & 1,586 & 1,586 & 1,586 & 1,586 & 1,586 & 1,586 & 1,586 & 1,586 \\
\hline 5to Lote reproductore & 358 & 358 & 358 & 358 & 358 & 358 & 358 & 358 & 358 & 358 & 358 & 358 \\
\hline Crias 5to Lote & 783 & 783 & 783 & 783 & 783 & 783 & 783 & 783 & 783 & 783 & 783 & 783 \\
\hline 6 Lote reproductores & 358 & 358 & 358 & 358 & 358 & 358 & 358 & 358 & 358 & 358 & 358 & 358 \\
\hline Crias 6to Lote & 783 & 783 & 783 & 783 & 783 & 783 & 783 & 783 & 783 & 783 & 783 & 783 \\
\hline 7 Lote reproductores & 761 & 761 & 761 & 761 & 761 & 761 & 761 & 761 & 761 & 761 & 761 & 761 \\
\hline Crias 7to Lote & 1,664 & 1,664 & 1,664 & 1,664 & 1,664 & 1,664 & 1,664 & 1,664 & 1,664 & 1,664 & 1,664 & 1,664 \\
\hline 8 Lote reproductores & 761 & 761 & 761 & 761 & 761 & 761 & 761 & 761 & 761 & 761 & 761 & 761 \\
\hline Crias 8to Lote & 1,664 & 1,664 & 1,664 & 1,664 & 1,664 & 1,664 & 1,664 & 1,664 & 1,664 & 1,664 & 1,664 & 1,664 \\
\hline 9 Lote reproductores & & & & & & & & 810 & & 810 & 810 & 810 \\
\hline Crias 9to Lote & & & & & & & & & & 1,772 & 1,772 & 1,772 \\
\hline 10 Lote reproductores & & & & & & & & & 810 & 810 & 810 & 810 \\
\hline Crias 10 moto Lote & & & & & & & & & & & 1,772 & 1,772 \\
\hline Numero de Cuyes & 30,100 & 30,100 & 30,100 & 30,100 & 30,100 & 30,100 & 30,100 & 30,910 & 30,910 & 33,492 & 35,264 & 35,264 \\
\hline Consumo Mensual Alfalfa & 7 & 7 & 7 & 7 & 7 & 7 & 7 & 7 & 7 & 7 & 7 & 7 \\
\hline Consumo Total Alfalfa & 207,690 & 207,690 & 207,690 & 207,690 & 207,690 & 207,690 & 207,690 & 213,279 & 213,279 & 231,095 & 243,322 & 243,322 \\
\hline Total Consumo Periodo Pre Operacional Kg. & & & & & $2,598,126$ & & & & & & & \\
\hline Rendimiento por Ha. Kg. & & & & & 72,000 & & & & & & & \\
\hline Total Instalacion Alfalfa $\mathrm{Ha}$ & & & & & 36 & & & & & & & \\
\hline
\end{tabular}

\begin{tabular}{|c|c|c|c|c|c|c|c|c|c|c|c|c|}
\hline \multirow{2}{*}{$\begin{array}{c}\text { Reproductores } \\
\text { Crias }\end{array}$} & \multicolumn{12}{|c|}{ MESES 2021} \\
\hline & Enero & Febrero & Marzo & Abril & Mayo & Junio & Julio & Agosto ; & ieptiembrt & Octubre & Noviembre & Diciembre \\
\hline 1er Lote Reproductore & 2,878 & 2,878 & 2,878 & 2,878 & 2,878 & 2,878 & 2,878 & 2,878 & 2,878 & 2,878 & 2,878 & 2,878 \\
\hline Crias 1er Lote & 6,295 & 6,295 & 6,295 & 6,295 & 6,295 & 6,295 & 6,295 & 6,295 & 6,295 & 6,295 & 6,295 & 6,295 \\
\hline 2do Lote Reproductores & 2,878 & 2,878 & 2,878 & 2,878 & 2,878 & 2,878 & 2,878 & 2,878 & 2,878 & 2,878 & 2,878 & 2,878 \\
\hline Crias 2do Lote & 6,295 & 6,295 & 6,295 & 6,295 & 6,295 & 6,295 & 6,295 & 6,295 & 6,295 & 6,295 & 6,295 & 6,295 \\
\hline 3er Lote Reproductores & 725 & 725 & 725 & 725 & 725 & 725 & 725 & 725 & 725 & 725 & 725 & 725 \\
\hline Crias 3er Lotes & 1,586 & 1,586 & 1,586 & 1,586 & 1,586 & 1,586 & 1,586 & 1,586 & 1,586 & 1,586 & 1,586 & 1,586 \\
\hline 4to Lote Reproductore & 725 & 725 & 725 & 725 & 725 & 725 & 725 & 725 & 725 & 725 & 725 & 725 \\
\hline Crias 4to Lotes & 1,586 & 1,586 & 1,586 & 1,586 & 1,586 & 1,586 & 1,586 & 1,586 & 1,586 & 1,586 & 1,586 & 1,586 \\
\hline 5to Lote reproductore & 358 & 358 & 358 & 358 & 358 & 358 & 358 & 358 & 358 & 358 & 358 & 358 \\
\hline Crias 5to Lote & 783 & 783 & 783 & 783 & 783 & 783 & 783 & 783 & 783 & 783 & 783 & 783 \\
\hline 6 Lote reproductores & 358 & 358 & 358 & 358 & 358 & 358 & 358 & 358 & 358 & 358 & 358 & 358 \\
\hline Crias 6to Lote & 783 & 783 & 783 & 783 & 783 & 783 & 783 & 783 & 783 & 783 & 783 & 783 \\
\hline 7 Lote reproductores & 761 & 761 & 761 & 761 & 761 & 761 & 761 & 761 & 761 & 761 & 761 & 761 \\
\hline Crias 7to Lote & 1,664 & 1,664 & 1,664 & 1,664 & 1,664 & 1,664 & 1,664 & 1,664 & 1,664 & 1,664 & 1,664 & 1,664 \\
\hline 8 Lote reproductores & 761 & 761 & 761 & 761 & 761 & 761 & 761 & 761 & 761 & 761 & 761 & 761 \\
\hline Crias 8to Lote & 1,664 & 1,664 & 1,664 & 1,664 & 1,664 & 1,664 & 1,664 & 1,664 & 1,664 & 1,664 & 1,664 & 1,664 \\
\hline 9 Lote reproductores & 810 & 810 & 810 & 810 & 810 & 810 & 810 & 810 & 810 & 810 & 810 & 810 \\
\hline Crias 9to Lote & 1,772 & 1,772 & 1,772 & 1,772 & 1,772 & 1,772 & 1,772 & 1,772 & 1,772 & 1,772 & 1,772 & 1,772 \\
\hline 10 Lote reproductores & 810 & 810 & 810 & 810 & 810 & 810 & 810 & 810 & 810 & 810 & 810 & 810 \\
\hline Crias 10 moto Lote & 1,772 & 1,772 & 1,772 & 1,772 & 1,772 & 1,772 & 1,772 & 1,772 & 1,772 & 1,772 & 1,772 & 1,772 \\
\hline Numero de Cuyes & 35,264 & 35,264 & 35,264 & 35,264 & 35,264 & 35,264 & 35,264 & 35,264 & 35,264 & 35,264 & 35,264 & 35,264 \\
\hline Consumo Mensual Alfalfa & 7 & 7 & 7 & 7 & 7 & 7 & 7 & 7 & 7 & 7 & 7 & 7 \\
\hline Consumo Total Alfalfa & 243,322 & 243,322 & 243,322 & 243,322 & 243,322 & 243,322 & 243,322 & 243,322 & 243,322 & 243,322 & 243,322 & 243,322 \\
\hline Total Consumo Periodo Pre Operacional Kg. & & & & & $2,919,859$ & & & & & & & \\
\hline Rendimiento por Ha. Kg. & & & & & 72,000 & & & & & & & \\
\hline Total Instalacion Alfalfa Ha & & & & & 41 & & & & & & & \\
\hline
\end{tabular}


Anexo 10

Ubicación óptima para instalación de pastos, centros de reproducción y sacrificio.

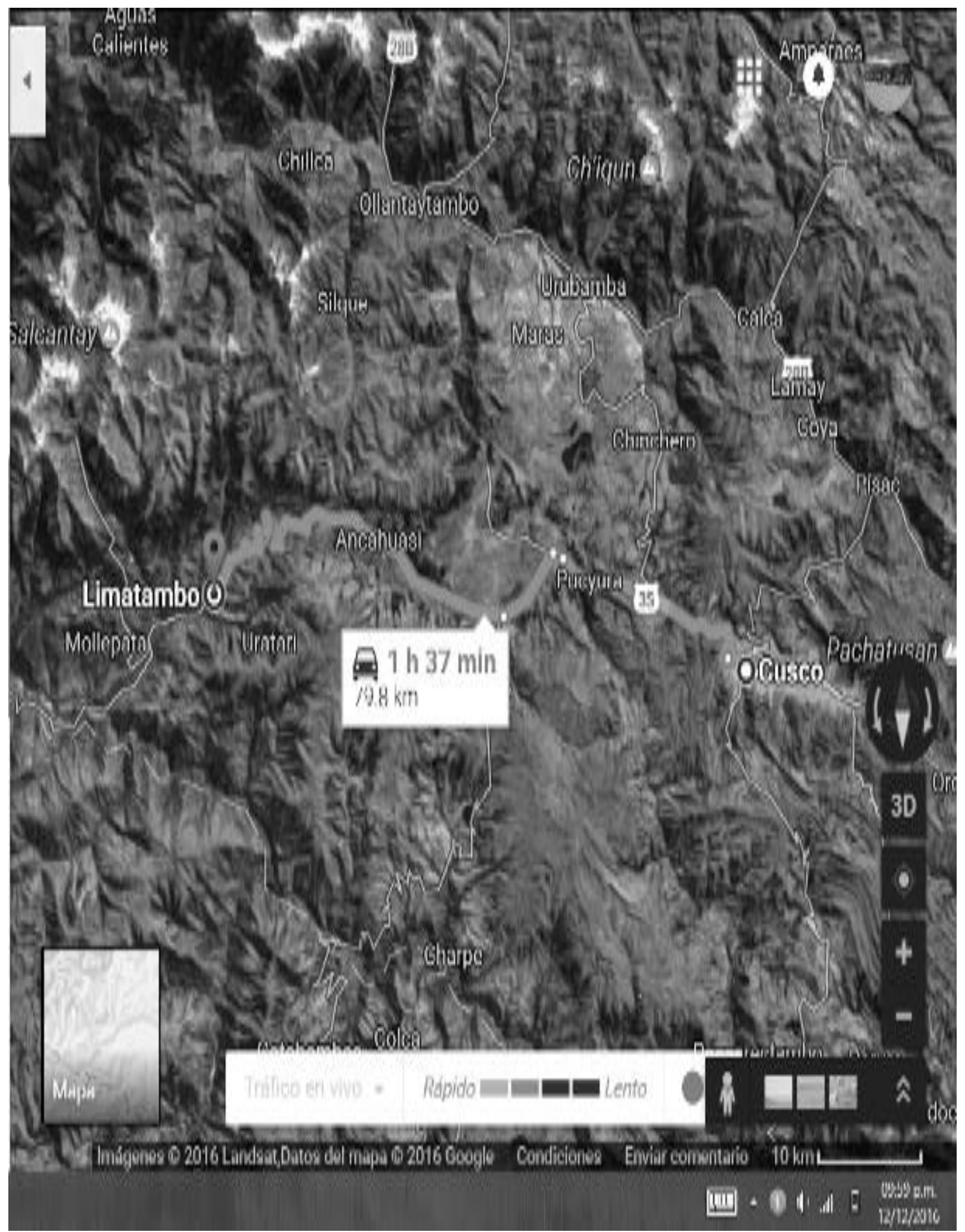


Anexo 11

Cuy empacado al vacío.
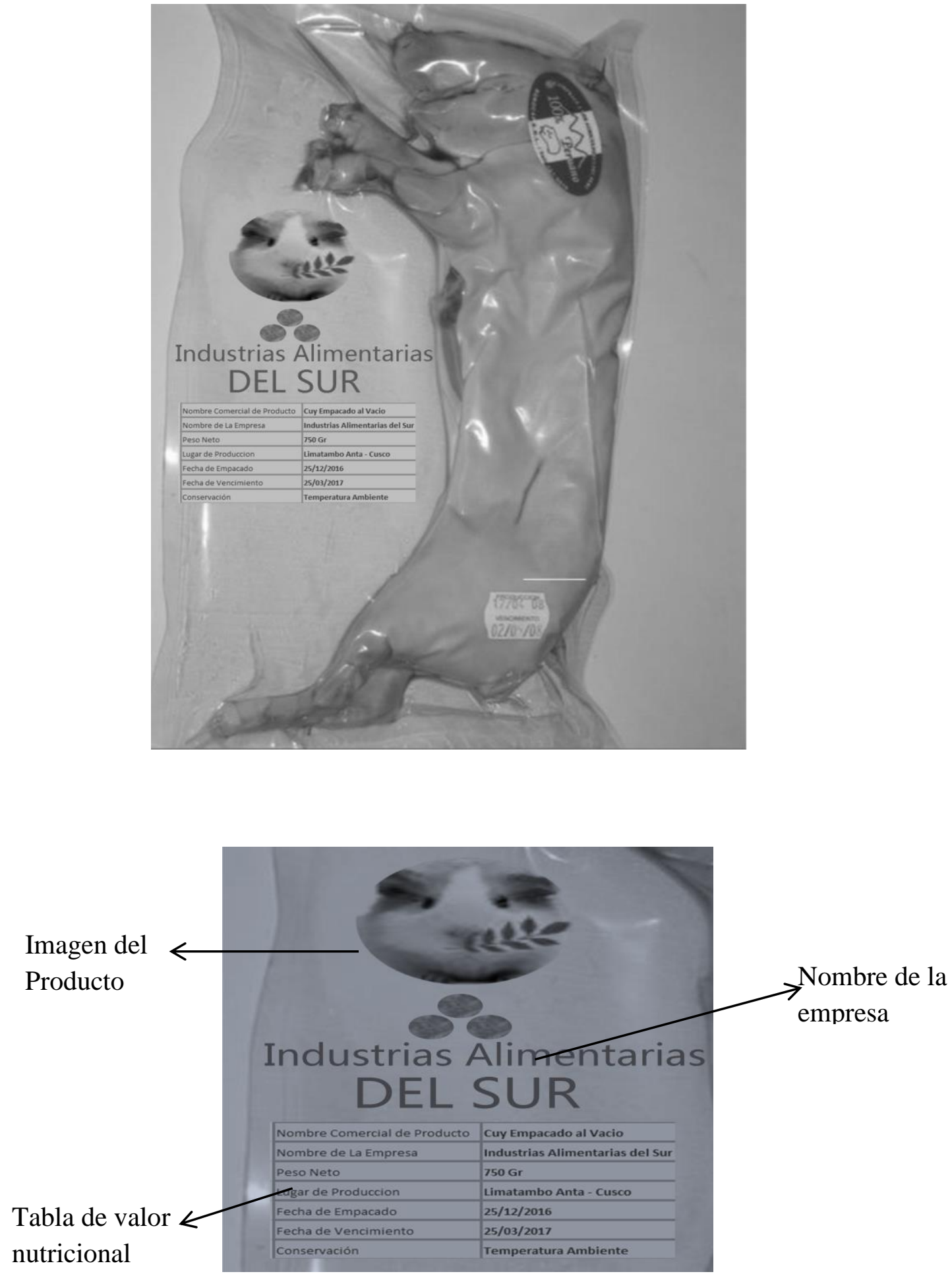
Anexo 12

Ubicación centro de comercialización de producto final en la ciudad del Cusco.

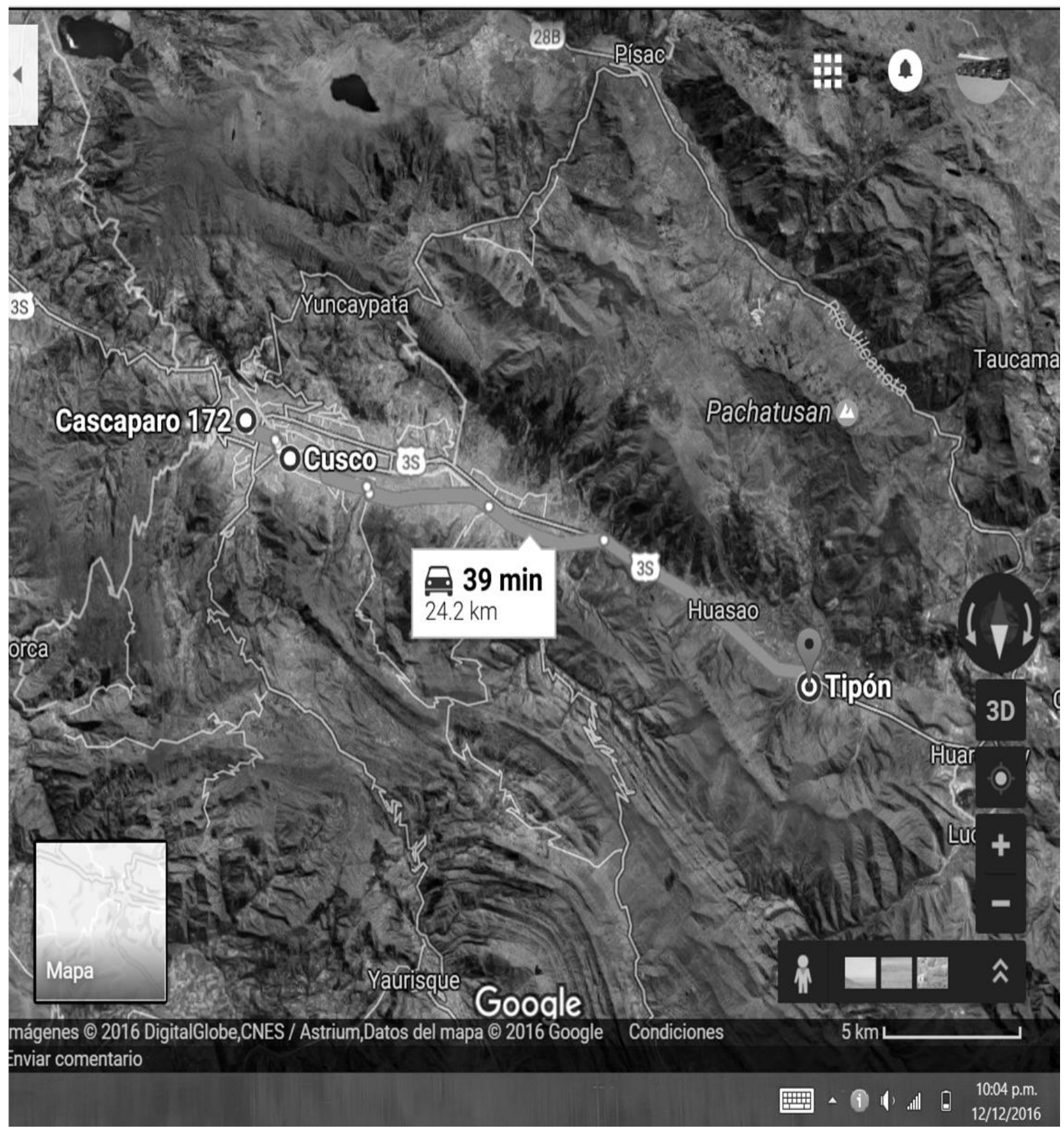


Anexo 13

Detalle inversión pre operativo Activo Fijo:

\begin{tabular}{|c|c|c|c|c|}
\hline Procesos & Activo & Cantidad & $\begin{array}{c}\text { Valor } \\
\text { Unitario }\end{array}$ & $\begin{array}{l}\text { Valor } \\
\text { Total }\end{array}$ \\
\hline Pastos & Motoneta & 3 & 6,102 & 18,306 \\
\hline \multirow[t]{2}{*}{ Sub Total } & & & & 18,306 \\
\hline & Terreno area reproductores $\mathrm{m}$. & 3,449 & 13 & 44,837 \\
\hline \multirow{4}{*}{$\begin{array}{l}\text { Crianza } \\
\text { Reproduccion }\end{array}$} & Edificaciones infraestructura reproductores $\mathrm{m}$. & 1,295 & 47 & 60,865 \\
\hline & Terreno area para engorde $\mathrm{m}$. & 1,046 & 13 & 13,598 \\
\hline & Edificaciones para engorde $\mathrm{m}$. & 364 & 47 & 17,108 \\
\hline & Furgon & 1 & 24,890 & 24,890 \\
\hline \multirow[t]{2}{*}{ Sub Total } & & & & 161,298 \\
\hline & Terreno area de sacrificio & 180 & 13 & 2,340 \\
\hline Sacrificio y & Infraestructura camal sacrificio & 180 & 593 & 106,740 \\
\hline Evicerado & Cocina industrial & 1 & 2,500 & 2,500 \\
\hline & Mesa de trabajo inoxidable & 3 & 1,017 & 3,051 \\
\hline \multirow[t]{2}{*}{ Sub Total } & & & & 114,631 \\
\hline & Empacadora al vacio & 2 & 2,797 & 5,594 \\
\hline Empacado y & Congeladora & 2 & 1,949 & 3,898 \\
\hline \multirow[t]{2}{*}{ Comercializacion } & Exibidor & 1 & 2,712 & 2,712 \\
\hline & Computadora con impresora & 1 & 1,441 & 1,441 \\
\hline Sub Total & & & & 13,645 \\
\hline TOTAL & & & & 307,880 \\
\hline
\end{tabular}

Anexo $\mathrm{N}^{\circ}: 14$

Detalle de costos para capital de trabajo pre operativo proceso de pastos.

\begin{tabular}{|c|c|c|c|c|c|c|}
\hline \multirow[t]{2}{*}{ Proceso } & ACTIVO & \multirow{2}{*}{$\begin{array}{c}\text { Cantidad } \\
1\end{array}$} & \multicolumn{2}{|c|}{$\begin{array}{l}\text { Valor } \\
\text { unitario }\end{array}$} & \multicolumn{2}{|c|}{ Valor Total } \\
\hline & Motoneta & & $\mathrm{S} /$. & 6,102 & $\mathrm{~S} /$. & 6,102 \\
\hline \multirow{8}{*}{$\begin{array}{c}\text { Producción de } \\
\text { pastos }\end{array}$} & Fumigadora & 1 & S/. & 162 & S/. & 162 \\
\hline & Segadora & 1 & $\mathrm{~S} /$. & 21 & $\mathrm{~S} /$. & 21 \\
\hline & Aspersores & 1 & $\mathrm{~S} /$. & 82 & $\mathrm{~S} /$. & 82 \\
\hline & Manguera de aspersor & 1 & $\mathrm{~S} /$. & 258 & $\mathrm{~S} /$. & 258 \\
\hline & Botas & 1 & S/. & 41 & $\mathrm{~S} /$. & 41 \\
\hline & Impermeables & 1 & $\mathrm{~S} /$. & 49 & $\mathrm{~S} /$. & 49 \\
\hline & Guantes & 1 & $\mathrm{~S} /$. & 11 & $\mathrm{~S} /$. & 11 \\
\hline & SUB TOTAL & & $\mathrm{S} /$. & 6,726 & $\mathrm{~S} /$. & 6,726 \\
\hline
\end{tabular}


Anexo $\mathrm{N}^{\circ} 15$

Detalle de costos cara capital de trabajo pre operativo proceso de crianza y reproducción.

\begin{tabular}{|c|c|c|c|c|c|c|c|c|c|c|}
\hline & & & \multicolumn{8}{|c|}{ ACTIVO FIJO DEPRECIABLE PRE OPERACIONAL } \\
\hline \multirow{12}{*}{$\begin{array}{c}\text { Crianza y } \\
\text { Reproducción }\end{array}$} & Terreno área para reproductores & 3449 & $\mathrm{~S} /$. & 13 & $\mathrm{~S} /$. & 2 & $\mathrm{~S} /$. & 15 & $\mathrm{~S} /$. & 44,837 \\
\hline & Edificaciones de infraestructura reproductores & 1295 & $\mathrm{~S} /$. & 47 & $\mathrm{~S} /$. & 8 & $\mathrm{~S} /$. & 55 & $\mathrm{~S} /$. & 60,865 \\
\hline & Terreno área para engorde & 1046 & $\mathrm{~S} /$. & 13 & $\mathrm{~S} /$. & 2 & $\mathrm{~S} /$. & 15 & $\mathrm{~S} /$. & 13,598 \\
\hline & Furgón & 1 & $\mathrm{~S} /$. & 24,890 & $\mathrm{~S} /$. & 4,480 & $\mathrm{~S} /$. & 29,370 & $\mathrm{~S} /$. & 24,890 \\
\hline & Reproductores ler lote & 2878 & $\mathrm{~S} /$. & 40 & $\mathrm{~S} /$. & 7 & $\mathrm{~S} /$. & 47 & $\mathrm{~S} /$. & 115,120 \\
\hline & Reproductores 2er lote & 2878 & $\mathrm{~S} /$. & 40 & $\mathrm{~S} /$. & 7 & $\mathrm{~S} /$. & 47 & $\mathrm{~S} /$. & 115,120 \\
\hline & Jaulas & 280 & $\mathrm{~S} /$. & 180 & $\mathrm{~S} /$. & 32 & $\mathrm{~S} /$. & 212 & $\mathrm{~S} /$. & 50,400 \\
\hline & Gasaperas & 719 & $\mathrm{~S} /$. & 12 & $\mathrm{~S} /$. & 2 & $\mathrm{~S} /$. & 14 & $\mathrm{~S} /$. & 8,628 \\
\hline & Guantes & 1 & $\mathrm{~S} /$. & 16 & $\mathrm{~S} /$. & 3 & $\mathrm{~S} /$. & 19 & $\mathrm{~S} /$. & 16 \\
\hline & Palas & 1 & $\mathrm{~S} /$. & 69 & $\mathrm{~S} /$. & 12 & $\mathrm{~S} /$. & 81 & $\mathrm{~S} /$. & 69 \\
\hline & Jabas de plástico & 1 & $\mathrm{~S} /$. & 607 & $\mathrm{~S} /$. & 109 & $\mathrm{~S} /$. & 716 & $\mathrm{~S} /$. & 607 \\
\hline & SUB TOTAL & & $\mathrm{S} /$. & 26,514 & $\mathrm{~S} /$. & 4,773 & $\mathrm{~S} /$. & 31,285 & $\mathrm{~S} /$. & 451,798 \\
\hline
\end{tabular}

Anexo $\mathrm{N}^{\circ}: 16$

Detalle de costos para capital de trabajo pre operativo proceso de sacrificio y eviscerado.

\begin{tabular}{|c|c|c|c|c|c|c|}
\hline & \multirow{2}{*}{$\begin{array}{r}\text { ACTIVO } \\
\text { Terreno área de sacrificio }\end{array}$} & \multirow{2}{*}{$\begin{array}{c}\text { Cantidad } \\
180\end{array}$} & \multicolumn{2}{|c|}{$\begin{array}{c}\text { Valor } \\
\text { unitario }\end{array}$} & \multicolumn{2}{|c|}{ Valor Total } \\
\hline & & & $\mathrm{S} /$. & 13 & $\mathrm{~S} /$. & 2,288 \\
\hline \multirow{13}{*}{$\begin{array}{l}\text { Sacrificio y } \\
\text { evicerado }\end{array}$} & Infraestructura camal de sacrificio & 180 & $\mathrm{~S} /$. & 593 & S/. & 106,780 \\
\hline & Cocina industrial & 1 & $\mathrm{~S} /$. & 2,500 & $\mathrm{~S} /$. & 2,500 \\
\hline & Mesa de trabajo inoxidables & 3 & $\mathrm{~S} /$. & 1,017 & $\mathrm{~S} /$. & 3,051 \\
\hline & Ollas 25 lt. & 1 & $\mathrm{~S} /$. & 528 & $\mathrm{~S} /$. & 528 \\
\hline & Balanza & 1 & $\mathrm{~S} /$. & 208 & $\mathrm{~S} /$. & 208 \\
\hline & Cuchillos & 1 & $\mathrm{~S} /$. & 306 & $\mathrm{~S} /$. & 306 \\
\hline & Jabas de plástico & 1 & $\mathrm{~S} /$. & 152 & $\mathrm{~S} /$. & 152 \\
\hline & Ganchos para oreado & 1 & $\mathrm{~S} /$. & 1,390 & $\mathrm{~S} /$. & 1,390 \\
\hline & Tachos para desperdicios & 1 & $\mathrm{~S} /$. & 361 & $\mathrm{~S} /$. & 361 \\
\hline & Escobas & 1 & $\mathrm{~S} /$. & 146 & $\mathrm{~S} /$. & 146 \\
\hline & Guantes & 1 & $\mathrm{~S} /$. & 174 & $\mathrm{~S} /$. & 174 \\
\hline & Buzo protector mameluco & 1 & $\mathrm{~S} /$. & 298 & $\mathrm{~S} /$. & 298 \\
\hline & Protector bucal & 1 & $\mathrm{~S} /$. & 69 & $\mathrm{~S} /$. & 69 \\
\hline
\end{tabular}


Anexo $\mathrm{N}^{\circ}: 17$

Detalle de Costos Para Capital de Trabajo Pre Operativo Proceso de Empacado y Comercialización.

\begin{tabular}{|c|c|c|c|c|c|c|}
\hline \multirow{2}{*}{ Proceso } & \multirow{2}{*}{$\begin{array}{l}\text { ACTIVO } \\
\text { Empacadora al vacio }\end{array}$} & \multirow{2}{*}{$\begin{array}{c}\text { Cantidad } \\
2\end{array}$} & \multicolumn{2}{|c|}{$\begin{array}{c}\text { Valor } \\
\text { unitario }\end{array}$} & \multicolumn{2}{|c|}{ Valor Total } \\
\hline & & & S/. & 2,797 & S/. & 5,593 \\
\hline \multirow{11}{*}{$\begin{array}{c}\text { Empacado y } \\
\text { comecialización }\end{array}$} & Congeladora & 2 & $\mathrm{~S} /$. & 1,949 & S/. & 3,898 \\
\hline & Exibidor & 1 & $\mathrm{~S} /$. & 2,712 & $\mathrm{~S} /$. & 2,712 \\
\hline & Computadora con impresora & 1 & $\mathrm{~S} /$. & 1,441 & $\mathrm{~S} /$. & 1,441 \\
\hline & Botas & 1 & $\mathrm{~S} /$. & 41 & $\mathrm{~S} /$. & 41 \\
\hline & Guantes & 1 & $\mathrm{~S} /$. & 103 & $\mathrm{~S} /$. & 103 \\
\hline & Buzo protector mameluco & 1 & $\mathrm{~S} /$. & 26 & $\mathrm{~S} /$. & 26 \\
\hline & Protector bucal & 1 & $\mathrm{~S} /$. & 82 & $\mathrm{~S} /$. & 82 \\
\hline & Escritorio & 1 & $\mathrm{~S} /$. & 205 & $\mathrm{~S} /$. & 205 \\
\hline & Silla & 1 & $\mathrm{~S} /$. & 196 & $\mathrm{~S} /$. & 196 \\
\hline & Mueble archivador & 1 & $\mathrm{~S} /$. & 287 & $\mathrm{~S} /$. & 287 \\
\hline & SUB TOTAL & & $\mathrm{S} /$. & 9,838 & S/. & 14,584 \\
\hline
\end{tabular}

Anexo 18

Estructura de financiamiento.

\begin{tabular}{lcc}
\hline \multicolumn{1}{c}{ Financiamiento } & Monto S/. & Estructura \\
\hline Capital Propio & S/. 522,744 & $76.26 \%$ \\
Deuda & S/. 166,964 & $23.74 \%$ \\
\hline
\end{tabular}

Anexo 19

Condiciones de financiamiento.

\begin{tabular}{lc}
\hline TCEA & $12.280 \%$ \\
TCEM & $0.97 \%$ \\
PRÉSTAMO & $\mathrm{S} / .166,964$ \\
CUOTAS & 60 \\
PERIÓDO DE GRACIA & 3 \\
\hline
\end{tabular}


Anexo 20

Cronograma de amortización de deuda

\begin{tabular}{|c|c|c|c|c|c|}
\hline \multicolumn{6}{|c|}{ Cuadro de Amortización de la Deuda - Expresado en Nuevos soles } \\
\hline Periódo & Cuota & Interés & Amortización & Saldo & Escudo Fiscal \\
\hline-3 & & & & S/.166,964 & $\mathrm{S} / .0$ \\
\hline-2 & & S/.1,619 & & S/.168,583 & S/.453 \\
\hline-1 & & S/.1,635 & & S/.170,218 & $\mathrm{S} / .458$ \\
\hline 0 & & S/.1,651 & & S/.171,869 & S/.462 \\
\hline 1 & $\mathrm{~S} / .3,792$ & S/.1,667 & $\mathrm{S} / .2,125$ & S/.169,744 & S/.467 \\
\hline 2 & $\mathrm{~S} / .3,792$ & S/.1,646 & $\mathrm{S} / .2,145$ & S/.167,599 & $\mathrm{S} / .461$ \\
\hline 3 & S/.3,792 & S/.1,626 & S/.2,166 & S/.165,433 & S/.455 \\
\hline 4 & S/.3,792 & S/.1,605 & $\mathrm{S} / .2,187$ & S/.163,245 & S/.449 \\
\hline 5 & S/.3,792 & S/.1,583 & S/.2,209 & S/.161,037 & S/.443 \\
\hline 6 & S/.3,792 & S/.1,562 & $\mathrm{S} / .2,230$ & S/.158,807 & S/.437 \\
\hline 7 & S/.3,792 & S/.1,540 & $\mathrm{S} / .2,252$ & S/.156,555 & S/.431 \\
\hline 8 & S/.3,792 & S/.1,518 & $\mathrm{S} / .2,273$ & S/.154,282 & S/.425 \\
\hline 9 & S/.3,792 & S/.1,496 & S/.2,295 & S/.151,986 & S/.419 \\
\hline 10 & S/.3,792 & S/.1,474 & $\mathrm{S} / .2,318$ & S/.149,669 & S/.413 \\
\hline 11 & S/.3,792 & S/.1,452 & $\mathrm{S} / .2,340$ & S/.147,328 & S/.406 \\
\hline 12 & S/.3,792 & S/.1,429 & S/.2,363 & S/.144,966 & S/.400 \\
\hline 13 & S/.3,792 & S/.1,406 & S/.2,386 & S/.142,580 & S/.394 \\
\hline 14 & S/.3,792 & S/.1,383 & $\mathrm{S} / .2,409$ & S/.140,171 & S/.387 \\
\hline 15 & S/.3,792 & S/.1,359 & $\mathrm{S} / .2,432$ & S/.137,738 & $\mathrm{S} / .381$ \\
\hline 16 & S/.3,792 & S/.1,336 & $\mathrm{S} / .2,456$ & $\mathrm{~S} / .135,282$ & S/.374 \\
\hline 17 & S/.3,792 & S/.1,312 & $\mathrm{S} / .2,480$ & S/.132,803 & S/.367 \\
\hline 18 & S/.3,792 & S/.1,288 & $\mathrm{S} / .2,504$ & S/.130,299 & S/.361 \\
\hline 19 & S/.3,792 & S/.1,264 & $\mathrm{S} / .2,528$ & S/.127,771 & $\mathrm{S} / .354$ \\
\hline 20 & S/.3,792 & S/.1,239 & S/.2,553 & S/.125,218 & S/.347 \\
\hline 21 & S/.3,792 & S/.1,214 & S/.2,577 & S/.122,641 & $\mathrm{S} / .340$ \\
\hline 22 & S/.3,792 & S/.1,189 & $\mathrm{S} / .2,602$ & S/.120,039 & $\mathrm{S} / .333$ \\
\hline 23 & S/.3,792 & S/.1,164 & $\mathrm{S} / .2,628$ & S/.117,411 & S/.326 \\
\hline 24 & S/.3,792 & S/.1,139 & S/.2,653 & S/.114,758 & S/.319 \\
\hline 25 & S/.3,792 & S/.1,113 & S/.2,679 & S/.112,079 & $\mathrm{S} / .312$ \\
\hline 26 & S/.3,792 & S/.1,087 & S/.2,705 & S/.109,374 & $\mathrm{S} / .304$ \\
\hline 27 & S/.3,792 & S/.1,061 & $\mathrm{S} / .2,731$ & S/.106,643 & S/.297 \\
\hline 28 & $\mathrm{~S} / .3,792$ & S/.1,034 & S/.2,758 & S/.103,886 & $\mathrm{S} / .290$ \\
\hline 29 & S/.3,792 & S/.1,008 & S/.2,784 & S/.101,102 & $\mathrm{S} / .282$ \\
\hline 30 & S/.3,792 & S/.981 & $\mathrm{S} / .2,811$ & $\mathrm{~S} / .98,290$ & S/.275 \\
\hline 31 & S/.3,792 & S/.953 & $\mathrm{S} / .2,839$ & $\mathrm{~S} / .95,452$ & S/.267 \\
\hline 32 & S/.3,792 & S/.926 & S/.2,866 & S/.92,586 & S/.259 \\
\hline 33 & S/.3,792 & S/.898 & S/.2,894 & $\mathrm{S} / .89,692$ & $\mathrm{~S} / .251$ \\
\hline 34 & S/.3,792 & $\mathrm{S} / .870$ & $\mathrm{~S} / .2,922$ & $\mathrm{~S} / .86,770$ & S/.244 \\
\hline 35 & S/.3,792 & $\mathrm{S} / .842$ & $\mathrm{~S} / .2,950$ & $\mathrm{~S} / .83,820$ & $\mathrm{~S} / .236$ \\
\hline 36 & S/.3,792 & $\mathrm{S} / .813$ & S/.2,979 & $\mathrm{S} / .80,841$ & $\mathrm{~S} / .228$ \\
\hline 37 & S/.3,792 & S/.784 & $\mathrm{S} / .3,008$ & $\mathrm{~S} / .77,833$ & $\mathrm{~S} / .220$ \\
\hline 38 & S/.3,792 & S/.755 & S/.3,037 & S/.74,796 & $\mathrm{S} / .211$ \\
\hline 39 & S/.3,792 & S/.725 & S/.3,066 & $\mathrm{S} / .71,730$ & $\mathrm{~S} / .203$ \\
\hline 40 & S/.3,792 & S/.696 & S/.3,096 & S/.68,634 & S/.195 \\
\hline 41 & S/.3,792 & S/.666 & S/.3,126 & S/.65,507 & S/.186 \\
\hline 42 & S/.3,792 & S/.635 & $\mathrm{S} / .3,156$ & $\mathrm{~S} / .62,351$ & S/.178 \\
\hline 43 & S/.3,792 & S/.605 & $\mathrm{S} / .3,187$ & S/.59,164 & S/.169 \\
\hline 44 & S/.3,792 & S/.574 & S/.3,218 & S/.55,946 & S/.161 \\
\hline 45 & S/.3,792 & S/.543 & S/.3,249 & $\mathrm{S} / .52,697$ & S/. 152 \\
\hline 46 & S/.3,792 & S/.511 & S/.3,281 & $\mathrm{S} / .49,416$ & S/.143 \\
\hline 47 & S/.3,792 & S/.479 & S/.3,313 & S/.46,103 & S/.134 \\
\hline 48 & S/.3,792 & S/.447 & $\mathrm{S} / .3,345$ & $\mathrm{~S} / .42,759$ & S/. 125 \\
\hline 49 & S/.3,792 & S/.415 & S/.3,377 & $\mathrm{S} / .39,382$ & S/.116 \\
\hline 50 & S/.3,792 & $\mathrm{S} / .382$ & S/.3,410 & $\mathrm{S} / .35,972$ & S/.107 \\
\hline 51 & S/.3,792 & S/.349 & $\mathrm{S} / .3,443$ & $\mathrm{~S} / .32,529$ & S/.98 \\
\hline 52 & S/.3,792 & S/.315 & S/.3,476 & $\mathrm{S} / .29,052$ & $\mathrm{~S} / .88$ \\
\hline 53 & S/.3,792 & $\mathrm{S} / .282$ & $\mathrm{~S} / .3,510$ & $\mathrm{~S} / .25,542$ & $\mathrm{~S} / .79$ \\
\hline 54 & S/.3,792 & S/.248 & S/.3,544 & $\mathrm{S} / .21,998$ & S/.69 \\
\hline 55 & $\mathrm{~S} / .3,792$ & $\mathrm{~S} / .213$ & S/.3,578 & $\mathrm{S} / .18,420$ & S/.60 \\
\hline 56 & S/.3,792 & S/.179 & S/.3,613 & S/.14,807 & $\mathrm{S} / .50$ \\
\hline 57 & S/.3,792 & S/.144 & $\mathrm{S} / .3,648$ & $\mathrm{~S} / .11,158$ & $\mathrm{~S} / .40$ \\
\hline 58 & S/.3,792 & S/.108 & S/.3,684 & S/.7,475 & $\mathrm{S} / .30$ \\
\hline 59 & S/.3,792 & $\mathrm{S} / .72$ & S/.3,719 & S/.3,755 & $\mathrm{S} / .20$ \\
\hline 60 & S/.3,792 & $\mathrm{S} / .36$ & S/.3,755 & $\mathrm{S} / .0$ & $\mathrm{~S} / .10$ \\
\hline
\end{tabular}


Anexo 21

Costos proceso de pastos.

\begin{tabular}{|c|c|c|c|c|c|c|c|c|c|c|c|c|c|c|c|c|c|c|c|c|c|c|c|c|c|}
\hline \multicolumn{26}{|c|}{ DETERMINACIÓN DE COSTOS PROCESO DE PRODUCCIÓN SIN IGV } \\
\hline 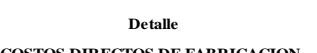 & $\begin{array}{l}\text { Unidad } \\
\text { Medida }\end{array}$ & Ene. & Feb & Mar & Abr & May & $\mathrm{Jun}^{\mathrm{ANO}}$ & 01 & Ago & Sep & Oct & Nov & Dic & Ene. & Feb & Mar & Abr & May & $\mathrm{Jun}^{\mathrm{ANN} O}$ & 22 & Ago & Sep & Oct & Nov & Dic \\
\hline $\begin{array}{l}\text { COSTOS DIRECTOS DE FABRICACION } \\
\text { Alqquiler de Terenon } 5 \text { ha } \\
\text { Alquiler de Terenon } 17 \text { ha. } \\
\text { AAqquiler de Terenon } 5 \text { ha. } \\
\text { Alquiler de terreno } 3 \text { ha } \\
\text { AAqquiler de Tereno } 6 \text { ha } \\
\text { Alquilier de Tereren } 5 \text { ha }\end{array}$ & $\begin{array}{l}\text { Ha. } \\
\text { Ha. } \\
\text { Ha. } \\
\text { Ha. } \\
\text { Ha. } \\
\text { Ha. }\end{array}$ & $\begin{array}{r}625.00 \\
2,125.00\end{array}$ & $\begin{array}{r}625.00 \\
2,125.00\end{array}$ & $\begin{array}{r}625.00 \\
2,125.00\end{array}$ & $\begin{array}{r}625.00 \\
2,125.00\end{array}$ & $\begin{array}{r}625.00 \\
2,125.00\end{array}$ & $\begin{array}{r}625.00 \\
2,125.00\end{array}$ & $\begin{array}{r}625.00 \\
2,125.00\end{array}$ & $\begin{array}{r}625.00 \\
2,125.00\end{array}$ & $\begin{array}{r}625.00 \\
2,125.00\end{array}$ & $\begin{array}{r}625.00 \\
2,125.50 \\
625.00\end{array}$ & $\begin{array}{r}625.00 \\
2,125.00^{\circ} \\
625.00\end{array}$ & $\begin{array}{c}625.00 \\
2,125.50^{\circ} \\
625.00\end{array}$ & $\begin{array}{r}625.00 \\
2,125.50^{\circ} \\
625.00\end{array}$ & $\begin{array}{r}625.00 \\
2,155.00^{\circ} \\
625.00\end{array}$ & $\begin{array}{r}625.00 \\
2,15.00^{\circ} \\
625.00\end{array}$ & $\begin{array}{r}625.00 \\
2,155.00^{\circ} \\
625.00\end{array}$ & $\begin{array}{r}625.00 \\
2,15.00^{\circ} \\
625.00\end{array}$ & $\begin{array}{c}625.00 \\
2,125.50^{\circ} \\
625.00\end{array}$ & $\begin{array}{r}625.00 \\
2,15.00^{\circ} \\
625.00\end{array}$ & $\begin{array}{r}625.00 \\
2,125.00^{\circ} \\
625.00\end{array}$ & $\begin{array}{r}625.00 \\
2,125.50^{\circ} \\
625.50 \\
375.00\end{array}$ & $\begin{array}{r}625.00 \\
2,125.00^{\circ} \\
625.00 \\
375.00\end{array}$ & $\begin{array}{r}625.00 \\
2,125.50^{\circ} \\
625.00^{2} \\
375.00\end{array}$ & $\begin{array}{r}625.00 \\
\quad 2,1155.00 \\
625.00 \\
375.00\end{array}$ \\
\hline 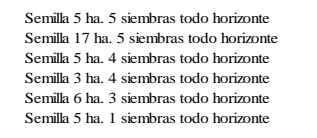 & $\begin{array}{l}\mathrm{Kg} . \\
\mathrm{Kg} . \\
\mathrm{Kg} . \\
\mathrm{Kg} . \\
\mathrm{Kg} . \\
\mathrm{Kg} .\end{array}$ & $17,000.00$ & $5,000.00$ & & & & & & & & & $5,000.00$ & & $\begin{array}{l}5,000.00 \\
17,000.00 \\
5,000.00\end{array}$ & & & & & & & & $3,000.00$ & & & \\
\hline $\begin{array}{l}\text { Abonos Adherentes } 357 \mathrm{~kg} \text {. Por } 5 \text { ha. } 5 \text { siemt } \\
\text { Abonos Adherentes } 357 \mathrm{~g} \text { k. Por } 17 \text { ha. } 5 \text { sien } \\
\text { Abonos Adherentes } 357 \mathrm{~kg} \text {. Por } 5 \text { ha. } 5 \text { siemt } \\
\text { Abonos Adherentes } 357 \mathrm{~kg} \text {. Por } 3 \text { ha. } 4 \text { siemt } \\
\text { Abonos Adherentes } 357 \mathrm{~kg} \text {. Por } 6 \text { ha. } 3 \text { siemt } \\
\text { Abonos Adherentes } 357 \mathrm{~kg} \text {. Por } 5 \text { ha. } 1 \text { siemt }\end{array}$ & $\begin{array}{l}\mathrm{kg} . \\
\mathrm{kg} \\
\mathrm{kg} \\
\mathrm{kg} \\
\mathrm{kg} \\
\mathrm{kg}\end{array}$ & $24,276.00$ & $7,140.00$ & & & & & & & & & $7,140.00$ & & $\begin{array}{r}3,570.00 \\
12,138.00 \\
3,570.00\end{array}$ & & & & & & & & $2,142.00$ & & & \\
\hline \multicolumn{26}{|l|}{$\begin{array}{l}\text { MANO DE OBRA DIRECTA } \\
\text { Personal Técnico }\end{array}$} \\
\hline 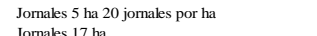 & jornal & $\begin{array}{l}250.00 \\
8500\end{array}$ & 250.00 & 250.00 & 250.00 & $\begin{array}{l}250.00 \\
8500\end{array}$ & 250.00 & $\begin{array}{l}250.00 \\
85000\end{array}$ & $\begin{array}{l}250.00 \\
8500\end{array}$ & 250.00 & 250.00 & 250.00 & 250.00 & 250.00 & 250.00 & 250.00 & 250.00 & 250.00 & 250.00 & 250.00 & 250.00 & 250.00 & 250.00 & 250.00 & 250.00 \\
\hline $\begin{array}{l}\text { Jornales } 17 \text { ha } \\
\text { Jonnals } 5 \text { ha } \\
\text { Jomalases } 3 \text { ha } \\
\text { Jomales } 6 \text { ha }\end{array}$ & & 850.00 & 850.00 & 850.00 & 850.00 & 850.00 & 850.00 & 850.00 & 850.00 & 850.00 & $\begin{array}{l}850.00 \\
250.00\end{array}$ & $\begin{array}{l}850.00 \\
250.00\end{array}$ & $\begin{array}{l}850.00 \\
250.00\end{array}$ & $\begin{array}{l}850.00 \\
250.00\end{array}$ & $\begin{array}{l}850.00 \\
250.00\end{array}$ & $\begin{array}{l}850.00 \\
250.00\end{array}$ & $\begin{array}{l}850.00 \\
250.00\end{array}$ & $\begin{array}{l}850.00 \\
250.00\end{array}$ & $\begin{array}{l}850.00 \\
250.00\end{array}$ & $\begin{array}{l}850.00 \\
250.00\end{array}$ & $\begin{array}{l}850.00 \\
250.00\end{array}$ & $\begin{array}{l}8550.00 \\
250.00 \\
150.00\end{array}$ & $\begin{array}{l}850.00 \\
250.00 \\
150.00\end{array}$ & $\begin{array}{l}8550.00 \\
250.00 \\
150.00\end{array}$ & $\begin{array}{l}850.00 \\
250.00 \\
150.00\end{array}$ \\
\hline $\begin{array}{l}\text { Jornales } 5 \text { ha } \\
\text { Ing. Anronomo }\end{array}$ & & $3,645.00$ & & & & & & & & & & & & & & & & & & & & & & & \\
\hline \multicolumn{2}{|c|}{$\begin{array}{l}\text { Ing. Agronomono } \\
\text { Tecico Agronomo } \\
\text { OTROS COSTOS DIRECTOS DE FABRICACION }\end{array}$} & 9,112.50 & $9,112.50$ & $\begin{array}{l}3.645 .00 \\
9,112.50\end{array}$ & $\begin{array}{l}3,344.300 \\
9,112.50\end{array}$ & $\begin{array}{l}3,646.500 \\
9,112.50\end{array}$ & $\begin{array}{l}3,643.00 \\
9,112.50\end{array}$ & $\begin{array}{l}3,6,65.00 \\
9,112.50\end{array}$ & $\begin{array}{l}3,346.500 \\
9,112.50\end{array}$ & $\begin{array}{l}3.643 .00 \\
9,112.50\end{array}$ & $\begin{array}{l}3,344.50 \\
9,12.50\end{array}$ & $\begin{array}{l}3,344.300 \\
9,112.50\end{array}$ & $\begin{array}{l}3 \\
9,6432.00 \%\end{array}$ & 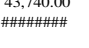 & & & & & & & & & & & \\
\hline Alquiler Tractor Instalacion 17 ha. & Horas & $7,480.00$ & & & & & & & & & & & & & & & & & & & & & & & \\
\hline 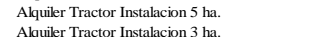 & $\begin{array}{l}\text { Horas } \\
\text { Horas }\end{array}$ & & & & & & & & & & & $2,200.00$ & & & & & & & & & & & & & \\
\hline 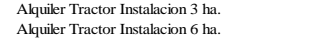 & $\begin{array}{l}\text { Horas } \\
\text { Horas }\end{array}$ & & & & & & & & & & & & & & & & & & & & & $1,320.00$ & & & \\
\hline 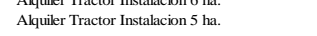 & $\begin{array}{l}\text { Holas } \\
\text { Horas }\end{array}$ & & & & & & & & & & & & & & & & & & & & & & & & \\
\hline COSTOS INDIRECTOS DE FABICACION & & & & & & & 0.00 & & & & & & & & & & & & 0.00 & & & & & & \\
\hline ora & $\begin{array}{l}\text { Unid. } \\
\text { Unid. }\end{array}$ & $\begin{array}{r}495.00 \\
64.50\end{array}$ & & & & & & & & & & & & $\begin{array}{r}594.00 \\
77.40\end{array}$ & & & & & & & & & & & \\
\hline Aspersores & Unid. & 500.00 & & & & & & & & & & & & 40 & & & & & & & & & & & \\
\hline $\begin{array}{l}\text { Manguera de aspersor } \\
\text { Bofug }\end{array}$ & Metros & 315.00 & & & & & & & & & & & & & & & & & & & & & & & \\
\hline $\begin{array}{l}\text { Botas } \\
\text { Inpermeables }\end{array}$ & & $\begin{array}{l}74.70 \\
8970\end{array}$ & & & & & & & & & & & & 149.40 & & & & & & & & & & & \\
\hline $\begin{array}{l}\text { Giuntes } \\
\text { Gutes }\end{array}$ & $\begin{array}{l}\text { Par } \\
\text { Par } \\
\text { unid. }\end{array}$ & 19.50 & & & & & & & & & & & & 39.60 & & & & & & & & & & & \\
\hline Gasolina & Gi & 153.60 & 153.60 & 153.60 & 153.60 & 153.60 & 153.60 & 153.60 & 153.60 & 153.60 & 153.60 & 153.60 & 153.60 & 153.60 & 153.60 & 153.60 & 153.60 & 153.60 & 153.60 & 153.60 & 153.60 & 153.60 & 153.60 & 153.60 & 153.60 \\
\hline $\begin{array}{l}\text { Costo Mensual } \\
\text { Postuccion Meses }\end{array}$ & & $\begin{array}{r}67,075.50 \\
-6205\end{array}$ & $28,901.10$ & $\begin{array}{l}16,761.10 \\
6205\end{array}$ & $16,761.10$ & $16,761.10$ & $\begin{array}{l}16,761.10 \\
6.295\end{array}$ & $\begin{array}{l}16,761.10 \\
6295\end{array}$ & $16,761.10$ & $\begin{array}{l}16,761.10 \\
6205\end{array}$ & $17,636.10$ & $31,976.10$ & $17,636.10$ \# & 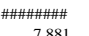 & $\begin{array}{r}4,878.60 \\
7801\end{array}$ & $4,878.60$ & $\begin{array}{r}4,878.60 \\
781\end{array}$ & $\begin{array}{r}4,878.60 \\
781\end{array}$ & $\begin{array}{r}4,878.60 \\
7881\end{array}$ & $4,878.60$ & $\begin{array}{r}4,878.601 \\
7\end{array}$ & $\begin{array}{l}11,865.60 \\
7881\end{array}$ & $\begin{array}{r}5,403.60 \\
7881\end{array}$ & $\begin{array}{r}5,403.60 \\
788\end{array}$ & $\begin{array}{r}5,403.60 \\
7881\end{array}$ \\
\hline $\begin{array}{l}\text { Produccion Mensual } \\
\text { Costo unitario Pastos }\end{array}$ & & $\begin{array}{l}6,295 \\
10,66\end{array}$ & $\begin{array}{r}6,295 \\
450\end{array}$ & 6,295 & $\begin{array}{r}6,295 \\
266\end{array}$ & $\begin{array}{r}6,295 \\
266\end{array}$ & 6,295 & 6,295 & $\begin{array}{r}6,295 \\
266\end{array}$ & 6,295 & $\begin{array}{c}6,295 \\
280\end{array}$ & $\begin{array}{c}6,295 \\
5,08\end{array}$ & 6,295 & 7,881 & 7,881 & 7,881 & 7,881 & 7,881 & 7,881 & 7,881 & 7,881 & 7,881 & 7,881 & 7,881 & $\begin{array}{l}7,881 \\
0.69\end{array}$ \\
\hline $\begin{array}{l}\text { Costo nutation Pastos } \\
\text { Costo Anal sin IGV }\end{array}$ & & 10.66 & 4.59 & & 2.66 & 2.66 & 2.66 & 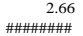 & 2.66 & 2.66 & 2.80 & 5.08 & 2.80 & 28.84 & & & & 0.62 & 0.62 & 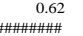 & 0.62 & 1.51 & 0.69 & 0.69 & 0.69 \\
\hline $\begin{array}{l}\text { Produccion Anual en Unid. } \\
\text { Costo Unitario Aliemntacion }\end{array}$ & & & & & & & & $\begin{array}{r}75,544 \\
3.71\end{array}$ & & & & & & & & & & & & $\begin{array}{r}94,572 \\
3.06\end{array}$ & & & & & \\
\hline
\end{tabular}




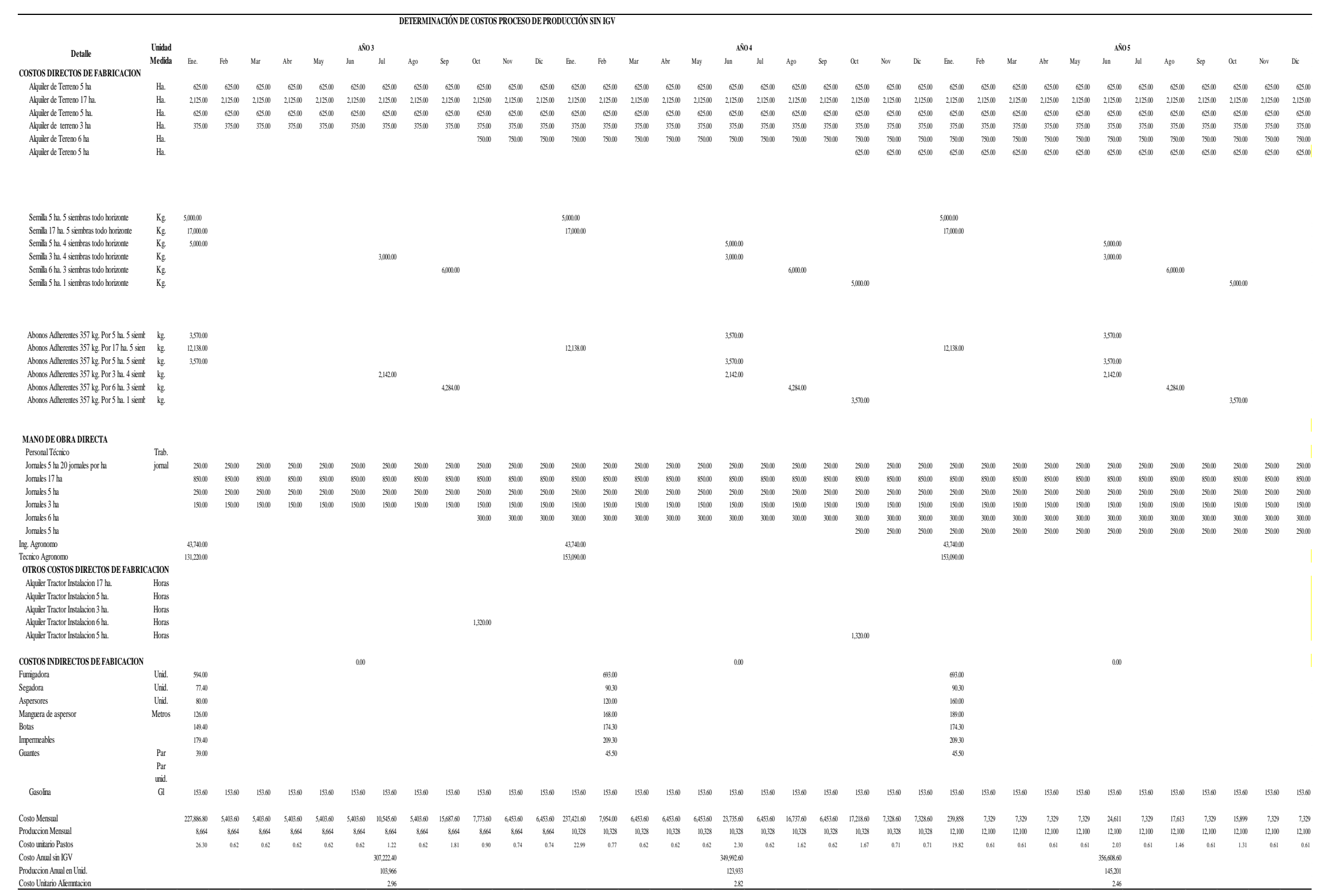


Anexo 22

\section{Costos proceso de crianza}

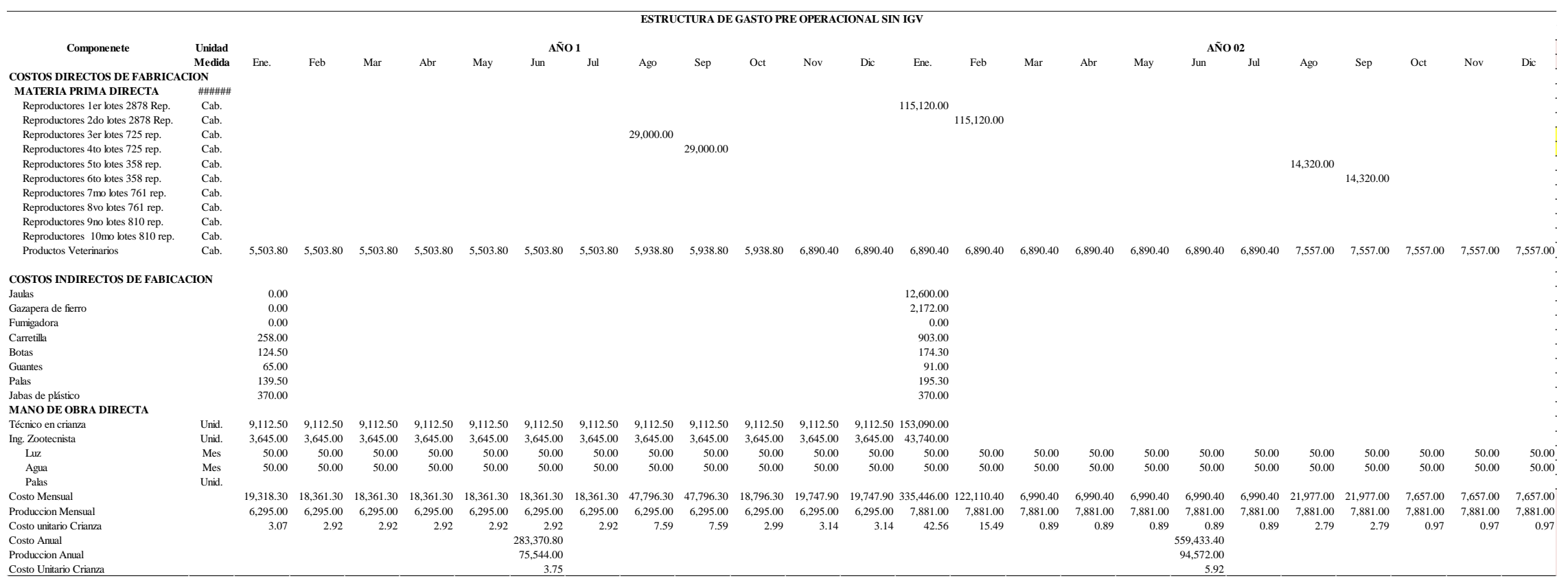




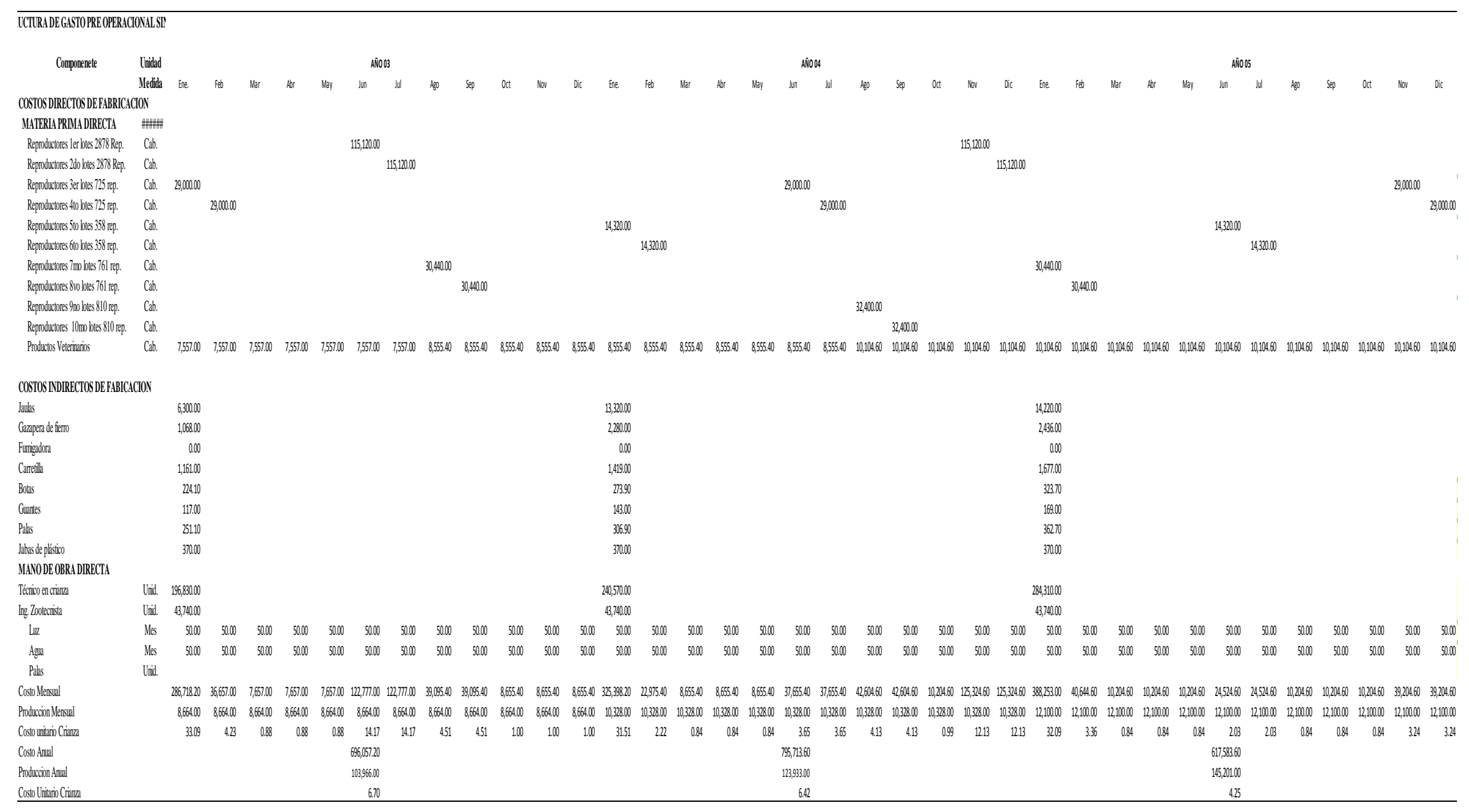


Anexo 23

\section{Costos proceso de sacrificio}

\begin{tabular}{|c|c|c|c|c|c|c|c|c|c|c|c|c|c|c|c|c|c|c|c|c|c|c|c|c|c|}
\hline \multicolumn{26}{|c|}{ ESTRUCTURA DE GASTO PRE OPERACIONAL SIN IGV } \\
\hline \multirow[t]{2}{*}{ Componenete } & \multirow{2}{*}{$\begin{array}{l}\text { Unidad } \\
\text { Medida }\end{array}$} & \multicolumn{12}{|c|}{ AÑ 001} & \multicolumn{12}{|c|}{ AÑ 002} \\
\hline & & Ene. & Feb & Mar & Abr & May & Jun & Jul & Ago & Sep & Oct & Nov & Dic & Ene. & Feb & Mar & Abr & May & Jun & Jul & Ago & Sep & Oct & Nov & Dic \\
\hline \multicolumn{26}{|c|}{$\begin{array}{l}\text { COSTOS DIRECTOS DE FABRICACION } \\
\text { Ollas } 25 \text { tt. }\end{array}$} \\
\hline \multicolumn{26}{|c|}{$\begin{array}{l}\text { Ollas } 25 \text { lt. } \\
\text { Balanza }\end{array}$} \\
\hline \multicolumn{26}{|l|}{ Cuchillos } \\
\hline \multicolumn{26}{|l|}{ Jabas de plástico } \\
\hline \multirow{2}{*}{\multicolumn{26}{|c|}{$\begin{array}{l}\text { Ganchos para oreado } \\
\text { Tachos para desperdicios }\end{array}$}} \\
\hline & & & & & & & & & & & & & & & & & & & & & & & & & \\
\hline \multicolumn{26}{|l|}{ Escobas } \\
\hline \multicolumn{26}{|l|}{ Guantes } \\
\hline \multirow{2}{*}{\multicolumn{26}{|c|}{$\begin{array}{l}\text { Buzo protector mameluco } \\
\text { Botas }\end{array}$}} \\
\hline & & & & & & & & & & & & & & & & & & & & & & & & & \\
\hline \multicolumn{26}{|l|}{ Protector bucal } \\
\hline \multicolumn{26}{|l|}{ MANO DE OBRA DIRECTA } \\
\hline Jornales & Jornales & $6,750.00$ & $6,750.00$ & $6,750.00$ & $6,750.00$ & $6,750.00$ & $6,750.00$ & $6,750.00$ & $6,750.00$ & $6,750.00$ & $6,750.00$ & $6,750.00$ & $6,750.00$ & $8,500.00$ & $8,500.00$ & $8,500.00$ & $8,500.00$ & $8,500.00$ & $8,500.00$ & $8,500.00$ & $8,500.00$ & $8,500.00$ & $8,500.00$ & $8,500.00$ & $8,500.00$ \\
\hline Veterinario & & 750.00 & 750.00 & 750.00 & 750.00 & 750.00 & 750.00 & 750.00 & 750.00 & 750.00 & 750.00 & 750.00 & 750.00 & 750.00 & 750.00 & 750.00 & 750.00 & 750.00 & 750.00 & 750.00 & 750.00 & 750.00 & 750.00 & 750.00 & 750.00 \\
\hline \multicolumn{26}{|c|}{ COSTOS INDIRECTOS DE FABICACION } \\
\hline \multicolumn{26}{|c|}{ OTROS COSTOS INDIRECTOS DE FABRICACION } \\
\hline Luz & Mes & 50.00 & 50.00 & 50.00 & 50.00 & 50.00 & 50.00 & 50.00 & 50.00 & 50.00 & 50.00 & 50.00 & 50.00 & 50.00 & 50.00 & 50.00 & 50.00 & 50.00 & 50.00 & 50.00 & 50.00 & 50.00 & 50.00 & 50.00 & 50.00 \\
\hline Agla & Mes & 45.00 & 45.00 & 45.00 & 45.00 & 45.00 & 45.00 & 45.00 & 45.00 & 45.00 & 45.00 & 45.00 & 45.00 & 45.00 & 45.00 & 45.00 & 45.00 & 45.00 & 45.00 & 45.00 & 45.00 & 45.00 & 45.00 & 45.00 & 45.00 \\
\hline Botas & Par & & & & & & & & & & & & & & & & & & & & & & & & \\
\hline Guantes & Par & & & & & & & & & & & & & & & & & & & & & & & & \\
\hline Buzo protectorpara todo tipo de Trabajo & Unid. & & & & & & & & & & & & & & & & & & & & & & & & \\
\hline Protector Bucal & Unid. & & & & & & & & & & & & & & & & & & & & & & & & \\
\hline Costo Mensual & & $7,595.00$ & $7,595.00$ & $7,595.00$ & $7,595.00$ & $7,595.00$ & $7,595.00$ & $7,595.00$ & $7,595.00$ & $7,595.00$ & $7,595.00$ & $7,595.00$ & $7,595.00$ & $9,345.00$ & $9,345.00$ & $9,345.00$ & $9,345.00$ & $9,345.00$ & $9,345.00$ & $9,345.00$ & $9,345.00$ & $9,345.00$ & $9,345.00$ & $9,345.00$ & $9,345.00$ \\
\hline Produccion Mensual & & $6,295.00$ & $6,295.00$ & $6,295.00$ & $6,295.00$ & $6,295.00$ & $6,295.00$ & $6,295.00$ & $6,295.00$ & $6,295.00$ & $6,295.00$ & $6,295.00$ & $6,295.00$ & $7,881.00$ & $7,881.00$ & $7,881.00$ & $7,881.00$ & $7,881.00$ & $7,881.00$ & $7,881.00$ & $7,881.00$ & $7,881.00$ & $7,881.00$ & $7,881.00$ & $7,881.00$ \\
\hline Costo unitario Crianzza & & 1.21 & 1.21 & 1.21 & 1.21 & 1.21 & 1.21 & 1.21 & 1.21 & 1.21 & 1.21 & 1.21 & 1.21 & 1.19 & 1.19 & 1.19 & 1.19 & 1.19 & 1.19 & 1.19 & 1.19 & 1.19 & 1.19 & 1.19 & 1.19 \\
\hline Costo Anual & & & & & & & $91,140.00$ & & & & & & & & & & & & $112,140.00$ & & & & & & \\
\hline Produccion Anual & & & & & & & $75,544.00$ & & & & & & & & & & & & $94,572.00$ & & & & & & \\
\hline Costo Unitario Crianza & & & & & & & 1.21 & & & & & & & & & & & & 1.19 & & & & & & \\
\hline
\end{tabular}




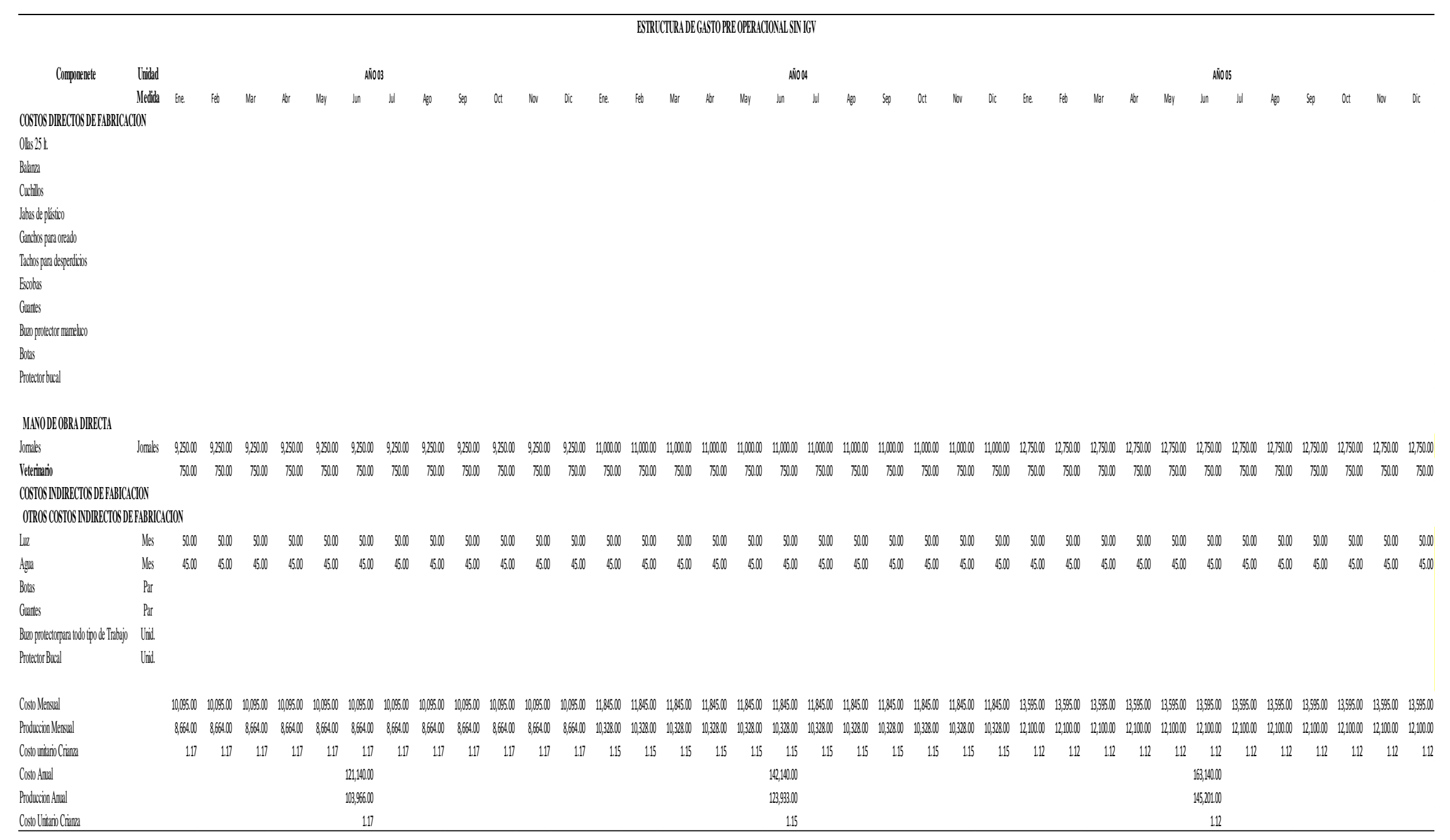


Anexo 24

Costos proceso empacado y comercialización

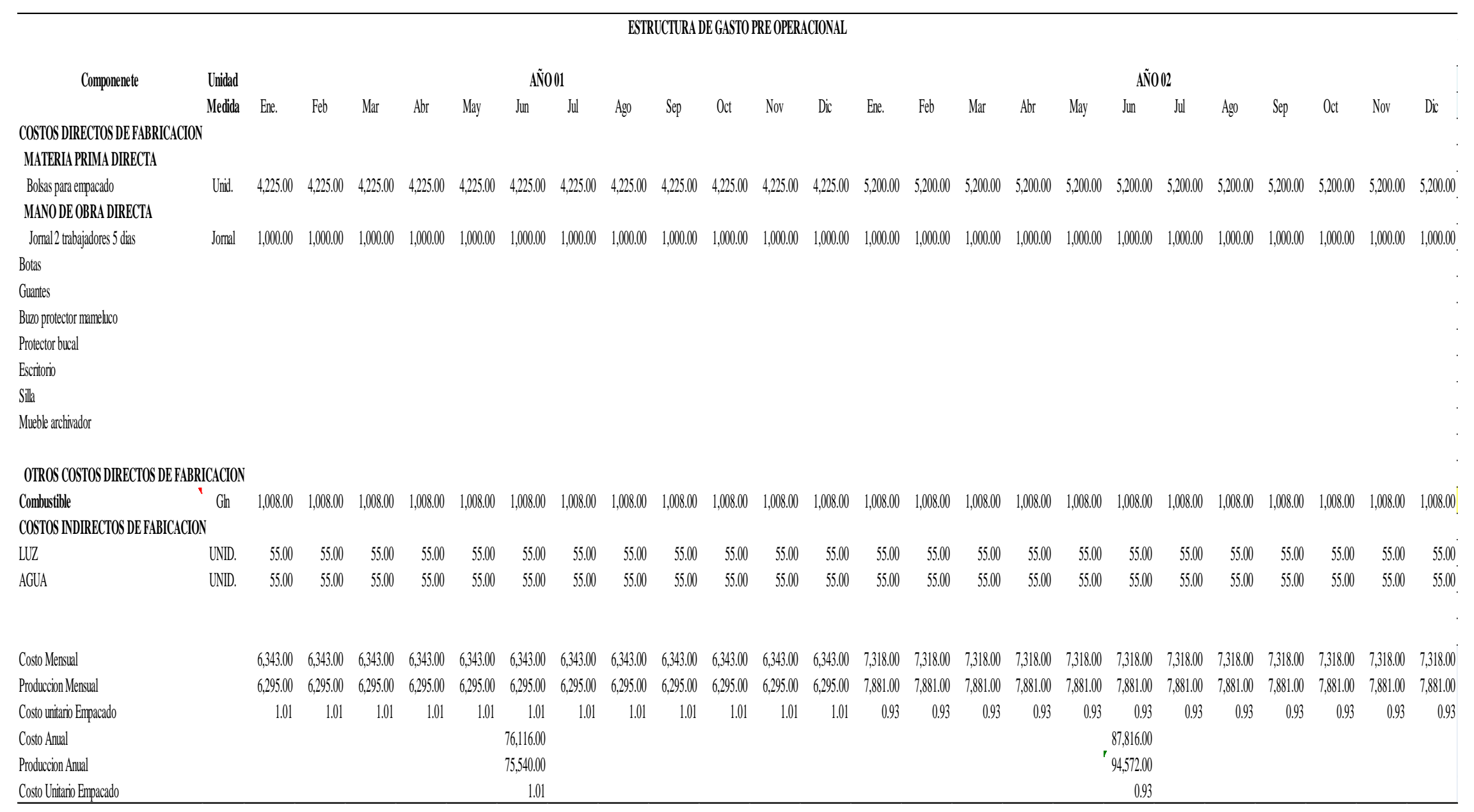




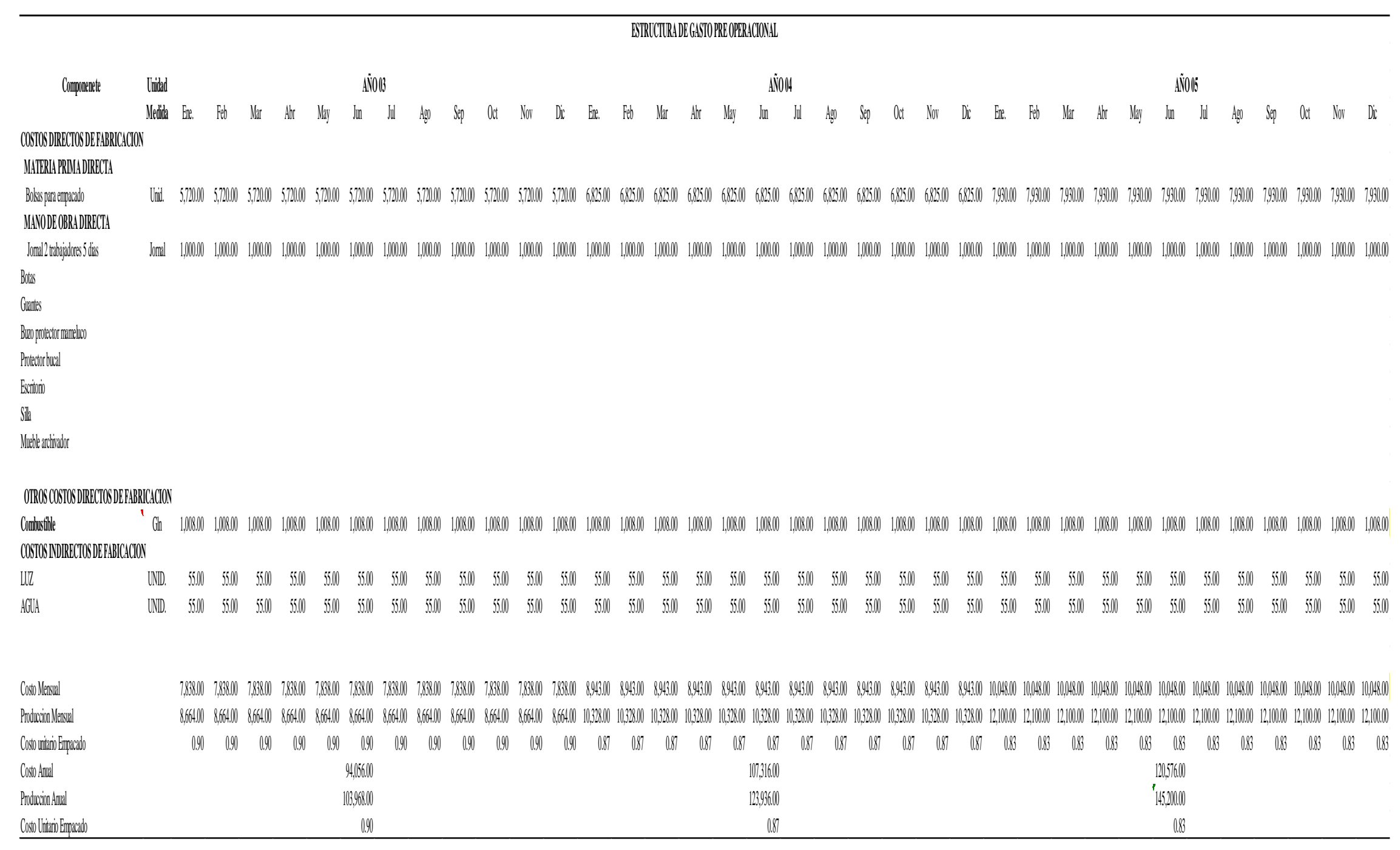


Anexo 25

Gastos administrativos y Gasto de ventas.

Gastos Administrativos (Expresado en nuevos soles sin IGV)

\begin{tabular}{|c|c|c|c|c|c|}
\hline Detalle & A ño 1 & A $\tilde{\mathbf{n o}} \mathbf{2}$ & A $\tilde{\mathbf{n o}} \mathbf{3}$ & A $\tilde{\text { o }} 4$ & A $\tilde{\mathbf{n}} \mathbf{5}$ \\
\hline Remume ración adminis trativa & $\mathrm{S} / .58,320$ & $\mathrm{~S} / .58,320$ & $\mathrm{~S} / .58,320$ & $\mathrm{~S} / .58,320$ & $\mathrm{~S} / .58,32 \mathrm{O}$ \\
\hline Artículos de oficina & S/. 3,166 & $S / .3,166$ & $S / .3,166$ & $S / .3,166$ & S/. 3,166 \\
\hline Luz & S/. 506 & S/. 506 & $\mathrm{~S} / .506$ & S/. 506 & S/. 506 \\
\hline Agua & $\mathrm{S} / .2 \mathrm{O3}$ & $\mathrm{S} / .2 \mathrm{O3}$ & $\mathrm{S} / .2 \mathrm{O3}$ & $\mathrm{S} / .203$ & $\mathrm{~S} / .203$ \\
\hline Contador & $\mathrm{S} / .4,800$ & $\mathrm{~S} / .4,800$ & $\mathrm{~S} / .4,800$ & $\mathrm{~S} / .4,800$ & $\mathrm{~S} / .4,800$ \\
\hline Asesor Legal & $\mathrm{S} / .2,160$ & $\mathrm{~S} / .2,160$ & $\mathrm{~S} / .2,160$ & $\mathrm{~S} / .2,160$ & $\mathrm{~S} / .2,160$ \\
\hline $\begin{array}{l}\text { Servicio de telefonía/internet } \\
\text { TOTAL SIN IGV }\end{array}$ & $\begin{array}{l}\text { S/. } 1,548 \\
\text { S/. 70,703 }\end{array}$ & $\begin{array}{l}\text { S/. } 1,548 \\
\text { S/. 70,703 }\end{array}$ & $\begin{array}{l}\text { S/. } 1,548 \\
\text { S/. 70,703 }\end{array}$ & $\begin{array}{l}\text { S/. } 1,548 \\
\text { S/. 70,703 }\end{array}$ & $\begin{array}{l}S / .1,548 \\
\text { S/. } 70,703\end{array}$ \\
\hline
\end{tabular}

\begin{tabular}{|c|c|c|c|c|c|}
\hline \multicolumn{6}{|c|}{ Gasto de Ventas (Expresado en Nuevos soles sin IGV) } \\
\hline Detalle & A $\tilde{\mathbf{n o}} \mathbf{1}$ & A $\tilde{\mathbf{n o}} \mathbf{2}$ & A ̃̃o 3 & A $\tilde{\text { no }} 4$ & A $\tilde{\text { oo }} \mathbf{5}$ \\
\hline Remuneración de Vent & $\mathrm{S} / .90,396$ & $\mathrm{~S} / .90,396$ & $\mathrm{~S} / .90$, & S/. 90,396 & S/. 90,396 \\
\hline Alquiler de local comercial & S/. 14,400 & S/. 14,400 & S/. 14,400 & S/. 14,400 & S/. 14,400 \\
\hline Combustible & S/. 8,746 & S/. 8,746 & $\mathrm{~S} / .8,746$ & S/. 8,746 & S/. 8,746 \\
\hline Total sin IGV & S/. 113,542 & S/. 113,542 & S/. 113,542 & S/. 113,542 & S/. 113,542 \\
\hline
\end{tabular}


Anexo 26

Depreciaciones por año y valor de deshecho.

Depreciaciones año uno

\begin{tabular}{|c|c|c|c|c|c|c|c|c|}
\hline DETALLE & $\begin{array}{c}\text { Valor de } \\
\text { adquisicion }\end{array}$ & $\begin{array}{l}\text { Vida util } \\
\text { años }\end{array}$ & $\begin{array}{c}\text { Depreciacion } \\
\text { Anual }\end{array}$ & $\begin{array}{c}\text { Años a } \\
\text { Depreciar }\end{array}$ & $\begin{array}{c}\text { Depreciacion } \\
\text { acumulada año } 5\end{array}$ & $\begin{array}{l}\text { Valor en } \\
\text { Libros }\end{array}$ & $\begin{array}{c}\text { Valor Comercial } \\
\text { año } 5 \%\end{array}$ & $\begin{array}{c}\text { Valor } \\
\text { Comercial año } \\
5 \mathrm{~s} / .\end{array}$ \\
\hline Terrenos 4935 & 57,135 & & & & & & $120 \%$ & 68,562 \\
\hline Motoneta & 6,102 & 5 & 1,220 & 5 & 6,102 & 0 & $20 \%$ & 1,220 \\
\hline Furgon & 24,890 & 5 & 4,978 & 5 & 24,890 & 0 & $20 \%$ & 4,978 \\
\hline Cocina Industrial & 2,500 & 5 & 500 & 5 & 2,500 & 0 & $15 \%$ & 375 \\
\hline Mesa de Trabajo 3 unid. & 3,051 & 5 & 610 & 5 & 3,051 & 0 & $15 \%$ & 458 \\
\hline Empacadora 2 unid & 5,593 & 5 & 1,119 & 5 & 5,593 & 0 & $15 \%$ & 839 \\
\hline Congeladora 2 unid- & 3,898 & 5 & 780 & 5 & 3,898 & 0 & $15 \%$ & 585 \\
\hline Exibidor & 2,712 & 5 & 542 & 5 & 2,712 & 0 & $15 \%$ & 407 \\
\hline Equipo de Computo & 1,441 & 5 & 288 & 5 & 1,441 & 0 & $10 \%$ & 144 \\
\hline Infraestructura Crianza y Reproduccion $1295 \mathrm{~m}+364 \mathrm{~m} * \mathrm{~s} / .47$ & 73,273 & 20 & 3,664 & 5 & 18,318 & 54,955 & $40 \%$ & 29,309 \\
\hline Infraestructura Camal $180 \mathrm{~m}^{*} \mathrm{~s} / .593$ & 106,740 & 20 & 5,337 & 5 & 26,685 & 80,055 & $40 \%$ & 42,696 \\
\hline Totales & 287,335 & & 19,038 & & 95,190 & 135,010 & & 149,573 \\
\hline
\end{tabular}

Depreciaciones año dos

\begin{tabular}{|c|c|c|c|c|c|c|c|c|}
\hline DETALLE & $\begin{array}{c}\text { Valor de } \\
\text { adquisicion }\end{array}$ & $\begin{array}{l}\text { Vida util } \\
\text { años }\end{array}$ & $\begin{array}{l}\text { Depreciacion } \\
\text { Anual }\end{array}$ & $\begin{array}{c}\text { Años a } \\
\text { Depreciar }\end{array}$ & $\begin{array}{c}\text { Depreciacion } \\
\text { acumulada año } 5\end{array}$ & $\begin{array}{l}\text { Valor en } \\
\text { Libros }\end{array}$ & $\begin{array}{l}\text { Valor Comercial } \\
\text { año } 5 \%\end{array}$ & $\begin{array}{c}\text { Valor } \\
\text { Comercial año } \\
5 \mathrm{~s} / .\end{array}$ \\
\hline Motoneta & 6,102 & 5 & 1,220 & 4 & 4,882 & 1,220 & $30 \%$ & 1,831 \\
\hline Infraestructura Crianza y Reproduccion $326 \mathrm{~m}+92 \mathrm{~m} * \mathrm{~s} / 47$ & 19,646 & 20 & 982 & 4 & 3,929 & 15,717 & $45 \%$ & 8,841 \\
\hline Totales & 25,748 & & 2,203 & & 8,811 & 16,937 & & 10,671 \\
\hline
\end{tabular}

Depreciaciones año tres

\begin{tabular}{|c|c|c|c|c|c|c|c|c|}
\hline DETALLE & $\begin{array}{c}\text { Valor de } \\
\text { adquisicion }\end{array}$ & $\begin{array}{l}\text { Vida util } \\
\text { años }\end{array}$ & $\begin{array}{c}\text { Depreciacion } \\
\text { Anual }\end{array}$ & $\begin{array}{c}\text { Años a } \\
\text { Depreciar }\end{array}$ & $\begin{array}{c}\text { Depreciacion } \\
\text { acumulada año } 5\end{array}$ & $\begin{array}{l}\text { Valor en } \\
\text { Libros }\end{array}$ & $\begin{array}{l}\text { Valor Comercial } \\
\text { año } 5 \%\end{array}$ & $\begin{array}{c}\text { Valor } \\
\text { Comercial año } \\
5 \mathrm{~s} / .\end{array}$ \\
\hline Motoneta & 6,102 & 5 & 1,220 & 3 & 3,661 & 2,441 & $40 \%$ & 2,441 \\
\hline Infraestructura Crianza y Reproduccion $161 \mathrm{~m}+45 \mathrm{~m} * \mathrm{~s} / 47$ & 9,682 & 20 & 484 & 3 & 1,452 & 8,230 & $50 \%$ & 4,841 \\
\hline Totales & $\mathbf{1 5 , 7 8 4}$ & & $\mathbf{1 , 7 0 5}$ & & $\mathbf{5 , 1 1 4}$ & $\mathbf{1 0 , 6 7 1}$ & & $\mathbf{7 , 2 8 2}$ \\
\hline
\end{tabular}


Depreciaciones año 4

\begin{tabular}{|c|c|c|c|c|c|c|c|c|}
\hline DETALLE & $\begin{array}{c}\text { Valor de } \\
\text { adquisicion }\end{array}$ & $\begin{array}{l}\text { Vida util } \\
\text { años }\end{array}$ & $\begin{array}{c}\text { Depreciacion } \\
\text { Anual }\end{array}$ & $\begin{array}{c}\text { Años a } \\
\text { Depreciar }\end{array}$ & $\begin{array}{c}\text { Depreciacion } \\
\text { acumulada año } 5\end{array}$ & $\begin{array}{c}\text { Valor en } \\
\text { Libros }\end{array}$ & $\begin{array}{c}\text { Valor Comercial } \\
\text { año } 5 \%\end{array}$ & $\begin{array}{c}\text { Valor } \\
\text { Comercial año } \\
5 \text { s/. } \\
\end{array}$ \\
\hline Infraestructura Crianza y Reproduccion $342 \mathrm{~m}+96 \mathrm{~m} * \mathrm{~s} / .47$ & 20,586 & 20 & 1,029 & 2 & 2,059 & 18,527 & $55 \%$ & 11,322 \\
\hline Totales & 20,586 & & 1,029 & & 2,059 & 18,527 & & $\mathbf{1 1 , 3 2 2}$ \\
\hline & & & & & & & Valor Comercial & 11,322 \\
\hline
\end{tabular}

Depreciaciones año cinco

\begin{tabular}{|c|c|c|c|c|c|c|c|c|}
\hline DETALLE & $\begin{array}{c}\text { Valor de } \\
\text { adquisicion }\end{array}$ & $\begin{array}{l}\text { Vida util } \\
\text { años }\end{array}$ & $\begin{array}{c}\text { Depreciacion } \\
\text { Anual }\end{array}$ & $\begin{array}{c}\text { Años a } \\
\text { Depreciar }\end{array}$ & $\begin{array}{c}\text { Depreciacion } \\
\text { acumulada año } 5\end{array}$ & $\begin{array}{l}\text { Valor en } \\
\text { Libros }\end{array}$ & $\begin{array}{l}\text { Valor Comercial } \\
\text { año } 5 \%\end{array}$ & $\begin{array}{c}\text { Valor } \\
\text { Comercial año } \\
5 \mathrm{~s} / .\end{array}$ \\
\hline Infraestructura Crianza y Reproduccion $365 \mathrm{~m}+102 \mathrm{~m} * \mathrm{~s} / .47$ & 21,949 & 20 & 1,097 & 1 & 1,097 & 20,852 & $60 \%$ & 13,169 \\
\hline Totales & 21,949 & & 1,097 & & 1,097 & 20,852 & & 13,169 \\
\hline
\end{tabular}

Valor de Salvamento Comercial

\begin{tabular}{lr}
\hline & Monto \\
\hline Valor comercial activos & 192,018 \\
Valor en Libros contable (-) & 201,996 \\
Utilidad antes del impuesto & $-9,979$ \\
Impuesto 28\% & 2794 \\
Utilidad neta & $-7,185$ \\
Valor en Libros contable (+) & 201,996 \\
Flujo Neto & $\mathbf{1 9 4 , 8 1 2}$ \\
\hline
\end{tabular}

Depreciacion acumulada anual

\begin{tabular}{lccccc}
\hline \multicolumn{1}{c}{ Procesos } & Año 1 & Año 2 & Año 3 & Año 4 & Año 5 \\
$\begin{array}{l}\text { Pastos, Crianza, } \\
\text { Sacrificio y }\end{array}$ & 19,038 & 21,241 & 22,945 & 23,975 & 25,072 \\
Empacado & & & & \\
\hline
\end{tabular}


Anexo 27

Tabulaciones de Datos: Encuestas a Familias, Restaurantes Turísticos y Tradicionales

\section{Análisis y procesamiento de datos.}

\section{Encuesta dirigida al poblador cusqueño por distrito.}

\section{P1. Grupo etareo}

\begin{tabular}{ccc}
\hline Grupo Etareo & $\mathrm{N}^{\circ}$ de personas & $\%$ \\
\hline 18 a 30 años & 204 & $34 \%$ \\
31 a 45 años & 276 & $46 \%$ \\
46 a 50 años & 66 & $11 \%$ \\
61 a mas & 54 & $9 \%$ \\
Total & 600 & $100 \%$ \\
\hline
\end{tabular}

P2. Género

\begin{tabular}{ccc}
\hline Sexo & $\mathrm{N}^{\circ}$ de personas & $\%$ \\
\hline Hombre & 340 & $57 \%$ \\
Mujer & 260 & $43 \%$ \\
Total & 600 & $100 \%$ \\
\hline
\end{tabular}

P3. ¿Por cuantas personas está compuesta su unidad familiar?

\begin{tabular}{ccc}
\hline Cantidad & $\mathrm{N}^{\circ}$ de personas & $\%$ \\
\hline Solo una & 11 & $2 \%$ \\
Dos a cuatro & 384 & $64 \%$ \\
Más de cinco & 205 & $34 \%$ \\
Total & 600 & $100 \%$ \\
\hline
\end{tabular}


P4. ¿En qué distritos del Cusco y provincias se encuentran viviendo actualmente?

\begin{tabular}{ccc}
\hline Distritos & $\mathrm{N}^{\circ}$ de personas & $\%$ \\
\hline Cusco & 120189 & $20 \%$ \\
San Jerónimo & 50886 & $9 \%$ \\
San Sebastián & 128514 & $22 \%$ \\
Santiago & 91327 & $15 \%$ \\
Wanchaq & 64561 & $11 \%$ \\
Saylla & 6033 & $1 \%$ \\
Calca & 72239 & $12 \%$ \\
Urubamba & 62885 & $11 \%$ \\
Total & 596634 & $100 \%$ \\
\hline
\end{tabular}

P5. ¿Cuál es el ingreso mensual que actualmente percibe como familia?

\begin{tabular}{ccc}
\hline Ingresos & $\mathrm{N}^{\circ}$ de personas & $\%$ \\
\hline Menos de 850 soles & 48 & $8 \%$ \\
Entre 851 a 2000 soles & 221 & $37 \%$ \\
Mayor a 2001 soles & 331 & $55 \%$ \\
Total & 600 & $100 \%$ \\
\hline
\end{tabular}

P6. ¿Usted consume carne en su menú diario?

\begin{tabular}{ccc}
\hline Variable & $\mathrm{N}^{\circ}$ de personas & $\%$ \\
\hline SI & 562 & $94 \%$ \\
NO & 38 & $6 \%$ \\
Total & 600 & $100 \%$ \\
\hline
\end{tabular}

P7. ¿Conoce las ventajas de comer carne de cuy?

\begin{tabular}{ccc}
\hline Variable & $\mathrm{N}^{\circ}$ de personas & $\%$ \\
\hline SI & 457 & $81 \%$ \\
NO & 105 & $19 \%$ \\
Total & 562 & $100 \%$ \\
\hline
\end{tabular}


P8. ¿En el año usted consume carne de cuy?

\begin{tabular}{ccc}
\hline Variable & $\mathrm{N}^{\circ}$ de personas & $\%$ \\
\hline SI & 487 & $87 \%$ \\
NO & 75 & $13 \%$ \\
Total & 562 & $100 \%$ \\
\hline
\end{tabular}

P9. ¿Alguna persona de su familia compra carne de cuy para preparar en casa?

\begin{tabular}{ccc}
\hline Variable & $\mathrm{N}^{\circ}$ de personas & $\%$ \\
\hline SI & 389 & $80 \%$ \\
NO & 98 & $20 \%$ \\
Total & 487 & $100 \%$ \\
\hline
\end{tabular}

P10. ¿Cómo lo compra?

\begin{tabular}{ccc}
\hline Variable & $\mathrm{N}^{\circ}$ de personas & $\%$ \\
\hline Vivo & 114 & $29 \%$ \\
Sacrificado eviscerado & 158 & $41 \%$ \\
Envasado & 0 & $0 \%$ \\
Cocido & 38 & $10 \%$ \\
Otros & 79 & $20 \%$ \\
Total & 389 & $100 \%$ \\
\hline
\end{tabular}

P11. ¿Dónde lo adquiere?

\begin{tabular}{ccc}
\hline Lugar & $\mathrm{N}^{\circ}$ de personas & $\%$ \\
\hline Minimarket & 14 & $4 \%$ \\
Mercado & 143 & $37 \%$ \\
En la calle & 25 & $6 \%$ \\
Ferias & 132 & $34 \%$ \\
Otros & 75 & $19 \%$ \\
Total & 389 & $100 \%$ \\
\hline
\end{tabular}


P12. ¿Para qué ocasiones lo compra?

\begin{tabular}{ccc}
\hline Ocasiones & $\mathrm{N}^{\circ}$ de personas & $\%$ \\
\hline Fines de semana & 29 & $7 \%$ \\
Aniversarios/Cumpleaños & 127 & $33 \%$ \\
Eventos u ocasiones & & \\
especiales & 151 & $39 \%$ \\
Otros & 82 & $21 \%$ \\
Total & 389 & $100 \%$ \\
\hline
\end{tabular}

P13. ¿Cuantas veces y con qué frecuencia al año en su casa compran carne de cuy?

\begin{tabular}{|c|c|c|c|c|c|c|c|c|c|c|c|c|c|c|}
\hline \multirow[b]{2}{*}{$\begin{array}{l}\text { Frecuencia } \\
\text { Nro de veces }\end{array}$} & \multicolumn{2}{|c|}{ Semanal } & \multicolumn{2}{|c|}{ Quincenal } & \multicolumn{2}{|c|}{ Mensual } & \multicolumn{2}{|c|}{ Trimestral } & \multicolumn{2}{|c|}{ Semestral } & \multicolumn{2}{|c|}{$\overline{\text { Anual }}$} & \multicolumn{2}{|c|}{ Total } \\
\hline & $\begin{array}{l}\mathrm{N}^{\mathrm{o}} \mathrm{de} \\
\text { personas }\end{array}$ & $\%$ & $\begin{array}{c}\mathrm{N}^{0} \mathrm{de} \\
\text { personas }\end{array}$ & $\%$ & $\begin{array}{l}\mathrm{N}^{0} \text { de } \\
\text { personas }\end{array}$ & $\%$ & $\begin{array}{c}\mathrm{N}^{0} \text { de } \\
\text { personas }\end{array}$ & $\%$ & $\begin{array}{c}\mathrm{N}^{0} \text { de } \\
\text { personas }\end{array}$ & $\%$ & $\begin{array}{l}\mathrm{N}^{0} \text { de } \\
\text { personas }\end{array}$ & $\%$ & $\begin{array}{c}\mathrm{N}^{0} \text { de } \\
\text { personas }\end{array}$ & $\%$ \\
\hline De 1 a 3 veces & 0 & $0 \%$ & 9 & $75 \%$ & 8 & $67 \%$ & 25 & $45 \%$ & 39 & $38 \%$ & 11 & $5 \%$ & 92 & $24 \%$ \\
\hline De 4 a 6 veces & 0 & $0 \%$ & 3 & $25 \%$ & 3 & $25 \%$ & 19 & $34 \%$ & 24 & $23 \%$ & 50 & $24 \%$ & 99 & $25 \%$ \\
\hline De 7 a 9 veces & 0 & $0 \%$ & 0 & $0 \%$ & 1 & $8 \%$ & 2 & $4 \%$ & 16 & $15 \%$ & 16 & $8 \%$ & 35 & $9 \%$ \\
\hline De 10 a 12 veces & 0 & $0 \%$ & 0 & $0 \%$ & 0 & $0 \%$ & 9 & $16 \%$ & 20 & $19 \%$ & 13 & $6 \%$ & 42 & $11 \%$ \\
\hline De 12 a más & 0 & $0 \%$ & 0 & $0 \%$ & 0 & $0 \%$ & 1 & $2 \%$ & 5 & $5 \%$ & 115 & $56 \%$ & 121 & $31 \%$ \\
\hline Total & 0 & $0 \%$ & 12 & $3 \%$ & 12 & $3 \%$ & 56 & $14 \%$ & 104 & $27 \%$ & 205 & $53 \%$ & 389 & $100 \%$ \\
\hline
\end{tabular}

P14. ¿Qué cantidad de cuyes compra para su consumo familiar al año?

\begin{tabular}{ccc}
\hline Cantidad & $\mathrm{N}^{\circ}$ de personas & $\%$ \\
\hline De 1 a 5 & 237 & $61 \%$ \\
De 6 a 10 & 59 & $15 \%$ \\
De 11 a 15 & 31 & $8 \%$ \\
De 16 a 20 & 31 & $8 \%$ \\
De 21 a 25 & 19 & $5 \%$ \\
De 26 a más & 12 & $3 \%$ \\
Total & 389 & $100 \%$ \\
\hline
\end{tabular}


P15 ¿Cuál es el precio que paga por cada cuy?

\begin{tabular}{ccc}
\hline Precio & $\mathrm{N}^{\circ}$ de personas & $\%$ \\
\hline s/15 a s/20 & 54 & $14 \%$ \\
s/ 21 a 25 & 144 & $37 \%$ \\
s/ 26 a s/ 30 & 70 & $18 \%$ \\
s/ 31 a más & 121 & $31 \%$ \\
Total & 389 & $100 \%$ \\
\hline
\end{tabular}

P16. Marque la característica que considera usted determinante para adquirir este animal

\begin{tabular}{|c|c|c|}
\hline Precio & $\begin{array}{c}\mathrm{N}^{\circ} \mathrm{de} \\
\text { personas }\end{array}$ & $\%$ \\
\hline Que tenga peso y tamaño ideal & 135 & $35 \%$ \\
\hline Facilidad de preparación & 20 & $5 \%$ \\
\hline Valor nutricional & 50 & $13 \%$ \\
\hline Precio & 120 & $31 \%$ \\
\hline Presentación del producto & 64 & $16 \%$ \\
\hline Total & 389 & $100 \%$ \\
\hline
\end{tabular}

P17. ¿Estaría dispuesto Ud. a comprar carne de cuy empacada al vacío?

\begin{tabular}{ccc}
\hline Precio & $\mathrm{N}^{\circ}$ de personas & $\%$ \\
\hline Definitivamente lo compraría & 203 & $52 \%$ \\
Probablemente lo compraría & 140 & $36 \%$ \\
Me seria indiferente comprar o no & 11 & $3 \%$ \\
Probablemente no lo compraría & 24 & $6 \%$ \\
Definitivamente no lo compraría & 11 & $3 \%$ \\
Total & 389 & $100 \%$ \\
\hline
\end{tabular}


P18. ¿Conoce usted algún establecimiento en el que vendan carne de cuy empacada?

\begin{tabular}{ccc}
\hline Variable & $\mathrm{N}^{\circ}$ de personas & $\%$ \\
\hline SI & 59 & $16 \%$ \\
NO & 319 & $84 \%$ \\
Total & 378 & $100 \%$ \\
\hline
\end{tabular}

P19. ¿Dónde le gustaría adquirirlo?

\begin{tabular}{ccc}
\hline Lugar & $\mathrm{N}^{\circ}$ de personas & $\%$ \\
\hline Minimarket & 166 & $44 \%$ \\
Mercados & 81 & $21 \%$ \\
Ferias & 42 & $11 \%$ \\
Tiendas & 4 & $1 \%$ \\
Otros & 85 & $22 \%$ \\
Total & 378 & $100 \%$ \\
\hline
\end{tabular}

P20. ¿Cuánto estaría dispuesto a pagar por unidad de este producto?

\begin{tabular}{ccc}
\hline Precio & $\mathrm{N}^{\circ}$ de personas & $\%$ \\
\hline s/15 a s/20 & 45 & $12 \%$ \\
s/ 21 a 25 & 136 & $36 \%$ \\
s/ 26 a s/ 30 & 140 & $37 \%$ \\
s/ 31 a más & 57 & $15 \%$ \\
Total & 378 & $100 \%$ \\
\hline
\end{tabular}


P21. ¿Por qué medio de comunicación recibe usted más publicidad de productos alimenticios?

\begin{tabular}{ccc}
\hline Cantidad & $\mathrm{N}^{\circ}$ de personas & $\%$ \\
\hline Televisión & 106 & $28 \%$ \\
Radio & 91 & $24 \%$ \\
Redes Sociales & 113 & $30 \%$ \\
Periódicos y & & \\
Revistas & 19 & $5 \%$ \\
Volantes & 7 & $2 \%$ \\
Afiches & & \\
Publicitarios & 42 & $11 \%$ \\
Total & 378 & $100 \%$ \\
\hline
\end{tabular}


Análisis y procesamiento de datos.

Encuesta dirigida a restaurante tradicional.

P1. ¿Qué tipo de restaurante es?

\begin{tabular}{ccc}
\hline Clase de restaurantes & Nro de Personas & $\%$ \\
\hline Turísticos & 74 & $57 \%$ \\
Tradicionales & 55 & $43 \%$ \\
Total restaurantes & 129 & $100 \%$ \\
\hline
\end{tabular}

P2. ¿Cuál es el cargo que ocupa en el restaurante?

\begin{tabular}{ccc}
\hline Cargo & $\mathrm{N}^{\circ}$ de personas & $\%$ \\
\hline Dueño Propietario & 49 & $89 \%$ \\
Administrador & 6 & $11 \%$ \\
Total & 55 & $100 \%$ \\
\hline
\end{tabular}

P3. ¿Este cargo le da la facultad de decidir las compras de alimentos para el restaurante?

\begin{tabular}{ccc}
\hline Variable & $\mathrm{N}^{\circ}$ de personas & $\%$ \\
\hline SI & 55 & $100 \%$ \\
NO & 0 & $0 \%$ \\
Total & 55 & $100 \%$ \\
\hline
\end{tabular}


P4. ¿En qué distrito del Cusco se encuentra su restaurante?

\begin{tabular}{ccc}
\hline Distritos & $\begin{array}{c}\text { Nro de } \\
\text { Restaurantes }\end{array}$ & $\%$ \\
\hline Cusco & 9 & $16 \%$ \\
San Jerónimo & 6 & $11 \%$ \\
San Sebastián & 6 & $11 \%$ \\
Santiago & 6 & $11 \%$ \\
Wanchaq & 3 & $5 \%$ \\
Saylla & 19 & $35 \%$ \\
Calca & 3 & $5 \%$ \\
Urubamba & 3 & $5 \%$ \\
Total & 55 & $100 \%$ \\
\hline
\end{tabular}

P5. ¿Cuál es la capacidad de comensales con la que cuenta su local?

\begin{tabular}{ccc}
\hline Cargo & $\mathrm{N}^{\circ}$ de personas & $\%$ \\
\hline Menor a 40 & 6 & $11 \%$ \\
Mayor a 40 & 49 & $89 \%$ \\
Total & 55 & $100 \%$ \\
\hline
\end{tabular}

P6. ¿En su restaurante prepara platos a base de carne de cuy?

\begin{tabular}{ccc}
\hline Variable & $\mathrm{N}^{\circ}$ de personas & $\%$ \\
\hline SI & 55 & $100 \%$ \\
NO & 0 & $0 \%$ \\
Total & 55 & $100 \%$ \\
\hline
\end{tabular}


P7. ¿Conoce usted proveedores de carne de cuy?

\begin{tabular}{ccc}
\hline Variable & $\mathrm{N}^{\circ}$ de personas & $\%$ \\
\hline SI & 34 & $62 \%$ \\
NO & 21 & $38 \%$ \\
Total & 55 & $100 \%$ \\
\hline
\end{tabular}

P8. ¿Cómo compra la carne cuy que prepara?

\begin{tabular}{ccc}
\hline Variable & $\mathrm{N}^{\circ}$ de personas & $\%$ \\
\hline Vivo & 24 & $44 \%$ \\
Sacrificado & & \\
eviscerado & 31 & $56 \%$ \\
Envasado & 0 & $0 \%$ \\
Cocido & 0 & $0 \%$ \\
Otros & 0 & $0 \%$ \\
Total & 55 & $100 \%$ \\
\hline
\end{tabular}

P9. ¿Dónde adquiere la carne de cuy que prepara?

\begin{tabular}{ccc}
\hline Lugar & $\mathrm{N}^{\circ}$ de personas & $\%$ \\
\hline Minimarket & 0 & $0 \%$ \\
Mercado & 18 & $33 \%$ \\
En la calle & 0 & $0 \%$ \\
Delivery & 34 & $62 \%$ \\
Otros & 3 & $5 \%$ \\
Total & 55 & $100 \%$ \\
\hline
\end{tabular}

P10. ¿Conoce las condiciones de crianza y de higiene del cuy que compra?

\begin{tabular}{ccc}
\hline Variable & $\mathrm{N}^{\circ}$ de personas & $\%$ \\
\hline SI & 3 & $5 \%$ \\
NO & 52 & $95 \%$ \\
Total & 55 & $100 \%$ \\
\hline
\end{tabular}


P11. De manera mensual ¿con que frecuencia compra carne de cuy?

\begin{tabular}{ccc}
\hline Frecuencia & $\mathrm{N}^{\circ}$ de personas & $\%$ \\
\hline Diario & 6 & $11 \%$ \\
Interdiario & 0 & $0 \%$ \\
Semanal & 43 & $78 \%$ \\
Quincenal & 3 & $5 \%$ \\
Una vez por & & $5 \%$ \\
mes & 3 & $100 \%$ \\
Total & 55 & \\
\hline
\end{tabular}

P12. ¿Qué cantidad de cuyes compra de manera mensual?

\begin{tabular}{ccc}
\hline Cantidad & $\mathrm{N}^{\circ}$ de personas & $\%$ \\
\hline De 1 a 50 cuyes & 3 & $5 \%$ \\
De 51 a 100 cuyes & 12 & $22 \%$ \\
De 101 a 150 & & \\
$\quad$ cuyes & 9 & $16 \%$ \\
De 151 a más & & \\
$\quad$ cuyes & 31 & $56 \%$ \\
$\quad$ Total & 55 & $100 \%$ \\
\hline
\end{tabular}

P13. ¿Cuál es el precio que paga según tipo de cuy que compra por unidad?

\begin{tabular}{|c|c|c|c|c|c|}
\hline $\begin{array}{c}\text { Montos en } \\
\text { soles }\end{array}$ & Cuy Vivo & $\begin{array}{c}\text { Cuy } \\
\text { Sacrificado } \\
\text { eviscerado }\end{array}$ & $\begin{array}{c}\text { Cuy } \\
\text { empacado }\end{array}$ & Total & $\%$ \\
\hline $\mathrm{s} / 15 \mathrm{a} \mathrm{s} / 20$ & 3 & 0 & 0 & 3 & $5 \%$ \\
\hline s/ 21 a 25 & 15 & 25 & 0 & 40 & $73 \%$ \\
\hline $\mathrm{s} / 26 \mathrm{a} \mathrm{s} / 30$ & 0 & 12 & 0 & 12 & $22 \%$ \\
\hline s/ 31 a más & 0 & 0 & 0 & 0 & $0 \%$ \\
\hline Total & 18 & 37 & 0 & 55 & $100 \%$ \\
\hline Total \% & $33 \%$ & $67 \%$ & $0 \%$ & $100 \%$ & \\
\hline
\end{tabular}


P14. Marque la característica que considera su empresa determinante para adquirir carne de este animal

\begin{tabular}{ccc}
\hline Característica & $\mathrm{N}^{\circ}$ de personas & $\%$ \\
\hline Que tenga peso y tamaño ideal & 28 & $51 \%$ \\
Facilidad de preparación & 2 & $4 \%$ \\
Facilidad de almacenamiento y conservación & 3 & $5 \%$ \\
Puntualidad en el abastecimiento & 15 & $27 \%$ \\
Cumplimiento de normas sanitarias & 7 & $13 \%$ \\
Total & 55 & $100 \%$ \\
\hline
\end{tabular}

P15. ¿Estaría dispuesto Ud. a comprar carne de cuy empacada al vacío?

\begin{tabular}{ccc}
\hline Variable & $\mathrm{N}^{\circ}$ de personas & $\%$ \\
\hline Definitivamente lo compraría & 25 & $45 \%$ \\
Probablemente lo compraría & 21 & $38 \%$ \\
Me seria indiferente comprar o no & 3 & $6 \%$ \\
Probablemente no lo compraría & 3 & $6 \%$ \\
Definitivamente no lo compraría & 3 & $5 \%$ \\
Total & 55 & $100 \%$ \\
\hline
\end{tabular}

P16. ¿Conoce usted las ventajas de adquirir carne de cuy empacada al vacío?

\begin{tabular}{ccc}
\hline Variable & $\mathrm{N}^{\circ}$ de personas & $\%$ \\
\hline SI & 24 & $46 \%$ \\
NO & 28 & $54 \%$ \\
Total & 52 & $100 \%$ \\
\hline
\end{tabular}


P17. ¿Dónde le gustaría adquirir carne de cuy empacada al vacío?

\begin{tabular}{ccc}
\hline Lugar & $\mathrm{N}^{\circ}$ de personas & $\%$ \\
\hline Minimarket & 0 & $0 \%$ \\
Mercado & 9 & $17 \%$ \\
Ferias & 0 & $0 \%$ \\
Entrega en & & \\
local & 43 & $83 \%$ \\
Otros & 0 & $0 \%$ \\
Total & 52 & $100 \%$ \\
\hline
\end{tabular}

P18. ¿Cuánto estaría dispuesto a pagar por una unidad de cuy empacado al vacío?

\begin{tabular}{ccc}
\hline Precio & $\mathrm{N}^{\circ}$ de personas & $\%$ \\
\hline s/15 a s/20 & 0 & $0 \%$ \\
s/ 21 a 25 & 36 & $69 \%$ \\
s/ 26 a s/ 30 & 16 & $31 \%$ \\
s/ 31 a más & 0 & $0 \%$ \\
Total & 52 & $100 \%$ \\
\hline
\end{tabular}

P19. ¿Por qué medio de comunicación recibe más publicidad en cuanto a productos alimenticios?

\begin{tabular}{ccc}
\hline Medios & $\mathrm{N}^{\circ}$ de personas & $\%$ \\
\hline Televisión & 9 & $17 \%$ \\
Radio & 29 & $56 \%$ \\
Redes Sociales & 14 & $27 \%$ \\
Periódicos y & & \\
Revistas & 0 & $0 \%$ \\
Volantes & 0 & $0 \%$ \\
Afiches & & \\
Publicitarios & 0 & $0 \%$ \\
Total & 52 & $100 \%$ \\
\hline
\end{tabular}


Análisis y procesamiento de datos.

Encuesta dirigida a administradores de restaurante turísticos.

P1. ¿Qué tipo de restaurante es?

\begin{tabular}{ccc}
\hline Clase de restaurantes & Nro de Personas & $\%$ \\
\hline Turísticos & 74 & $57 \%$ \\
Tradicionales & 55 & $43 \%$ \\
Total restaurantes & 129 & $100 \%$ \\
\hline
\end{tabular}

P2. ¿Cuál es el cargo que ocupa en el restaurante?

\begin{tabular}{ccc}
\hline Cargo & $\mathrm{N}^{\circ}$ de personas & $\%$ \\
\hline Dueño & 30 & $41 \%$ \\
Gerente & 14 & $19 \%$ \\
Administrador & 30 & $41 \%$ \\
Total & 74 & $100 \%$ \\
\hline
\end{tabular}

P3. ¿Este cargo le da la facultad de decidir las compras de alimentos para el restaurante?

\begin{tabular}{ccc}
\hline Ítem & $\mathrm{N}^{\circ}$ de personas & $\%$ \\
\hline SI & 74 & $100 \%$ \\
NO & 0 & $0 \%$ \\
Total & 74 & $100 \%$ \\
\hline
\end{tabular}


P4. ¿En qué distrito del Cusco se encuentra su restaurante?

\begin{tabular}{ccc}
\hline Distritos & Nro de Restaurantes & $\%$ \\
\hline Cusco & 47 & $64 \%$ \\
San Jerónimo & 2 & $3 \%$ \\
San Sebastián & 1 & $1 \%$ \\
Santiago & 1 & $1 \%$ \\
Wanchaq & 3 & $4 \%$ \\
Saylla & 1 & $1 \%$ \\
Calca & 5 & $7 \%$ \\
Urubamba & 14 & $19 \%$ \\
Total & 74 & $100 \%$ \\
\hline
\end{tabular}

P5. ¿Cuál es la capacidad de comensales con la que cuenta su local?

\begin{tabular}{ccc}
\hline Cargo & $\mathrm{N}^{\circ}$ de personas & $\%$ \\
\hline Menor a 40 & 3 & $4 \%$ \\
Mayor a 40 & 71 & $96 \%$ \\
Total & 74 & $100 \%$ \\
\hline
\end{tabular}

P6. ¿En su restaurante prepara platos a base de carne de cuy?

\begin{tabular}{ccc}
\hline Variable & $\mathrm{N}^{\circ}$ de personas & $\%$ \\
\hline SI & 74 & $100 \%$ \\
NO & 0 & $0 \%$ \\
Total & 74 & $100 \%$ \\
\hline
\end{tabular}

P7. ¿Conoce usted proveedores de carne de cuy?

\begin{tabular}{ccc}
\hline Variable & $\mathrm{N}^{\circ}$ de personas & $\%$ \\
\hline SI & 46 & $62 \%$ \\
NO & 28 & $38 \%$ \\
Total & 74 & $100 \%$ \\
\hline
\end{tabular}


P8. ¿Cómo compra la carne cuy que prepara?

\begin{tabular}{ccc}
\hline Variable & $\mathrm{N}^{\circ}$ de personas & $\%$ \\
\hline Vivo & 15 & $20 \%$ \\
Sacrificado eviscerado & 59 & $80 \%$ \\
Envasado & 0 & $0 \%$ \\
Cocido & 0 & $0 \%$ \\
Otros & 0 & $0 \%$ \\
Total & 74 & $100 \%$ \\
\hline
\end{tabular}

P9. ¿Dónde adquiere la carne de cuy que prepara?

\begin{tabular}{ccc}
\hline Lugar & $\mathrm{N}^{\circ}$ de personas & $\%$ \\
\hline Minimarket & 0 & $0 \%$ \\
Mercado & 3 & $4 \%$ \\
En la calle & 0 & $0 \%$ \\
Delivery & 71 & $96 \%$ \\
Otros & 0 & $0 \%$ \\
Total & 74 & $100 \%$ \\
\hline
\end{tabular}

P10. ¿Conoce las condiciones de crianza y de higiene del cuy que compra?

\begin{tabular}{ccc}
\hline Variable & $\mathrm{N}^{\circ}$ de personas & $\%$ \\
\hline SI & 2 & $3 \%$ \\
NO & 72 & $97 \%$ \\
Total & 74 & $100 \%$ \\
\hline
\end{tabular}


P11. De manera mensual ¿con que frecuencia compra carne de cuy?

\begin{tabular}{ccc}
\hline Frecuencia & $\mathrm{N}^{\circ}$ de personas & $\%$ \\
\hline Diario & 0 & $0 \%$ \\
Interdiario & 0 & $0 \%$ \\
Semanal & 34 & $46 \%$ \\
Quincenal & 18 & $24 \%$ \\
Una vez por mes & 22 & $30 \%$ \\
Total & 74 & $100 \%$ \\
\hline
\end{tabular}

P12. ¿Qué cantidad de cuyes compra de manera mensual?

\begin{tabular}{ccc}
\hline Cantidad & $\mathrm{N}^{\circ}$ de personas & $\%$ \\
\hline De 1 a 20 cuyes & 45 & $60 \%$ \\
De 21 a 40 cuyes & 12 & $16 \%$ \\
De 41 a 60 cuyes & 10 & $14 \%$ \\
De 61 a más cuyes & 7 & $10 \%$ \\
Total & 74 & $100 \%$ \\
\hline
\end{tabular}

P13. ¿Cuál es el precio que paga según tipo de cuy que compra por unidad?

\begin{tabular}{|c|c|c|c|c|c|}
\hline $\begin{array}{c}\text { Montos en } \\
\text { soles }\end{array}$ & Cuy Vivo & $\begin{array}{c}\text { Cuy } \\
\text { Sacrificado } \\
\text { eviscerado }\end{array}$ & $\begin{array}{c}\text { Cuy } \\
\text { empacado }\end{array}$ & Total & $\tilde{\mathrm{n}} \%$ \\
\hline $\mathrm{s} / 15 \mathrm{a} \mathrm{s} / 20$ & 0 & 0 & 0 & 0 & $0 \%$ \\
\hline s/ 21 a 25 & 15 & 29 & 0 & 44 & $59 \%$ \\
\hline $\mathrm{s} / 26 \mathrm{a} \mathrm{s} / 30$ & 0 & 30 & 0 & 30 & nor \\
\hline s/ 31 a más & 0 & 0 & 0 & 0 & $100 \%$ \\
\hline Total & 15 & 59 & 0 & 74 & \\
\hline Total \% & $20 \%$ & $80 \%$ & $0 \%$ & $100 \%$ & \\
\hline
\end{tabular}


P14. Marque la característica que considera su empresa determinante para adquirir carne de este animal

\begin{tabular}{ccc}
\hline Característica & $\mathrm{N}^{\circ}$ de personas & $\%$ \\
\hline Que tenga peso y tamaño ideal & 18 & $24 \%$ \\
Facilidad de preparación & 7 & $9 \%$ \\
Facilidad de almacenamiento y conservación & 7 & $9 \%$ \\
Puntualidad en el abastecimiento & 10 & $14 \%$ \\
Cumplimiento de normas sanitarias & 32 & $43 \%$ \\
Total & 74 & $100 \%$ \\
\hline
\end{tabular}

P15. ¿Estaría dispuesto Ud. a comprar carne de cuy empacada al vacío?

\begin{tabular}{ccc}
\hline Variable & $\mathrm{N}^{\circ}$ de personas & $\%$ \\
\hline Definitivamente lo compraría & 44 & $60 \%$ \\
Probablemente lo compraría & 15 & $20 \%$ \\
Me seria indiferente comprar o no & 0 & $0 \%$ \\
Probablemente no lo compraría & 15 & $20 \%$ \\
Definitivamente no lo compraría & 0 & $0 \%$ \\
Total & 74 & $100 \%$ \\
\hline
\end{tabular}

P16. ¿Conoce usted las ventajas de adquirir carne de cuy empacada al vacío?

\begin{tabular}{ccc}
\hline Variable & $\mathrm{N}^{\circ}$ de personas & $\%$ \\
\hline SI & 44 & $59 \%$ \\
NO & 30 & $41 \%$ \\
Total & 74 & $100 \%$ \\
\hline
\end{tabular}


P17. ¿Dónde le gustaría adquirir carne de cuy empacada al vacío?

\begin{tabular}{ccc}
\hline Lugar & $\mathrm{N}^{\circ}$ de personas & $\%$ \\
\hline Minimarket & 0 & $0 \%$ \\
Mercado & 0 & $0 \%$ \\
Ferias & 0 & $0 \%$ \\
Entrega en local & 74 & $100 \%$ \\
Otros & 0 & $0 \%$ \\
Total & 74 & $100 \%$ \\
\hline
\end{tabular}

P18. ¿Cuánto estaría dispuesto a pagar por una unidad de cuy empacado al vacío?

\begin{tabular}{ccc}
\hline Precio & $\mathrm{N}^{\circ}$ de personas & $\%$ \\
\hline $\mathrm{s} / 15$ a s/20 & 0 & $0 \%$ \\
$\mathrm{~s} / 21$ a 25 & 30 & $41 \%$ \\
s/ 26 a s/ 30 & 44 & $59 \%$ \\
s/ 31 a más & 0 & $0 \%$ \\
Total & 74 & $100 \%$ \\
\hline
\end{tabular}

P19. ¿Por qué medio de comunicación recibe más publicidad en cuanto a productos alimenticios?

\begin{tabular}{ccc}
\hline Medios & $\mathrm{N}^{\circ}$ de personas & $\%$ \\
\hline Televisión & 0 & $0 \%$ \\
Radio & 14 & $19 \%$ \\
Redes Sociales & 60 & $81 \%$ \\
Periódicos y Revistas & 0 & $0 \%$ \\
Volantes & 0 & $0 \%$ \\
Afiches Publicitarios & 0 & $0 \%$ \\
Total & 74 & $100 \%$ \\
\hline
\end{tabular}


Anexo 28

\section{Ficha Técnica del Estudio Dirigida a Público en General}

\begin{tabular}{|c|c|}
\hline Unidad de Observación & $\begin{array}{l}\text { Personas que se encuentran entre los } 18 \text { a } 75 \text { años } \\
\text { de género masculino y femenino que están en los } \\
\text { NSE A,B, C de la región del Cusco en número de } \\
596634 \text { personas }\end{array}$ \\
\hline Ámbito geográfico poblacional & Región del Cusco \\
\hline & $\begin{array}{l}\text { Cusco, San Sebastián, San Jerónimo, Saylla, } \\
\text { Wanchaq, Santiago, provincias de Calca y }\end{array}$ \\
\hline Ámbito geográfico muestral & $\begin{array}{l}\text { Urubamba, lugares donde existe mayor consumo de } \\
\text { carne de cuy }\end{array}$ \\
\hline Tipo de investigación & $\begin{array}{l}\text { No experimental de corte transversal de tipo } \\
\text { correlacional -causal }\end{array}$ \\
\hline Proceso de muestreo & Probabilístico estratificado \\
\hline Cuestionarios validos & 600 \\
\hline Error muestral al & $4 \%$ \\
\hline Nivel de confianza & $95 \%$ \\
\hline $\begin{array}{l}\text { Fecha de realización de trabajo de } \\
\text { campo }\end{array}$ & 20 de enero del 2018 \\
\hline Técnica utilizada & Encuesta \\
\hline Trabajo de campo & $\begin{array}{l}\text { Recolección de información mediante cuestionario } \\
\text { de encuestas }\end{array}$ \\
\hline Diseño de muestral & Estratificado \\
\hline Nivel de supervisión & $100 \%$ \\
\hline Tipo de estudio & Probabilístico \\
\hline
\end{tabular}


Anexo 29

\section{Ficha Técnica del Estudio}

Dirigida a Restaurantes Turísticos y Tradicionales

Unidad de Observación

Empresas naturales y jurídicas pertenecientes al sector Comercio debidamente registradas y acreditadas en la Dirección Regional de Comercio y Turismo del Cusco, dedicadas al rubro de la restauración en número de 144 divididas en 84 restaurantes turísticos y 60 tradicionales.

Ámbito geográfico poblacional Región del Cusco

Cusco, San Sebastián, San Jerónimo, Saylla, Wanchaq,

Ámbito geográfico muestral Santiago, provincias de Calca y Urubamba, lugares donde existe mayor consumo de carne de cuy.

Tipo de investigación

No experimental de corte transversal de tipo correlacional causal

Proceso de muestreo

Probabilístico estratificado

Cuestionarios validos

74 restaurantes turísticos y 55 restaurantes tradicionales.

Error muestral $4 \%$

Nivel de confianza

$95 \%$

Fecha de realización de trabajo 20 de enero del 2018 de campo

Técnica utilizada

Encuesta

Trabajo de campo

Recolección de información mediante cuestionario de encuestas

Diseño de muestral

Estratificado

Nivel de supervisión

$100 \%$

Tipo de estudio

Probabilístico 


\section{Bibliografía}

- Alles, Martha. Dirección Estratégica de Recursos Humanos - Gestión por Competencias, 3ra Edición, Buenos Aires - Argentina, Ed. Granica, 2009.

- Chiavenato, Idalberto. Comportamiento Organizacional - La Dinámica del Éxito en las Organizaciones, 2da edición, McGraw - Hill, 2015.

- David, Fred R. Conceptos de Administración Estratégica. 14th Edición, Pearson Education, Mexico, 2013.

- D’Alessio, Fernando A. EL Proceso Estratégico - Un enfoque de Gerencia, 2da Edición, Pearson Education, México, 2013.

- Groppelli, Angelico A.; EHSAN Nikbakht, Finance, 8va Edición, Ed. Barron's Educational Series Inc., USA, 2012.

- Hernandez, Abraham. Formulación y Evaluación de Proyectos de inversión, 4ta Edición, Ed. Thomson, 2005.

- Lawrence, Gitman J.; ZUTTER, Chad J. Principios de Administración Financiera, 12th Edición, Ed. Pearson Educación, México, 2012.

- Robbins, Stephen P. Comportamiento Organizacional. 15th Edición, Pearson - Prentice Hall, México, 2013.

- Sapag Chain, Nassir. Proyectos de Inversión - Formulación y Evaluación, 2da Edición, Ed. Pearson Educación, Chile, 2011.

- Thompson, Arthur A.; STRICKLAND, A. J. Administración Estratégica, Teoría y Casos. 18th Edición, McGraw - Hill, 2013. 


\section{Referencias Electrónicas}

- Administración en teoría, Herramientas Administrativas o Gerenciales, (en línea) THOMPSON B. Janneth M., 2009, disponible en: http://administracionenteoria.blogspot.pe/

- www.apeim.com.pe/wp-content/themes/apeim/docs/nse/APEIM-NSE-2016.pdf

- Customized Geometric risk premium estimator, CONSULTADO EN NOVIMEBRE DEL 2016, (en linea)

- www.dracusco.gob.pe/

- http://www.damodaran.com

- https://www.inei.gob.pe/

- Indicadores de Riesgo Para Países Emergentes, Índice de Bonos de Mercados Emergentes, Bloomberg y Reuters, (en línea) consultado en Noviembre del 2016, disponible en: https://www.bloomberg.com/.../mejor-apuesta-en-bonos-son-los-paisesemergentes

- Indicadores Tasa de Inflación Perú, Consultado en noviembre del 2016, (en línea), disponible en: http://es.tradingeconomics.com/peru/inflation-cpi

- Indicadores Tasa de Inflación Perú, Consultado en noviembre del 2016, (en línea), disponible en: http://www.bcrp.gob.pe/estadisticas/cuadros-de-la-nota-semanal.html

- Indicadores Tasa de Inflación Estados Unidos de Norte America, Consultado en noviembre del 2016, (en línea), disponible en: http://es.global-rates.com/estadisticaseconomicas/inflacion/indice-de-precios-al-consumo/ipc/estados-unidos.aspx

- Ministerio de Trabajo y Promoción Del Empleo, Diario Oficial El Peruano - Normas Legales, Reglamento de Ley $\mathbf{N}^{\circ} \mathbf{2 9 7 8 3}$, Ley de Seguridad y Salud en el Trabajo D.S. 005-2012-TR, (en línea), Lima - Perú miércoles 25 de abril de 2012 pg. 464861, disponible en: http://www.mintra.gob.pe/LGT/ley_seguridad_salud_trabajo.pdf

- www.regioncusco.gob.pe/

- Real Academia Española, Diccionario De Lengua Española, (en línea) Madrid, 2017, disponible en: http://dle.rae.es/?id=UC5uxwk

- http://www.stern.nyu.edu/ adamodar/New_Home_Page/data.html

- http://www.stern.nyu.edu/ adamodar/New_Home_Page/datafile/variable.htm

- http://www.stern.nyu.edu/ adamodar/pc/datasets/indname.xls 
- Sánchez Ballesta, Juan Pedro (2002): Análisis de Rentabilidad de la empresa, [en línea] 5campus.com, Análisis contable, consultado en noviembre del 2016, disponible en: http://ciberconta.unizar.es/leccion/anarenta/analisisR.pdf 